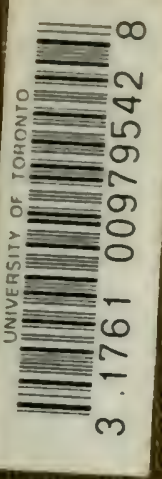

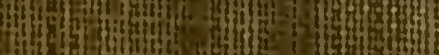

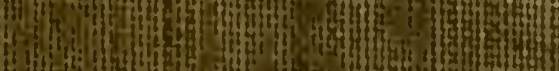
H.th i. if ing $^{2}$ th ? (y)

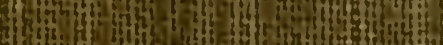
Whitinith

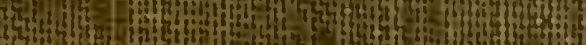
co is 13 3 h ithat Hof

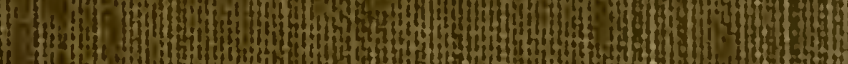

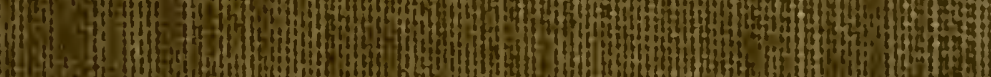
it. Hhth 4.

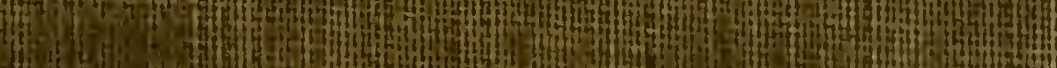
815. 15.

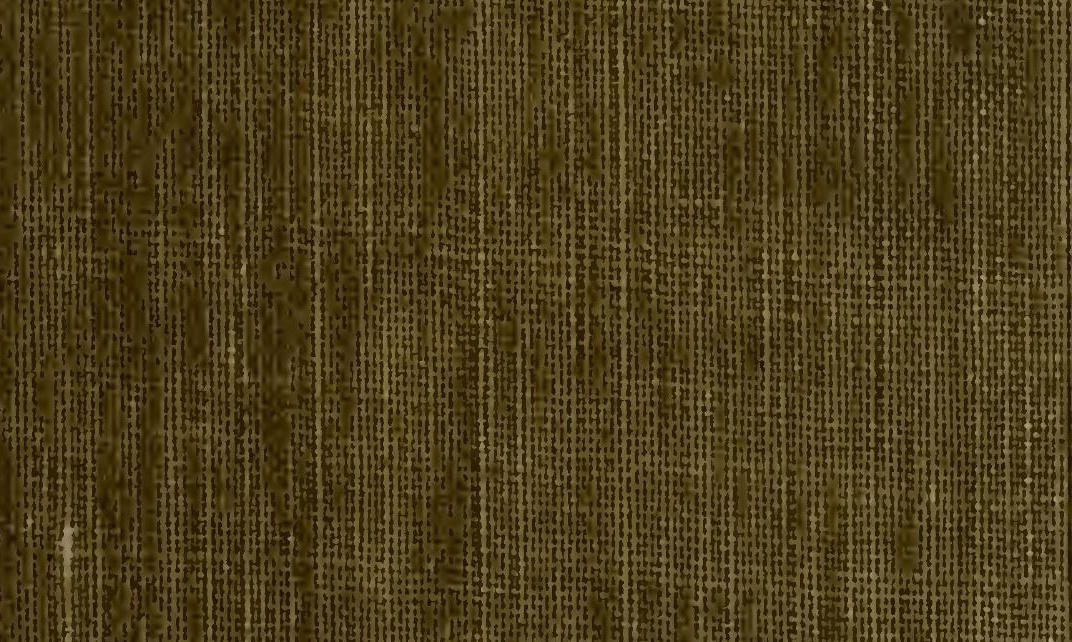

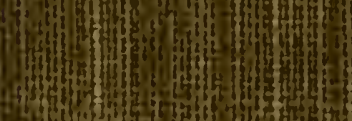





AGRICLLTURAL AND BIOLOGICAL PUBLICATIONS CHARLES $\vee$. PIPER, CoNsultiNg EdTor

THE BEGINNINGS

$\mathrm{OF}$

AGRICULTURE IN AMERICA 


\section{McGRAW-HILL AGRICULTURAL AND BIOLOGICAL PUBLICATIONS}

Dr. Chas. V. Piper, Consultixg Editcr

Babcock and Clausen's-

GENETICS IN RELATION TO AGRICULTURE

Babcock and Collins'GENETICS LABORATORY MANUAL

Shull. La Rue and Ruthren'sPRINCIPLES OF ANIMAL BIOLOGY

Shull's-

LABORATORY DIRECTIONS IN PRINCIPLES OF ANIMAL BIOLOGY

Thalcher's-

CHEMISTRY OF PLANT LIFE

Hayes and Garber'sm.

BREEDING CROP PLANTS

Sharp':-

AN INTRODUCTION TO CYTOLOGY

Fernald's-

APPLIED ENTOMOLOGY

Adams'-

FARM MANAGEMENT

Gardner. Brafford and Hooker'sFUNDAMENTALS OF FRUIT PRODUCTION

Cruess and Christie'

LABORATORY MANUAL OF FRUIT AND VEGETABLE PRODUCTS

Pipet and Mrrse' $8-$
THE SOYBEAN

Carrier's-

THE BEGINNINGS OF AGRICULTURE IN AMERICA 
, 

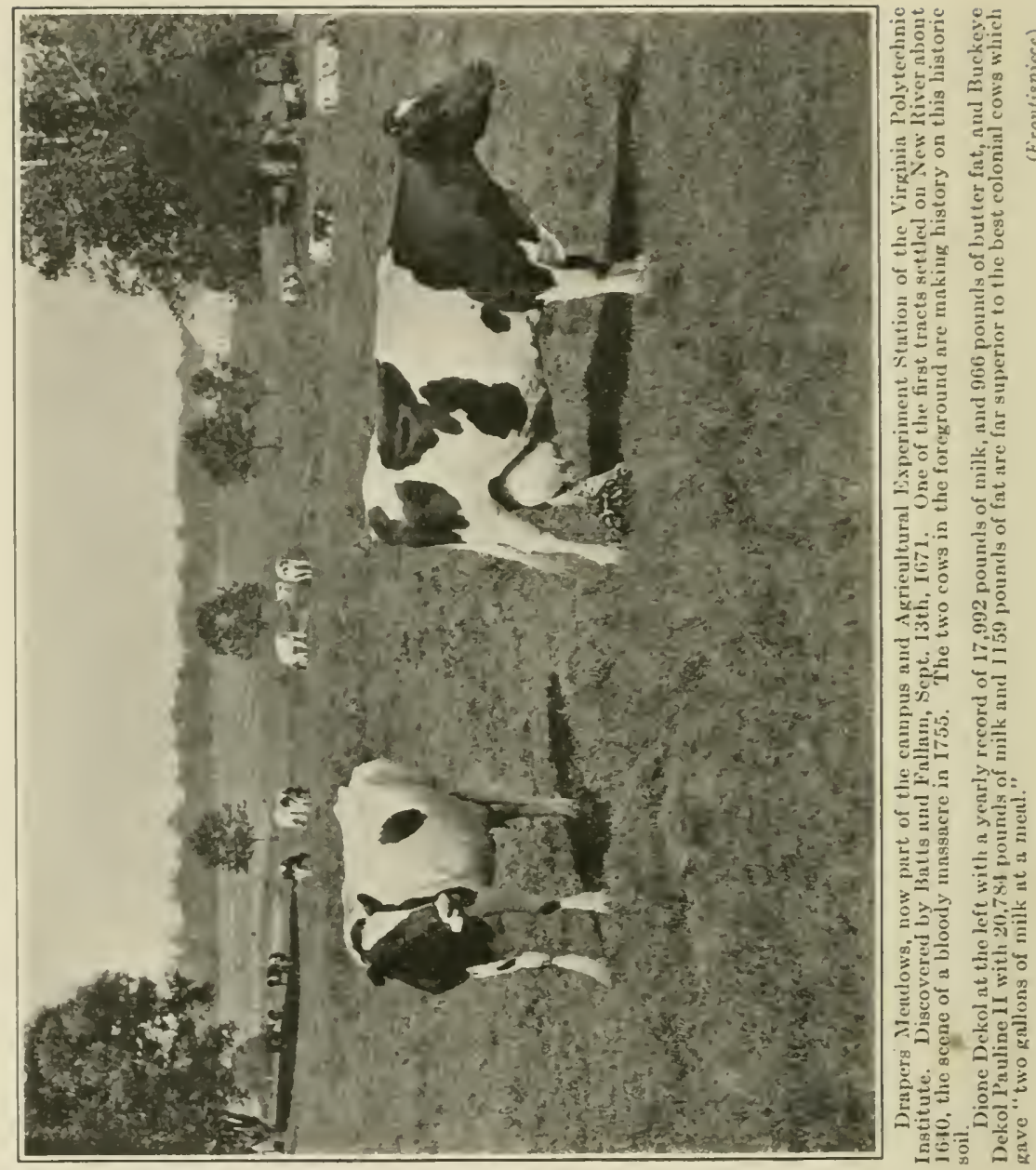


\section{THE BEGINNINGS OF AGRICULTURE IN A MERICA}

$\mathrm{BI}$

LYMAN CARRIER. B. S., M. AGR.

AGRONOMIST, BEREAU OF PLANT INDESTRY

CNITED STATES DEPARTMENT OF AGRICULTLRE

First Edition

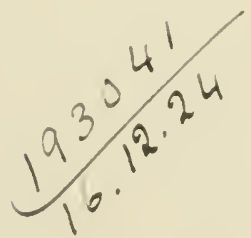

MCGRAW-HILL BOOK COMPANY, INC.

NEW YORK: 370 SEVENTH AVENUE

LONDON: 6 \& 8 BOLVERIE ST., E. C. 4

1923 
Copyright, 1923, hy the

McGraw-Hyll Book Company, Ixc.

PRINTED IN THE UNITED STATES OF AMIERICA

THE MAPLE PRESS - YORK PA 


\section{PREFACE}

Those engaged in research in agricultural history are in much the same position as contractors employed to construct a building. It is necessary to wait until the preliminaries are accomplished, the ground cleared, materials collected and founclation laid before work on the superstructure commences. The public may be annoyed by the activities of the workmen, shocked by the unsightly heaps of raw material, and the peace of the community disturbed by the noise of the construction. Such annoyances are inevitable and should be borne with patience.

The agricultural historians have no dangerous buildings to demolish. The field is practically free from debris. An inadequate supply of suitable building material and a shortage of laborers are the most serious obstacles to be overcome.

This book has been prepared for the purpose of bringing together from widely separated and often nearly unavailable sources, pertinent facts and observations on the early history of agriculture, especially in America. If successful in this purpose this book should render inexcusable some of the ridiculous blunders which even the most scholarly historians occasionally make when they try to discuss the fundamental industry of farming. To this purpose the writer has kept his own conjectures as to what might or might not have taken place out of the book as far as possible. The facts as I see them have been given and allowed to tell their own story from which the reader may draw his own conclusions. It is intencled that this book may serve as a text in agricultural courses in our schools and colleges. It is not designed in any sense as a substitute for, but a supplement, of the many excellent colonial histories now available. A knowledge of the main important facts in our carly history on the part of the reader is taken for granted.

An adequate history of agriculture in the United States has yet to be written and, when it is, it must, to be reliable, be based on a thorough understanding of farming achievements of the colonists. The agricultural retrospects of our country which 
have appeared so far have crred in minimizing the colonial and Indian farming in order to show a wonderful advancement made since we became a nation.

Portions of the subject which have been competently covered in other publications are touched on but briefly in this book and the reader's attention is directed to the more comprehensive work. The writer regrets exceedingly the brevity with which many important subjects have had to be treated. Such subjects as governmental bounties and their effects, the silk, the oil, and the dye-stuff industries are well worthy of monographs. We need also biographies of the influential colonial agriculturists who contributed so much to the general welfare of our country and the agriculture of each and every state needs a volume.

It is hoped that this book may assist in future research in the subject. For that reason the quotations are given as full as space will allow and much care has been exereised in copying verbatim the passages in the editions cited, even to perpetuating the vagaries of old English spelling and grammar with the exceptions that $n$ and $v$ and $i$ and $j$ have been changed to agree with modern usage. That there have been no mistakes made in copying these citations, while devoutly wished, is a state of perfection which past experience shows the writer should not expect. But I trust the inadvertences of this character are not so numerous or important as to cause any great difficulty or to render the meanings unintelligible.

Lymax Carrier.

Washington, D. C., November, 1922. 


\section{ACKNOWLEDGMENTS}

Much help and encouragement has been received in the preparation of this book, from many people. The librarians of the United States Department of Agriculture have rendered invaluable aid in procuring rare editions and suggesting possible sources of information. The meetings of the Agricultural History Society have furnished much information and many obscure items of interest. In this connection I wish especially to mention R. H. True, O. C, Stine, G. X. Collins, F. L. Lewton, Cicorge K. Holmes and Mary G. Lacy from whose papers I have taken material. I have also made free use of an extensive bibliography of literature containing items pertaining to agricultural history which has been collected in the Office of Forage Crop investigations largely the work of Katherine Bort, and I have received many helpful suggestions from members of the staff of that organization. To all of these I am very grateful.

L. C. 


\section{REFERENCES}

A bibliography of the literature from which the material in this book was obtained, is arranged in the closing chapter to which the reader is referred by numbers in parentheses in the text. Where more than one reference is made to a publication the citation of volume and page is included with its number in the parenthesis. The years given in parentheses in the text refer to the approximate time the observations were made and often do not agree with the date they were published. 


\section{CONTENTS}

Preface. . . . . . . . . . . . . . . . vii

ACKNOWLEdGeNTS . . . . . . . . . . . . . . . . . ix

\section{CHAPTER I}

Valee of Agriccltural History

Begiunings of Life-Theory of Evolution-Effects of Environment on Species-Determination of Plant History-Biological Evidence-Ancient Deposits-Historical Evidence-Philological Evidence-Origin of Food Plants-Primitive Agriculture-Plant Culture-Most Food Plants Domesticated by Savages-Food of the Lake Dwellers-Domestication of Animals-Early Civilizations in Dry Climates-Accumulations of Wealth-Food Essential-Conditions Favoring Development of Civilization-Great Civilized Zone-Importance of Agriculture-Division of LaborRural Class Inappreciated.

\section{CHAPTER II}

Old World Agriceltere.

Agriculture of Asia Minor-Egypt-Spain-Italy-Flanders and Holland-England-Simple Agriculture.

\section{CHAPTER III}

Auericax Indias a - Castern Indians-Early Accounts Faulty-
Clases of Indians-EasteContrasts between Indian Tribes-Evidence of Abundance-White Man's Debt-Indian Farming Helpful-Division of LaborDomestic Life Not Unhappy -Cooperation.

\section{CHAPTER IV}

Natural Vegetation in Eastern duerica.

Forage Plants-Wild Rye-Wild Rye Lsed for Food-Wild Rye in the Ohio Valley-Broom Straw-Wire Grass-Natural Food Products of the Indians-Berries-Grapes-Plums--Persimmons - Ground Nuts-Wampee or Tuckahoe-Cassava not grown in Carolina-Conti-Other Marsh food Plants-Prickly Pear-Nuts -Maple Sugar-Clearing Land-Cleariugs in Virginia-New England-Other Clearings. 


\section{('HAPTER Y'}

INdian AgRicultire:

Crops Grown by the Indians-Confusion of History-MaizeVarieties-Yiclds-Early Referenees-Cuba-Texas-CanadaRoanoke Island-Virginia-Later Deseriptions-VirginiaLouisiana-Queber-Illinois-Cooking Methods-Beans and Peas-Species of Lathyrns-Beans Found by Columbus-By Cartier in C'anda-In Virginia-In Maryland.

\section{CHAPTER VI}

Indian Crops-Continued .

Tobaeco-Mentioned by Columbus-Carticr in Canada-Grown in Virginia-New England-Taken to Spain-To England'Tobacco Culture-Squashes, Pumpkins and Gourds-Gourds Common to Both Hemispheres-Cueurbits in Virginia- In Canada-Sunflowers and Artichokes-Sweet Potato-Sold in England-Grown in Virginia.

\section{CHAPTER VII}

Indian Crops-Continued .

Watermelons-Colocynth in Egypt-Unknown to Early Botanists - Melons Grouped with Cucumbers-First Botanical Description of Watermelon-Introduction of Melons in America-Spanish References-Common in the West Indies-Grown in Canada-In Carolina-Not Mentioned by Smith-Grown by the Delaware Indians-Along the Hudson-In New England-Found by the French in Illinois-Considered Native in Canada-Evidence of American Origin-Indian Names-Not Mentioned in AfricaMelons of Asia-Chinese Evidence-Old World Melons of Cucumber Type-Indian Folklore.

\section{CHAPTER VIII}

Souti and Central Anerican Indian Crops.

Peanuts-Introduction into North America-PotatoesHow Brought to England - Early References-Acosta-GerardeClusius-Murray's Account-A History-Hariot Planted Potatoes In Ireland-Potatoes Not Popular in England-Taken to South Carolina-English Opinions-Potatoes in North America-Wild Potatoes-Cassara-Pineapples-Peppers-Tomatoes.

\section{CHAPTER IX}

Miscellaneous Indian Products and Practices . . . . . . . Fiber Plants-Cotton-Origin of Cotton Varicties-Cotton Culturc-Indian Cultural Methods-North Carolina MethodsHill Planting in New York-Virginia Corn Culture-Rhode Island 
Corn Culture-Clean Cultivation-Indian vs. Old World CultureIndian Methods Adopted by the Colonists-Fertilization-Rotation of Fields-Fertilizing With Fish-Iroquois Manured Their Fields-Storing Their Crops-Lnderground Pits-Southern Corn Cribs-Domesticated Animals-Turkeys-Buffalo IntractableQuick to Adopt the Horse.

\section{C'HAPTER X}

Exploration Pemiod.

Pishing Expeditions-Trying European Crops in AmericaSouthern Exploration-Poultry in the Southwest-Introduction of Cattle-Hogs in Bermuda-American Crops in the Old WorldPortuguese Great Explorers-Maize in Afriea-Sweet Potatoes in Indiana-Later Agriculture in Africa-Spanish Settlements and Influence-Policy Liberal-Introduced Live Stock-Florida and New Mexien Settled-Products-Obtained from SpaniardsColonial Trade-Large Herds of Cattle.

\section{CHAPTER XI}

Exglish Colonial settlenents.

United States Needs No Colonies-Delay in Settling AmericaStrong Manhood Needed-Feudal System and American Colonization-Merchant Promoters-Virginia Colony-Policy of John Smith-First Attempts at Farming-Indian Prisoners Saved the Colony-Kemps and Tassore Set at Liberty-First White Farmer-First Livestock-Starving Time-Beginnings of Indian Troubles-Iord Delaware's Greed-Gov. Dale Takes ChargeOther Work Underway-Settlement at Henrico-Appomattox Lands Seized - Gov. Dale's Plans-Agriculture Stifled-Tobacco- Varieties-South American Varieties-First Big Crop-Policy Changed-Efforts to Restrict-Culture General-Condition in 1629-Colony Grows-Fluctuating Prices-Diversified FarmingRolling Houses-Efforts to Sustain Higher Prices-Improvement of the Crop-Other Crops Grown-Agriculture by Legislative Enactment-Silk-Bounties on Silk-Staple Produets Encouraged. Live-stock in Virginia-Values of Dressed Meats-Exporting Hides, Sheep and Mares Prohibited-Final Results.

\section{CHAPTER XII}

Massachusetts and New Haupsirire.

Plymouth Settlement-A Fortunate Discovery-Building at Plymouth-How Squanto Saved the Colony-Squanto's Experiences -Corn Planting in 1621-Communistic Labor-Communism Abandoned-Private Ownership of Land-Perseverence-Expansion-Seeds and Plants to be Sent in 162S-Settlement of Massa- 
chusetts Bily-Shipping Live Stock-Better Conditions-Source of Live Stock-Inflated Prices-Depression-Live Stock Management-No Fence Law-Embargo on Sheep-IIay Making-Sult Marsh Hay Inferior-Grain Growing-Winter Wheat Introduced -Rye Adapted to New England-Work Animals-Food Stuffs Plentiful-Garden Crops-Orchards-Fiber Plants-Lack of Money Crops-Iron Manufacture-Thrift-Country Described -New Hampshire-Timothy-Agriculture Secondary.

\section{CHAPTER XIII}

New York and New Jersex . . . . . . . . . .

Inducements-Dutch Good Farmers-Farm Houses-Trouble with the Government-Orchards-Clover-Long Island SettledSocial Life-Increase in Land Values-Commerce-Financial Statement-Outlay-Receipts-An Important Crop-General Farming-Exports-New Jersey Types of Soil-Live Stock-Land Ownership-Early Accounts of Farming-Fast and West Jersey Contrasted-Farm Practices-Orchards-Fiber Crops-ExportsNew Jersey Described.

\section{CHAPTER XIV}

Maryland and Delaware and Pennsylyania . . . . . . .

A Well Planned Expedition-Fortunate Location-Corn-Tobacco Culture-Live Stock Industry-Wild Cattle-Price Fixing-Land Titles-Titles of Nobility-Indentured Servants-Periods of Service-Gain in Wealth Delaware-Swedish Settlements-Agriculturists-Swedish Influence on Pennsylyania-Swedish Farming -Pennsylvania Settlement-Title to Land-Servant Class Prominent-Building a Pioneer Home-First Clearings Often SoldHelp from Surrounding Settlements-Thrifty Dutch-Accumulation of Wealth-Wheat Growing-Manuring-Crops ProducedTobacco Inferior-Lead in Agriculture-Scientific KnowledgeExports-Summary.

\section{CHAPTER XV}

Connecticut and Rhode Island.

Plans to Colonize-A Disastrous Attempt-Connecticut Settled -Livestock Industry-Iand Grants-Regulatory Laws-Fairs or Markets-Selfsufficing Agriculture-Over-production of WheatBarberry Eradication-Hemp Ordered Sown-Ship Sent for Cotton-Sheep Raising Encouraged-Exports-Tobacco-Later History-Rhode Island-Conditions Favorable-Climate and Lay of Land-Indian Farming-Food Stuffs-Dependence on the Indians-Land Holdings-Compelled to Improve PropertyLarge Farms-Swine Production-Branding Law-Grist MillsSmall Grains-Dairying-Importing Cattle-Dairying Profitable -Commeree-Social Life-Summary. 
Means of Communication-Pioneer Settlers-First SettlementUtilization of Pastures-Livestock-All the Year Grazing-Early Farming Crops Grown-Exports of Agricultural Products-South Carolina-Unhealthy Coast Conditions-Ashley River Settlement -Experimental Farm-Cotton-Imported Live Stock from New York-Horse Breeding-Governmental Policies-Grand Model of Government-Nllotment of Land-Grand Model UnworkableRice Culture-Low Land Crop-Harvesting-Indigo Culture (Jbjections to Rice and Indigo-Labor-Social Life-Live Stock Ranches-Indian Troubles-Commeree and Industry-SilkGeorgia-Settlement at Savannah Aid from South Carolina-Land Holdings-Gardens-Experimental Gardens-Another AccountAllowed to Decay-First Publically Owned Testing Garden-Early Enterprises-Silk Produetion-Expensive Silk-Change in Management-Public Filature-Bounties on Food Stuffs-General Farming-Cattle Ranches-Slavery-Exports.

\section{CIAPTER XVIII}

French Settlements and Influence

Beginnings of Agriculture-Jesuit Farms-Governmental AidLive Stock-Fort Frontenac Built-Agricultural Expansion-Illinois Settled-Exports from Illinois-Mississippi Settled-Mississippi Bubble-Contributions to American Agriculture-Perique Tobacco-Effect on the English Colonies.

\section{CHAPTER XVIII}

Colonial Expansion.

New England Difficulties-New York Limitations-Restrictions of the Southern Colonies-Crossing the Mountains-Western Maryland and Virginia Settled-Kentucky Explored-Driving Cattle to Market-Advancenent in Agricultural Knowledge-Trials of Early Agricultural Writers-Washington's Opinion of Agricultural America-A Live-Stock Comment.

\section{CHAPTER XIX}

Introduction of European Crops.

Grasses and Clovers-English Grass-Claverack-Grown in Pennsylvania-Rerl Clover in New York-Bluc Grass-Species Not Well Defined-Grass in Rhode Island-Timothy-Orchard Grass-Rye Grass-Crab Grass-Nut Grass-Alfalfa-Alfalfa in the West Indies-In Georgia-Sent to Pennsylvania-In South Carolina-Mentioned by Washington-Millet-Used by SlavesMillet in New England-Cowpeas-In Asia-On the American 
Contineut-In . New lingland-In South Carolina-In North Carolina-lixported-The Term Cowpea First Used-Grown by the Indians. Sorghum-Introdued by Slaves-Hops-Native species.

\section{('HAT'TER XI}

INTHOduction of Domestic Antmals.

Swine-Salt Pork Exported-Cattle-Black Cattle-Sheep and Goats-Prejudice Against Mutton-l'oultry-IIorses-Racing on Long Island-In Virginia Narragansett Pacer-Origin of the Breed - Pacers Popular.

\section{CHAPTER XII}

Farm Implements and the Use of Fertilizers.

Plows-Harrows-Cultivators-Rollers-Netal Working Prohibited-Use of Manure-Lime-Oyster Shell Lime-Limestone in New Jersey-Used as Fertilizer in New York-Land Plaster-C'sed hy Richard Peters-Stable Manure - I Commereial Commodity.

\section{C'HAP'TER XXII}

Silatery. . . . . .

An aid to Colonial Farming-Negros More Immune to Malaria than Whites-Slavery Profitable in the South-Slavery in Massachusetts and Rhode Island-In Connecticut-In New YorkSlaves as Skilled Artisans-Freed in the North-Slavery Limited in Fxistence-Conditions Relieved by New Settlements-Stratified Social Life.

\section{CH.APTER YYIII}

Tile Effect of Colonila Comierce on Igricultere. . . . . . 279 Started in New England-Early New England Boats-The Dutch West India Company-Ship Building in Rhode Island-River Craft-Ship Owmership Centered in New England-Commercial Products-Commerce of Pennsylvania and New York-New England Exports-Decline of Farming in New England-Navigation Laws-Manufacturing Inevitable.

\section{CHAPTER XNIY}

The Influence of the Maxtfacture of Alcololic Beverages ox Colonial Agricultere. .

Alcoholic Beverages Considered Healthful-Supply Inadequate at Jamestown-Pilgrims Preferred Beer to Water-Heavy Drinking Prohibited in Connecticut-Wine as a Commereial Product-New England Beer-Strawberry Wine-Virginia Beverages-Liquors 
Became a Commercial Commodity-Indian Trade-Evils-Rum as a Medium of Exehange-Beginnings of Whiskey ManufactureSummary.

\section{CHAPER IIV}

Relations With the Mother Country.

English Commerce Built on Ameriean Trade-New England Lacked a staple Product - ship Building Materials-Other Beneficial Commodities-Textile Raw Products Inadequate-Dye stuffs a Failure Except Indigo-Wines Lnsatisfactory-Oil Products-Metals a Disappointment-Quit Rents-Independence Inevitable-1 summary of the situation.

BIBliograpitY . . . . . . . . . . . . . . 308

IXDEX. . . . . . . . . . . . . . . . . . . . . . . . . 



\title{
THE BEGINNINGS OF AGRICULTURE IN AMERICA
}

\author{
('HAPTER I
}

\section{VALUE OF AGRICULTURAL HISTORY}

The true history of a people includes all of the events connected with them. No such record ever has or could be made. Historians must select from the great multitude of happenings such items which in their judgment are of most value to future generations. If the historian is unprejudiced and impartial he reports the mistakes and failures as well as the successful exploits. They are of equal value as guides for actions under similar circumstances in the future. This is the great value of history. We have no way of judging the future except by the past. Unfortunately most histories deal largely with the spectacular military operations or political upheavals and very little with the peaceful pursuits which make a country prosperous. Wars are often hindrances to progress. They are enormously destructive of lives and property. Moreover a nation, in an impoverished or destitute condition, can not wage war successfully. An army without adequate munitions may often retreat and eseape destruction but an army without food is at the mercy of its enemy. The history of agriculture is as valuable to the agriculturist as political history is to the political economist or ehurch history to the theologian.

\section{BEGINNINGS OF LIFE}

While the proof is far from absolute and any one may question the conclusions who will and not be denied material for an argument, the consensus of opinion of scholars who have studied available evidence obtained from rocks and the skeletal remains of organisms found in them, together with all known facts gathered in biological sciences, is strongly in favor of the theory that the earth was a lifeless mass of molten material rotating through space for a long period of time, probably many millions of years. On the duration of that period authorities differ. It is quite 
clear, however, that the lifeless period was equal in length if not longer than the period which has elapsed since life appeared on the earth. When life funally appeared, that is, living things possessing skeletons which could be preserved in rocks as fossils, the species were of a very simple structure or what are termed species very low in the seale of derelopment. They were all of a marine nature. There was a period perhaps when all forms of living things had to live in water and were of similar form and structure all over the worlel. At any rate there was no known locality or isolated region on the earth eapable of supporting life which did not possess living organisms, of which the oldest specimens coming down to us are all of a similar character.

Superimposed above the rocks which bear fossils of these simple early forms are other rocks which were formed in much later geologieal ages and which contain fossils of more complex organisms, and rocks of still later formations contain fossils of still higher types until we find fossils closely resembling the plants and animals which exist at the present time. As these living forms ascend in the seale of development a greater differentiation of types and species in certain localities of the earth is found than existed in the early geologieal ages.

\section{THEORY OF EVOLUTION}

It is now believed by a great many students of biological sciences that the different species of plants and animals which exist today have been gradually developed from lower forms instead of each having had a separate and distinct ereation. This is known as the theory of evolution. It is based on two natural laws directly opposed to each other,-the law of variation whereby no two individuals even of the same species are exactly alike, and the law of heredity whereby offspring resemble to a greater or less degree their parents. Whenever there has been a variation possessed by any individual which was an aid to that individual in securing its food, in protecting it from the weather, which made it less likely to be seen or destroyed by its enemies or which was beneficial in any manner, the likelihood of that individual persisting and perpetuating its kind was increased and by the law of heredity that variation was likely to be transmitted to its progeny. It has been by this means of natural selection or the "survival of the fittest" that the higher or more complex species have been evolved from lower or simpler species. 
Whether it took forty million years or ten times that number to develop living species to the remankible condition now existing is a question which ean not he answered with any degree of certainty.

The process of evolution has uncluubterly been greatly hastened by the rare though not in our time entirely unknown appearance of sports or individuals which differ much from their parents. Where there is a marked difference the progeny is known as a mutation.

Another factor which aids in originating new forms has been the crossing or interbreeding among different species. The resulting progeny of such a eross is known as a hybrid. A hybrid may resemble one parent more than the other, or it may distinetly differ from either, but in most eases there is a blending or combining of the characters of both parents. It should be borne in mind that it is only among elosely related or similar species that a crossing occurs which results in fertile offspring. Were it not for this provision of nature the highly differentiated species would not have developed. Promiscuous interbreeding would have resulted in a homogeneous or mongrel race of living organisms.

\section{EFFECTS OF ENVIRONMENT ON SPECIES}

While the early living things were all of a similar nature the conditions or environment under which species have developed from those primary forms have had a tremendous influence in determining the kind of an organism which is evolved. The climatic factor is of great importance. It is quite likely that there were no great differences in climate between the polar regions and the tropics during the early periods when life was first created, but as the carth cooled and seasonal variations became more pronouneed, the peculiar climate of a region shaped and modified the forms which developed in that region. When radical climatic changes took place as in the glacial periods it frequently happened that whole races of living forms were destroyed as they could not adapt themselves to the new conditions and their place was taken by speeies better equipped for the changed environment. The tendency to isolation of species in regions set off from the rest of the world by natural barriers, such as occans, lakes, rivers, mountains and deserts has led to the wonderful multitude of different forms of plants and animals 
which have come into being. Since man has assumed domination on the earth he has to some extent overcome the effect of these barriers and the transportation of species from one locality to another has been facilitated.

Between the Old World and the New, or between Australia and the rest of the world, there are much clearer lines of demarcation separating species than exists among the species on the continents of Europe, Asia and Africa.

Nevertheless, there are several species common to both hemispheres, especially in the northern latitudes and we have the incontrovertible fact that there were human beings in America before the white man came who differed not in essential characteristics from old World human beings, and it is possible, even probable, that they brought some Old World products with them if they came originally from the Old World.

\section{THE DETERMINATION OF PLANT HISTORY}

Biological Evidence.-In determining the origin of cultivated plants, the biological evidence is usually given first consideration. Few species of plants or animals are indigenous to both Eurasia and America except those of aretic or subarctic regions. The coconut palm and the bottle gourd are exceptions to this rule. There were two lines of entry of plants and animals to North America from the Old World, one by the way of Greenland to Labrador from Europe, the other through Alaska from Asia. If the range of the plant or animal immigrant is not continuous through either of these routes, it is considered strong evidence that the species was introduced after the discovery of America. On the other hand if there exists no record of a food plant or animal in the Old World literature prior to the discovery of America the presumption is, that it is of American origin. The habitat of wild prototypes or closely related species is also helpful in determining the origin of a domestic species.

Ancient Deposits.-In sereral instances the question of whether a plant belonged originally to the Old or the New World has been settled beyond dispute by the finding of identifiable remains in ancient deposits. There are but a few places in the world where seeds and portions of plants have been definitely preserved from ancient times. The tombs of Egypt, the ruins at Pompeii, the kitchen refuse of the Lake Dwellers have been 
helpful in establishing the history of plants of the Old World, while the graves of Peru, the cliff dwellings of Arizona and the mounds of the Ohio and Mississippi valleys have furnished much positive information for America. ${ }^{1}$ The identification of plants in ancient decorations is sometimes helpful but often leads to wrong conclusions.

Historical Evidence.-Historical data including the botanical descriptions are next in value. Such evidence must be used with caution or it will lead to error as often as to the truth. It is only when a large number of references and observations by different writers are brought together and carefully compared and analyzed that it is safe to draw conclusions. Frequently when enough painstaking research has been done the historical record is such that it will remove all doubt.

Philological Evidence.-The fourth class of evidence is embodied in the names by which species are commonly known. Sometimes, but not by any means always, a name is imported with a plant. When the origin of such names can be decided without any doubt, the original home of the species may be suspected. Here again extreme caution must be observed for the instances where wrong names have come into common use are numerous.

Some of the common names which have persisted in English nomenclature indicate the round-about-way in which American products reached England, as for instances the Jerusalem artichoke and the Irish potato. Some misleading names which were once in common use have been dropped as French beans for Phaseolus vulgaris, Turkey wheat for Maize, and Spanish potatoes for sweet potatoes. But perhaps the most flagrant injustice in names was committed when the great American bird, was designated the turkey.

\section{ORIGIN OF FOOD PLANTS}

With many of our most common food plants it is impossible to determine with any degree of certainty the particular locality in which they were originally brought into cultivation. It has

${ }^{1}$ For the identification of ancient remains found in America, see: Wittmack, L. In Reiss and Stubel, "Necropolis of Ancon in Peru," vol. III, plates 105 to 107. Berlin 1880-1887; also Trans. Acad Sci. of St. Louis, vol. XV, p. 10, 1905; Harshberger, John W., Bull. Mus Sci. and Arts Tniv. of Pa. vol. I, No. 3, 1898; Nordenskiold, G. "Cliff Dwellers of the Mesa Verde," Trans. by D. Lloyd Morgan, p. 94. Stockholm. 
now been well established that human beings have dwelt on this: earth many times the 5926 years which has been popularly taken to have elapsed since the creation of the first man. The common belief, of this short period of man's existence, should be discarded along with the once popular conceptions that the earth was flat, that it constituted the principal creation and that it oceupied the center of the uniserse.

If it is granted that the first human beings appeared not 4004 B.C. but thousands of years carlier, then it is easily conceivable that this earth has had many populous tribes and nations rise and fall, that there have been many migrations of peoples accompanied by distributions and redistributions of food plants, that many cultivated erops have been discarded, forgotten and rediscovered. Unquestionably, "the greatest study of mankind is man" and about all the knowledge we have in regard to some of the early peoples relates to the products they used for food and the means they had for sceuring those products.

\section{SIMILARITY OF PLANTS IN THE OLD AND NEW WORLDS}

There are many similarities between food plants of the tropical and subtropical regions of the Old World and the New. Investigators of the subject are not agreed as to how these similarities eame about. Some believe that there must have been at some time prior to the royage of Columbus communication directly between the two hemispheres, while others insist that these similar plants have been disseminated since the discovery of America. Still others make an casy though unsatisfactory explanation, by aseribing these different products to separate creations under similar conditions. Take for instance yams and sweet potatoes, plantains and bananas, or the various species of caladiums, as colocasia and taro. The resemblances are too strong to be lightly explained by chance development, and the evidence that they were known around the world in pre-Columbian times appears too clear to be casily refuted. Likewise among animals, there are striking resemblanees even though there are distinet differences. Monkeys are found, though of different species, both in Africa and South America. The Old World crocodile and the New World alligator have many characteristies in common. The tapir of Tasmania and the tapir of Central and South Ameriea are very similar and both are relies 
of a large group of animals that once roamed over the carth. The African parrots and the South Ameriean maeaws have peculiarities in common. All of these species perish if exposed in cold climates which apparently precludes the possibility of their dissemination through cither the Iabrador or the Alaska route of entry under their present climatic conditions.

Primitive Agriculture.-Agricultural pursuits antedate by thousands of years recorded history. Many writers have speculated on the origin of agricultural practices. Some have held that primitive man was first of all a hunter of wild game. Others with perhaps more reason to justify their conclusions argue that the first human beings on the earth were vegetarians, that they collected plants and seeds for food before they became acquainted with the taste of flesh in their diet. Necessity for sustenance has been the primary force in agricultural progress. The greater the need, the greater and more rapid has been the adrancement, provided means were available for satisfying that need. Primitive people, with a scanty food supply, take up new productions with less conservatism than do well established races with adequate rations.

Plant Culture a Start towards Civilization.-One of the greatest erents leading to civilization must have occurred when primitive man first began plant culture, by gathering seeds and sowing them in favorable locations for their growth. What led to that first attempt? Had the wonderful phenomenon of nature, the germination of seed, the subsequent growth and final fruition excited his curiosity? Did he accidentally drop in a rich soil some of the sceds which he had gathered for food and thus observe a more vigorous growth than obtained amid natural conditions? Was it an attempt to increase the supply of some more palatable species? These questions are asked to direct attention to the situation, as obviously they can not be answered. But what ever the occasion or the motive which animated the act, the fact that he had sown seed and harvested a crop was of a tremendous import. If his habitation had been at all fixed previously, it was due to favorable shelter or protection or a perennial food supply as fish, game, ete. Now there was a further incentive to live in or near one locality. He must remain to gather the fruits of his labor. What a stimulus to mental effort those first essays at plant culture must hare been to the undeveloped savage mind. 
Most Food Plants Were Domesticated by Sarages. - It is a significant fact that practically all of our food plants have been domesticated by what are termed savages. In many cases the wild form from which the food plant was obtained has entirely disappeared. The great cereal wheat would survive in most parts of the world but a few years if it were not for the assistance of man in gathering the seed and preparing the soil for its culture. It makes a very scanty growth when compelled to compete with other plants and its natural enemies as birds and other animals would soon complete its destruction if it were thrown on its own resources. Perhaps in the remote past wheat did not have so many enemies, and maybe the conditions were more favorable for its growth or perhaps the original wheat plant was like some of our wild grasses toclay and has been brought to its present state of perfection through selection of the better strains by man. No matter which supposition is true the domestication of wheat antedates recorded history as wheat kernels preserved in the kitchen refuse of the Swiss Lake Dwellers and in the tombs of Egypt do not differ in general appearance and size from varieties grown today. Civilized man has received a rich inheritance from the uncivilized past.

Food of the Lake Dwellers.-The kitchen refuse of the Lake Dwellers in Europe throw much light on the antiquity of cultivated crops on that continent, but the use of the plants mentioned in northern Europe was undoubtedly much later than the period when these same crops were commonly cultivated in the Mediterranean region and in Asia Minor. "From the very commencement," says Munro, "the lake-dwelling colonists cultivated flax, two or three varieties of barley and wheat, millet and peas. The only addition that appears to have been made in the Bronze Age were the oat (Avena sativa) and the dwarf field bean (Faba vulgaris) of a strikingly small size. On the other hand we have to note the absence of winter wheat, rye, hemp, and most of the culinary and garden vegetables. Fruits and berrics were largely used as food, but there is no evidence to show that they were cultivated. Among these the following have been identified: apples, pears, plums, sloes, one or two species of cherry, raspberries, blackberries, and strawberries, hazel and beechnuts, water chestnuts, poppies, etc. Grape-stones from Wangen were hesitatingly included in Professor Heer's list of fruits from the lake dwellings. . . Bread 
was made only of wheat and millet, that of the latter generally containing some grains of wheat and linseed. Cakes made of the seeds of the poppy were also found at Robenhausen" (\$1 p. 536).

Domestication of Animals. - Second only to the culture of plants was the taming of animals and controlling their existence for the benefits of human kind. It is possible and quite likely that the domestication of animals occurred independently of the raising of food plants. Perhaps animal husbandry preceded agronomic activities. Here again numberless questions arise. What was the first animal to be tamed? Was it a bird or beast? Did primitive man keep it as a pet companion or to let it grow that it might furnish more food? Whatever the purpose, when man became master of lower animals he took a long step towards civilization. Some primitive peoples have never taken that step. It has been argued with convineing plausibility that the early civilizations of Asia were due to the numerous native species of animals on that continent which are capable of domestication. Not only did the control of other animals stimulate mental acitivity on the part of man, but the use of animal products as milk, flesh and eggs in the diet aided in physical development and made conditions more favorable for a large population.

\section{EARLY CIVILIZATIONS IN DRY CLIMATES}

There were four regions in which civilizations developed at a comparatively early date. One of these was in southwestern Asia especially along the Tigris and Euphrates valleys, while Egypt in Africa was another seat of early advanecment. In Mexico and Peru the natives of the New World had made great strides towards achieving affluence and social order. It is reasonable to expect to find certain conditions common to all four of these regions which might explain the cause of their civilizations. There is climatic similarity in all four countries, that is, they are all arid to sub-humid and warm to hot. All possess areas of land which are capable of producing abundant food crops. Another feature worth noting is that in all foul locations storage of food from one harvest to the next and from periods of plenty for periods of scarcity is not only necessary for the maintenance of a large population but the climate is favor- 
able to such preservation. One looks in vain for a civilization which developed where harvests extended throughout the year as in lumid tropical climates. So the storing of food may be anded to the list of factors involved in creating a higher order of human beings and the advancement in that art played no small part in the spread of eivilization.

Accumulation of Wealth. - The change from pure savagery to crop culture and to the care and rearing of animals was marked by another characteristic of eivilized man-the acquiring of wealth. 'The seed saved from one crop for next season's planting, the vessels in which it was stored, the animals kept for breeding purposes, all represented true wealth. Effort had been expended in obtaining them and their possession enabled their owner to maintain a higher standard of living. The earliest evidence of man's existence on this earth, evidence antedating by many eenturies written history, shows man to have had in his possession many useful implements for hunting, tillage, defense and offense. From the days of primitive man to the present the peaceful production of wealth has been constructive. It has been this which has made a nation or people great. A knowledge of the effects which various government policies have had on the industrial development of a country is of greater practical value than knowing the tacties of its military leaders. The time should come when the success of a nation is measured less by the size of its military maehine and more by the material welfare, eomforts and happiness of its people.

Food Essential.-Progress in the development of the human race is in direct ratio to the plentifulness of its foodstuffs. Living on the natural products of the land obtained by hunting and fishing makes men physically strong but fails to develop their mental faculties. No great civilization has ever been produced under such conditions. The seanty products produeed naturally and the uneertainty of procuring them render a large population under such conditions impossible.

Conditions Favoring Development of Civilization.-When food is too easily obtained people become indolent, dissipated and degenerate. On the other hand, if the struggle for existence is too intense, poverty and ignorance result. The condition in which evolution is most favored is where the foodstuffs are abundant but where the expenditure of considerable human effort is necessary to obtain them. 
Great Civilized Zone.-The greatest development of the human race measured by achievements has been in a belt of the earth bordered on one side by the frozen regions of the North and on the other by the ferer infested tropics. Modern sanitation is doing much to extend this belt to the southward. A similar belt in the Southern Hemisphere offers an equally good opportunity for adrancement in areas where the conditions of rainfall are favorable to the production of crops.

Importance of Agriculture.-Agriculture ol at least the possibility of securing agricultural products is the basis for suceess of any civilized people. It furnishes the sustenance of life on which all other operations depend. A large population may be sustained by agriculture alone, that is, the people may be fed and clothed. By engaging in manufacturing, a still larger number of people may be supported and a higher standard of living may be maintained. Farmers more than any other elass may be said to be creators of new wealth. Other so-called producers only utilize natural resourees which have been stored up by a beneficent providence. All deposits of minerals or the products of a forest may be destroyed, but the agriculturist, if he takes the proper eare of his farm, may go on producing erops indefinitely. In growing a crop of corn, wheat or cotton, in reforesting a cut-over tract, or in raising flocks of live stock he has produced something of value to society which did not exist before.

Division of Labor.- When some of the population devote their whole time to manufacturing clothing or implements, the farmers have more time to devote to raising erops or rearing live stock. Another class of people may undertake the matter of transporting the products of the farms to those engaged in the manufacturies and in return take the manufactured goods to the tillers of the soil. This also furnished employment to more individuals and is for the good of society. Still another class may be rendering a useful service in mining, another in lumbering. while still others aid all by promoting their physical, intellectual, moral and spiritual well-being. This division of labor is essential for the good of the country as a whole. As workers become expert in certain lines they produce more efficiently and abundantly.

Rural Class Unappreciated.-The importance of farmers to a nation has not always been appreciated. Too often the ruling class has looked upon farmers as a necessary adjunct to feed themselves and the commereial classes, but of 110 other value to 
the nation. The need of agricultural products is easily understood; not so the welfare of those who produce them. The terms plebe, boor, serf, villain, heathen, pagan and peasant which have been bestowed upon agriculturists in the past by those who have felt themselves to be their superiors carry a eertain amount of odium. Not many centuries ago the tillers of the soil in Europe were considered as belonging to the soil they tilled. Ownership of them was transferred along with the land like houses, barns, or fences.

Agriculturists not Combative.-When human beings engaged in agricultural pursuits, especially erop production, they lost much of the warlike spirit which characterizes savage races. To live in peaceful enjoyment of their possessions is a greater boon to farmers than the glories of conquest. This characteristic has made farming nations easy victims of the warrior elasses. The history of the Euphrates and Egyptian civilizations reveals a suecession of conquests of the crop-growing farmers of the valleys by the nomadie hunters and stoekmen from the hills. The conquerors, adopting in time the peaceful occupations of the localities they conquered, usually lost much of their combativeness, and in eourse of a few generations were in turn overwhelmed by stronger tribes from the hills. Gradually it beeame neeessary for the agriculturists to support and maintain a professional soldier class in order to be protected from outside aggression. As the military forees usually were the dominant ruling elass of the country they frequently beeame arrogant and oppressed the unorganized producers. A six thousand year's struggle of farmers to control their own destinies marks the development of eivilizations anong the white races. There have been numerous revolts and uprisings of farmers usually referred to by historians as periods of "Agrarian Discontent." Publie sehools and universal edueation have done much in Ameriea to enable farmers to safeguard their interests, but there is still a great deal to be accomplished before the oceupation of farming receives the respect and emoluments which its service to human society entitles it. 


\section{CHAPTER II}

\section{OLD WORLD AGRICULTURE}

The highest developed agriculture in pre-Columbian times was in the countries bordering on the Mediterranean Sea. There were located the most advanced civilizations. That body of water could be traversed without the guiding hand of the magnetic needle. It was the main highway of travel and commerce between the West and the East. Its shores and the fertile valleys of the streams flowing into that sea had been the seats of ancient learning which have so wonderfully influenced the development of the nations of northern and western Europe and through them America. The influence of those countries on the agricultural development of the Occident has been no less marked than on its intellectual achievements. We must know the agricultural conditions of these countries at the time America was discovered to understand the influence which they had on American farming and in turn to appreciate the wonderful effect that America has had on the agriculture of the eivilized and much of the semi-civilized peoples of the world.

Agriculture of Asia Minor.-Rauwolff, a Hollander, who visited Asia Minor in 1573-4 has given a fairly complete list of food products used by the Turks and Syrians around Tripoli and Aleppo at a time before American products had been introduced to any great extent. "In these gardens, as we came in, we found all sorts of sallating and kitchen-herbs, as Endive, Lettice, Ruckoli, Asparagus, Seleri, whose tops are very good to be eaten with salt and pepper, but chiefly that sort that eometh from $\mathrm{Cy}$ prus, Taragon by the inhabitants called Tarchon, Cabbages, Colliflowers, Turneps, Horse-radishes, Carrots, of the greater sort of Fennel, Onions, Garlick etc. And also fruit, as Watermelons, ${ }^{1}$ Melons, Gourds, Citruls, Melongena, Sesamum (by the natives called Samsaim the seeds whereof are very much used to strow upon their bread), and many more; but chiefly the Col-

1 (Angurix) See discussion under watermelons. 
ocasia, which is very common there, and are sold all the year long: . . IIere groweth a great quantity of Sugar-eanes so that there is yearly sold a great many sugar-loaves that are made thereof

There are also abundance of delicate orchards, that are filled with Oranges, ('itrons, Lemons, Adam's-Apples, Sebesten, Peaches, Morelloes, and Pomegranates etc., and anongst them you find sometimes Apples and Pears but very few nor so many sorts, nor so big, nor so well coloured as ours. . They have abundance of Pulses in these countries which they feed upon, so that you see several in their Batzars which sell nothing else but them. Among the rest you will find abundance of Phaseoli, or Kidney-beans, ${ }^{1}$ little and great ones very white; and many sorts of Cicer, which they call cotane. . . These put me still in mind of another strange plant, by the Arabians call'd Mas, whose leaves and cods are pretty like our Phaseolus, and the cods contain little round seeds, something less than our pease of a dark green colour . . Clusius, calleth it, in his Epitome of the Indian plants, by the name of Mungo" (96). It should be noted in these quotations that the use of celery as a food originated in the Mediterranean region rather than in England where it grows wild and where it has usually been thought to have been domestieated. Ray (1663) confirms this when he observes in regard to Italy, "They use several herbs for Sallets which are not yet, or have been but lately used in England, v. g. selleri, which is nothing else but sweet smallage the young shoots whereof, with a little of the head of the root, eut off they eat raw with oyl and pepper" $(96, v .1$, p. 346$)$.

Colocasia one of the most prominent of the carly food plants of Asia Minor belongs to the Caladium or elephant-ear genus of plants. Taro and dasheen are names also given to the same or similar species of this genus in other parts of the world. The starchy tubers which resemble Irish potatoes are the parts usually eaten, although the stems and leaves, cooked in the same manner as spinach is customarily prepared, are edible. The Caladiums are wide spread and appear to be indigenous in the West Indies and Central America as well as in the Old World.

Sebesten was a plum-like fruit of the genus Corida.

The term Adam's apple may have meant a citrus fruit, Citrus medica, from a fanciful belief that that fruit still bears the imprint of Adam's teeth or it may have been the plantain Musa paradisiaca

Cowpeas. 
which was also considered by many to have been the furbidden fruit. The plantains are so closely related to the bananas that no one has been able as ret to distinguish elearly the history of each. There are a large number of species of these plants apparently indigenous to the New World as well as a still greater number of species found in the East Indies and other parts of the Orient. This would indicate that the genus Musa is native to both hemispheres.

In addition to the garden vegetables mentioned by Rauwolff, there were the bread grains or field crops of wheat, barley, rye, millet and sorghum.

Agriculture in Egypt.-The valley of the Nile has had a well advanced agriculture for at least six thousand years. Historical records do not go back to the time when the Egyptians did not have domesticated cattle, sheep, goats, swine, horses, donkeys and fowls or when they raised not crops for human food. Farming in Egypt was not the simple art so often pictured. The floods of the Nile were uncertain in rolume, having much the same effect as extreme droughts and freshets in humid climates. The Egyptian farmer had to fight constantly against the eneroachment of rushes and other weeds. He had to find or develop winter growing crops that would mature after the floods had subsided in early summer and before hot weather came the following spring. He had to devise methods of storing grains and forage during seasons of plenty for times of scarcity. The earliest accounts show that the ancient Egyptians raised mainly wheat, barley, lentils and millet; oil producing plants such as the castor bean and sesame; and many regetables which were used for salarls.

Ray about 1660 collected the following information from several travelers to Egypt. "Their diet is generally simple, abhoring mixtures and variety. Rice boiled in mutton broth, Lentils, Pulse, and legumes; Bete, Mallows, call'd Baima, Cucumbers, Melons, Citruls, Dates, Figs of the Syeamore, Plantanes, Pomegranates, Grapes, Oranges, Lemons, Citrons, Sugar-canes, Colocasia root, ete. make up the greater part of the dict. The richest sort eat mutton, poultry, and sereral sorts of fish from the Nile, . . All their bread is made of Wheat, and they make abundance of milk-meats. Their kitehen herbs are water'd every day, all their gardens being planted near the banks of the Nile, which is one reason that their sallating is more watry and 
insipid than in Italy; yet if they did not water them every day in Egypt, they would soon be dried up" (96, v. 2, p. 412).

Agriculture of Spain.-Spain was the leading civilized nation of the world during the century eulminating in the discovery of America and the circumnavigation of the earth a few years later. Her people were intelligent. They possessed wealth. They were enterprising and venturesome. More than this Spain had the best farming elass of the world at that time in her Mohammedan population. The Moors may be said to have been natural farmers. They were unusually successful

\section{LAC, CASEVS, BVTYRVM.}

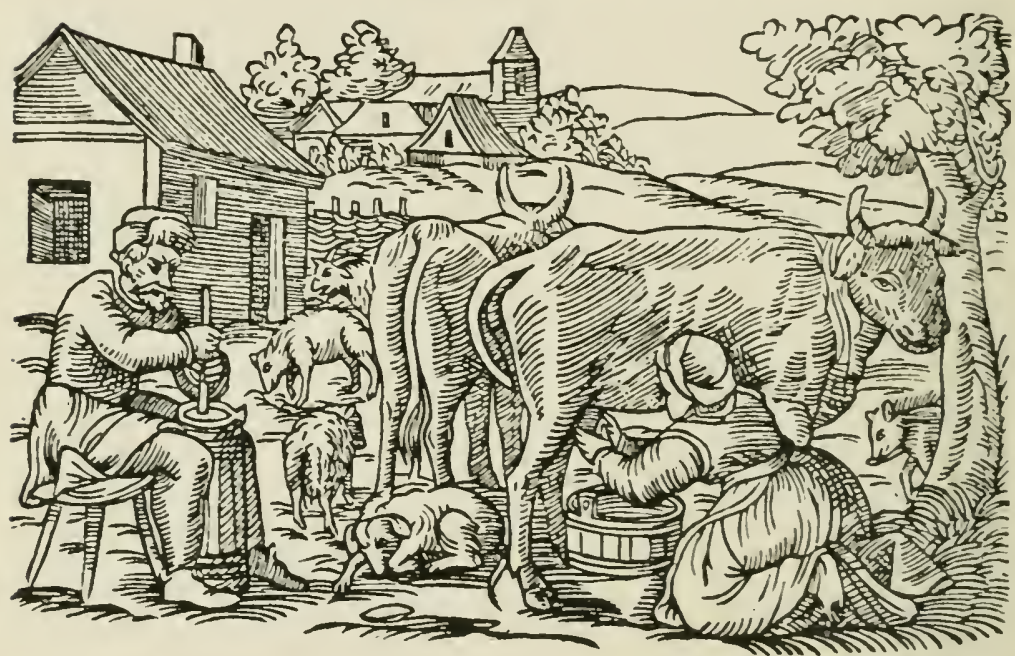

FIG. 1.-A sixteenth century dairy farm scene in Europe. From Mattioli, 1598.

as animal husbandmen and exercised a high degree of intelligence in their agricultural pursuits. Excellent breeds of live stock, orchard fruits and farm crops had been developed by them or obtained by them from still earlier peoples. Much of the foundation stock of our fastest horses, our fine-wooled sheep, our best asses came originally from Spain. The wave of religious fervor which resulted in the expulsion of the Moors from Spain simultaneous with the discovery of America marked the beginning of decadence in the great Spanish nation. Great wealth acerued to Spain as the result of the discovery of 
America, but it could not replace the intelligent, industrious, thrifty agricultural people she had driven out of her realm.

Agriculture of Italy.-The ancient Romans had made great progress in farming before the Christian Era. Ox and horse labor had displaced much of hanc. labor. They had practically all of the small grains which we have now and many of the forages. Wheat, barley, rye, millet and sorghum were the most common field crops of grain. Clover and alfalfa were grown for forage. After the fall of the Roman Empire the erops of the early Romans were still grown and the vineyards, orchards, herds and flocks of Italy still produced food for man. Dairying was in common practice, (Fig. 1) especially in the northern part of Italy and the art of curing and storing of forage was wcli understood and commonly practiecd.

Agriculture of France.-The agriculture of southern France was much like that of Italy and the other Mediterranean countries. In northern France crops adapted to cooler climates such as oats, buckwheat and the hardier grasses and clovers were grown in addition to the other common grain erops. The French had developed orcharding to a high degree. We are inclebted to them for many of our finest varieties of pears, cherries, and European grapes. The foundations had been laid even at that early date for the breeds of heavy draft horses and high producing dairy cows which have since become famous.

Agriculture of Flanders and Holland.-Improvement of agricultural practices coincident with the revival of lcarning made great advancement in Flanders and the neighboring low countries. These improved methods in the culture of plants and the improved breeds of live stock have been of great benefit to America. In many cases however, the introduction of Flemish agriculture into America has been indirect, through the adoption in England of improvements made on the Continent. Heavy draft horses and black eattle from which the modern black and white dairy breeds originated, may be mentioned among the most valuable contributions to agriculture from the low countries of northern Europe. But no less important was their introduction and dissemination of forage plants from the Mediterranean region.

Agriculture of England.--The northern or colder nations of Europe were many centuries behind the Mediterranean nations in agricultural improvement. England at the time of the dis- 
covery of America was still controlled by the feudal system. The land was owned in large estates or manors by feudal barons. Farm work was performed by serfs. Agriculture was looked upon as a necessity to existence and not as a business enterprise. Transportation and trade in farm products were extremely limited. Consumption of ten took place near the fields of production. It was easier for a baron to move his family and retinue of servants to different parts of his estate than to transport his foodstuffs to one habitation.

Simple Agriculture.-There were two main features of early English farming, grain growing and live-stock husbandry. Wheat, barley, buckwheat, peas and oats were grown for human food and oats and other grasses for forage. The natural regetation furnished a great deal of grazing. It should be noted that of the erops mentioned, all were seeded broadcast and none required inter-tillage. Housing and feeding live stock were seldom practiced. Large numbers of eattle, sheep, horses, poultry, and swine were kept, but mostly on commons or open pastures. Improvement of breeds and good care were practically impossible under such conditions. Inferior and diseased animals mingled at will with those which were healthy and thrifty. There was no incentive for attempting the improvement of grass lands. Neither could grass be rotated with grain or root crops as certain areas were permanently set aside for pasture or meadow while others were used exclusively for crops.

Dairying had made some advance. This work was done mostly by women. Butter and cheese making were part of the regular duties of the farmers' wives and daughter's.

The implements used in farm work were crude. A few hoes and mattocks, seythes, reaping hooks, spades and wooden plows about completes the list. The entire supply of tools for' an average farm could have been hauled on one of their two wheeled carts.

Gardening was coming into general practice to supply the home table with salads or greens. Peas, beans, turnips, and hops for brewing were the common garden plants of that time. It was in the growing of these that the value of tillage was finally demonstrated.

In Hartlib's Legacie first issued in 1651 is reproduced an appeal from James I, the ruler in Great Britain at the time when the first permanent English colonies were settled in America, in 
behalf of agrieulture in England, in which he gives a partial list of economie plants introduced into Britain. The list as given includes, "Wheat, Barley, Cherries, Hops, Licorish, Potatoes, Apricockes, Peaches, Melicotones, Rape, Colliflower, Creat Clover, Canary seed and," he adds "we know, that most of these have been brought to perfection, even in our days" (46). 


\section{CHAPTER III}

\section{AMERICAN INDIANS}

America before the advent of the white man, was peopled with a dark skinned race with high check bones, dark straight hair and usually flat features. These were very unlike any known people in the Old World. Through a mistake of Columbus who thought he was on the eastern coast of $\lambda$ sia they were called Indians.

How long the Indians had resided in America or from whence they came is not known. That they had been here for a great many years is proved by the ancient remains, such as, the mounds of the central states and the pueblos or eliff dwellings of the South-west. It was once thought that these remains represented the work of a race of people more industrious than and distinct from the Indians. The names "Mound Builders" and "Cliff Dwellers" have been commonly applied to them. It is now generally believed that there were no great differences between the Mound Builders and the present day Indians. This has been shown from the excavations of numbers of mounds and pueblos. All of the articles found buried in these ruins and they are numbered by the thousands are similar to those used by the Indians. They consist mainly of arrow heads, stone hatchets, skiming stones and various cooking and other household utensils. From this evidence it is safe to conclude that the Mound Builders were the ancestral races of the Indians of today.

Classes of Indians.- The Indians were separated into a great many tribes differing much in appearance, habits, customs and language. Indians have been classified according to their apparent relationships as evideneed by their speech. Those possessing strong similarity in language are considered to have sprung from one common stock in comparatively recent times. Where there is no similarity in their languages that is where they do not have many words in common the separation occurred at a more remote period. Indians behaved much after the manner of bees. When the tribe became too numerous for the food supply in a region, a portion would swarm sometimes going long 
distances and set up a new habitation. As most of them had no written language their dialects soon became corrupted and unintelligible to members of other tribes.

The Bureau of American Ethnology has classified fifty-nine different races of the North American Indians based largely on linguistic characteristics. Each racial language was usually further divided into many dialects.

Eastern Indians.-The Indians east of the Mississippi River were grouped into three main stocks or races, the Maskokis, the Algonquins and the Iroquois. Each consisted of several tribes. The Maskokis inhabited the region around the Gulf of Mexico and as far north as the southern boundary of Tennessee. The most important tribes in the Muskhogean race were the Seminoles of Florida, the Creeks in South Carolina and Georgia, the Choctaws in the southern parts of Mississippi and Alabama, and the Chickasaws north of the Choctaws.

The Algonquins and Iroquois were intermixed over the northeastern part of the continent. There were two strong Iroquois tribes in the South, the Cherokees in Tennessee and the Tuscaroras in western North Carolina. The rest of the Iroquois race were seated in central and western New York. The Powhatans of Virginia and the Narragansetts of Rhode Island were the most important of the Algonquins and the Five Nations of the Iroquois, later known as the Six Nations were the most powerful of all the eastern Indians. Both the Powhatans and the Five Nations had formed confederacies of the surrounding tribes and had made some advancement towards civilization. There was a bitter warfare of long standing between the Algonquins and Iroquois. When the French, under Champlain, first explored Canada they engaged in a war with the Algonquin Indians against the Iroquois of New York. This made the Five Nations enemies of the French and allies of the English, an incident that had a great influence in the final settlement and possession of this country.

Early Accounts Faulty.--The earliest European accounts of the Indians differ widely. This is not surprising. Indian tribes were as unlike as those of other races. Some tribes of Indians were extremely low in the social scale, living more like wild beasts than human beings. Such tribes usually wandered about and gathered whatever natural products they could find for food. On the other hand, most tribes had fixed habitations and had 
developed a semblance of civilization. The European traveler may have accurately deseribed the particular Indians with which he came in contact, but no onc narative can be taken to show the life of Indians in general. These accounts, too, were often highly colored with personal prejulies. Some writers greatly exaggerated the virtues of the Indians as others unfairly condemned them. On the whole the agricultural attainments of the Indians were more accurately described than other features of their life and habits.

Contrasts between Indian Tribes.- In studying customs onc must keep in mind that there were these many gradations of tribes based on intelligence and industry. An example of some of the poorer tribes may be found among the Indians near the Gulf of Mexico. These lived during the winter months on the fleshy roots of plants growing in the swamps along the coast. As these roots became unfit for food in the spring the savages migrated northward and westward and in the summer and fall subsisted on the fruit of the prickly pear and nuts from the natural pecan and walnut groves. Between these two periods such Indians spent a miserable existence living on anything of an animal or vegetable nature which they could find. Numbers of them starved to death.

Other tribes lived almost entirely by hunting. The Algonquin Indians along the lower St. Lawrence River are examples of this class. Had there been a highly developed agricultural tribe in that region the history of the French in America might have been a very different story. There were other tribes which practiced both hunting and crop growing. Such Indians inhabited much of the North Atlantic regions from Carolina to Canada.

The most powerful and highly developed of these Indians were the Iroquois or Five Nations of western New York. The Iroquois grew large fields of corn and beans, pumpkins, squashes, etc.

There were still other tribes such as the Zuni and Hopi Indians of New Mexico and Arizona who still live almost entirely on the results of their agricultural labors. Some of these tribes have developed systems of intensive farming which today furmish subsistence to large numbers of people under dry inhospitable conditions that would discourage any white farmer from attempting there to make a living. The Indians who engaged 
in agricultural pursuits have had a marked influence on the development of America, and not only America, but the whole civilized world. It is also true that it was these agricultural Indians which caused the most trouble for the European settlers in America. A tribe of under-nourished Indians seldom began a war on other tribes or on the whites. Most of the Indian campaigns eame after seasons of abundant erops. Raiding Indian settlements and destroying their crops just before corn harvest was a favorite means of protection practiced by the colonists against Indian depredations.

Evidence of Indian Abundance.-The following account of a commanding officer of a French expedition, in 1687, against the Iroquois Indians of Western New York is typical:

Then we spent five or six days in cutting down the Indian corn with our swords. From thence we marched to the two little villages of the Garonhies and the Danoncaritaoui which lay about two or three leagues off. Having done the like exploits there, we returned to the lake side. In all these villages we found plenty of horses, black cattle, fowl and hogs $(90)$.

The more substantial Indians, like the Iroquois referred to here, soon obtained mostly by theft, large numbers of animals from the colonists.

The early Kentucky pioneers frequently made attacks on the Shawnee Inclians on the Wabash in late summer, knowing if they did not they in turn would be attacked during the fall or winter.

The White Man's Debt to the Indians. - The bitter struggles between the white men and Indians created animosities and prejudices which have obscured the real benefits which have come from the red men. The contact of the white men with the Indians has usually been disastrous to the latter. The Indians have either been annihilated or else rendered impotent by the vices of the whites. Even with the benevolent attitucle which our country has of late years assumed towards these natives there is little of real value which has been rendered to the Indian. The Indian has never been repaid and never can be repaid for the land which he possessed in undisputed title three hundred years ago.

Indian Farming Helpful.-On the other hand crops and their method of eulture developed by the Indians have been appropriated by the white man and have proved of untold value to humanity. Many instances are on record where the early colon- 
ists were saved from starvation through the generosity of neighboring Indians. Historians have until late years dwelt too much on the dark phases of the colonial life. They have recounted the massacres and eruelties and too often have left out the more pleasant relationships of the two peoples, and they have not always recounted the aggravations which led to atrocities. That the Indians were cruel, treacherous, and revengeful is well established. But it is probable that the white men would not have acted differently if their positions had been reversed.

Division of Labor.-The Indians had developed a division of labor among themselves which has often been misunderstood. The men did the hunting, fishing and fighting while the women cooked, farmed and carricd the burdens. This has led many writers to picture the Indian men as over-bearing and the women as the unhappy slaves of their husband-masters. It should be noted that the success of an Indian male either as a hunter or warrior depended above all on his agility. They were often compelled to perform feats of great strength and endurance. Menial or farm labor would have rendered them incapable of that fleetness of foot or dexterity of hand which was absolutely necessary to their existence. There is no evidence that the life of the squaws in most tribes was usually unhappy. They worked hard, but they enjoyed their labor and took great pride in their gardens and fields. The domestic life of the Indians would surely compare favorably with that of the inhabitants of the slums of our eitics today or to thousands of peasants of eastern Europe and was far superior to that of hundreds of thousands of Asiatic peoples at the present time. In some tribes the squaws ruled the household and if the husband became objectionable he was unceremoniously ejected from the lodgings. Several instances are reported by the early explorers where whole tribes were ruled by squaws.

Domestic Life Not Unhappy.-The facts seem well authentieated that the Indian women looked forward to the coming of spring and their work in the ficlds with a great deal of pleasure. There they could visit with their friends, enjoy the frolicing of their children, and vie with one another in gardening skill.

Strachey, (1610) wrote in regard to the Indians in Virginia:

The women, as the weaker sort, be put to the easier workes, to sow their corne, to weed and cleanse the same of the orabauke, doder and choak weed, and such like, which ells would wynd about the corne and 
hinder the growth of $y^{\circ}$ : for by reason of the rankness and lustiness of the ground such weedes spring up very easely and thick, and if not pluckt awaie, the corne would prosper so much worse; for which they keepe the hillocks of their corne and the passadg between (for they set their wheat as we doc our hoppes an equal distance one hill from another) as neat and cleane as we doe our garden bedds (120, p. 111).

Roger Williams who had an unusually good knowledge of the Narragansett Indians describes this division of labor and the part performed by the squaws thus:

The women set or plant, weede, and hill, and gather and barne all the corne, and Fruites of the field: Yet sometimes the man himselfe, (either out of love to his Wife, or care for his Children or being an old man) will help the Woman which (by the eustome of the Countrey) they are not bound to ...

Their women constantly beat all their corne with hand; they plant it, dresse it, gather it, barne it, beat it, and take as inuch paines as any people in the world.

$(129$, p. 65).

The woman of the family will commonly raise two or three heaps of twelve, fifteene or twentie bushells a heap, which they drie in round broad heaps; and if she have helpe of her children or friends, much more (129).

Cooperation.-Joutel, a companion of La Salle, describing the practices of the Mississippi Valley Indians says:

When they design to till the ground they give one another notice, and very often above a hundred of each sex meet together. When they have tilled that piece of land, after their manner, and spent part of the day, those that the land belongs to give the others to eat, and then they spend the rest of the day dancing and merrymaking. This same is practiced from canton to canton, and so they till the land all together. This tillage consists in breaking up just the surface of the earth with a sort of wooden instrument, like a little pickaxe, which they make by splitting the end of a thick piece of wood, that serves for a handle, and putting another piece of wood, sharp pointed at one end, into the slit. This instrument serves them instead of a hoc, or spade, for they have no iron tools. When the land has been thus tilled or broken up, the women sow and plant the Indian corn, beans, pompions, watermelons and other grain and garden ware which is for their sustenance (22). 


\section{('HAP'TER IV'}

\section{NATURAL VEGETATION IN EASTERN AMERICA}

While the Atlantic slope of Ameriea was heavily timbered one should not make the mistake that has been made by some writers who have stated that "it was one solid forest except where broken by streams of water." The extensive salt marshes along the coast were then as now entirely devoid of trees and shrubs. There were extensive elearings made around Indian habitations which will be discussed later in more detail. In addition there were numerous open meadows which may have been former Indian villages or places where for some reason trees did not thrive.

In many parts of the country, especially on the limestone clay soils, the forest had become reduced to scattering trees of very large size. This condition was brought about probably by a survival of the fittest. As the forest became older and older the weaker specimens among the trees became overshadowed and finally succumbed while the conditions became less and less favorable for seedling trees and shrubs to grow. Annual fires also contributed towards keeping down the undergrowth. A favorite means of describing this open condition of the woods was to say that a "team and coach might be driven among the trees without injury."

Few Forage Plants Native to America.-The Indians of North America had no use for hay and the natural flora of this continent is extremely poor in forage plants suitable for cultivation. Of all the hay and pasture plants of importance east of the Mississippi River there is scarcely one which is not an introduced species. The Indian practice of burning areas to attract deer, elk and buffalo with the succulent growth of grass which sprang up" after the fire had passed might be eited as a step towards pasture management.

Many of the early explorers wrote in enthusiastic terms of the "goodly meadows" in America not knowing that the salt marsh grasses which they saw near the coast were very inferior for forage. If these accounts are disregarded and some of the propaganda for inducing settlers to come to America discounted, 
one may form a fairly accurate conception of the natural vegetation at the time of the scttlements.

Wild Rye Grasses Most Common Species in the North.The common grass along the Atlantic Coast from Virginia northward was wild rye (Elymus sp.) (Fig. 2).

Cartier (1534) found all the open spaces in the woods of Nora Scotia "full of wild corn, that hath an car like unto rye" (90, v. II, p. 636).

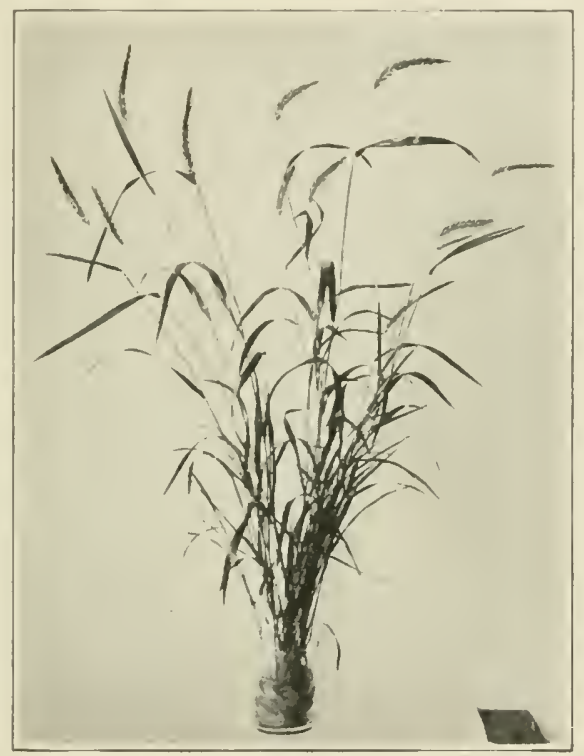

FIG. 2.-One of the wild ryes (Elymus Striatus). Note the resemblance the head bears to domesticated rye. (Courtesy U.S. Dept. of Agr.)

It was certainly wild rye which the Northmen in pre-Columbian times referred to as "self-sown wheat-fields" (104) commentators and translators of early travel journals frequently try to identify as Indian rice (Zizania sp.) or rice eut grass (Homalocenchrus sp.) the "wheat" or "rye "which the explorers for want of better terms frequently used. Some of the wild ryes have heads that to a superficial observer resemble the eereals wheat or rye. On the other hand the Indian rice species have open heads more nearly resembling oats and would never be mistaken for either wheat or rye. (Fig. 3.)

Wild Rye Used for Food in Virginia.-Captain John Smith, writing of Virginia, said: "Mattoume groweth as our bents do 
in meddows. The seede is not much unlike to rie, though much smaller. This they (the Indians) use for a dainty bread buttered with deare suet (110)."

Kalm (1749) states:

I have been assured that these plants (Elymus sp.) grow in great plenty in Newfoundland, and on other American shores; the places covered with them looking, at a distance, like corn fields (90, v.'III, p. 669).

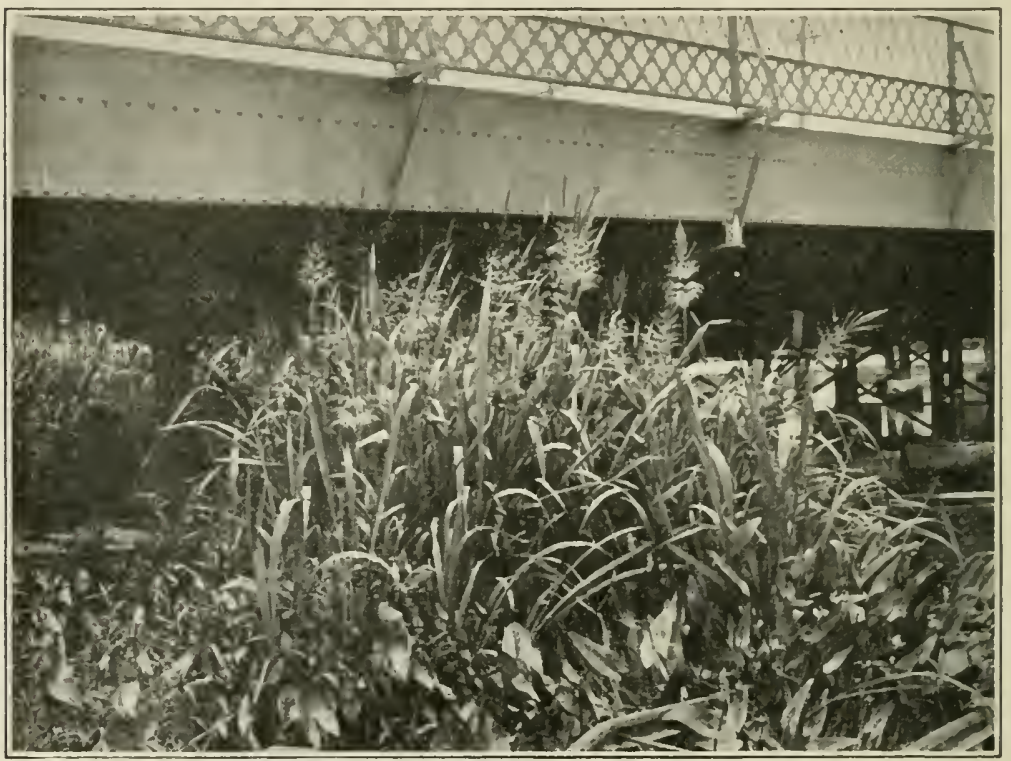

Fig. 3.- Wild rice (Zizania aquatica). A valuable native food plant of America. One of the wampees (sagittaria latifolia) at the left below. (Courtesy A. S. Hitchcock.)

I'ild Rye in the Ohio Valley.-The wild rye was not confined to the coast as it is frequently mentioned by the first explorers in Ohio and Kentucky. Gist in his diary for January 27, 1750, while he was in southern Ohio wrote:

This night it snowed and in the morning the snow was six or seven inches deep, the wild rye appeared very green and flourishing through it and our horses had fine feeding (40).

And Imlay (1792) for Kentucky says:

The rye grass when it arrives at maturity is from two feet and a half to three and a half and the head and beard resembles the real rye and sometimes produces a small grain long and slender not unlike rye. Whether cultivation would bring it to the same perfection I can form no idea: It is however certain that it is a very valuable grass (58). 
A few species of wild legumes as vetches and lathyrus were often found growing with the wild rye and added much to its forage value.

Broom Straw Native to the Middle Atlantic.-In the Middle Atlantic colonies broom straw (Andropogon sp.) was the dominant grass.

Kalm (1749) says:

The first plant which struck my eyes (near Philadelphia) was an Andropogon, or a kind of grass, and grass is a part of Botany I always delight in (65). Mitchell (1767) writing of North Carolina says: Their pastures are covered with a tall rank weed, more like Bent than pasture grass; which is as dry as a stick, and as yellow as straw, insomuch that nothing will taste it. This their common pasture grass is so rank, hard, and dry, that they make their brooms of it, as they do here with heath or birchen rods, and know it by no other name in most of the colonies but more broom straw (76, p. 153).

Wire Grasses Farther South.--Romans (1775) gives an excellent description of Florida grazing conditions. Deseribing the pine land "commonly called pine barren" he says:

It is on this kind of land, that immense stocks of eattle are maintained, although the most natural grass on this soil is of a very harsh nature, and the cattle not at all fond of it, it is known by the name of wire grass; and they only eat it while young; for the procuring it young or renewing this kind of pasture the woods are frequently fired, and at different seasons, in order to have a succession of young grass, but the savannahs that are interspersed in this kind of land furnish a more plentiful and more proper food for the cattle (100).

As these conditions still prevail over large areas in the southern coastal plain it must be aecepted that they were the same before the white men penetrated that region.

Natural Food Products of the Indians.-The Indians used in their diet many wild products not now considered edible by white peoples and others which have since become cultivated crops. Practically every plant producing a seed large enough to be gathered in quantity, most fleshy rooted plants and nearly everything in the nature of animal flesh were utilized. They had worked out methods of preparation which rendered several poisonous plants wholesome. Among the natural products which have been domesticated first place should be given to berries. The Indians did not eultivate these it being unnecessary, as they grew wild in sufficient abundance to supply their wants. 
Berries.-The strawberry known to the Europeans prior to the introduction of American sorts was an almost useless plant, the fruit being small and tasteless. The American strawberries were very abundant around the Indian habitations, and were mentioned in many accounts of the early writers from Florida to New England. Few American products received such universal commendation. Williams (1643) enthusiastically states:

This Berry (strawberry) is the wonder of all the Fruits growing naturally in those parts; it is of itself excellent so that one of the ehiefest Doctors of England was wont to say, that God could have made, but God never did make a better Berry: In some parts where the Natives have planted, I have many times seen as many as would fill a good ship within few miles compasse; the Indians bruise them in a Morter, and mixe them with meale and make a strawberry bread $\left(129\right.$, p. 121). ${ }^{1}$

In addition to strawberries there was an abundance of bush fruits as blackberries, huckleberries, black raspberries, cranberries and gooseberries, all of which were gathered in their season by the Indians, and from which many sorts have been selected and domesticated.

Grapes.-Nearly every traveler to America both before and during the early years of the settlements noted the abundance of wild grapes. They were everywhere along the Atlantic coast, great vines extending to the tops of the tallest trees. To the Frenchmen, America gave promise of another grape industry equal to that of the southern part of France. To those of north European countries it offered a relief from the heary toll exacted by France, Italy, Spain and Portugal for wines. If grapes grew so luxuriantly in a natural state what might they not do if trimmed and cultivated? When John Hawkins (1565) found the French settlement under Laudonniere in a half starved condition in Florida they (the French) had already made 20 hogsheads of wine from the native grapes although they had failed to raise enough food to meet their needs and were dependent upon the Indians for sustenance (29).

There are two kinds of grapes wrote Hariot, in 1586, in reference to Carolina "the one is small and sour, of the ordinary" bigness as ours in England; the other far greater and of itself luscious sweet." (90 v. II p. 593). The large one was no doubt

${ }^{1}$ For the origin of commercial varieties of strawberries sce FlETCHER, S. IV., Procecdings of the Twelfth Annual Meeting of the Society for Horticultural Science. 
the scuppernong still a very popular grape in the South Atlantic region.

$A$ Dutch writer in 1644 says:

Here (New York) is also a sort of Grapes which grow very large, each Crape as big as the end of one's Finger or a middle sized Plumb and because they are somewhat filny, we eall them speck Druyren (Pork grapes) ( $4 \bar{\tau}, \mathrm{v} . \mathrm{I}, \mathrm{p} .51 \mathrm{~s})$.

In a description of New Netherland of 1649 one may recognize the ancestry of several of our popular varicties.

The grapes are of many varieties; some white, some blue, some very fleshy and fit only to make raisins of; some again are juicy, some very large, others on the contrary small; their juice is pleasant and some of it white, like French or Rheinish Wine; that of others, again, a very deep red like Tent, some even paler (14).

In the first attempts in vineyard planting in America the improved European varieties were used, varieties which will not succeed well out of doors in eastern North America. The selection of the best of the native vines finally led to the present grape industry of the East while the culture of the European sorts is confined to the Pacific coast.

Plums.-The native American plums of which there were several different species were commonly gathered by the Indians. They apparently made little or no effort to cultivate them but were content with the natural product. American horticulturists have selected a great many varieties and in some parts of the country especially in the central states the American varieties are grown to a greater extent than are the Old World sorts.

Edward Winslow writing in 1621 from Plymouth to his friend Morton in England says:

Here are grapes, white and red, and very sweet and strong also; strawberries, gooseberries, raspas, ets.; plums of three sorts, white, black, and red, being almost as good as a clamson (134).

Persimmons.-The persimmon was an important fruit with the Indians as it was later with the eolonists. Not only was the fruit eaten when ripe but large quantities were gathered and dried for future use. Hariot (1585) says:

Medlars, a kind of very good fruit; so ealled by us chiefly for these respects: First in that they are not good until they be rotten, then in that day they open at the head as our medlars, and are about the same bigness: otherwise in taste and colour they are far different; for they are 
as red as cherries and very swect; hut whereas the cherry is sharp sweet, they are luscions sweet $(90, v .11,1) .599)$.

Ground Nuts.--One of the most important wild plants used for food by the Indians, ground nuts, (Apios tuberosa) is now almost a rarity. It was formerly very abundant along the Atlantic seaboard from ('anada southward to Florida. Hariot (15S5) deseribed it under the Roanoke island Indian nane of openauk. These, les says:

Are a kind root of round form, some of the higness of walnuts, some far greater, which are found in moist and marsh ground growing many together one by another in ropes, as thougl they were fastened with a string. Being boiled or sodden they are good meat. Mronardes ealleth these roots beadi or l'eter nostri of Santa Inclena (90 v. II, p. 5!s).

This description was taken by sereral English writers to mean potatoes which led to the erroneous conclusion that potatoes were native to Virginia.

Wampee or Tuckahoe. '- The southern Indians made great use of the roots of a group of plants called in Virginia tuckahoe and farther south, wampee. Cabeza de Vaca (1527-36) who spent several years a prisonel among the Texas coast Indians wrote:

For among many other painful labours, I was compelled to digge Roots under the water, and among the Canes where they grew under the ground. And herewith I had my fingers so spoyled, that a straw that should have touched me, would have drawne bloud (94).

('apt. John Snith (1607) states:

The chicfe roote they (the Virginia Indians) bave for foode is called Tockawhoughe. It groweth like a flagge in low muddy freslies. These rootes are much of the greatness and taste of Potatoes (110).

The tuckahoe of the Virginia Indians belonged to the Arum family of plants (Peltandra rirginica). A large fungus growth found in sandy soils of the (arolinas was sometimes called tuckahoe. This in all probability" was the "Okeepenauk" which Hariot described as "of round shape found in dry grounds, some are of the bigness of a man's head. They are to be eaten as they are taken out of the ground for by reason of their dryness, they will neither roast nor seethe."

1 The most prominent of these plants are the arrowheads, Sagittaria, especially s. latifolia, the arrow arum ('Peltandratirginica), and the pickerelweed (Pontederia cordata). 
The term wampee of the Carolina Indians included the tuckahoc of Virginia and some other plants (Saggittaria sp.) (Fig. 3). This group of plants has been very confusing to agricultural writers as the name wamper meant sometimes one thing sometimes another.

Cassava Not Grown in Carolina.--Hariot (158.5) gives a clescription of a root used by the Indians on Roanoke Island, ealled by the natives coscushaw which appears to have been wampec and not cassava which the members of the Raleigh colony knew only by reputation.

Coscushaw some of our company took to be that kind of root which the Spaniards in the West Indies call eassary where upon also many called it by that name; it groweth in very muddy pools, and moist grounds. Being dressed according to the country manner, it maketh a good bread, and also a good spoon-meat, and is used very much by the inhabitants. The juice of this root is poison, and therefore heed must be taken before anything be made therewithal, either the roots must be first sliced and dried in the sun, or by the fire, and then being pounded into flour, will make good bread; or else while they are green they are to be pared, cut in pieces and stamped: loaves of the same to be laid near or over the fire until it be sour: and then being weil pounded again, bread or spoon-meat very good in taste, and wholesome, may be made thereof (90, r. II, p. 59S).

Beverly (1705) says of Tuckahoe:

It grows like a Flag in Miry Marshes, having roots of the Magnitude and Taste of Irish Potatoes which are easy to be dug up. . Which while crude is of a very lot and Virulent Quality. But they manage it so, as in case of Necessity to make Bread of it (9).

Jones (1724) gives the use made of these plants by the early colonists.

In the Marshes, and Woods, and old Fields is good Range for Stock in Spring, Summer and Fall; and the Hogs will run fat with certain Roots of Flags and Reeds which abounding in the Marshes they root up and eat (63).

Kalm (1749) tried to reconeile the many conflicting identifications which had been made of tuckalsoe and from a South Carolinian he found visiting at the home of John Bartram near Philadelphia he elicited the following information:

It grows in several swamps and marshes and is commonly plentiful. The hogs greedily dig up its roots with their noses in such places; and the Indians in Carolina likewise gather them in their rambles in the woods, dry them in the sun-shine, grind them, and hake bread of them. 
Whilst the root is fresh it is larsh and acrid, but being dried it loses the greatest part of its aerimony. To judge by these qualities the Tuckahoe may very likely be the Arum Virginianum.

This man also confimed the statement made by Jones that hogs ate them, digging them under water, and that the hogs beeame very fat. These roots sometines were as large as a "man's thigh" (65 v. 1, pp. 225 and 386 ).

Katniss, another Indian food, Kalm described as a root oblong in shape " $11 \frac{1}{2}$ inches long and 1 inch and a quarter broad."

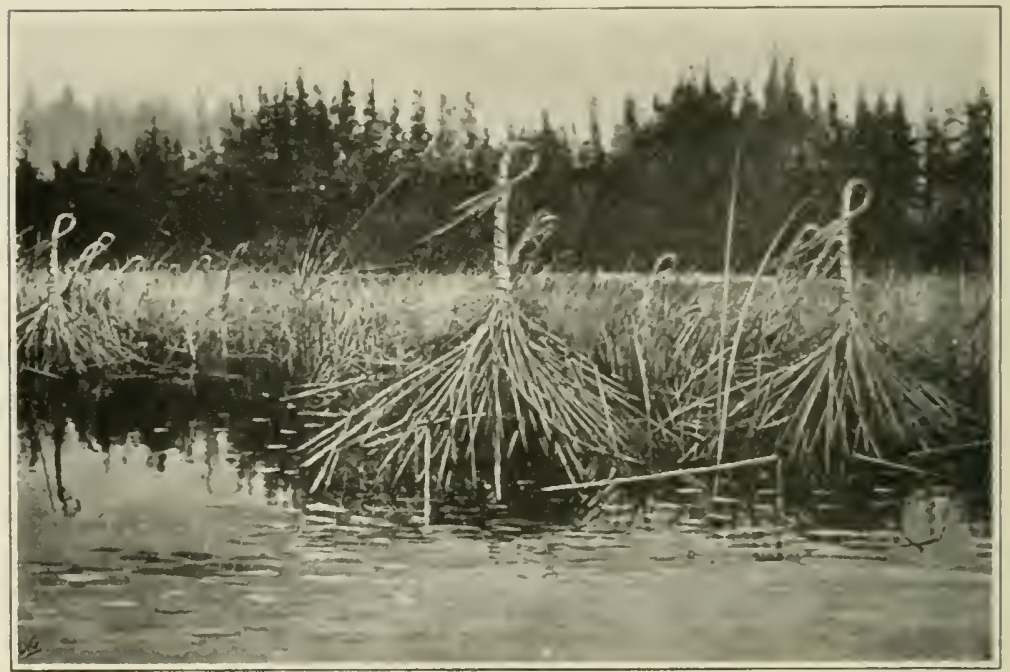

Fig. 4.- Wild rice tied in bundles preparatory to harvesting. (Courtesy Burcau of Ethnology.)

This, he says is "an arrow-head sagittaria and is only a variety" of the Swedish arrow-head or Sagittaria sagittifolia."

Conti, the fleshy underground stems of the genus Lamina, from which a white flour was made was one of the most important bread plants of the Florida Indians (109).

The Indians made a flour, from the rhizomes of eatstail flag (Typha), which was made into bread.

Indian Rice.-The seed of Indian rice (Zizania aquatica) was the main support of some of the tribes around the Great Lakes and was used by all the Indians where ever it grew from the Great Lakes to the Gulf of Mexico (Figs. 4 and 5).

Coxe (1722) is probably referring to Indian rice when he says: 
Besides, this country affords another sort of excellent corn, which is the most like oats of any European grain, but longer and larger; and I have been assur'd by many eredible persons, who often out of curiosity, had divers ways prepared it, that it far exceeds our best oat meal. This is not sown and cultivated by the Indians, but grow spontaneously

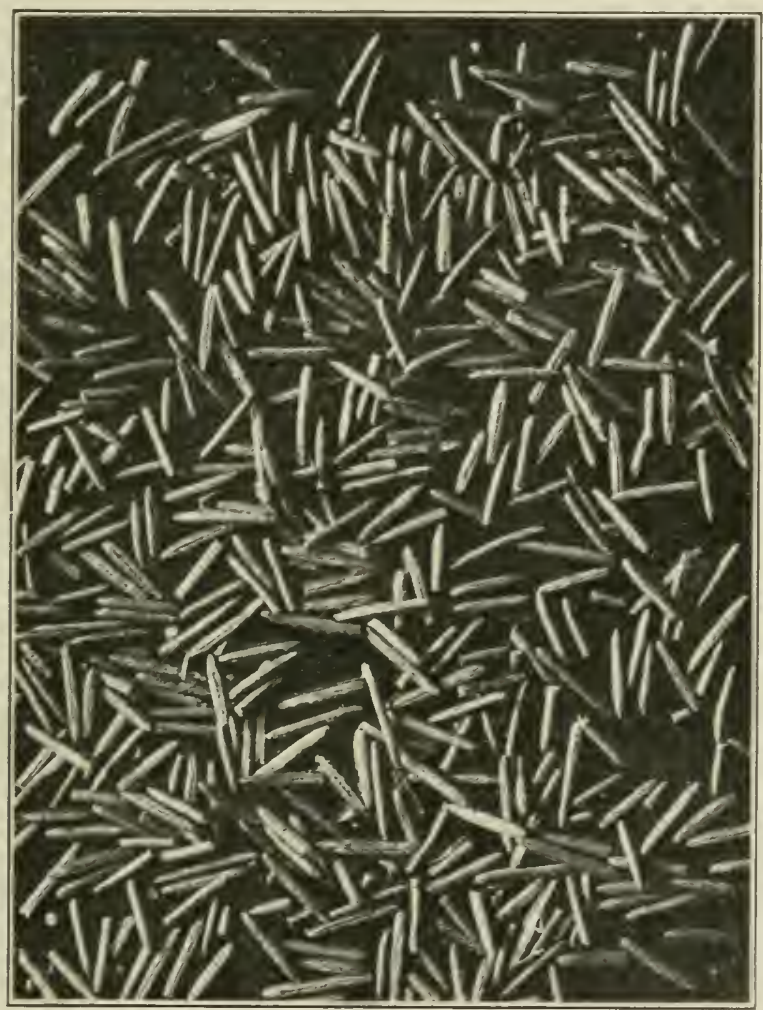

FIG. 5.-Seed of wild rice natural size. (Courtesy Bureau of Ethnology.)

in marshy places, in and by the sides of rivers, like reeds or rushes. The Indians when it is ripe, take handfulls, shake them into their canows; what escapes them falling into the water, without any further trouble, produces the next year's crop (23).

This Indian rice is also probably the plant referred to by French and Spanish writers as mill or millet. The expression often being "maize and mill" or "a plant like unto mill."

Cane.-The seed of the common cane in the Mississippi Valley was also used for food. But this was an irregular and uncertain crop as is indicated in the following passage. 
After a certain number of years, the large canes bear a great abunlance of grain, which is somewhat like oats, lut about three times as large. The natives carefully gather these grains and make bread or gruel of them. This flour swells as much as that of wheat (69) (4).

There is some evidenee which indieates that the Indians by burning the eanebrakes were able to make them bear grain more regularly than they do naturally. The young shoots of the cane were llsed much as asparagus is now.

Prickly Pear.-In the South and Southwest the fruit of the eacti (Opuntia sp.) was a farorite food product. It was designated by the Mexican Indians as "tune" or tuna." Hariot (1;85) found it on Roanoke Island and says:

Mutaquesumnauk, a kind of pleasant fruit, almost of the shape and bigness of English pears, but that they are perfeet red eolour as well within as without. They grow on a plant whose leaves are rery thick, and full of prickles as sharp as needles (90, v. II, p. 599).

Cates (1609) found them on the Bermuda Islands and deseribes them as:

A kinde of Pease of bigness and shape of a Katherine Peare, wee found growing upon the Rockes full of many sharpe subtill prickles (as a Thistle) which we, therefore ealled, The Prickle Peare, the outsicle greene, but being opened, of a deepe murrie, full of juyce like a Mulberry and just the same substance and taste, wee both eate them raw and baked (94 ร. 19, p. 20).

These were sometimes designated "Indian figs" by English writers. The Indians of the Southwest made preserves of the tuna, euring them in a large amount of their own juice (j1).

Father Allouez a Jesuit explorer in the Illinois country 1675-77 wrote:

They (Indians) eat 14 kinds of roots, which they find in the prairies; they made me eat some and I found them good and rery sweet. They gather from trees and plants 42 different kinds of fruit all of which are excellent $(121$, v. 60, p) 161$)$.

Nuts.-The pecan groves of Texas and the lower Mississippi Valley fumished the main article of food for some of the poorer tribes in those regions for a period of a few weeks in the fall. The more provident Indians gathered these nuts as well as the walnuts, chestuuts, hazel nuts, chinquapins in other parts of the country cracked them and pounded the meats when well dried into flour which would keep indefinitely. This nut flour they used 


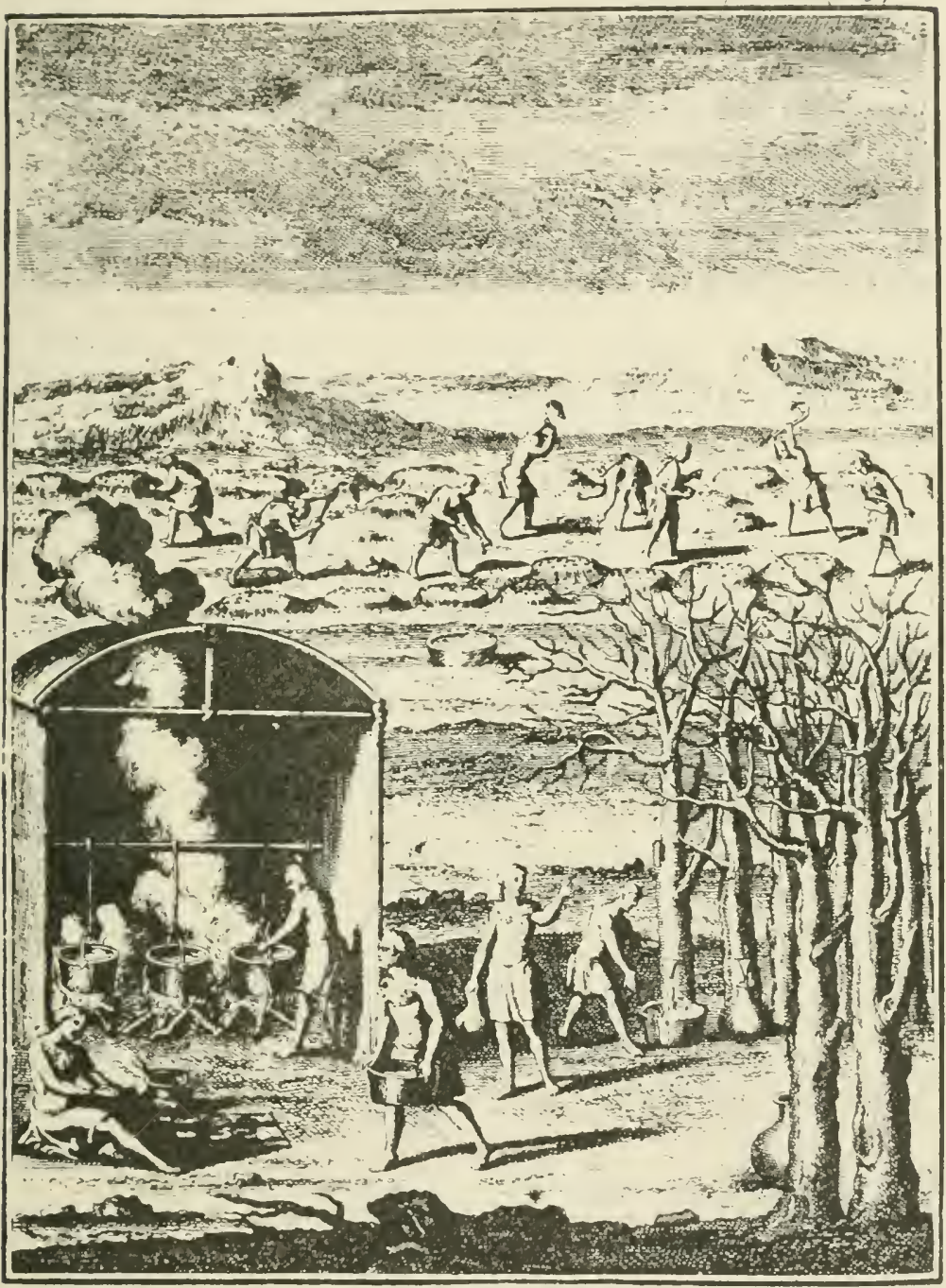

Fig. 6,-Indians boiling maple sap below. Planting eorn above. Note hill planting. Some parts of this pieture evidently copied from John White and Le Moyne (see Figs. 7 and 21). P'ieture by Lafitau, 17:24. 
to season their gruels or to mix in their bread of maize. In the Biedma aceount of De Soto's experlition one of the tribes of Indians risited was said to "live here in walled rillages and make a great deal of oil from nuts" (36, v. II, p. 101).

Oak acorns were also made into flour and used in making bread the ill effects of the tannin which they contain being obviated by the process of preparation for eooking.

Maple Sugar.-The Indians had learned the art of boiling the sap of maple trees to form syrup and sugar. Joutel (1687) mentions maple sugar making among the Illinois Indians. "There being no sugar eanes in that country, those trees (maple) supplied that liquor, which being boiled up and evaporated, turned into a kind of sugar somewhat brownish, but very good" (22, v. II, p. 227).

"There is no lack of sugar in these forests," wrote one of the Jesuits of Canada in 1723. "In the spring the maple trees contain a fluid somewhat resembling that which the canes of the islands contain. The women busy themselves in receiving it into ressels of bark, when it trickles from these trees; they boil it and obtain from it a fairly good sugar. The first which comes is the best" (121, v. 67, p. 95) (Fig. 6).

Clearing Land.-The Indians were able to clear land overgrown with trees without saws, axes or other tools of metal. Capt. John Smith states that they accomplished this by first bruising the bark near the roots and then seorehing them with fire. By this method they had made many extensive clearings in the eastern part of the continent. The Indians usually pieked the most fruitful soil in their locality for their farming and we find them generally situated on river bottoms or near other bodies of water. Probably the advantages for hunting and fishing had much to do with the selection of a site for planting but the Indians understood the value of a good soil. When fire wood became scarce they sometimes changed their habitations and the cleared fields which they had abandoned together with the cleared land which the colonists either bought or took by force was an important factor in the early development of farming in Ameriea. The extent of some of these elearings is indicated in the quotations at the close of this passage. These clearings were of inestimable value. It is safe to say that it would have taken at least one generation of settlers to have cleared the land in the condition which the white men found it in certain localities. Clearing land is a laborious process even with modern imple- 
ments and it was much more diffieult with the limited equipment of tools which the pioneers had three centuries ago. But what was more important than the labor involved was the matter of time. It was necessary for the colonists to produce food erops at once and they did not have the time to clear land before seeding. The Jamestown colony unfortunately did not select one of these clearings and the "Starving Time" was the result.

Clearings in Virginia.-Frequent mention of these clearings were made by the early Virginia colonists as the following illustrate:

This place I call Pamaunches pallace . . . The platt of grownd is bare without wood some 100 acres, where are set beanes, wheate, peaze, tobacco, Gourdes, pompions and other thinges unknowne to us in our tongue $(110, \mathrm{p} . \mathrm{LI})$.

Powhatan's "birth right" at or near the falls of the James.

It is scituat upon a highe Hill by the water syde, a playne betweene it and the water, 12 score (yards) over, whereon he sowes his wheate, beane, peaze, tobacco, ponpions, gourdes Hempe flaxe, etc. ${ }^{1}$ (110, p. XLIII).

Thier houses are in the midst of thier fields or gardens, which are small plots of ground. Some 20 acres. Some 40. Some 100. Some 200. Some more. Some less. In some places from 2 to 50 of those houses together or but a little separated by groves of trees $(110$, p. 363).

Strachey (1612) describing the country about the present site of Hampton, Ta. states:

It is an ample and faire countrie indeed, an admirable porcion of land, comparatively high, wholesome and fruictfull; the seat sometyme of a thowsand Indians and three hundred Indian howses, as it may well appeare better husbands (farmers) then in any parte ells that we have observed, which is the reason that so much ground is there cliered and opened, enough alreddy prepared, to receive corne or make viniards of two or three thowsand acres $(120$, p. 60$)$.

\section{Clearings in New England.}

The Narragansetts subsisted by hunting and fishing and partially by agriculture. Their lands for eight or ten miles distant from the seashore were cleared of wood and on these prairies they raised Indian corn in abundance and furnished the early settlers of Plymouth and Massachusetts with large quantities for their subsistence (124).

${ }^{1}$ The writer was designating the Indians Crops by names of English crops which they resembled. Powhatan's "birth-right" was one of the first Indian sites to be seized by the English. 
The pilgrims found on Cape Corl "much plain ground about fiftie Acres fit for the plow, and some signes where the Indians had formerly planted their corne" (94, v. 19, p. 316).

A "Reverend Divine" (Higganson?) wote from eastrin Massachusetts:

"Yet in divers places there is much ground cleared by the Indians. . I am told about three miles from us a Man may stand on a little hilly place and see divers thousands of acres of ground as good as need to be. and not a tree in the same" (35).

Edward Winslow and Steven Hopkins the first of the Pilgrims to visit Massasoit describe in $162 \mathrm{l}$ the comntry along the Taunton River.

The ground is very good on both sides, it being for the most part cleared. Thousands of men have lived there, which died in a great plague not long since; and pity it was and is to sceso many goodly ficlds, and so well seated, without men to dress and manure the same. . . As we passed along, we observerl that there were few places by the river but had been inhabited; by reason whereof much ground was elear, save of weeds, which grew higher than our heads (131, pp. 206-7).

Other Clearings. - "The first comers found land fit for use formerly cleared by the savages who had ficlels there," wrote Jogues in $164 t$ after a risit with the Dutch in New Netherland (107).

Clearings in Georgia. - The town of Frederica Creorgia, according to Moore, (1736) "is situated in the Island of St. Fimons, in the middle of an Indian Ficld, where our Pcople found 30 or 10 Acres of Land cleared by them" (79, p. 54).

Clearings in the Middle West.-Thesc Clearings were not confined to the Atlantic coast. The early explorers of the Ohio Valley found many open meadows which were probably sites of former Indian settlements. "Big Meadows" the first battle ground of the French and Indian War is an example.

The exceptions should be carefully noted in the following observation by Hugh Jones (1724).

The whole Country is a perfect Forest, except where the Woods are cleared for Plantations, and old Fields, and where have been formerly Indian Towns, and poisoned Fields and Meadows, where the Timber has been burnt down in Fire-hunting or otherwise (63 p. 3ij). 


\section{('H.IPTER V'}

\section{INDIAN AGRICULTURE}

The statement that the "Indians were not agriculturists, but lived mainly by hunting and fishing," has been frequently and persistently made by historical writers. This eoneeption appears to be the most conmon belief despite the fact that the evidenee without any likelihood for refutation proves the contrary. That there were a few wandering tribes of Indians has no more significance than have the tramps and scalawags in our own society. The historical evidence beyond question proves that the great majority of the Indians lived in fixed habitations, tilled the soil, (Fig. 7 ) and subsisted fully as much if not more on their agricultural products, than they did on those of the chase. The more the matter is studied from an unprejudiced point of view the more remarkable appear their achievements in farming. No people anywhere in the world ever made greater strides in plant breeding than did the Ameriean Indians.

Crops Grown by the Indians. - A brief enumeration of the erops and practices which we have obtained from the natives of this hemisphere speaks for itself. From the Indians we have maize and the methods of its culture, potatoes both sweet and Irish and their culture, tobaceo and its culture, peanuts, some varieties of cotton, all the edible beans except horse beans and soybeans, all varieties of squashes as the Hubbard, erooknecked cymlings and cushaws, ficld pumpkins, sunflowers, Jerusalem artichokes, tomatoes, garden peppers, pineapples, watermelons, cassava, bananas, also many native plants have since been more or less domesticated as strawherries, American grapes, raspberries, blackberries, gooscberries, pecans, walnuts, butternuts, hickory nuts, chinquapins, chestnuts, pinon nuts, besides a number of other food producing plants the use of which has been abandoned.

A comparison crop by crop taking into consideration, acreage and value of these produets with all the other crops now grown in the United States shows quite clearly that our agriculture is at least one-third native American. 


\section{The Tovvne of Secota.}

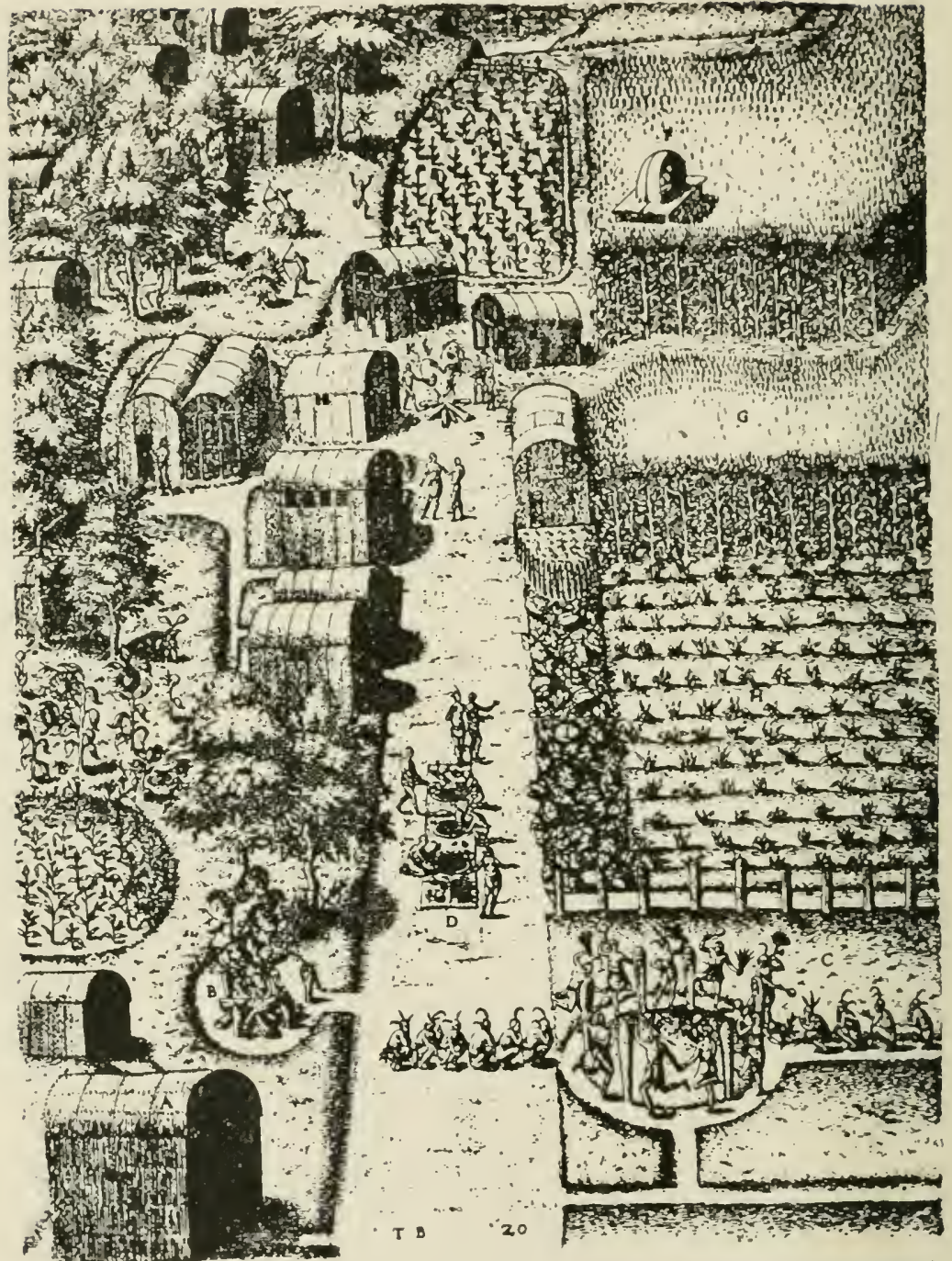

Fic 7 - The Toun, "North Carolina. E, Above centre street, to F, Little watch-house, in cornfield. G, Field of ripe corn. H, Newly planted corn. Sunflowers and tobacco at the left margin. Piciure by John White, Roanoke Island, 1586. 
Confusion of History.-Many of the American plants were first received in northern and western Europe as curiosities by the old herbalists - the "fathers of modern botany." These plants came more frequently from the Mediterranean region than directly from America and were designated accordingly. What makes the record still more confusing was the attempt of these herbalists to identify every plant in terms of the ancient descriptions of Theophrastus, Dioscorides, Pliny and Galen. There are scarcely any American plants, tobacco and sunflowers exeepted, which were not given an Old World origin by some of these early botanists. It was not until Alphonse deCandolle published his eomprehensive work on the "Origin of Cultivated Plants" in 1884 that the correct source of most American plants was recognized. Candolle was not fully conversant with the flora and history of America and made some errors and drew some wrong conclusions. But most of these mistakes have been corrected by subsequent writers. ${ }^{1}$ The record in the case of a few plants is still far from clear.

Maize.-The one crop which stands preeminently at the head of the list of American farm products-maize or corn is of Indian origin. The Indians had achieved marvelous progress in its culture. It was the most widely grown of all their domesticated plants. A wild prototype of corn has never been found and in its present highly developed condition could not exist anywhere in a wild state. Through the years, perhaps millennimus, which the Indians had cultivated corn they so modified its habits of growth that they had strains suitable not only for greatly varied elimatic and soil conditions, but for many special purposes of use as well. All of the changes and improvements in corn which the white man has been able to accomplish in the past four centuries are insignificant when compared with the work of the Indians with this plant. A recent finding of a fossil ear of maize in South America places the culture of this plant and the presence of man in America back into very remote ages (Fig. 8).

Varieties of Indian Origin.--The Indians had the flint corns of New England and the prolific eorns of the South. They originated the dent corns of the Middle West. They had corn that would mature in less than 90 days in southern Canada and which

${ }^{1}$ See Gray and Trumbull, Review of Candolle's Origin of Cultivated Plants, American Journal of Sci, third Series, vols. 25 and 26. 
grew but four or five feet in height. In the South some of their strains of corn required five months to mature and the stalks grew to a height of ten or twelve foet. Corns for special purposes as for meal making, for popping, for parching, to be eaten whole and sweet corn for roasting ear's were commonly grown.

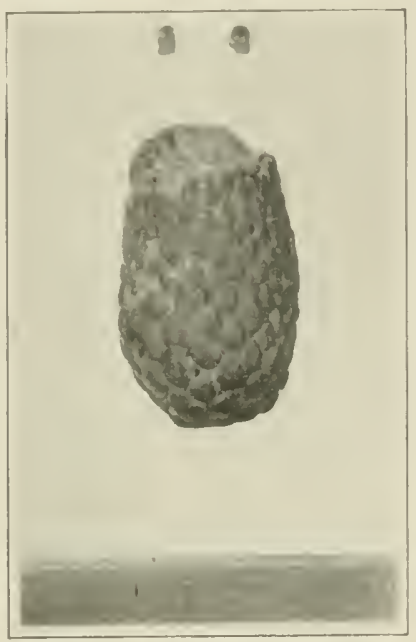

FIG. 8-A fossil ear of maize obtained by Dr. F. H. Knowlton in 1914, from a collector of curios, Cuzco, Peru. (Courtesy G. N. Collins.)

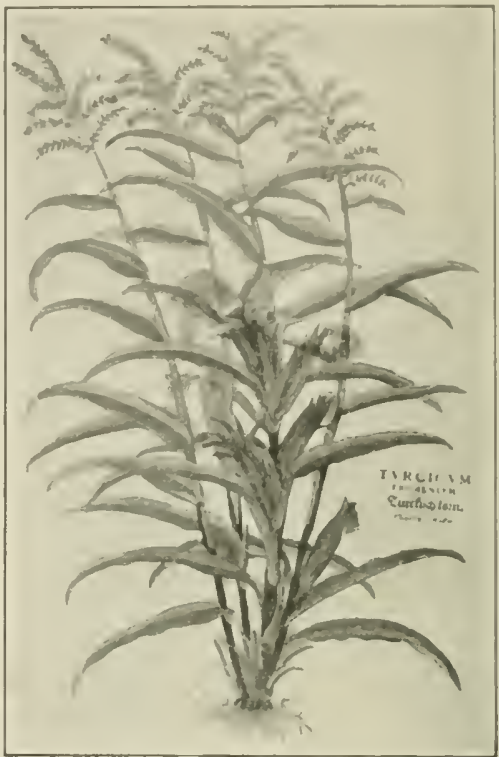

FIG. 9.-An early picture of maize by Leonard Fuchs, 1542. This was in colors. The bands about the ear were added to show the different colored varieties.

Yields Produced by the Indians.-The work of white men to improve corn has been directed almost entirely towards increasing yields and the quality has been quite generally disregarded. Whether our improved commercial varieties or corn outyield or not the old Indian sorts is impossible to determine. Study of all available accounts of yiclds of carly days fails to show that there has been any great improvement. The descriptions of plants, the number of ears to the stalk, the number of rows of grain on an ear and the number of grains in a row as given in the earliest accounts of Indian corn, while not equal to the extreme cases sometimes found, correspond rery closely with average farm crops at the present time (Figs. 9 and 10). The commercial varieties have been quite generally purified in regard to color, set Indian tribes still have strains distinctly pure as far as color is 
concerned which they use in their religious ecremonies. On one point there seems to be a distinct difference in methods of breeding between white men and the lndians. The white men have been working towards the isolation of pure strains, the Indians with the exception of special purpose strains, allowed

The forme of the eares of Turkie Wheare.

3 Frumensi Indusipic.z. Turkie Wheate in the hushe, as allonaked or bare.
4 Frumentum Indicum album.

The eare of whitc Turkie Wheate.

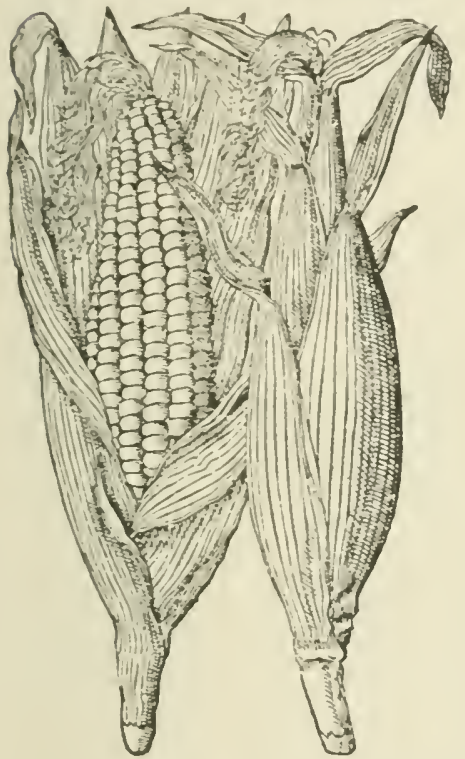

FIG. 10.-Ears of muize. Gerarde, 1597. Cut No. 3 was used also by Bouhin,

1598.

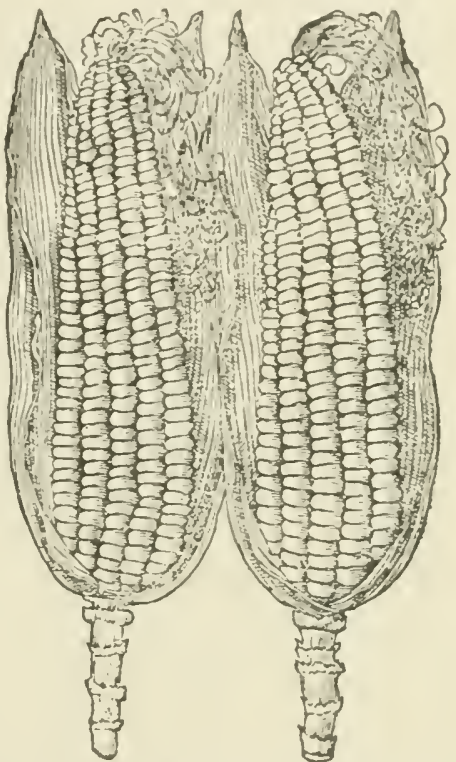

wide mixing of varieties. It is still a debatable question whether a heterozygous condition is not the better for this erop.

Hariot (1585) gives an estimate of the yields from an acre of mixed crops in North Carolina as follows:

The ground being thus set aceording to the rate by us experimented, an English acre containing forty perches in length and four in breadth, doth there yield in crop or of come of corn, beans and pease, at the least 200 London bushels, besides the Macoequer, melden and planta solis: when as in England 40 bushels of our wheat vielded out of such an acre is thought to be much $(90, \mathrm{p} .597)$.

Smith (1630) reports a yicld of $36 \mathrm{t}$ bushels of Indian corn from 13 gallons of seed. This was grown by a man in New England. 
Computed at the usual rate of seeding this would give about 45 bushels to the acre $(110$, p. 952).

Early References to Maize.-The first descriptions by Europeans of corn are interesting. A number of the following eover a wide variety of conditions.

Maize Found, in 1492, in Cuba.-The Columbus expedition reported on the return from the first trip to Cuba.

That there was a great deal of tilled land, some sowed with those roots a sort of beans, and a sort of grain they eall maize, which was well tasted, baked or dried, and made into flour (90, v. II, p. 3S).

Maize in 1527-36 in Texas.-Alvaro Nunez (Cabeza de Vaca) reported in regard to certain Indians of Texas:

The Indians of that place had much Maiz, and that there were smal Pulse which are like to our Ciches and Gourds (94 v. 17, p. 448).

Maize in 1534 in Canada.-Cartier says for Canada:

As far as I understand there growth likewise a kind of millet as big as peason like unto that which groweth in Brasil which they eat instead of bread. They have great store of it (90, v. II, p. 637).

\section{Maize in 1585 on Roanoke Island.-Hariot writes for North} Carolina:

Pagatour: A kind of grain so called by the inhabitants; the same in the West Indies is ealled Maize. Englishmen call it Guinea-wheat, or Turkey-wheat, according to the names of the countries from whence the like hath been brought. The grain is about the size of our ordinary English peas, and not much different in form and shape; but of divers colours, some white, some red, some yellow, and some blue. All of them yield a very white and sweet flour: being used aecording to his kind, it maketh a very good bread. . . There are three sorts, of which two are ripe in eleven or twelve weeks at the most, sometimes in ten, after the time they are set, and are then of height in stalk about six or seven foot. The other sort is ripe in fourteen, and is about ten feet high; of the stalks some bear four heads, some three, some one, and some two, every head containing 5,6 , or 700 grains, within a few, more or less (90, v. II, p. 595).

Maize in 1607 in Virginia.-Capt. John Smith of Jamestown fame observed:

Every stalke of their eorne commonly beareth two eares, some 3, seldome any 4 , many but one, and some none. Every eare ordinarily hath betwixt 200 and 500 graines. The stalke being green hath a sweet juice in it, somewhat like a suger Cane which is the cause that when they gather their corne greene, they suck the stalkes $(110, p .62)$. 
Later Descriptions of Maize.-There are many later descriptions of maize one of the best of which is by Beverly (1705):

There are four Sorts of Indian Corn; two of which are early ripe, and two late ripe. . . The two Sorts which are early ripe, are distinguished only by the Size which shows itself as well in the Grain, as in the Ear, and the Stalk. There is some Difference also in the Time of ripening. The lesser Size of Early ripe Corn, yields an Ear not much larger than the Handle of a Case Knife, and grows upon a Stalk, between three and four Foot high. Of this is made two Crops in a Year, and perhaps there might be Heat enough in England to ripen it.

The larger Sort differs from the former only in Largeness, the Ear of this being seven or eiglit Inches long, as thick as a Child's Leg and growing upon a Stalk nine or ten Foot high. This is fit for eating about the latter End of June, whereas the smaller Sort (generally speaking) affords Ears fit to roast by the Middle of June. The Grians of both these Sorts, are as plump and swell'd as if the Skin were ready to burst.

The late ripe Corn is diversifi'd by the Shape of the Grain only, without any Respeet to the aceidental Differences in Colour, some being blue, some red, some yellow, some white, and some streak'd. That therefore which makes the Distinction, is the Plumpness or Shrivelling of the Grain; the one looks as smooth, and as full as the early ripe Corn, and this they call Flint-Corn; the other has a larger Grain, and looks shrivell'd with a Dent on the Back of the Grain, as if it had never eome to Perfection; and this they eall She-Corn. This is esteem'd by the Planters, as the best for Increase, and is universally chosen by them for planting; yet I ean't see but this also produces the Flint-Corn, accidentally among the other $(9, \mathrm{pp}, 125-6)$.

Maize in 1719 in Louisiana.-LePage du Pratz gives this interesting account of corn culture:

Louisiana produces sereral kinds of Maiz, namely Flour maiz, which is white. with a flat and shrivelled surface and the sof test of all the kinds; Homony corn which is round, hard, and shining; of this there are four sorts, the white, the yellow, the red, and the blue, the maiz of these two last colours is more common in the high lands than in the lower Louisiana. We have besides small eorn or small Maiz so called because it is smaller than the other kinds. New settlers sow this eorn upon their first arrival, in order to have whereon to subsist as soon as possible, for it rises very fast, and ripens in so short a time that from the same field they may have two crops of it in one year. Besides this it has the advantage of being more agreeable to the taste than the larger kind (69, p. 226).

Maize Near Quebec.-Rale, a missionary to the Abnakis who lived "three leagues from Quebec" wrote his nephew: 
In the beginning of June, or when the snow is almost wholly melted they plant . . . what we eall Turkey wheat or "Indian Corn." Their manner of planting it is to make with the finger or with a little stick, separate holes in the ground, and to drop into each one eight or nine grains which they cover with the same soil that had been taken out to make the hole. Their harvest is made at the end of August (121, v. 67, p. 141).

Corn in Illinois in 1822. - Woods, a settler in Illinois, wrote:

There are several sorts of Indian corn and of different colours; namely white, red, yellow, mixt, ete. A small sort of yellow corn is ripe much sooner than most of the other sorts, but yields a small produce. White and Yellow are the most common sorts but there are several kinds of these. A good ear of corn contains from 14 to 20 rows, and from 40 to 50 grains of eorn in each row. A hundred middling ears of corn will yield a bushel of clean corn (132).

Indian Methods of Cooking Maize.-From narratives of early travelers we get not only interesting items in regard to the use of Maize by the Indians but also the origin of many of our substantial articles of food made from this grain. Perey (1607 Virginia) says:

The manner of baking of bread is thus. After they pound their wheat into flowre, with hote water they make it into paste and work it into round balls and Cakes; then they put it into a pot of seething water; when it is sod thoroughly, they lay it on a smooth stone, there they harden it as well as in an Oren $(110$, p. LXIX).

White (1634 Maryland) states:

They (Indians) live for the most part on a kind of paste which they call Pone, and Omini both of which are made of Indian corn (12S).

Penn (1683 Pennsylvania) writes "Their diet is maiz or Indian corn . . called homine" (93).

Wood (1635 New England) gives "nocake. . Indian Corne parched in the hot ashes" (131).

According to the best accounts "jonny eake" is a corruption of "journey-cake" meaning small cakes of eoln meal used while traveling.

Williams (1643 Rhode Island) describes the Indians favorite article of diet, berry bread made of corn meal and such berries as happened to be ripe as strawberries, raspberries, huckleberries, ete. (129 p. 122). Modifications of this bread are still very popular in New England. This list of Indian methods of cooking and using maize might be extended indefinitely. 
Beans and Peas.-Crops of the pulse family of plants have been grown for food from ancient times. The mere citation of all the references made to these plants would fill a volume. Most of the statements refer to crops by name only. In some there are deseriptions only and in others descriptions accompanied by illustrations. I3ut these names, deseriptions and pictures have been so badly confused and jumbled by recent as well as carly writers that it is impossible to untangle the evidence and say positively from the historical sources alone where the various species of beans and peas originated. Fortunately there are other sources of evidence, such as the habitat of wild prototypes and ancient remains which aid in drawing conelusions. Several critical studies of all available cvidence in regard to origin of these plants have been made from which may be safely concluded that all of the many varieties of kidney beans, lima beans, scarlet runner beans, and tepary beans are of American origin. What makes the record confusing is in the ancient literature phaseolus meant an entirely different thing, namely our common cowpea. The Indian beans include a great many varieties which are now grown as field and garden sorts. The early writers on American crops usually employed the term "beanes and pease." Just what was meant by the term "pease" is now difficult to determine. The Canada field pea and common garden peas of the North are Old World plants and were grown abundantly in North European countries. Apparently "pease" was used to designate more than one different species.

Peas in the North a Species of Lathyrus. "-In Canada "pease" meant a Lathyrus-a plant which still grows abundantly along the Atlantic coast of Labrador. For instance in the Patent for Nora Scotia (1623) it is stated:

The Pease grow every where in abundance, very big and good to eate, but taste of the Fitch (fitch $=$ reteh) $(94$, v. 19, p. 339).

And Whitbourne (1618) states in regard to Newfoundland:

Without the labour of mans hand, greate plentie of greene Pease and Fitches, faire, round, full and wholesome as our Fitches are in England; of which I have there fed many times; the hawmes of them are good fodder for Cattle, and other Beasts in the winter, with the helpe of Hay (94, v. 19, p. 432$)$.

In the southern colonies pease may have meant a small seeded bean.

${ }^{1}$ Lathyrus maritimus (L). Bigal. 


\section{Hariot (1585) mentions:}

Wickonzour, called by us Pease, in respect of the beans for distinetion sake, beeause they are much less although in form they little differ: but in goodness of taste much like and are far better than our English pease.

Several of the early botanists identified Wiekonzour as Calavances which are now commonly known as cowpeas. The evidence indicates that cowpeas were not native to America but as shown in the discussion of that erop they might have been aceidentally introduced among the southern Indians before the time of Hariot. It is certain that the Inclians were quick in recognizing the merits of eowpeas and were growing them in the South very soon after the Virginia settlements if not earlier. A brief resume of some of the most important historical references to beans follow: (See also cowpeas).

Beans Found by Columbus.-Columbus in November 1492 found on the Island of Cuba "faxones" and "favas" very different from those of Spain. The word "faxones" meant Vigna sinensis or cowpeas and "favas" sometimes spelled "habas" meant Vicia faba or horse beans. Bcans called variously as "fesoles," "judias," "frejoles," frijoles, ete., are frequently mentioned in Spanish literature, a review of which simply confirms the above conclusions. The American beans were probably taken to Spain by Columbus and have no doubt been cultivated there ever since.

Cartier Found Beans in Canada.-The French expedition under Cartier (1535) found beans in Canada and probably took seed of them back to France. Cartier wrote:

They have also great store of peason and beans of every color yet differing from ours (90, v. II, p. 656).

The English learned of this species of beans from the French and for many years "French beans" was synonymous with "Indian beans" and "American beans" and referred to Phaseolus vulgaris. Some French and English writers, due probably to the peculiar fascination which everything Turkish had on the western European mind at that time, ealled them Turkish beans.

Beans in Virginia.-Hariot (1585) in his description of the products on Roanoke Island says:

Okindigier, called by us beans, because in greatness and partly in shape they are like to the beans in England, saring that they are flatter, of more divers colours, and some pied. The leaf also of the stem is much differ- 
ent. In taste they are altogether as good as our English peas (90, v. II, p. 595).

Smith (1607) found the Indians growing what he called pease and beans in Virginia. He wrote:

They plant also pease they eal Assentamens, which are the same they eal in Italye, Fagioli. Their Beanes are the same the Turkes eal Garnanses, but these they much esteeme for dainties (110, p. 62).

SMILAX HORTENSIS.

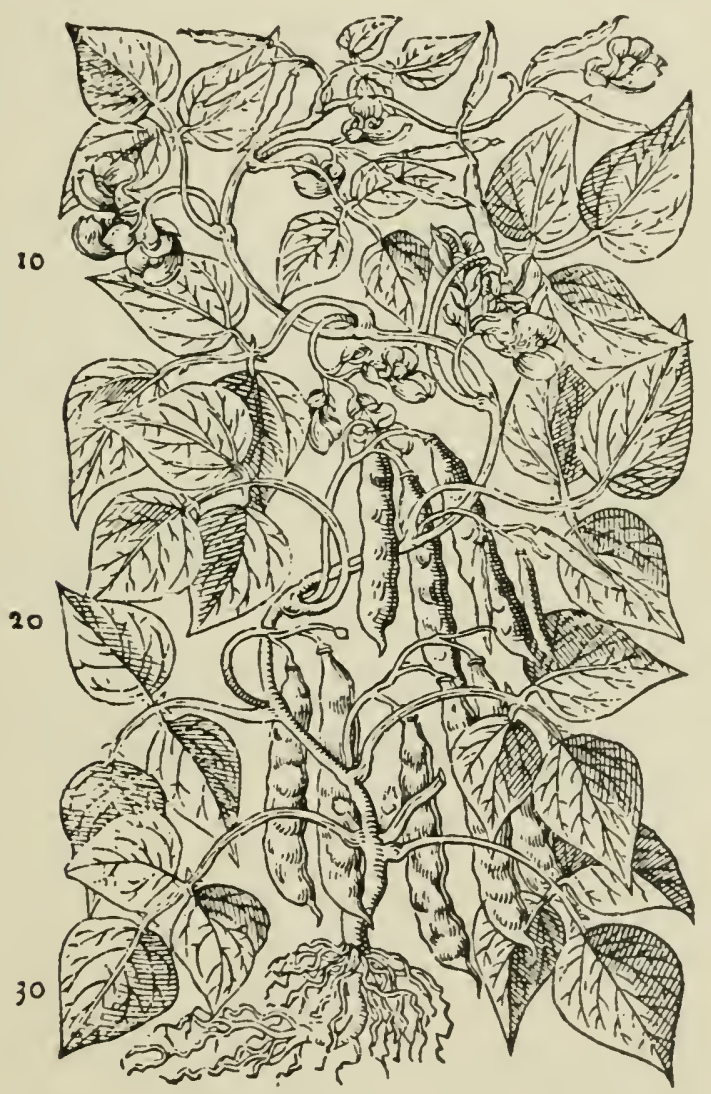

FIG. 11.-American Beans. Bauhin, 1598. Fuchs, 1542 also lists and illustrates this plant.

Smith's knowledge of plants was not extensive and this statement is eapable of several interpretations. It may or may not be literally true; the Virginia Indians may have been growing two 
distinetly different varieties of Phaseolus v'ulgaris; they may have obtained cowpeas from the West Indies; and we know the American beans had been introduced into Italy and Turkey by that time.

That Smith was familar with the beans of Turkey before he came to America is evidenced by an account of his imprisonment by the Turks in 1596, where we are told:

The Ruler and his friends fed upon Pillow which is boyled Rice and Garnancis with bits of Mutton, etc. (94, v. VIII, p. 337).

Leonard Fuchs (1542) gives a description and picture of Ameriean beans under the name of Smilax hortensis. Mattioli (1598) also lists these beans using the same name as used by Fuchs but has a much better illustration (Fig. 11).

Rauwolff in 1574 observed that the Maronites, "a sort of Christians" who dwelt on Mount Libanus in Palestine: "Keep a very severe order, and never eat flesh, and on their fasts neither butter nor eggs, but live upon fruits, as beans, peas, French beans, and such other common victuals" (96, v. II, p. 301), which shows that American beans reached Asia Minor at a date prior to Smith's experiences in that region.

Beans in New England and Virginia.-The Pilgrims (1620) found beans as well as corn stored in the ground by the Indians of Eastern Massachusetts (94, r. 19, p. 320) and Beverly (1705) says of Virginia:

The Indians sow'd Peas sometimes in the Intervals of the rows of Corn, but more generally in a Patch of Ground by themselves. They have an unknown Variety of them, (but all of a Kidney-Shape) some of which I have met with wild $(9$, p. 127). 


\section{CH.AP'TER VI}

\section{INDIAN CROPS, CONTINUED}

Tobacco.--Tobacco was quite generally grown over both North and South Americas and the West Indies. Nearly all tribes, especially those most adranced towards civilization, were addieted to its use. It may be classed among the few luxuries in which the Indians indulged. They, however, looked upon it not as a luxury but a necessity, believing that its use was essential to good health. It was also an important factor in their religious rites. This was the only cultivated erop in which the men of some tribes would labor. While in some eases both the men and women used tobaceo, in most tribes it was used only by the men. Like corn, tobaceo has been so long under cultivation that the sort commonly raised does not now grow wild any where although the other species of this genus are found wild in America.

A few of the many references to tobaceo by the early explorers show how widespread was its use. Other plants were sometimes used as substitutes for tobaceo when the latter was unavailable and it is not always certain that the writers were describing tobacco. The quotations which follow leave little doubt as to the identity of the plant mentioned.

Tobacco. Mentioned by Columbus.-In the account of the fourth voyage of Columbus it is stated while they were on the coast of South America:

Whilst they (the Indians) were here the Cacique and chief men never ceased putting a dry herb into their mouths and chewing it, and sometimes they took a sort of dry powder they carried with that herb, which looks very odd (90, v. II, p. 137).

According to Monardes:

The proper name of it amongest the Indians is Pcciclt, for the name of Tahaco is given to it of our spaniardes by reason of an Ilande that is named Tabaco (77).

Oviedo (1.535) gives tobacco as the name of a $\mathrm{Y}$-shaped tube with which the Indians of Haiti used to suck cojoba, a narcotic powder, into their nostrils. As the taking of this cojoba was 
confused by early as well as late writers with smoking tobacco, it is quite likely that the word tobacco came from the instrument used in taking the powder rather than from the island of Tabaco as given by Monardes. ${ }^{1}$

Canada Indians Raiscd Tobacco.-The French navigator James Carticr in his Relation of his Second voyage to New France in 1535 in describing the Indians along the St. Lawrence River states:

There groweth also a certain kind of herb, whereof in summer they make great provision for all the year, making great account of it, and only men use it, and first they eause it to be dried in the sun, then wear it about their neeks wrapped in a little beasts skin, made like a little bag, with a hollow piece of stone or wood like a pipe: then when they please they make powder of it, and then put it in one of the ends of said cornet or pipe, and laying a cole of fire upon it, at the other end suck so long that they fill their bodies full of smoke, till it cometh out of their mouth and nostrils, even as out of the tunnel of a chimney. They say that it doth keep them warm and in health: they never go without some of it about them. We ourselves have tried the same smoke, and having put it in our mouths, it seemed almost as hot as pepper $(90, \mathrm{v}$. II, p. 656).

Rale (1723) wrote of the Abnakis near Quebec:

"They are devoted to tobaceo: men, women and girls all smoke the greater part of the time. To give them a piece of tobaceo pleases them more than to give them their weight in gold."

Tobacco in Carolina.-Hariot's description reads:

There is an herb which is sowed apart by itself, and is called by the inhabitants uppowoc: In the West Indies it hath divers names, according to the several places and countries where it groweth and is used; The Spaniards generally eall it Tabacco. The leaves thereof being dried, and brought into powder, they use to take the fume or smoke thereof, by sucking it through pipes made of clay (90, v. II, p. 597).

Tobacco in New England.-Roger Williams gives this account for Rhode Island:

They generally all take Tobaceo; and it is commonly the only plant which men labor in; the women managing all the rest; they say they take Tobaceo for two causes; first, against the rheume, which causeth the toothake, which they are impatient of ; secondly, to revive and refresh them, they drinking nothing but water (129, p. 43).

Tobacco Early Taken to the Old World.-Tobacco was taken to Europe by the Spaniards at a very early date and was first

${ }^{1}$ Sce Erxst, Dr. A. Etymology of the Word Tobacco; American Anthropologist, v. 2, p. 133, 1889. 
grown, says Monardes, as an ornamental. It was also taken to Africa and the Orient by the Portuguese where its use quickly spread, especially, among the Mohanmedans. In India where many were accustomed to chewing betel nuts and leaves tobaceo beeame very popular.

William Finch, an English merchant writing in 1607 of sierra Leone, Africa states: "Tobaceo is planted about every man's house; which seemeth halfe their food."

William Dampier, in 1686, while referring to tobaceo on the Island of Mindanao says; "I believe the Seeds were first brought hither from Manila by the Spaniards, and even thither in all probability from America" (24).

The botanical name Nicotiana, together with nicotine the name of the active principle of tobaceo, are derived from Nieot the name of a French ambassador to Portugal who about 1560 first introduced tobacco into France (77, Fol. 42).

Tobacco; When First Taken to England.-John Hawkins appears to have been in command of the first English expedition that beeame acquainted with the use of this herb. Deseribing his visit in 1565 to the ill-fated French colony in Florida, he reports:

The Floridians when they travell, have a kinde of herbe dried, who with a cane and an earthen cup in the end, with fire, and the dried herbs put together, doe sucke thorow the cane the smoke thereof, which smoke satisfieth their hunger, and therwith they live foure or five dayes without meat or drinke, and this all the Frenchmen used for this purpose (29).

Credit has usually been given Sir Walter Raleigh for the introduction of tobacco into England. But the English sailors under Hawkins were undoubtedly the first English to acquire the tobacco habit. Raleigh gave the sanction of the British nobility to the prastice of smoking or drinking tobacco and was very much responsible for the popularity of tobaceo in England during his time. It is easy to see that Raleigh was influenced in his own use and his advoeacy of its use by others through the report of his friend and employe Thomas Hariot, and the evidenee shows that a considerable amount of tobacco was brought to England by Sir Francis Drake when he returned with Raleigh's second colony. This eommendation of Hariot (15S5) the chronicler of the Raleigh expedition, in regard to the Indian's use of tobaceo reads: 
We ourvelves, during the time we were there, used to sucke it after their manner, as also since our returne, and have found many rare and wonderful experiments of the vertues thereof, of which the relation would require a volume by itselfe: the use of it by so many of late men and women of great calling as els, and some learned physicians also, is sufficient witnesse $(42$, v. III, p. 330). Also (90, v. II, p. 59S).

A violent controversy over the effects of tobacco was soon raging in Europe which has never been entirely stilled, although the amount of tobaceo consumed has steadily increased.

Tobacco Culture.-The early writers deseribed at considerable length, the mamner of using tobaceo but were silent as to the Indians method of growing it. With no direct statements to guide us we must draw our own conclusions from whatever available evidence there is. The Indians raised their tobaceo on a plat of ground by itself, that is, it was not planted in mixtures as was the usual case with their other crops. It is a erop that requires a great deal of care and skill in growing. The European settlers in Amcrica had no crop that required methods of culture similar to those employed in growing tobacco except cabbages. The carliest available detailed deseriptions of tobacco growing describe the methods that are now in use. Putting these facts together one may be justified in assuming that the early European tobacco growers followed closely the Indian practices with perhaps the exception of topping and that there have been no essential changes made in the eulture of tobaceo since. Even the names of rarieties now grown go back to the carliest records concerning the crop.

Holm, from notes made by P. Lindstrom a civil engineer about 1642 in New Sweden reseribes tobaceo culture as follows:

In the first place, the seed is sown for planting in beds in the same manner as cabbage; afterwards, when the plant is suffieiently grown, it is planted in hillocks, where it grows so high as to reach a tall man under the arm. The soil where tobaceo should be sown and planted, is saltpetre earth, which is not found every where. Every three or four weeks the planter visits his tobacco plantation, and cuts off the top of each plant, except those which are to be kept for sced (52).

Clayton $16 S S$ makes similar observations for Virginia. To quote:

Now it being early in the year when they sow their seed, viz., about the fourteenth of Jauuary, they corer the ground to secure . . . their tender plants from the niping frosts . . with a few Oak-leaves or 
the like. . . Now you must know they top their Toluaren, that itake away the little top-bud, . . . generally when it lats shot forth four or six leaves (35, v. III, No. 12, pl). Is, 22).

Topping the tobacco plants, that is removing the terminal bud after a certain number of leaves liare set, appears not to lave been practiced by the Indians. It was used as an experlient to limit the production of tobacco to the very best grades, inaugurated by the Virginia planters in 1621 and the tobacco growers in all parts of the country have followed this practice ever since.

Squashes, Pumpkins and Gourds.-The Indians grew a number of plants with creeping vines which the white explorers harl never seen and to which they gave the names of European

I Pepomaximus oblongus. The great long Pompion.

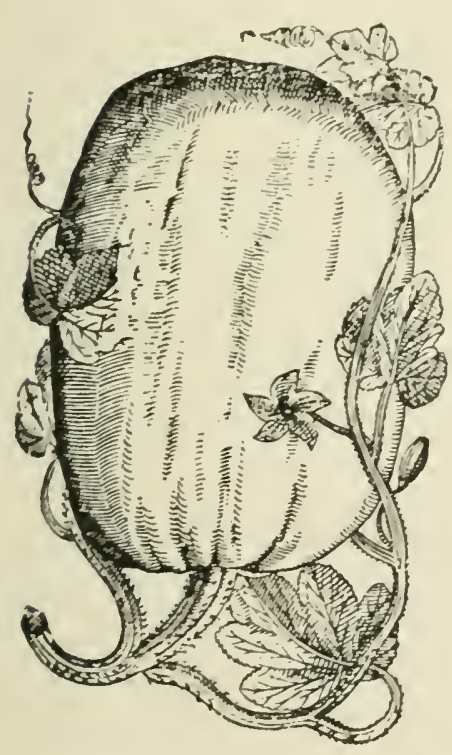

2 Pepomaximus rotundus. The great round Pompion.

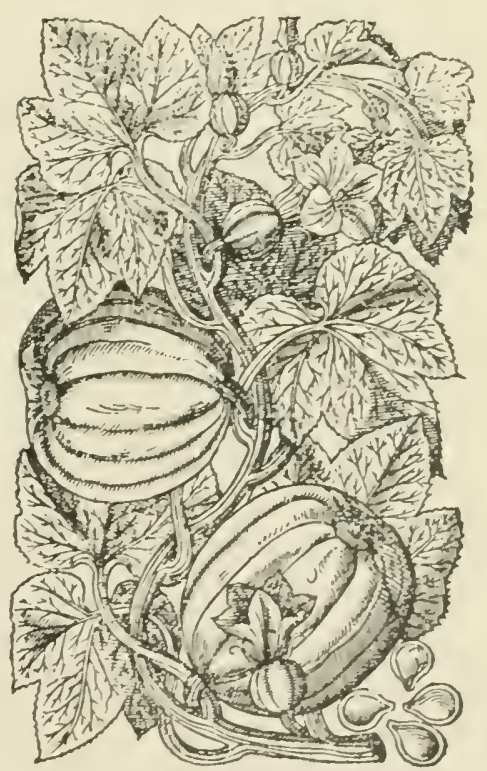

Fig. 12,- The Old World Pompions. Cierarle, 1597.

plants which they nearest resembled. It is difficult now to settle definitely the native habitat of some of these plants as Old World species were introduced into America and American species were grown in the Old World before botanists hack definitely described and identified them. There were plants, growing in Europe at the time of the discovery of America, known in English 
as pompions. (Fig. 12) and others by the French called eitruls, but the evidence seems quite clear that all the squashes, and the ordinary field pumpkin grown now in Ameriea were common food crops of the Indians. These plants were generally grown in their corn fields in much the same manner as yeltow pumpkins are now in some loealities.

Gourds Common to Both Hemispheres.--It has been established beyond reasonable doubt that the bottle or pilgrim's gourd was grown in ancient times both in the Old World and also in America. This has been proved by the finding of remains of these plants in the graves at Ancon, Peru, in old abandoned cliff dwellings in Arizona as well as in Egyptian tombs and in the buried eity of Pompeii.

Seeds stems and in some instances well preserved shells of pumpkins and squashes have been found in the cliff dwellings of Arizona.

Hariot (5S5) described these plants as follows:

Macokuer, according to their sereral forms, called by us pompions, melons, and gourds, beeause they are of the like forms as those kinds in England. In Virginia such of several forms are of one taste, and very good, and do also spring from one seed. There are of two sorts, one is ripe in the space of a month, and the other in two months (90 r. II, p. 596).

Smith (1616) enumerates "pumpions" and "gourds" among the Indian crops of New England (110, p. 207).

Cucurbits in Virginia.-Beverly gives a detailed deseription of these. He says:

Several Kinds of the Creeping Tines bearing Fruit, the Indians planted in their Gardens or Fields, because they wou'd have Plenty of them always at hand; such as, Musk-melons, Water-melons, Pompions, Cushaws, Macocks and Gourds.

1. Their Musk-melons resemble the large Italian Kind, and generally fill four or five Quarts.

2. Their Water-melons were much more large, and of several Kinds, distinguished by the Colour of their Meat and seed; some are red, some yellow, and others white meated; and so of the seed, some are yellow, some red, and some black; but these are never of different Colours in the same Melon. This fruit the Muscovites call Arpus; the Turks and Tartars. Karpus, because they extremely cooling: The Persians call them, Hindnanes, because they had the first Seed of them from the Indies. They are excellently good, and very pleasant to the Taste, as also to the Eye; having the Rind of a lively green Colour, 
streak'd and water'd, the Meat of a Carnation, and the siced black, and shining, while it lies in the Melon.

3. Their Pompions I need not describe, lut must say they are much larger and finer than any I ever heard of in England.

4. Their Cushaws are a kind of Pompion, of a bluish green Colour streaked with White, when they are fit for Le. They are larger than the Pompions, and have a long narrow Neck: Perhaps this may be the Ecushaw of T. Harriot.

5. Their Macocks are a sort of Melopepones, or lesser sort of Pompion, or Cushaw. Of these they have great Variety; but the Indian Name Macock serves for all, which Name is still retain'd among them. Yet the Clypeatae are sometimes call'd Cymnels (as are some others also) from the Lenten Cake of that Name, which many of them very much resemble. Squash or Squanter-squash, is their Name among the Northern Indians, and so they are call'd in New Tork and New England. These being boil'd whole, when the Apple is young, and the shell tender, and dished with Cream or Butter, relish very well with all sorts of Butcher's Meat, either fresh or salt. And whereas the Pompion is never eaten till it be ripe, these are never eaten after they are ripe.

6. The Indians never eat Gourds, but plant them for other Uses. . . For, when it is ripe, the Rind dries, and grows as hard as the Bark of a Tree, and the Meat within is so consumed, and dried away, that there is then nothing left but the Seed, which the Indians take clean out. and afterwards use the shells instead of Flagons and Cups; as is done also in several othel Parts of the World (9, pp. 123-5).

Cucurbits in Canada.- Kalm made an attempt to determine the habitat of the various cultivated plants of America and his statements are of much value. He wrote in regard to Canada:

Gourds of several kinds, oblong, round, flat or compressed, crooknecked, small, ete. . . The French bere eall them citrouilles, and the English in the colonies, punpkins." . . . However they plant more squashes than common gourds (65, v. II, p. 3\$s).

LaHontan is evidently describing squashes of the hubbard type when he says:

The citruls of this country are sweet, and of a different nature from those of Europe; and I am informed, that the American citruls will not grow in Europe. They are as big as our melons, and their pulp is as yellow as saffron. Commonly they are baked in orens, but the better way is to roast them under the embers as the savages do $(90, \mathrm{v}$. III, p). $360)$.

Sunflowers and Artichokes.-The Sunflower grows wild over a considerable area of America, especially in the prairic states. 
The Indians along the Atlantic coast had domesticated the plant and were utilizing the seed for food purposes. Its showy flowers attracted the attention of the European explorers, and several mythical tales were related about it. One of these sponsored by Monardes (1574) was to the (effect that the face of the flower turned to the sun at all hours of the day. The seed of sunflowers was used as an ingredient in soups by the Indians but it does not appear to have been very extensively cultivated.

Jerusalcm articholes were grown by the Indians over a wide range. The aggressive habits of this plant often made it a nuisance in the gardens of the early pioneers. For a brief time artichokes were highly exploited as a food crop. They were served in 1616 at a Royal banquet in Paris $(99$, p. 47). But their popularity soon subsided and artichokes dropped from being a royal dish to a more useful purpose as a forage for swine. The true artichoke is an Old World edible plant belonging to the thisthe family:

A few of the carly accounts of these American plants follow: Hariot found sunflowers in 1585 on Roanoke Island about which he observes:

There is also another great herb, in the form of a marigold, about six foot in height, the head with the flower is a span in brearth. Some take it to be plante solis: Of the seeds hereof they make both a kinde of bread and broth $(90, \mathrm{v}$. II, p. 596).

Gerarde (1596) lists both sunflowers and Jerusalem Artichokes.

In regard to the former he states: "Some have reported it to turn with the sun which I could never observe although I have indeavored to find out the truth of it," and for Jerusalem artichokes, "Neither came it from Jerusalem or out of Asia but out of America" (39) (Fig. 13).

Murray gives the following explanation of the derivation of the term Jerusalem Artichoke which is plausible in view of the facts that the plant is not an Artichoke and never came from Jerusalem.

The name of Jerusalem Artichoke is considered to be a corruption of the Italian (Firasole Articioceo or Sunflower Artichoke (82).

Sweet Potato.-C'olumbus found the Indians of Cuba growing sweet potatoes and they were reported later by various Spanish expeditions to Mexico and South America. They were known by the Indian names, batatas and padades from whence comes our trrm potato. Sweet potatoes beame popular with the Spaniards 
and Portugese who took them to Europe, Asia and Afriea, where their culture soon became general. It is diffieult to learn to what extent sweet potatoes were cultivated by the Indians within the boundaries of what is now the United States. Hariot mentions

1 Flos Solismaior.

The greater Sunne flower.

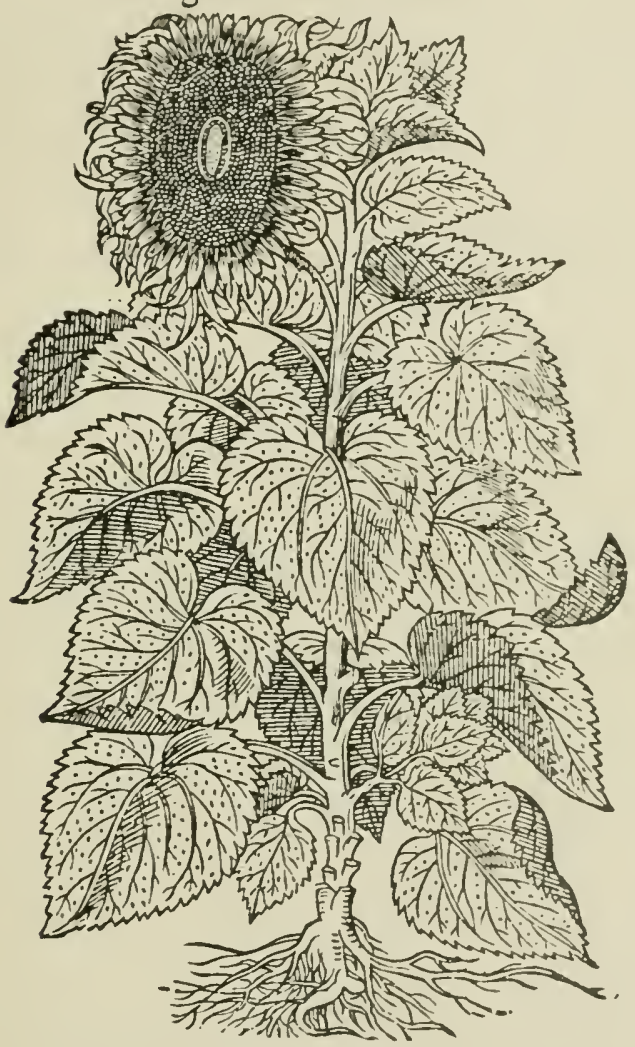

Fig. 13.-Sunflower. Gerarde, 1597.

four root crops used by the Inclians of Eastern North Carolina but none of the deseriptions fits the sweet potato. The numerous relations of the Jamestown colony are also silent as to the culture of this plant by the Indians although Smith states that "Tockawhoughe" roots are much of the greatness and taste of Potatoes. Sweet potatoes had become well known in England under the name of Spanish potatoes before the Jamestown settlement. It is probably safe to say that sweet potatoes were 
introduced into the southern colonies by the white settlers but there is a strong possibility that the plant had been grown there before by some of the tribes about the Gulf, especially those offshoots of Central Ameriean or West Indian tribes. There was also a wild variety of this plant which grew in moist places in he Gulf coast region.

As a food plant sweet potatoes became an immensely important crop to the early colonists and were grown as far north as Albany, N. Y. Sweet potatoes were early taken to the East Indies although there is elear evidence that there was a similar crop probably a variety of yam, grown in the Orient before the discovery of Amcrica.

References to Sweet Potatoes.-In the account of the first voyage of Columbus it is stated:

They (the Indians) gave them (the Spaniards) some boiled roots to eat not unlike chestnuts in taste. . . There was a great deal of tilled land some sowed with those roots (90, v, II, p. 3S).

Van Linschoten a traveler in India in 15S3 says:

There grow in India many Iniamos and Batatas. These Iniamos, are as bigge as a yellow Root, but somewhat thicker and fuller of knots, and as thicke, on the one place, as in the other, they grow under the Earth like Earth-Nuts, and of a Dun colour, and white within like Earth-nuts, but not so sweet. The Batatas are somewhat red of colour, and of fashion almost like the Iniamos. but sweeter of taste like an Earth Nut. These two fruits are very plentifull (94, v. X, p. 298).

Clusius described and gave an illustration of sweet potatoes in 1601. This was copied in the revised edition of Gerarde's Herball in 1636 where it is stated that "potato's grow in India, Barbarie and Spain."

Sold in England.-There are many earlier references to potatoes in English literature than the following but few give the price they brought in the market. After describing Irish potatoes Hought on (1699) adds:

There is a sort brought from Spain, that are of a longer form, and are more luscious than ours; they are much set by, and sold for six pence or eight pence the pound. Whether these differ any more than what is caused by the different soils they grow in, I know not (54).

Smith mentions "white red and yellowed coloured potatoes" among the products introduced into Bermuda by the English, and states: 
A small ship coming in December (1621) lat from the summer (Bernuda) Islands to Virninia hrought thither from thence these plants viz. . . vines of all sorts, Orange and Lemon trees, sugar canes, Cassado roots (which mike bread) Pines, Plantains, Potatoes and sundry other fruits and plant s not formerly seen in Virginia (94, v, XIX, p. 147 ).

Strachey, however, says that potatoes had been given a trial in his time $(1610-12)(120, p .31)$.

Grown in Virginia.-Beverly (1705) gave a somewhat detailed description of the sweet potatoes grown in Virginia. To quote:

Their Potatoes are either red or white, about as long as a Boy's leg, and sometimes as long and big as both the Leg and Thigh of a young Child, and very mueh resembling it in shape. I take these Kinds to be the same with those, which are represented in the Herbals, to be Spanish Potatoes. I am sure, those call'd English or Irish Potatoes are nothing like these, either in Shape, Colour or Taste. The Way of propagating Potatoes there, is by cutting the small ones to Pieces, and planting the Cuttings in Hills of loose Earth: But they are so tender, that it is very difficult to preserve them in the Winter; for the least Frost coming at them, rots and destroys them; and therefore People bury 'em under Ground, near the Fire Hearth, all the Winter, until the Time comes that their seedings are to be set $(9$, p. 127).

Hughes (1750) for Barbadoes says:

I shall . . clivide them (potatoes) into the white and red, the long and the round Sort. Each of these differs from the English Potato by being propogated by a Slip or Vine which they produce instead of upright Stalks. Another remarkable Difference is the West-India Potatoes have all a sweetish Taste (55).

Kalm mentions having yams for which he gives the botanical name Dioscorea alata, served him at the home of Benjamin Franklin in 1749. These, he says: "Are white and taste like common potatoes but not quite so agreeable" (65, v. II, p. 66). They were evidently not a home grown product but probably had been brought to Philadelphia from the West Indies. 


\section{C'HAP'TER VII}

\section{INDIAN CROPS, CONTINUED}

Watermelons.-The watermelon is considered an African product by most plant historians. The available evidence however points more strongly to an American origin than it does to an African. Watermelons were not known to the ancient Greeks and Romans-a fact that is significant as the plant is admirably adapted to the soil and climate of those countries and is now grown there in abundance. It has often been asserted that watermelons were grown by the ancient Egyptians, the proof most often eited being some outlined ovals in Egyptian pictures, evidence of very doubtful value.

Colocynth in Egypt.-The Egyptians grew the colocynth or bitter melon, a plant very similar to the watermelon in appearance and from the seeds of which is derived a drug. Leaves and seed of this have been found in mummy wrappings in old Egyptian tombs. This plant was well known in Europe. Turner (1551) lists:

Coloquintida a round fruite like a ball excedyngly bytter, whyche ye must gather when it begyneth fyrst to be turned into a pale yelloishe calour (122).

Fuchs had also deseribed it nine years earlier (Fig. 14).

The colocynth has been considered the primitive form of the watermelon by several botanists which has had much influence in shaping opinion on the subject of the native habitat of the latter (105).

Watermelons were found growing wild in great abundance in Equatorial Africa about the middle of the nineteenth century by Livingston which Alphonse deCandolle asserts "settles the question" as to its native home. It is not clear, however, how this settles the question. There are numerous instances where plants which were undoubtedly introduced species show an aggressiveness in their new environment unsuspected in their native habitat.

Watermelons Unknown to Early Botanists.-The watermelon is not described in any of the European "herbals" of the sixteenth century. 
This omission from the early plant catalogues argues strongly against the oft repeated assertion that watermelons were well known by the ancient Egyptians. No other food plant of any importance native to Africa was overlooked by these medicobotanists or, for that matter, by the farmers on the north side of the Mediterranean Sea. A fruit with the peculiar properties of the watermelon could searcely have escaped attention of the ancient physicians who were ever alert for the unusual in plants to aid in their fight against human ailments.

The eitation by Linnaeus, Candolle and several other botanists of the Anguria of Mattioli (1598), (Fig. 15) as a synonym of watermelon is evidently an error. The anguria of Mattioli is apparently the same melon as the cucumer citrulus of Fuchs (15+2) (Fig. the waterme'on. the primitive form of 16), the citrulli of Turner (1551)

who says, "some of this kyndes now are ealled citrulli of their citrone coloure and this kyude hath brode and whyte sede"; the Cucumis citrulus of Dodoens (1563) who states: this species of cucumbers is called Cucumis citrullus and by some Anguria, by the Apothecaries citrullum and from that word the German citrullen, in French Coneombre eitrin; and the eitrull eucumber of Gerarde (1597).

Gerarde used the same identical illustration as Mattioli (Fig. 15) and gives this description:

The Citrull Cucumber hath many long, flexible, and tender stalks, trailing upon the ground, branched like unto the Vine, set with certain great leavess deepeley cut, and very much jagged: among which come foorth long clasping tendrels, and also tender footstalkes, on the endes whereof do grow flowers of a golde yellowe colour: The fruite is somewhat rounde, streaked or ribbed with certain deepe furrowes alongst the same, of a greene colour above, and underneath on that side that lieth upon the grounde something white: the outwarde skin whereof is 
very smooth; the meate within is indifferent harde, more like to that of the Pompion then of the Cucumber or muske Melon: the pulp wherein the seede lieth, is spungie and of a slimie sulsstance: The seede is long,

\section{Cirrulus of ficinarum. Citrull Cueumber.}

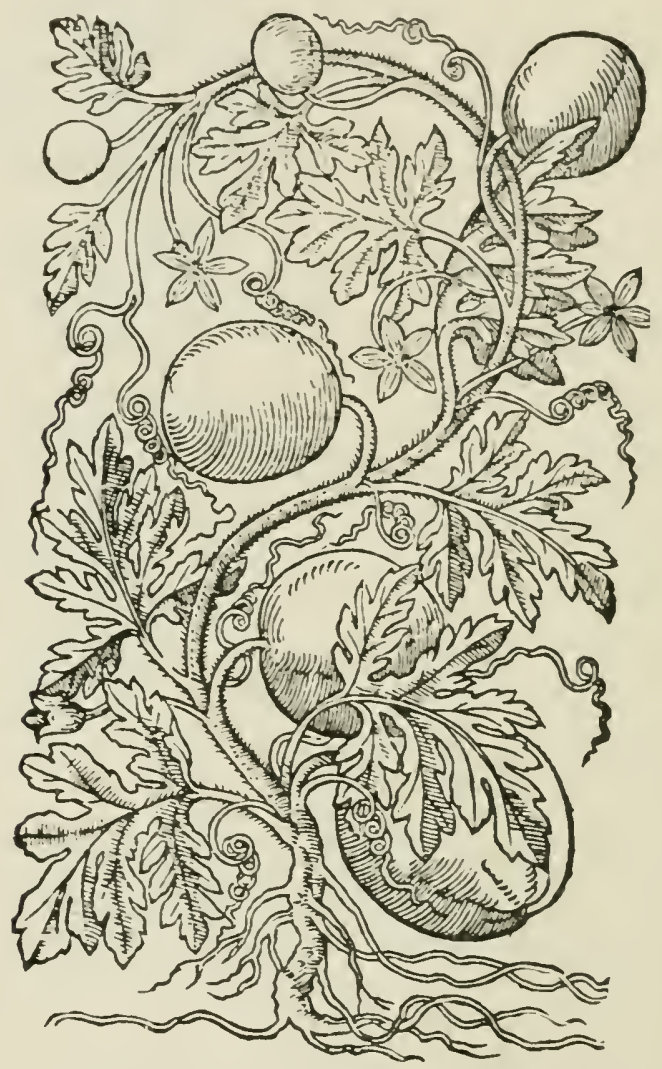

FIG. 15.-Citrull cucumber of Gerarde, 1597, and Angurix of Bouhin, 1598. Erroneously considered a watermelon.

flat and greater then those of the Cucumbers: The shell or outwarde barke is blackish, sometimes of an orerworne reddish colour. The fruite of the Citrull doth not so easily rot or putrifie as doth the Melon, which being gathered in a faire dry day, may be kept a long time, especially being covered in a heape of Wheate, as Mathiolus saith, but according to my practise you may kecpe them much longer and better, in a heape of dry sande. . . . The citrull prospereth best in hot regions as in Sicilia, Apulia, Calabria and Syria, about Alepo and Tripolis $(39$, p. $76 \bar{\tau})$. 
There are several statements in this account, all of which are confirmed by other sixtenth century botanists, which prove conclusively that the anguria or citrull was not the watermelon.

\section{Celarde also says:}

There be divers:orts of melons found at this day, differing very notablie in shape and proportion, as al:o in taste, according to the climate and countrie where they growe: but of the ancients there was onley one and no more, which is that Melopepo called of Cialen cucumis, or Galens cucumber. Notwithstanding some have comprehendened the Muske Melons under the kinds of Citruls wherein they have greatly erred: for doubtless, the Muske Melon is a kinde of Cucumber, according to the best approved authors $(39$, p. 760$)$.

This grouping of melons with cueumbers should be borne in mind in considering the early references to melons in America. There was at that time a plant known to the English as "Spanish Cowcumbers," the fruit of which resembled a watermelon but its leaves were not deeply cleft.

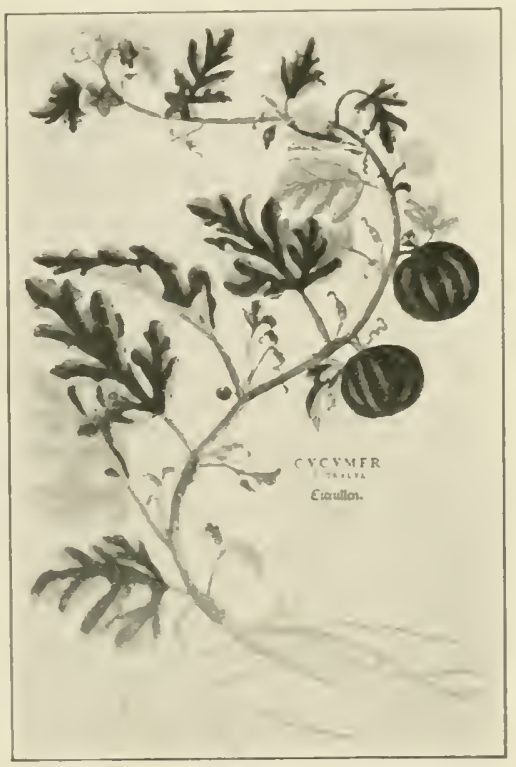

FiG. 16.-Cucumber eitrules, Fuchs, 1542. Evidently the same plant as shown in Fig. 15.

First Botanical Description of Watermelons.-In the revised edition of Gerardé's "herball" (1636, p. 921) may be found among other additions to the earlier work "Virginia Watermelons." The plant described is unquestionably the true watermelon.

The description reads:

This Melon or Pompion is like and fully as big as the common Pompion, in spreading rumning creeping branches, leaves, floures, and clasping tendrels; the fruit is of a very blackish greene colour and extendeth it selfe in length neere foure inches, and three inches broad, no bigger nor longer than a great apple, and grow alongst the branches forth of the bosomes of the leares not farre from the root even to the tops of the branches, containing a substance pulp and flat seed like the ordinarie 
Pompion; the root is whitish and disperseth itselfe very far abroad in the earth and perisheth about the beginning of Winter.

This description is dated "Octob. 10, 1621," and signed "John Coodyer." It is apparent that this description was written from inferior specimens, probably grown in Fugland. The seed most likely was obtained from America. The earliest recorded uses so far found of the English term "watermelon" is that of "Terry in 1616 (sec p. 107). The word became common from that time on in English literature. The equivalent words in other European languages do not appear to antedate this by very many years.

The Introduction of Musk Melons in America.-There are many references to melons in the early American historical sources. The Spanish evidence although melons are frequently cited is not very helpful. Melons were listed among the plants introduced into the West Indies but nothing appears to indicate the species.

Peter Martyr (1511) relates that:

On the shore of this ryver (in Hayti) they have lymyted and enclosed certeyne grounde to make gardeynes and orchiardes in the which al kyndes of bygger herbes, as radyshe letuse, eolewortes, borage, and such other, waxe rype within XVI dayes after the seede is sowen. Lykewyse Melones, Gourdes, Cueumers, and suche other, within the space of XXYVI dayes" and again on Darien "herbes of the bygger sorte as gourdes, melones, eueumers, pompons, citrons and suche other, coome to their perfection in the space of thirtie dayes (30).

Spanish References to Melons.-One frequently finds the Spanish words "Melons" and "Calabazas" in accounts of early Spanish travels in the Southwest but these have been usually taken to mean muskmelons and gourds. As it is now known positively that the Indians of that region raised squashes and pumpkins as well as gourds, the terms were probably used in a general sense to include those plants. The Spanish word "sandia" for watermelon does not appear in any of the journals of the very earlicst explorers so far studied. The evidence indicates that the Indians of the arid regions of the southwest did not raise watermelons before the coming of the Spaniards. No identifiable seed or other remains have ever been found in the cliff dwellings; neither was the figure of the watermelon used in any Indian pottery or pictures so far discovered. A study of the language of the Tewa Indians of that region indicates a Spanish introduction of watermelons among that tribe (17, Bul. 55). 
In a description of New Mexico by Oñate in 1599 occurs the first use so far found of a word which has been translated watermelons (117). While the original text is not available the translator writes that he "quite uniformly rendered melons as melons (meaning Musk Melons, or C'antaloupes) and sandias as watermelons." Nothing in Onate's statement shows whether the watermclon was native or introduced.

Watermelons Common in the West Indies.-Watermelons were grown extensively in the West Indies and most North European peoples obtained their first knowledge of this fruit as they passed by those islands on their way to North America. Andrew White with the first expedition to Maryland carly in 1634 wrote back immediately after his arrival a description of the voyage. From this the following is extracted:

Then about $t$ in the evening we came before Matilena (Martinique) where we came to ankor, and 2 canowes of starknaked Indians came paddleing aboard us, with parrats, pumpkins, callabashes, bonana's, muskmellons, watermellons and the like to exchange with us (8.5).

Melons in Canada.-The historical evidence for the humid region along the Atlantic seaboard is of a more convincing character. Cartier (1535) while exploring the St. Lawrence River uses the French words "mellons" and "concombres," which he says wcre very large, in describing the Indian products of that region. Hakluyt (about 1600) using the best botanical language of the time translated these words "musk melons and cucumbers" neither of which is likely to have been grown in Canada in the sixteenth century. Modern translators have rendered these terms "squashes and pumpkins," which of course is at best only a guess.

Jcan Ribault found the Indians of Florida in 1562 growing "beans, gourdes, cowekcumbers, citrons, peasen, and many other fruites and rootes unknown unto us" (33).

The word "citron" now commonly applied to the variety of melons used for preserving was formerly used loosely to designate any fruit of yellowish color as the citrus fruits, oranges and lemons.

Melons Found in North Carolina.-Melons appear several times in the accounts of the various Raleigh expeditions to North Carolina. Barlowe (1584) says:

He (an Indian ehief) sent us divers kindes of fruites, Melons, Walnuts, Cueumbers, Gourdes, Pease and divers rootes, and fruites very excellent 
good, and of their countrey Corne, which, is very white, faire and well tasted (29, p. 234).

While visiting a tribe ruled by a squaw, he records:

She brought us into the inner roome, where shee set on the boord standing along the house, some wheate like furmentie, sodden Venison, and roasted, fish sodden, boyled and roasted, Melons rawe, and sodden (29, p. 235).

Hariot (15S5) mentions a group of plants which the Carolina Indians called Macocquer. These he says:

According to their several formes called by us Ponpions, Mellions and Gourds, because they are of the like formes as those kindes in England (44, p. 22).

Captain John White in command of the relief expedition sent to Roanoke Island in 1587 wrote:

We found the fort rased downe, but all the houses standing unhurt, saving that the neather roomes of them, and also of the forte, were overgrowen with Melons of divers sortes, and Deere within them, feeding on those Miclons (29, p. 2SS.)

While these sixteenth century American melons may have been merely squashes or pumpkins there is nothing in the statements which would exclude watermelons. On the contrary there is good presumptive evidence that the melons which were served "rawe" might have been watermelons.

Watermelons Not Mentioned in Virginia by Smith.-Captain John Smith makes no mention of watermelons in his description of Virginia first published in 1612, but under date of 1623 in his General History of the Bermudas, mentions both muskmelons and watermelons among the plants introduced into those islands by the English after their settlement in 1612 (110, p. 629). This absence of melons from Smith's description of Virginia has little weight one way or the other. He was equally tardy in recounting the Pocahontas episode. There were no Indians in the Bermudas at the time of the settlement of those islands by the English.

In an appeal for the encouragement of agriculture in England, James I (died 1625) recites the great benefits which had come to that country from introduced species of plants and adds:

So for New England, why should we thinke, that the Indian Corne, the Marsh-wheate, that excellent Rie, the Pease, (which never are eaten with maggots), the French or Kidney beanes, the Pumpions, Squashes, 
Water-Mellons, Musk-Mellons, Hurtleberries, Wilde Hemp, Fir, etc. of those parts, are altogether useless for us ? (46).

Watermelons Grown by the Delaware Indians.-IIolın from notes given him by his grandfather, a chaplain, in 1642, in the Swedish settlements on the Delaware only two years after the first European farming was attempted in that region, wrote a history of New Sweden. In this book the European crops including musk-melous grown by the Swedes are listed together and then the native Indian products are discussed from which is taken the following:

There is, also, amongst other things, a most beautiful and excellent fruit, which we call, in Sweden, water-melon. It grows in rows like pompions, and some of them are so large that three tankards full of liquor may be extracted out of one melon. When they are cut the inside is of a beautiful flesh colour; the taste is delightful, and it melts in the mouth like sugar (52).

Watermelons Grown along the Hudson River.-Vries (1641) in describing the Indian products of the Hudson River legion says "There are also pumpkins watermelons, and melons"1 (126).

In a Description of New Netherland written in July 1649 the writer states:

All garden fruits succeed likewise very well there, but are drier, sweeter and better flavored than in Netherland. As a proof of this, we may properly instance melons and citrons or water-melons, which readily grow, in New Netherland, in the fields, if the briars and weeds be only kept from them, whereas in Netherland they require particular attention in gardens, either from amateurs or those who raise them for profit, and yet are not near as perfect nor as palatable as they usually are in New Netherland (14).

This item is of interest in establishing the approximate date of the growing of watermelons in northern Europe on a commercial scale.

Watermelons in New England.-Josselyn who first visited New England in 1638 says:

The water-melon is proper to the country, the flesh of it is of a flesh colour, a rare cooler of Fearers and excellent against the Stone (6t).

The French Found Watermelons in Illinois.-Marquette (1673) found the Illinois Indians growing "melons which are excellent especially those that have red seeds" (48) also (121 v.

1 The original Dutch being "Oock wassen ahier veel Pomponen, Water-lamonen, ende Lamonen." 
59, p. 127). This could scarcely mean anything but watermelons and such an interpretation is amply confirmed by other French explorers in that region. Joliet wrote under date of June 15th, 167.4 "They (the Illinois Inclians) have abundance of WaterMelons, Citruls and Gourds" (48 v. II, p. 622).

Joutel (1687) one of the survivors of the last LaSalle expedition in Texas gave in an account of an Indian tribe on the lower Mississippi: "The women sow and plant, the Indian eorn, beans, pompions, watermelons and other grain and garden ware which is for their sustenace." And again while a little below St. Louis "we met a company of Indians . . . they came, caressed and presented us with some watermelons they had."

At an Indian village farther up the Mississippi, where they lodged the women brought them: "Bread, gourds, beans, and watermelons a sort of fruit proper to quench thirst, the pulp of it being no better than water."

At Ft. Louis on the Illinois river Joutel states: "The Indian women daily brought in something fresh, we wanted not for watermelons, bread made of Indian corn, baked in the embers and other such things" (22, v. II, pp. 139, 191, and 222) (36, v. I, pp. 173-4).

Binneteau a Jesuit Priest stationed in the Illinois Country wrote in 1699, in regard to the gardens of that region: "One of their finest ornaments is what we eall the watermelon which grows to an extraordinary size. It has a very sweet taste and differs from our melons because it does not turn yellow. These melons are eaten without salt, and are harmless even when caten in quantitics" (121, v. 65, p. 75 ).

Watermelons Considered Native to Canada.-La Hontan a military Commander in Canada from 1683 to 1691 wrote extensively on the natural history of that region. Among the agricultural products of the Hurons he lists watermelons and sweet citruls (squashes) but does not mention cucumbers or muskmelons. "The watermelons, says La Hontan, called by the Spaniards Algiers, melons are round and thick like a ball; some are red, and some white; and the kemels, which are very large, are sometimes black, sometimes red; as for their taste it is exactly the same with that of the Spanish or Portuguese melons" $(90$, v. III, p. 360$)$.

Drawing Conclusions.-There are many more references to watermelons subsequent to the ones given here which credit the 
plant to America. 'These appear to be enough, however', to prove that the North American Indians were cultivating the watermelon all along the Atlantic seaboard and in the Mississippi Valley at the time of the English, Dutch, Swedish and French settlements. That they were not introduced from northern Europe is clearly evident because the plant was unknown there in the sixteenth century. Several explanations may be deduced from the conflicting data. There is the possibility that seed of watermelons may have been distributed on the American continent from Spanish introduction in the West Indies by fishermen or exploring expeditions prior to the settlements. Some seraps of eridence may be given which argue strongly against such an introduction.

Evidence Indicates an American Origin.--If the watermelon is an Old World plant as generally supposed it was grown in the sixteenth century only in a tropical or subtropical climate. It seems highly improbable that the Indians could have taken this plant and developed varieties which would mature in southern Canada in the short time which this must have been aceomplished if the watermelon was introduced by the Spaniards.

Another point is worth noting. The African melons are frequently bitter and often solid and unedible in a raw condition like the citron melon.

If the American melons were derived from the same source we might expect an oceasional reversion to that type. There is no evidence of bitterness in the American melons even in the wild sorts of the South.

Indian Linguistic Evidence.-Many of the Indian tribes had distinctive Indian words in their vocabularies for the watermelon. Those along the Delaware river called it "shijtamen" (52, p. $150)$.

In Choctaw watermelon was "shukshi" and the core of a watermelon "skukshi nipi" (17, Bul, 46). The Biloxi Indians knew the watermelon as "onthan" (17, Bul. 47). While this linguistic evidence does not possess any great value it is equally as cogent as the Arabic words which are so frequently given as proof that watermelons are native to Asia and Africa.

Watermelons Not Mentioned in Early African Travels.There are accounts of travels in Africa contemporaneous with those here given of American exploration in which a search has as yet failed to reveal any mention of watermelons in Africa in 
the sixteenth or seventeenth centuries. John Leo 1535 speaks of the kingdom of (iago 500 miles soutl of the Niger River as abounding "with melons, citrons, and Rice."

Francis Moore a factor in the Royal African Company stationed on the Gambia river in Africa (1730-35) wrote a book describing the country and its products $(7 S)$. Subsequently he visited Georgia about which he also wrote a book. Moore says nothing about watermelons in Africa but mentions them several times in his Georgia treatise (79).

The Melons of Asia.-The early travelers to Asia Minor mention a species of melons which has quite generally been rendered watermelons in English. The most common Arabie word for these being batteca supposed to be a corruption of the Hebrew word battechim. It has been spelled in many different ways. Wherever this word batteca occur's in old Arabic writings it has usually been taken to mean watermelons and it apparently forms the sole proof of the spread of watermelons around the Mediterranean region in pre-Columbian times so frequently stated as a fact by plant historians.

However a study of the melons known in Turkey-in-Asia prior to the probable introduction of the watermelon indicates that the batteca was an entirely different melon. The following quotation from Raurolff's (1573) account of the garden produce around Aleppo shows one type of melon:

Of Pumpions, Citruls and Cucumis-anguinus, which they call Gette, they plant as many as they have oceasion for; but many more Angurien, an Indian Muskmillion, or Water-melons, which they call Batiechas ${ }^{1}$ but Serap. Dullaha, they are large, of greenish colour, sweet and pleasant to eat, and very cooling wherefore they esteem them to be their best fruits; but Chiefly those, which have more red than white within; they are very innocent and harmless, and keep so long good, that they sell them in their Batzars all the winter long. Moreorer there are three sorts of those plants which the Arabians call Melanzana, Melongena, and Beudengian, (Bedengian) as Ash-coulour'd, yellow; and flesh-colour'd which are very like one another in their erookedness and length, and like unto the long Gourds (96, v. II, p. 48).

The long keeping quality of these melons excludes watermelons and the whole description applies to the Persian, some rarieties of which have a reddish or pinkish colored flesh, better than it

I Original Dutch: "d'Indiaansche Meloenen vande gemeene Man Batiechas genaamt." This shows that the term watermelon was added by the translator. 
does to watermelons. Russel in 1794 gives "Batech" as the Arabic word for Cueumis melo or muskmelon and "Jibbes" as Cueumis citrullus or watermelon (102).

On the other hand, Van Linschoten, an Asiatic traveler, in 15S3, says: "There are also in India many Melons, but not so good as those in Spaine, for that they must be eaten with Sugar, if you will have any sweetnesse in them: but there is another sort like Melons, called Patecas or Angurias, or Melons of India, which are outwardly of a darke greene colour, inwardly white with black kernels: they are very waterish and hard to bite, and so moist, that as a man eateth them, his mouth is full of water, but yet very sweet, and very cold and fresh meate, wherefore many are eaten after Dinner to coole men" (94, pp. 29t-5). There seems to be no reason for doubting that Van Linschoten is describing the watermelon which may well have been introduced into India at that date by the Portugals. It is easy to see how Ray, who translated Rauwolff's deseription, may have been led into error by confusing these two distinct types of melons which were known by the same name.

The difficulties encountered when one tries to identify the ancient Arabian melons as watermelons is well exemplified in an article "Etudes sur les nome Arabes de diverses familes de vegetaux" by J. J. Clement-Mullet in the "Journal Asiatique" for January and February, 1870 where some seven different varieties of melons, some with long crooked neeks, some with pronouneed odors, some with rough surfaces, some pear-shaped, and some jar-shaped are all grouped under the term pastique the French word for watermelon. That the ancient Arabians had a great many varieties of melons is well authenticated but it is much more likely that the watermelon was introduced among these people in more modern times and that they, following the usual procedure, gave to it a name of one of their similar plants than that they had kept all knowledge of such a fruit for a thousand years or more from the Europeans.

Evidence of Ancient Chinese Culture of Watermelons Unsatisfactory.-Equally unsatisfactory have been the attempts to prove the ancient culture of watermelons in the Orient from Chinese sources. Laufer who accepts the conclusions of Alphonse deCandolle and A. Engler that the watermelon is native to Afriea, asserts:

The theory is based on the observation that the watermelon grows spontaneously in South Africa, but it is not explained by what agencies 
it was disseminated from there to Aneient Egypt. Nevertheless, the available evidence in Asia seems to me to speak in favor of the theory, that the fruit is not an Asiatic eultiration; and, since there is no reason to credit it to Europe, it may well be traceable to an $A$ friean origin.

By this method of reasoning it is only necessary to carry the process of elimination one step further to prove America to be the native habitat of this plant as Australia, is certainly out of the question. Laufer further observes:

If it is eorreet that the first report of the watermelon reached the Chinese not earlier than the tenth century (and there is no reason to question the authenticity of this account), this late appearance of the fruit would rather go to indieate that its arrival in Central Asia was almost as late or certainly not much earlier.

The first indentifiable description of the melon known in Chinese as "si kwa (melon of the west)" given by Laufer reads with the Chinese characters omitted:

The man who introdueed the fruit into China proper was Hun Hao (A.D. 1090-1155), ambassador to the Kin or Jurei., among whoin he remained for fifteen years (1129-43). In his memoirs, entitled sun mo ki wen, he has the following report: "The watermellon (si kwa) is in shape like a flat Acorus, but rounded. It is very green in color, almost blue-green. In the course of time it will change into yellow: This Cucurbitacea ( $t$ ' ie) resembles the sweet melon (tien kwa, Cucumis melo), and is sweet and crisp. Its interior is filled with a juice which is very cold. Hun Hao, when he went out as envoy, brought the fruit lack to China. At present it is found both in the imperial orchards and in village gardens. It can be kept for several months, aside from the fact that there is nothing to prevent it from assuming a yellow hue in course of time. In P' o-yan there lived a man who for a long time was afflicted with a disease of the eyes. Dried pieces of watermelon were applied to them and caused him relief, for the reason that cold is a property of this fruit." Aceordingly the watermelon was transplanted into China proper only in the latter part of the twelfth century (66).

What there is in this description that should lead any one to identify "si kwa" as the watermelon (Citrullus vulgaris) is not readily apparent. On the other hand the description applies so well to the Christmas or the eassaba types of melons to leave no doubt that such a melon was the one imported by Hun Hao. With this seemingly positive proof that the earliest si kwa was not the plant which we know as watermelon the rest of the evidence given by Laufer that watermelons were known in Asia in pre-Columbian times, all of which is apparently based on this term si kwa, has no foundation. 
Old World Melons of the Cucumber Type.-Several of these Old World melons as the cassaba, the honey dew, the Persian and the Christmas, all of which have cucumber like seeds, long keeping qualities, a tendeney to turn yellow when mature and a cucumber like flavor when immature or of inferior quality, have in recent years become popular in the United States. Of these the Christmas melon most closely resembles the watermelon in outward appearance and a casual description of it, such as travellers usually write, might easily be mistaken for that of the watermelon.

Watermelons in Indian Folklore.-One of the most striking bits of evidence indicating that the watermelon is native to America, is given by LePage du Pratz a Frenchman who lived for sixteen years (1718-34) among the Natchez, a small independent tribe of Indians on the Mississippi River near the present site of the city of that name. The Natchez were a decadent tribe long past the crest of its power. How long they had dwelt there no one knows. LePage du Pratz could gather little from their traditions except that they were once a powerful tribe which had followed, the usual course of Indian history, namely lise, prominence, and decay. The Natchez possessed intelligence above the average of the Indians in the Mississippi Valley. Among other advancements they had created a sort of ealender for the reckoning of time. This ealender LePage du Pratz describes as follows:

The Natchez begin their year in the month of March, as was the practice for a long time in Europe, and divide it into thirteen moons. At every new moon they celebrate a feast, which takes its name from the principal fruits reaped in the preeding moon, or from animals that are then usually hunted.

The first moon is ealled that of the Deer, and begins their new year.

The second moon, which answers to our April, is ealled the strawbery moon, as that fruit abounds then in great quantities.

The third moon is that of the Small Corn. This moon is often impatiently looked for, their erop of large corn never sufficing to nourish them from one harvest to another.

The fourth is that of Water-melons, and answers to our June.

The fifth moon is that of the Fishes: in this month also they gather grapes, if the birds have suffered them to ripen.

The sixth, which answers to our August, is that of the Mulberries. At this feast they likewise carry fowls to the Great Sun. 
The seventh, which is that of Maiz, or Great Corn. 'This feast is beyond dispute the most solemn of all.

The eighth moon is that of Turkies, and answers to our October.

The ninth moon is that of the Buffalo. . . .

The tenth moon is that of Bears.

The eleventh answers to our January, and is named the Cold-meal Moon.

The twelfth is that of Chestnuts. That fruit has been gathered long before, nevertheless it gives its name to this moon.

Lastly the thirteenth is that of Walnuts, and it is adder to complete the year. It is then they break the nuts to make bread of them by mixing with them the flours of Maiz (69, p. 336).

Of these thirteen products watermelons for which is named the fourth month or feast is the only one of which there can be any doubt as to its being native to America. In this case there is no reason for thinking these Natchez had made an exception to the usual Indian custom by naming one of their important feasts or eeremonials after a crop introduced by the white men. The Natchez and other Mississippi Valley Indians had peaches and figs when the Frenchmen first explored that region but these LePage du Pratz says "The natives had doubtless got . . . from the English colony of Carolina" (69 p. 234).

Until more convincing evidence to the contrary is brought to light it seems advisable to consider the genus Citrullus as common to both hemispheres the same as the eommon gourd and seven other genera of eucurbits. ${ }^{1}$ At present the evidence favors the American Indian as the discoverer and domesticator of the edible watermelon. ${ }^{2}$

${ }^{1}$ See Engler and Prantl. Die Naturlichen Planzenfamilien, IV, 5, p. 9, Leipsig, 1 S97.

${ }^{2}$ See also Melvin Raxdolpit Gibmore's discussion of this subject 17, 33rd Aun. Rept., p. 120). 


\section{CHAPTER VIII}

\section{SOUTH AND CENTRAL AMERICAN INDIAN CROPS}

In this list will be considered only such plants which were native to South or Central America and the Caribbean Islands at the time of discovery and which have come into general culture in North America. These include peppers, pineapples, tomatos, peanuts, Irish potatoes, and cassava, but not bananas, cacao, coconuts, Brazil nuts and many others which must be added to the list of American food products to give full credit to America for the contributions of this hemisphere to the food plants of the world.

Peanuts.-The consensus of opinion of modern investigators of the subject gires Brazil as the original habitat of the peanut. The earliest account as yet found of them is by Monardes (1574).

Monardes evidently did not try to grow the peanut and as the pods do not have roots he erroneously thought they were not produced by a plant. His description follows:

They sent me from the Peru a fruite very good, that groweth under the yearth, and very faire to beholde, and of a very good taste in eatying, this fruite hath no roote, nor doeth produce any plante, nor plante doeth produce it, but that it is growen under the grounde as the Turmas bee growyng under the yearth, which are called of the yearth: It is of the greatenesse of halie a finger rounde, and rounde about theim with a very faire woorke, it is of a baie coullour: It hath within it a little cernell, that when it is drie, it maketh a sounde within like to an Almonde: The rinde of it is taunie, and somewhat white, parted into twoo partes like unto an Almonde. It is a fruite of good savour and taste, and eatying of it it seemeth that you eate Nuttes. This fruite groweth under the yearth, in the Coaste of the River of Maronnon, and it is not in any other parts of all the Indies: It is to bee eaten greene and drie, and the best way is to toste it, it is eaten alwaies after meates, as fruite eaten laste of all, because it drieth muche the stomack and leaveth it satisfied, but if you eate muche of it, then it gereth hearinesse to the hedle. It is a fruite in greate reputation, as well emongest the Indians, as the spaniardes, and with greate reason, for I have eaten of them, whiche they have brought me, and thei have a good taste. It seemeth a temperate fruite ( $\overline{7}$, Fol. 93). 
No Old World description prior to that has come to light. The East Indian names of peanuts are the same or similar to South American Indian words used to designate this plant. Peanuts must have been taken to Africa and eastern Asia by the Spaniards or Portugese very soon after the discovery of America. 'The natives of Africa adopted them at once as they did several other American plants. This fact confused some of the early botanists into believing that peanuts were native to Afriea. Hans Sloane in 1707 says:

I saw in this Harbour and Bay (Jamaica) a ship come from Guinen, loaded with blacks to sell. . . . I was assured that the Negroes feed on Pindals, or Indian Earth-Nuts, a sort of Pea or Bean, producing its pods underground. Coming from Cruinea hither, they are fed on these Nuts or Indian-Corn boiled whole twice a day (10S).

How early peanuts became a common food erop in Africa is indicated by Battell who was a prisoner in Africa from 1589 to 1607. He says:

They have good Peason somewhat bigger than ours but they grow not as ours do. For the Poodes grow on the rootes underneath the ground (94, v. VI, p. 405).

Introduction into North America.-The introduction of peanuts into North America was probably coincident with the introduction of negroes. In the Gulf States peanuts are still commonly called pindars. The record of peanuts is obscured by having been called earth nuts which was also applied to several entirely different plants. ${ }^{1}$

Danckaerts (1679) while in New York wrote:

They brought us some ground-nuts, but although the Dutch eall them so, they were in fact potatoes, for of ground-nuts, or mice with tails, there are also plenty (25).

The Royal Society of Arts offered in 1775, a premium for ground-nuts grown in the American colonies and shipped to England stipulating that there should be "not less than two tons for the purpose of expressing oil."

Potatoes.-The Irish, or as it is sometimes called, white potato, was introduced into the present territory covered by the United States from Europe by the British colonists. They were not

1 For more comprehensive statements in regard to the origin of peanuts see: Candolle, Origin of our Cultivated Plants, $1 S 55$ and Waldrox, contributions from the Botanical Laboratory of the University of Pennsylvania, vol. IV, no. 2, p. 302. 
natives of Ireland as the common name might indicate but of Peru in South America. There they were called papas by the Peruvian Indians. The term potato was applied to this plant through confusion with the sweet potato.

Many erroneous statements in regard to the history of the Irish potato have appeared in English agricultural literature. It is not known when the Spaniards first took Irish potatoes to Europe but it may have occurred soon after the conauest of Peru. This is of little importance as the Spaniards much preferred the sweet potato and were not responsible for introducing the other into European agriculture.

The mistakes of many writers on this subjeet has been due to an incomplete knowledge of all the facts surrounding the introduction. The statement of Dr. John Mitchell (see p. 84) is so complete that little need be added. The account in Murray's Dictionary is also given because it represents an exhaustive research into the history of the potato. It does not however take into consideration some historieal facts which have a bearing on the matter.

How Potatoes Were Brought to England.-Sir Franeis Drake in 1585-6 conducted a piratical expedition to the West Indies. He captured several towns and cities and held each until its release was purchased by the inhabitants, and also seized and plundered sereral Spanish ships. For some reason, either fearing capture by the Spaniards if he returned to Europe by the usual route or because of sickness among his men as think some authorities, he eruised up the Atlantic Coast to return by a more northern route. He found the second Raleigh colony on Roanoke Island in a destitute condition and took the survivors back to England with him. Drake and Raleigh were old friends. Raleigh was interested in agrieulture and had then recently acquired a large estate near Cork in Ireland. It is a natural supposition that Drake had obtained the potatoes from the Spaniards in the West Indies where they grow fairly well in the mountainous sections and gave them to Raleigh, and that Raleigh gave them a trial on his Ireland farms as has been so commonly stated.

This probaby does not represent Drake's first acquaintance with Irish potatoes. During his voyage around the world in 1578 while off the west coast of South America it is recorded:

We being on land the people came downe to us to the water side with shew of great courtesie bringing to us potatoes Rootes and two rery fat sheepe (94, v. II, p. 130). 
* VII. SOlanVM TVBE rofumcfculentum. *
- SOLANI TVBERCSi li. dix sefructus. "
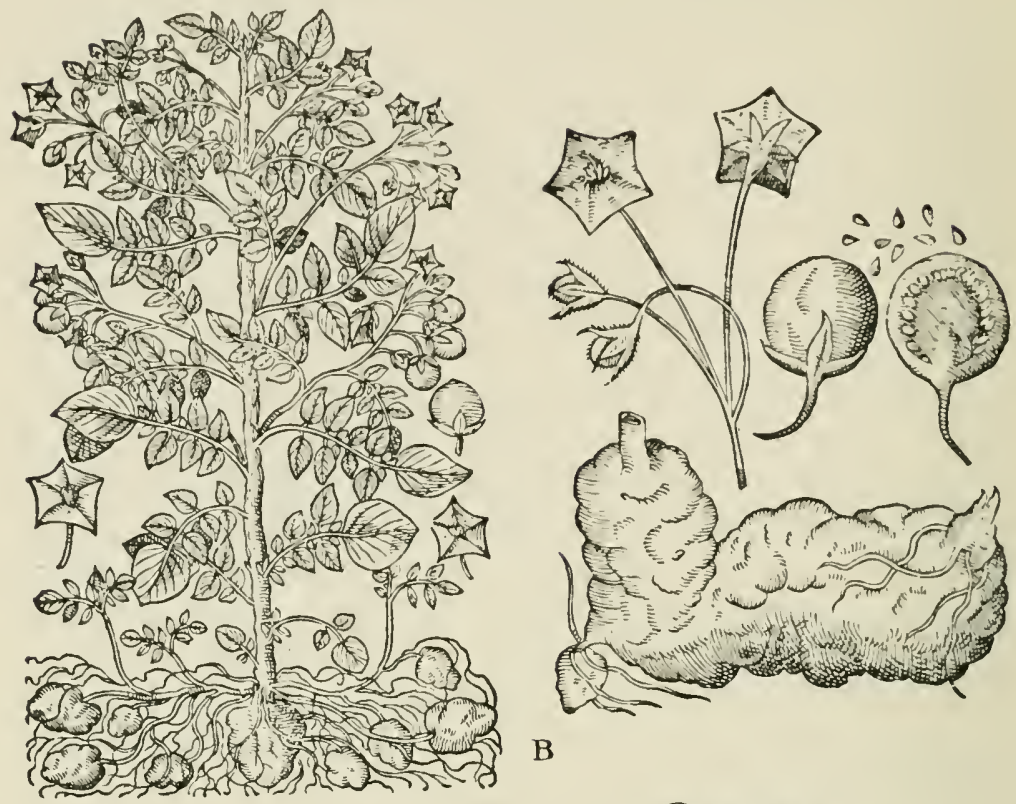

B
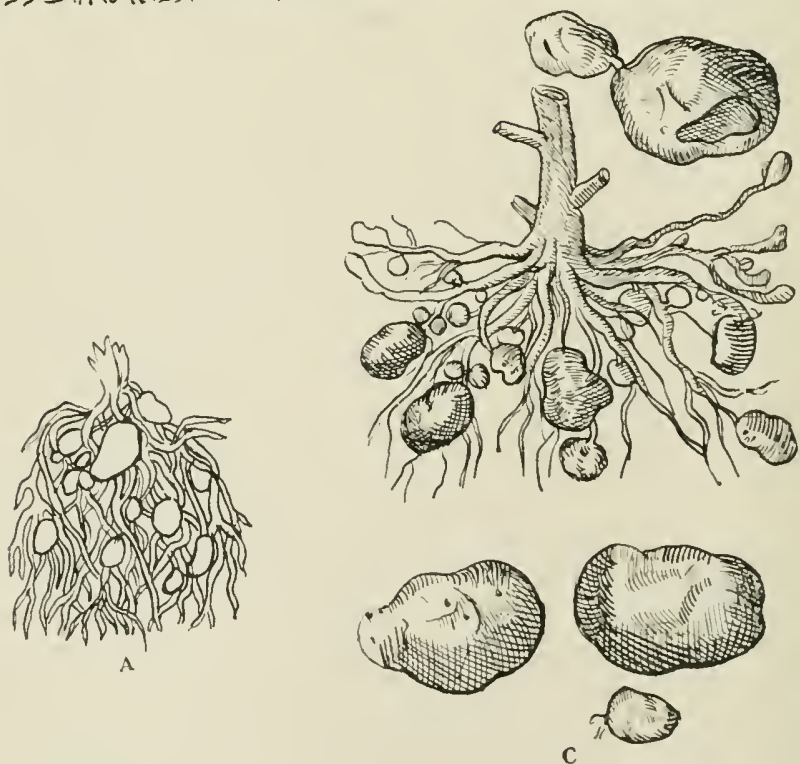

F1a. 17.-Early pictures of Irish potatoes. A, Gerarde, 1597; B, Bouhin, 1598; C, Clusius, 1601. 
Early References to Potatoes.-The following list of athoriative sources of information give a fairly eomplete story in regard to the early history of this crop:

Joseph Acosta in 158S in describing the products of Peru states:

let the want they have of bread is countervailed with the roots they sow, the which they call Papas and they grow in the carth. This root is the Indians foode; for drying it and making it cleane they make that which they call chugno which is the bread and nurishment of those Prorinces $(94, v . \mathrm{XT}$, p. 55).

Gerarde (1597) gives a picture of Irish potatoes and says:

It groweth naturally in America where it was first discovered, as reporteth C. Clusius, since which time I have received rootes herof from Virginia, otherwise called Norembega, which growe and prosper in my garden, as in their orne natire countrie $(39$, p. 781) (Fig. 17).

Clusius stated that he received, in 1588 , two tubers from $\mathrm{N}$. V. Philippo of Sivy, that he was uncertain where they were obtained but that it was either from Spain or America. He also mentions having receired specimens from G. Garret of London (68). Nuch of the confusion by early botanists in identifying potatoes came from mistaking the plant described by Hariot (1585) and called by the Carolina Indians openawk (Apios tuberosa) to be the same as potatoes.

Under the term "Potatoes" in Murray"s New English Dictionary may be found the following:

Described in 1553 under the name of papas in the Cronica de Peru of Piedro Cieza Chap. XL p. 5. Introduced into Spain from Quito, soon after 1580 and thence 1585 into Italy; in 1587 grown at Mons in Hainault whence in $15 S 8$ two tubers were obtained and grown by the botanist Clusius, keeper of the Botanical Garden to Maximilian II; described by him as Papas Perunanum. Soon grown in other botanic gardens as at Breslau in 1590 . The plant may have been brought independently to England where Gerarde had it growing in 1596; but he was in error in his statement that he obtained it from Yirginia (whence the erroneous name Virginia potatoes long kept up by English writers) for the plant is not native of Virginia and was not cultivated there in 16th century. In 1693, its introduction into Ireland was attributed to Sir Walter Raleigh after his return from Virginia (where he nerer was).

There are some minor discrepancies between this account and that of Mitchell which follows but nothing to indicate that the main facts as recorded by Mitchell are incorrect. 
A History of Potatoes.-Mitchell, (1767) the botanist and historian, who lived for several years in Virginia and returned to England in 1746 , gives a history of potatoes. He says:

These common potatoes are the Papas of Peru where they grow naturally, and were the only bread Corn that the natives had upon their cold mountains, or have to this day. They likewise grind them to meal, and make a bread of it, called Chunno, which is famous in history; with this the Indians supplied the mines of Potosi, (Bolivia) and grew richer by the trade than the Miners. The Spaniards likewise make a great variety of dishes with them, unknown to us, and live upon them like the common people of Ireland. They were first brought to Europe by Sir Francis Drake, in his return from the expedition to the Spanish West Indies in 1586. He then brought the colony of Virginia home with him, and among the rest the famous mathematician Thomas Heriot, who was sent thither by Sir Walter Raleigh to explore the productions of the country, and brought these roots with him; he gave them to Gerard the botanist, who first planted them in London, and sent them to Clusius in Holland, who planted them in Burgundy, and sent them to Italy; as appears from the works of these and several other authors. It was from this their introduction into Europe, that they are said by most of our writers to have been natives of Virginia, where they will hardly grow, and will not thrive, unless they are planted in the following manner. They should be planted in trenches like Celeri, and earthed up to the top of the stalk in like manner, till they come to be in blossom; by that means they spread and grow to a great size under ground . . . This method of cultivating potatoes is necessary on another account, in order to divest them of the rank and poisonous quality of the Solanum, of which they are a species. This is so strong in them where they grow on the surface of the ground exposed to the sun in hot climates, that the very hogs will not taste them; and I have known people who could not set at table where they were, for this their poisonous scent, of which the hogs are more sensible than we are. . . . It was for this reason, that when they were first planted in Burgundy, the use of them was condemned by law . . . the general use that is made of them seems to have been owing to an accident in Ireland, in the time of the civil wars, when the armies destroyed the fields of corn; but some fields of potatoes, we are told, throve very well after they were trampled by them, and supplied the want of Corn as they have ever since $(76$, p. 72$)$.

Hariot Responsible for Potatoes in Ireland.--If any one man is to be given eredit for the introduction of Irish potatocs into European agriculture the honor should go to Thomas Hariot rather than to Drake or Raleigh. 
Thomas Hariot a contemporary of Galilieo and fully the equal of the Italian in mathematical and astronomical achievements although not so good a publicist was an employe and warm personal friend of Sir Walter Raleigh. He was ineluded in the second Raleigh expedition to Roanoke Island to describe the inhabitants and natural products of Ameriea. Hariot spent an entire year on Roanoke Island and his descriptive relation is the first accurate English account of the American Indians and products. On his return to England in 1586 he was sent to manage Raleigh's Ireland estate. It was undoubtedly Hariot who supervised the first planting of potatoes in Ireland (118).

Potatoes Not Popular in England.-Potatoes were slow in becoming popular in England. This was due to a lack of knowledge in regard to their culture and preparation for the table. Every one knows the unpleasant taste of a raw potato, also that a soggy half-cooked potato is not fit to eat. Still more unfit for food is one that has turned green from exposure to sunlight. The records indicate that the English tried to grow potatoes at first in broadcast plantings without sufficient covering of earth, and it is further stated that they did not know how to cook them properly.

Potatoes to be Taken to South Carolina.-Andrew Pereival was instructed by Lord Shaftsbury in regard to the settlement in 1674 on Edisto river in South Carolina in the following words:

You are to endeavor to make Irish potatoes grow and to have sufficient stock of them to supply your necessity if your other provisions should fail they serveing in Ireland both boyled, roasted, and baked on such occasions (116).

English Opinions.-In Houghton's Husbandry under date of Dec. 15,1699 is this statement:

Potatoe is a baceiferous herb, with esculent roots, bearing winged leaves and a bell flower, . . . they were brought to Lancashire, where they are very numerous, and now they begin to spread all the kingdom over. They are a pleasant food boil'd or roasted, and eaten with butter and sugar (is).

Houghton's estimate of the quality of potatoes does not appear to have been shared by the majority of his countrymen or not at least by the literary elass for several years. Mortimer in 1707 says:

Potatoes are planted in several parts of our Country to a very good advantage, being casily encreased by cutting the Roots into several 
pieces, each piece growing as well as the whole Root. . . The same Root is very near the nature of the Jerusalem Artichoak, which is not so good or wholesome. These are planted either of Roots or Seeds, and may probably be propagated in great quantities, and prove good Food for Swine (SO).

Sloane (1707) observes:

Many live very well on vegetables. . . others live on flesh only, most on both Vegetables and Flesh. Many live on the Irish Patatas, a sort of Solanum, on which I have heard they live in the mines of Potosi (Bolivia) and in Ireland (10S, v. I, p. xxi).

Browne (1756) writing in regard to Janaica says:

Irish Potato, Great quantities of this root are annually imported into Jamaica from Laneaster and Ireland; and the plant is often cultivated in the cooler mountains of the Island, but does not thrive well as many other European regetables, though frequently raised with such success as to be sold in large quantities in the public markets (15).

Miller (1754) gives some points of interest but as to the time of the introduction from America is in error.

The common Name of Potato seems to be only a Corruption of the Indian Name Batatas. This Plant has been much propogated in England within thirty Years past; for although it was introduced from America about the Year 1623, yet it was little cultirated till of late; these roots being clespised by the Rich and seemed only proper Food for the meaner Sort of Persons; however, they are now esteemed by most People; and the quantity of them cultivated near London, I believe, exeeds that of any other part of Europe ( $\overline{7} 5)$.

Potatoes in North America.-The culture of Irish potatoes in the English colonies of America as a staple crop appears to have taken place between 1705 and 1749 . Beverly in deseribing the potatoes of Virginia under the carlier date says: "I am sure those called English or Irish Potatoes are nothing like these either in shape, or taste." And Kalm in his account of Albany, New York, where he was in 1749 says, "Potatoes are generally planted." That he was refering to Irish potatoes is evidenced by his next statement that: "Bermuda Potatoes (Convolvulus Batatas) have likewise been planted here and suceced pretty well" (65, v. II, p. S9). While at Montreal Kalm wrote: "Few people took notice of potatoes; and neither the common (Solanum tuberosum) nor the Bermuda ones (Convolvulus Batatas) were planted in Canada" (65, v. II, p. 274).

${ }^{1}$ The words "which is" were changed to "but" in subsequent editions. 
While it is possible that potatoes may have been brought to the northern colonies before they were to Virginia, the half century 1700-50 corresponds to the period when potatoes beeame popular in England and it was about that time when they became a prominent food product in the colonies. It was also a period in which a large number of Irish immigrants came to America.

The term Irish in connection with potatoes is misleading but is justified in honor of that race who first taught the rest of the civilized world the value of this important food plant. The first use of that term found so far is that of Shaftsbury in 1674 (p. 8.5).

Wild Potatoes.-Other species of Solanum closely related to S. tuberosum are natives of the Rocky Mountain region of North America from Colorado southward to Mexico. These were probably the food plants of the Colorado beetle or potato bug before the introduction of potato growing in the United States. Rose mentions among other useful plants of Mexico, potatoes growing wild in the mountains which were used as a flavoring for soups but not as a vegetable (101).

Cassava.-Cassava was a very important food plant in the West Indies and South America. The Indians had a method by which the juice which in some species is poisonous was expressed and the pulp, after drying and being beaten into a powder was rendered harmless and wholesome for making bread. The plant was known by many names as yuca, mandepore, manyoc, manihot, mandioza, and cassaba.

The Spaniards and Portuguese looked upon cassava as one of the most valuable food plants found in America and it was early introduced into African agriculture, where it beeame a leading food crop of the natives. It was probably grown to some extent in the southern part of our country. Hariot (1685) deseribed a root used by the Indians of Eastern North Carolina that he thought might be cassava but his description fits so well to wampee afterwards known to be a common food of the Indians in that region that it is quite likely he was mistaken. Cassava was introduced by the English at Jamestown from Bermuda in 1621. This plant has never been of very great importance in this country, although large quantities of tapioca which is made from its roots are consumed annually. There have been some extensive trials made of it in modern times as a forage for hogs. Lord Shaftsbury instructed his representative who was sent in 
1674 to settle on the Edisto river to stop at the Bermudas and among other things to inform himself:

In the way of planting and useing Cassatha for brearl and Drinke which I am informed growes in Virginia.

Pineapples.-Pineapples are unquestionably native to America. Oviedo deseribed them, in 1526, and gave an illustration of the fruit nine years later. Prior to the discovery of America the term pine apple was applied to the fruit of the pine tree or what is now known as a pine cone. The term pineapple tree was sometimes used instead of pine tree. In Peter Martyr's Decades one finds the statement:

For excepte pine apple trees and date trees there growe none in these Islands (West Indies) that are knowen to us (31).

The name beeame applied to the plant now known as the pineapple through the resemblanee which its fruit bears to a pine cone. "Nana" soon corrupted by the Whites into "ananas" was the American Indian name for this plant. Pinas or pines was also a common designation by the Europeans.

The Spanish and Portugese travelers took pineapples to the East Indies very early as some of the eitations under the exploration period show. It was given unstinted praise by the early writers-"The most excellent fruit in America" wrote Jean de Lery (1578).

The outdoor field eulture of pineapples in United States did not take place until about 1860 in the Florida Keys. ${ }^{1}$

Peppers.-Mention is made elsewhere of the desire of North European peoples for condiments to impart palatability to the monotonous diet of the fifteenth century. The early explorers were always on the search for new spices especially those of a pungent or aromatic nature, rather than more substantial food plants. From the West Indies and Mexico they obtained the bush or garden pepper-a notable contribution to this elass of vegetables. These were mentioned by several Spanish writers.

Monardes (1577) says:

Pepper from America, tall bush, some pepper be long, others rounde, others of the making of Mellons, others of cherries but all bee at the beginning when they be not ripe verie green and when ripe verie redde.

${ }^{1}$ For a discussion of the history of pineapples and an excellent bibliography see H. Harold Hume. Report Florida Agr. Exp. Station for 1906 
Tomato.-Another of the Central American products is the tomato. This was a common edible product of the Indians and was quickly utilized by the Spaniards who took the plant to Europe. The close botanieal relationship of the tomato to the

P O A A MORIS.

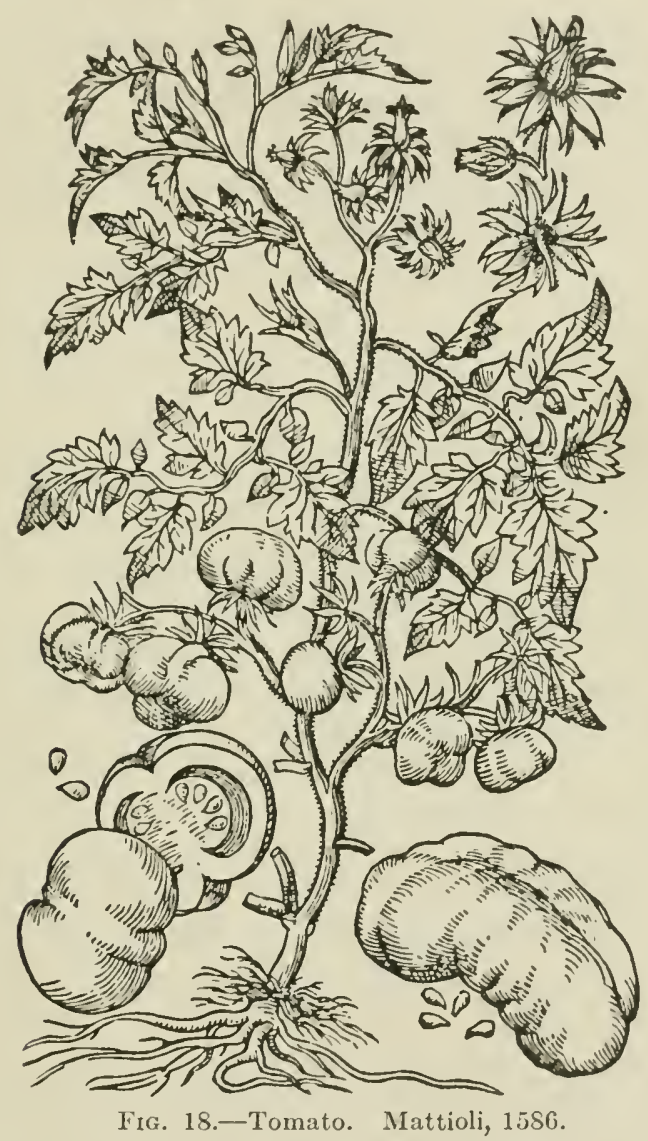

deadly nightshade restricted its use in North European countries. Just when this plant entered into English eookery is difficult to say. It was apparently of little importance prior to the nineteenth century. That the tomato was a well developed food plant in the sixteenth century is evideneed by Fig. 18 .

Acosta (1588) informs us:

They (The Indians) use also Tomates, which are cold and very wholesome. It is a kinde of graine great and full of juyce, the which gives a goorl taste to sauce, and they are good to eate (9t, v. XV, p. 10s). 


\section{CHAP'TER IX}

\section{MISCELLANEOUS INDIAN PRODUCTS AND PRACTICES}

Fiber Plants.-The Indians used the fibers of a great many different plants to make strings, nets and in some cases clothing. The Indians of Carolina used silk grass, a sedge (Eriophorum virginicum) which grew naturally in wet places.

The Raleigh Colony (1585) took to England a quantity of this sedge from which a piece of "silk brogham" was made, about which much favorable comment was expressed and the Jamestown colonists were expected to gather silk grass by the shipload to send to England.

The northern Indians used a species of wild hemp, (A pocynum cannabinum) also wild flax (Linum virginianum) but none of these plants has been found of sufficient value to justify its being brought under domestication.

Cotton.-Fibers from the bolls of cotton plants have been used by human beings for clothes and other purposes from very ancient times. The cotton cloths of India were famous in Europe before the time of Columbus. Nerertheless spun cotton was one of the first American products mentioned by the narrators of the Columbus expeclitions. Clanea, (1494) in one of the earliest written documents relating to Columbus which has been prescrved, states in regard to the second expedition.

He found also a great quantity of cotton, both spun and already prepared for spinning (115).

This was on the island of Guadalupe. It is also said by Ferdinand Colon, son of Columbus, that on the first royage, "they saw above twelve thousand five hundred pounds of spun cotton in one house." This writer says:

"the cotton grows, naturally about the fields like roses, and open of themselves when they are ripe, but not all at the same time; for upon one and the same plant they have seen a little, young bud, another open, and a third eoming ripe, . . . none of them (the Indians) make use of it to clothe themselves but only to make nets for their beds which they call hamacas" (90, v. II, p. 3S). 
Rochefort describes this same bush cotton and says:

There is another kind of Cotton-tree which creeps along the ground like an unsupported vine; this bears the best and most e-teemed Conton: Of both there are made Cloths, and several cheap stuffs, very useful in House keeping (99).

Both of these trpes of cotton are still common in the West Indies. There is little evidence that the Indians ever cultivated this crop and we do not find them using it north of where it is perennial, that is, where it is killed by frost. The Spanish explorers of the South-west about $15 t 0$ frequently mention cotton among the articles possessed by the Indians of Arizona and New Mexico. It is quite possible that it was a cultivated crop in that region.

Origin of Cotton Varieties Uncertain.-It is impossible at the present time to say with any degree of certainty just what varictics of cotton have been derived from native American plants and what ones from the Old World sorts. Many of the upland strains grown in the United States become peremnial if taken south of the frost line and this, while indicating an American parentage does not entirely preclude the possibility of an Asiatic origin. Perennial cottons, although not at all common, were not unknown in Asia in pre-Columbian time, as the following observation of Marco Polo (1271-9S) in regard to a kingdom in India shows:

Their cotton trees are of very great size, growing full six paces high, and attaining to an age of 20 years. It is to be observed, however, that when the trees are so old as that, the cotton is not good to spin, but only to quilt or stuff beds withal. Up to the age of 12 years indeed the trees give good spinning cotton, but from that age to 20 years the produce is inferior (135).

There is also the possibility that some of the varieties now grown are the results of erossing of Asiatic and American plants. The sea-island or Egyptian (Gossypium barbadense) and upland ( $G$. hirsutum) cottons have been quite generally credited to America, the proof of this being based largely on botanical relationships.

Cotton Culture in the South.-In the eighteenth century cotton growing had become an important industry in the South but almost the entire product was consumed at home. English manufactures favored the East Indian cotton because that fiber was white and wore white while the West Indian cotton although 
of longer staple turned yellow. Seed of the Asiatic cottons were obtained and those types were found to thrive in the southern colonies. In 1746 some of this introduced cotton was sent from Virginia to Manchester where it sold for eighteen pence a pound, the price of the best at that time (76, p. 147).

The American export trade in cotton did not develop to any great importance until after the Revolution. ${ }^{1}$

Storing Their Crops.-The chief means which the Indians had for preserving their food products was drying or drying and smoking. Some Indians built corn cribs on platforms of poles supported a few feet above the ground by posts in which they dried their corn when it was gathered. The curing was sometimes luastened by fires built underneatlı. This method also prevented much of the weevil injury which is so destructive of stored grain in warm climates. As soon as the corn or other seeds were thoroughly dried they were stored in huge baskets which receptacles often occupied a large part of the room in their houses. Tribes which went on hunting trips in the winter or had winter residences away from their summer habitations usually buried their corn and beans and other seeds in baskets in the ground.

Underground Pits.-A New England writer described this method in 1632 .

Their (Indians) Barnes are holes marle in the earth, that will hold a Hogshead $[7$ bu.] of corne a piece in them. In these (when their corne is out of the huske and well dried) they lay their store in great baskets (which they make of sparke) with matts under about the sides and on top: And putting it into the place made for it they cover it with earth: And in this manner it is preserved from destruction or putrifaction to be used in case of necessity and not else (35, v. II, p. 30).

Southern Corn Cribs.-De Soto found the Southern Indians storing their maize in "a barbacoa, which is a house with wooden sides, like a room, raised aloft on four posts, and has a floor of cane" (70).

Meat was preserved by drying and smoking after being cut in strips. The same method was employed in preserving the common pumpkin. Nuts were dried and the meats after being pulverized into a powder would keep for months. In some tribes very little provision was made for future wants. Feasts and

${ }^{1}$ See discussion under South Carolina, and also Frenelı Settlements, pp. 201 and 221. 
famines were the common order, and the Indians reflected these conditions in their physical appearance being at some times fat and lazy, at others lean and hungry (Fig. 19).

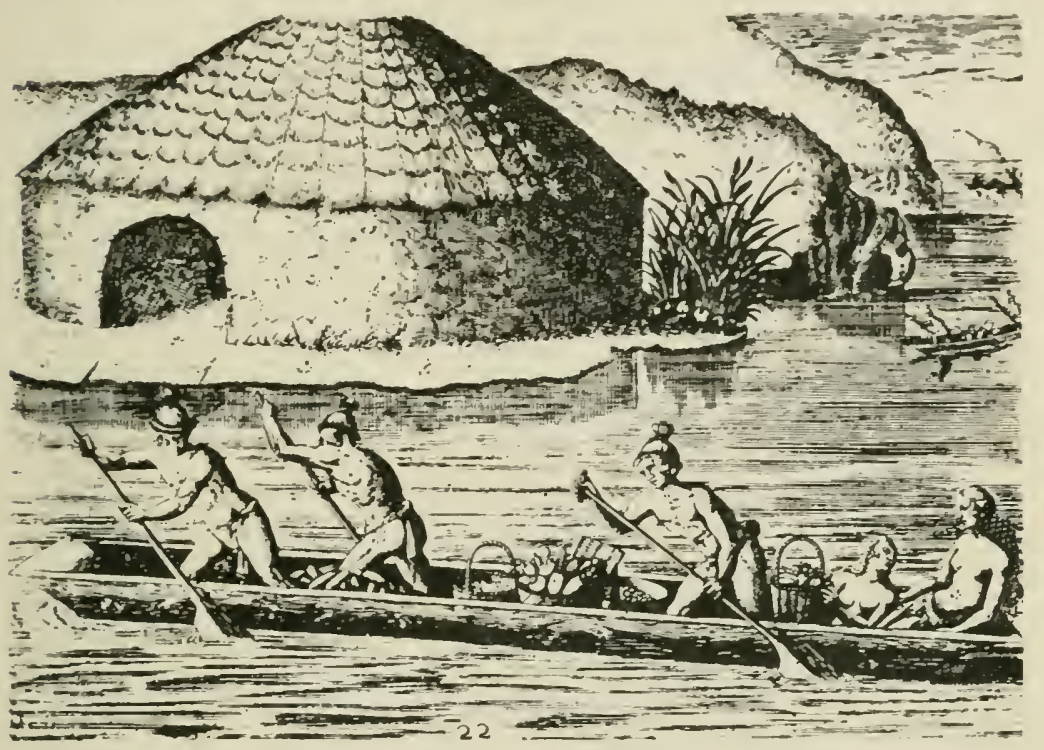

Fig. 19.-A public granary in Florida. The Indians are bringing in their products for storage. Le Moyne, 1564.

Cultural Methods of the Indians.-Tillage as practiced by the Indians was distinctive and differed materially from European methods. It has been noted that the field crops grown in England before the discovery of America were mainly broadcast seeded. Practically every crop which the Indians grew required intertillage. This difference is enough to show that American farm practices have been greatly influenced by the Indian agriculture. Intertillage with such crops as corn, tobacco, sweet potatoes, and beans had been commonly practiced in America by the white men more than one hundred years when Jethro Tull in England wrote his "Horse Hoeing Husbandry" and had heen in use by the Indians untold centuries before. The deseriptions of methods of seeding and planting given by the early writers on American affairs give such full and explicit accounts that comment seems unnecessary. The Indian methods of growing corn are interesting in their differences or the resemblances which they bear to modern corn culture in the localities to which these deseriptions apply. 


\section{North Carolina Methods.-Hariot (15S5) wrote for Roanoke} Island:

Then their setting or sowing is after this manner: first, for their corn, beginning in one corner of the plot, with a pecker they make a hole, wherein they put four grains, with care that they touch not one another (about an inch asunder), and cover them with the mould again, and so throughout the whole plot, making such holes, and using them after such manner, but with this regard, that they be made in ranks, every rank differing from the other half a fatham or a yard, and the holes also in every rank as much. By this means there is a yard square ground between every hole; where according to discretion here and there, they set as many beans and pease: in divers places also among the seeds of Macocquer (squashes and pumpkins) melden and plantn solis (sunflowers) (90, v. II, p. 596).

\section{Hill Planting in New York.}

They (Indians) make heaps like mole hills each about 2 1/2 feet from the others which they sow or plant in April with maize in each heap 5 or 6 grains, in the middle of May when the maize is the height of a finger or more they plant in each heap 3 or 4 Turkish beanes which then grown up with and against the maize which serves for props for the maize grows on stalks similar to sugar cane (14, 2nd ser., $r$. II, p. 34S).

\section{Virginia Corn Culture.}

The greatest labour they take, is in planting their corne, for the country naturally is overgrowne with wood. To prepare the ground they bruise the barke of the trees near the root, then do they scortch the roots with fire that they grow no more. The next yeare with a crooked peece of wood, they beat up the woodes by the rootes; and in that moulds they plant their corne. Their manner is this. They make a hole in the earth with a sticke, and into it they put 4 graines of wheat and 2 of beanes. These holes they make $t$ foote one from another. Their women and children do continually keep it with weeding, and when the corne is growne midle high, they hill it about like a hop-yard (110, pp. 61-2).

Rhode Island Corn Culture.-Crows and blackbirds were very destructive in the Indians corn fields and they have ever since been in those of the white men. Roger Williams gires several interesting observations in this regard.

Against the Birds the Indians are very carefull, both to set their corne deep enough that it may have a strong root, not so apt to be pluckt up, (yet not too deep, lest they bury it, and it never come up) as also they put up little watch houses in the middle of their fields, in which they, or 
their biggest children lolge, and early in the morning prevent the Bircls, ete.

In regards to the erow he says:

These Birds although they doe the eorne also some hurt, yet searee will one Native amongst an hundred wil kil them, beeause they have a tradition, that the Crow brought them at first an Indian Graine of Corne in one Eare and an Indian or French Beane in another, from the Great God Kautantowits field in the Southwest from whence they hold came all their Corne and Beans. . Then a field is to be broken up, they have a very loving sociable speedy way to dispatch it; all the neighbors men and Women, forty, fifty, a hundred, ete., joyne, and come in to help freely (129, pp. 114-23).

Clean Cultivation.-An other work is their planting of corn, says Wood (1629) in his New England Prospect,

wherin they exceede our English husbandmen, keeping it so cleare with their Clamme shell-hooes as if it were a garden rather than a corne-field, not suffering a choaking weede to advanee his audacious head above their infant corne, or an undermining worme to spoile his spurnes (131, p. 100).

Indian vs Old World Culture.-One peculiarity of Indian tillage needs especial emphasis. In their common method of hill planting, the soil in the intervening spaces was not broken. The hills were from 12 to 20 or more inches in diameter and the soil in these hills was all that was stirred or loosened. All weeds were kept cut or pulled out. As the corn plants grew some loose dirt was scraped around them. These hills were used over and over in successive seasons and became quite sizable mounds remains of which have persisted in some localities until modern times (Fig. 20). In the southwestern part of Michigan the early settlers found large tracts of ridged land evidently relics of Indian agriculture. It is now thought these were corn fields in which the seeding was made in continuous rows instead of hills. Le Moyne pictures row planting in Florida (Fig. 21).

Indian Methods Adopted by the Colonists.- The colonists followed the Indian methods of seeding but often neglected the weeding and were frequently subjected to ridicule for their shiftlessness by the painstaking squaws. In using animals for corn cultivation it was found most feasible to kill the weeds by stirring the intervening ground. Modern implements and methods of cultivation were subsequently evolved. Various theories have been advanced to show the value of stirring the soil 


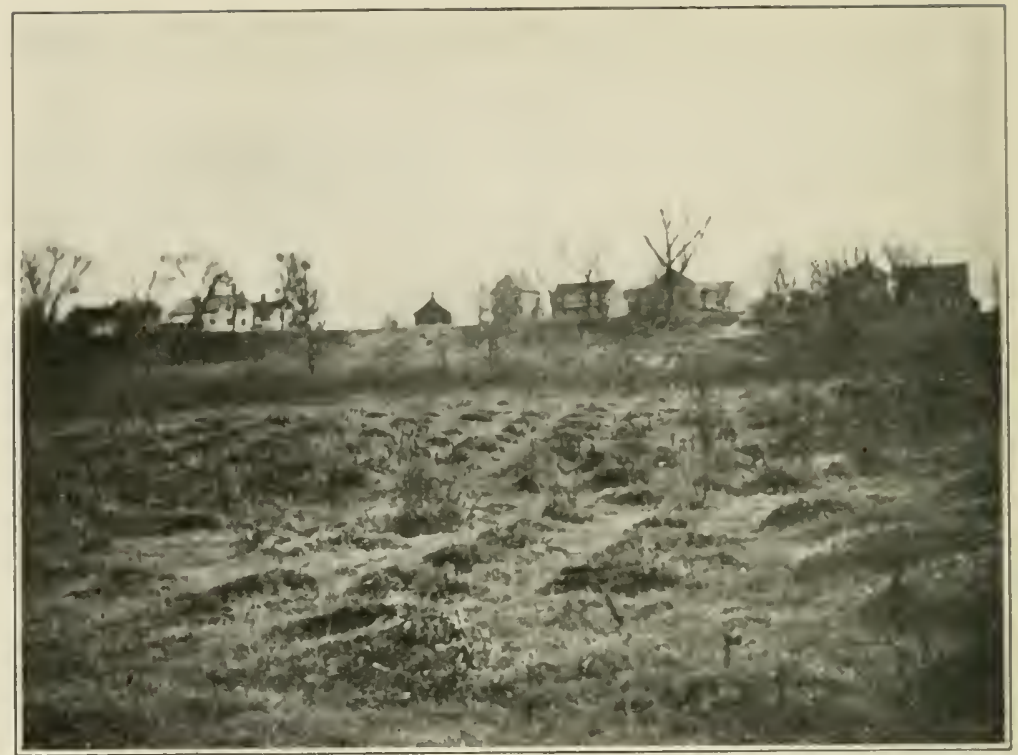

FIG. 20.-An old Indian corn field, Northampton, Massachusetts. Deeded to the colonists, 1654. (Courtesy Dr. H. H. Wilder.)

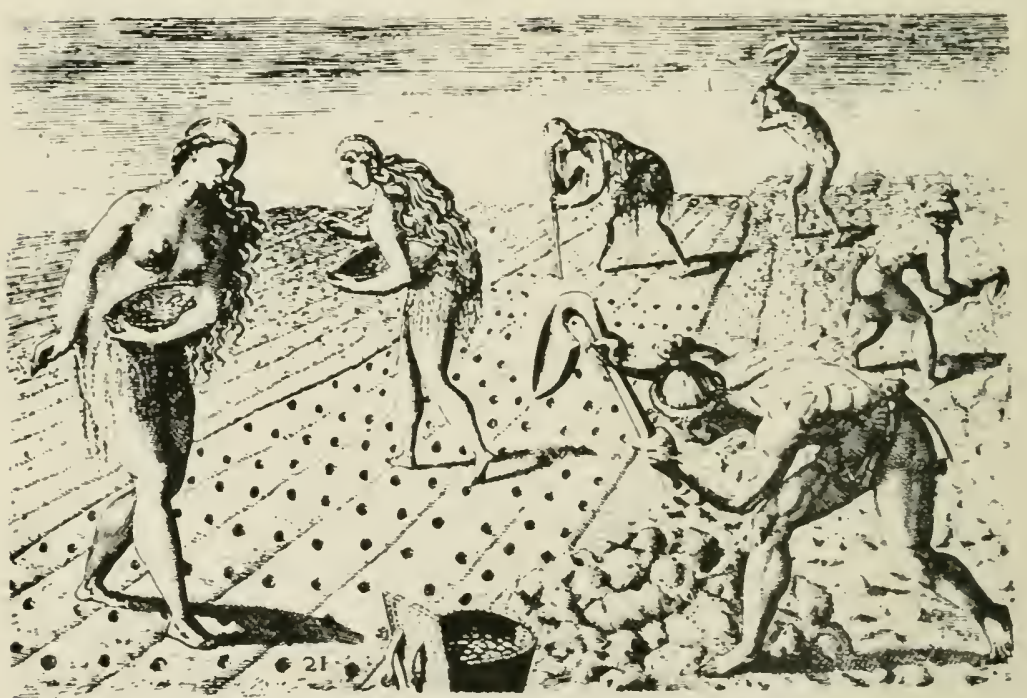

FIG. 21.-Indians planting corn and beans in Florida. Note row planting, also division of labor. Le Moyne, 1564. 
but reeent investigations prove that in most eases the crops which the Indians grew are not benefited by cultivation if the weeds are kept out by other means. This is only one of several instances where modern investigators have discovered that the farming practices of the American Indians were based on sound principles.

Fertilization.-While the Indian could searcely have avoided observing the beneficial effects of decaying organic matter on plant growth yet they appear to have made little use of manures outside of New York and New England. Hariot (1555) observed for Roanoke Island.

The ground they never fatten with muek, dung or any other thing, neither plough nor dig it as we in England, but only prepare it in sort as followeth. A few days before they sow or set, the men with wooden instruments made almost in form of mattoeks or hoes with long handles; the women with short peckers or parers, because they use them sitting, of a foot long, and about five inches in breadth, do only break the upper part of the ground to raise up the weeds, grass, and old stubs of corn stalks with their roots. The which after a day or two days drying in the sun, being scraped up into small heaps, to save them labour for earrying them, they burn into ashes. And whereas some may think that they use the ashes for to better the ground, I say that then they would either disperse the ashes abroad, which we observed they do not, except the heaps be too great, or else would take special care to set their corn where the ashes lie, which also we find they are careless of. And this is all the husbanding of their ground that they use (90, v. II, p. 596).

Rotation of Fields.-The Indians in this land of boundless acres practiced a rotation of fields rather than rotation of crops. A field was cropped until it no longer produced profitable yields, then it was abandoned and new land cleared. The colonists followed the Indians example, as clearing new land was cheaper than fertilizing old. So we may add to the many other practices obtained from the Indians the method of restoring fertility by "resting the land." This practice has been almost universally condemned by European writers, but it is in the main the more profitable method to follow where land is plentiful. The fact that America has been able to raise and transport to Europe and undersell the European farmers in their own markets is sufficient proof of the practicability of American methods in general. As land becomes more scarce in proportion to the population the Indian method of resting a field has had to be abandoned but it is still practiced in some sections as for instance in the light tobaceo districts. 
Fertilizing with Fish.-The only localities along the Atlantic coast where the Indians resorted to artificial fertilization to keep up the production of their fields appear to have been New York and New England. Smith (1630) says:

In Virginia they never manure their overworne fields, which is very few, the ground for the most part is so fertile: but in New England they doe, sticking at every plant of corne, a herring or two; which commeth in that season in such abundance, they may take more than they know what to do with $(110$, p. 952$)$.

It may be noted that the river-bottom lands in Virginia where the Indians had their corn fields still produce abundant crops.

The English settlers in New England adopted this practice of fertilizing with fish and lands along streams where these fish, commonly ealled by the English alewives, were plentiful brought a much better price than those on streams which did not have them. Morton (1632) gives further information along this line.

There is a Fish (by some called shadds by some allizes) that at the spring of the year passe up the rivers to spaune in the ponds: And are taken in such multitudes in every river that hath a pond at the end that the inhabitants dung their ground with them. You may see in one township a hundred acres together set with these Fish, every acre taking 1000 of them and an acre thus dressed will produce and yield so much corne as 3 acres without fish and (least any Virginia man would inferre hereupon that the ground of New England is barren, because they use no fish in setting their corne, I desire them to be remembered, the cause is plainne in Virginia) they have it not to sett. But this practice is onely for Indian Maise (which must be set by hands) not for English corne (35, v. II, p. 60).

Iroquois Manured Their Fields.-Hennepin (1675-81) observed that the Iroquois "manure a great deal of Ground for sowing their Indian Corn in, of which they reap ordinarily in one Harvest as much as serves 'em for two years" (4S, v. I, p. 46).

No further details are given and the Iroquois methods of farming before they became modified by contact with the whites were never adequately described. Most of the white men who were eye witnesses and wrote of Iroquois affairs were prisoners and were much too occupied with other matters during their sojourn with those tribes to pay attention to their domestic oceupations. The diaries kept by the soldiers during Sullivan's raid into the Iroquois country, in 1779 , have numerous state- 
ments to the effeet that the corn which they destroyed was the best they had ever seen.

Domesticated Animals.-Of the various animals domesticated for the use of man, the Old World speeies greatly outnumber those of the New World. Nevertheless, the Indians had domestieated every native species that has proved eapable of domestication. Numerous tribes of Indians lad dogs "which howled but did not bark." In the Great Plains area dogs were used as beasts of burden. With two poles one on either side fastened at one end to a sort of collar or harness over the dog's shoulders and the other ends of the poles dragging on the ground these animals hauled the household equipment when the Indians were migrating from place to place. Northern tribes had tame hawks, which were used to keep small birds from destroying their corn fields. Southern tribes had tame geese and turkeys and pheasants.

The patient Llama and kindred species of the Andean region of South America were domestieated and used as beasts of burden, for food and their wool for weaving.

Turkeys.-By far the most valuable of the Indian's domestic animals was the turkey. These magnificent birds were unknown in Europe before the discovery of America, while tame turkeys were common among the tribes of the West Indies.

Peter Martyr (1511) speaks of them "as peacocks and others whiche they francke and feede in their houses." Also in commenting on the generosity of the Indians he states:

They gave them (the Spaniards) also a greate multitude of theyr peacockes bothe eockes and hennes deade and alyve as well to satisfie theyr present necessitie, as also to cary with them into Spayne for encrease (30, p. 129).

Tusser (1573) enumerates the meats suitable for a Christmas dinner in this manner.

Beef, mutton and pork, shred pies of the best.

Pig, veal, goose, and capon and Turkey well drest.

In commenting on the agricultural produets which had been introduced into England, Hakluyt, in 1582, mentions "Turky" coeks and hennes about fifty yeres past" (42) which would make turkeys probably the first American product to enter into English agriculture.

In Mexico and the southern parts of the United States tame turkeys were kept in large flocks. In the relation of DeSoto's 
expedition it is stated they received 700 turkeys from one tribe. While turkeys were not domesticated fowls in the North the wild ones were present in such large numbers and so easy to kill that there was little need of domesticating them.

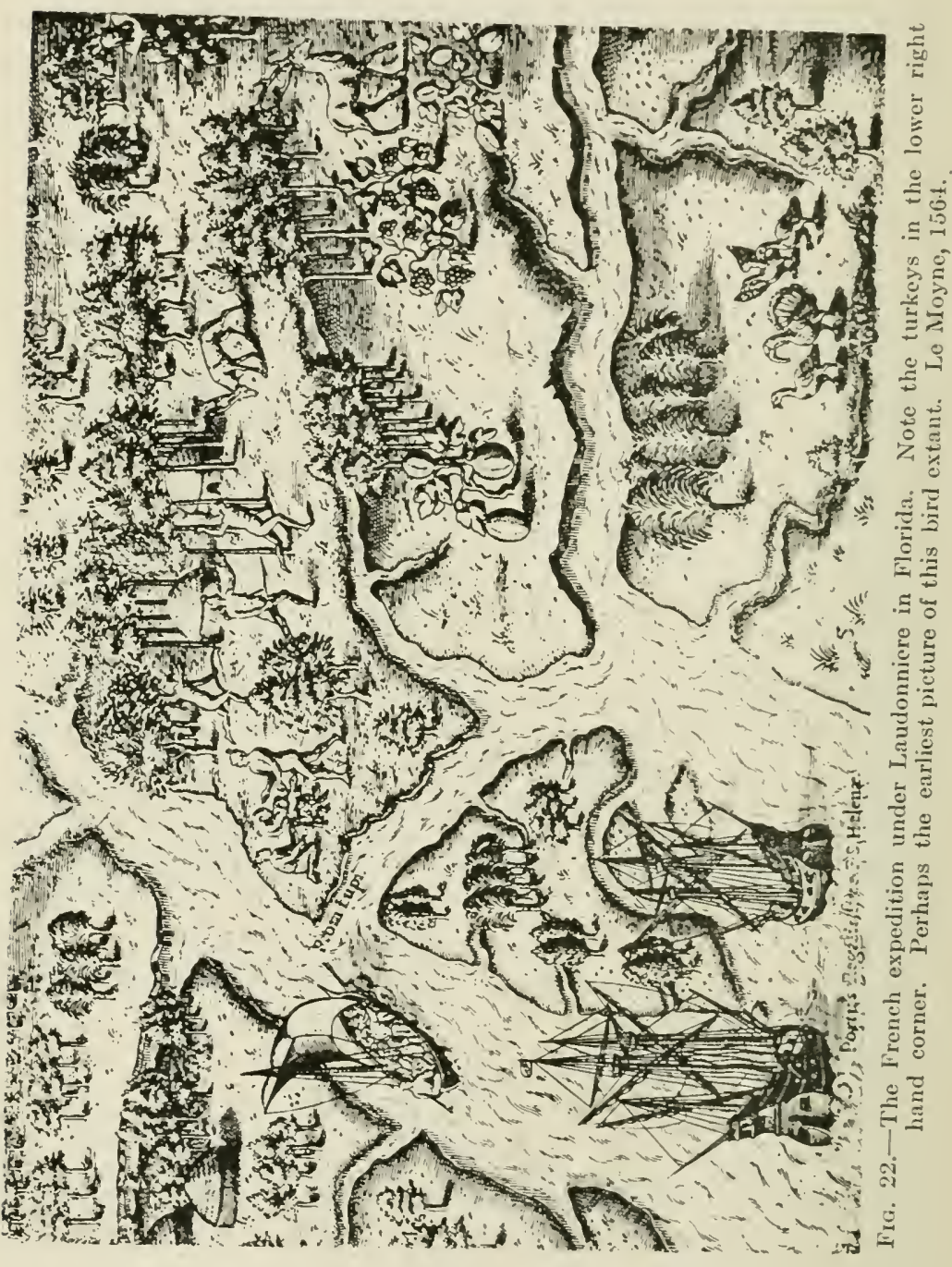

Hennepin saw great numbers of "Wild Turkey Cocks" in 1678, near Niagara Falls and two years later while among the Indians on the lower Mississippi River, says: 
I observed they have tame Poultry, as Hens, Turkey-Coeks, and Bustards which are as tame as our Geese (48, p. 192).

LePage du Pratz (1719-3 t) describing the turkeys of Louisiana states:

The feathers of the turkey are of a duskish grey, edged with a streak of gold colour, near half an inch broad (69, p. 276).

Buffalo Intractable.-It is interesting to compare the optimistic assertions of some of the early explorers in regard to the feasibility of the domestication of the American bison with the actual experiences of the Spaniards in New Mexico when it was attempted. The American buffalo has never been domesticated.

Indians Quick to Adopt the Horse.-Nothing brought to America by the white men was more highly prized by the Indian's than the horse and many of the Great Plains tribes became expert riders before they had ever seen a white man, their mounts being escapes from some of the carly Spanish expeditions. 


\section{CHAPTER X}

\section{EXPLORATION PERIOD}

From the diseovery of America until the settlements of the English on the Atlantic coast more than a century later, there were few events which influenced the future agricultural development of this country outside of the Spanish colonization. It was a period of discovery and exploration.

North-western Europe at that time was just awakening from the "Dark Ages." The people were acquiring wealth and demanding a greater variety in their diet and more and better clothing. Especially did they crave sugar and spices and other tropical products. Travelers to the far East had brought back pepper, nutmegs, ginger, cloves, cinnamon, as well as silks, carpets, tapestries and cotton cloths of better quality than anything made in Europe. They had also fascinated the home folks with wonderful and fantastic accounts of Arabia and India then called the "Moguls Country." Printing presses, but recently invented, aided greatly in disseminating this information.

When the first explorers to America returned with nothing but what they obtained from squalid savages, underfed and scantily clad, it is not surprising that northern Europe took little interest in the new discoveries. Had it not been for the cod fishing around Newfoundland and the hope of finding a direct sea route to Asia there would probably have been little known about the main land of North America by the English for a great many years. There were regular fishing trips to Labrador and Newfoundland made by boats from Britain, France, Portugal and Spain from early in the sixteenth century. These fishermen have left few accounts of their exploits. It is known that they usually crossed the ocean following in general the routc of Columbus and then sailed north along the coast. They were frequently forced to stop to repair their ships, to take on fresh water, and collect wood for fucl. 
Fishing Expeditions.-Cartier (1534) records:

Whilst we were in the sayd Saint Peters Islands (Gulf of St. Lawrence) we met with many ships of France and of Britaine (42, v. III, p. 284).

Hakluyt published a letter from an English fisherman which gives the ships fishing at Newfoundland in 1578 as:

Spaniards 100, Biskaire 20 to 30 more, Portugals 50, French and Britons 150 (42, v. III, p. 171).

Trying European Crops in America.-This fisherman also adds

I have in sundry places sowen Wheate, Barlie, Rie, Oates, Beanes, Pease and seedes of herbs, kernels, Plumstones, nuts, all of which prospered as in England.

This tendency of sailors to satisfy their curiosity in regard to whether European plants would grow in America has been mentioned by several explorers.

Cartier (1540) during this third voyage to Canada assures us:

We sowed seeds of our country as cabbages, turnips, lettuces and others, which grew and sprung up out of the ground in eight days.

Here we set 20 men to work, which in one day had laboured about an acre and a half of the said ground, and sowed it, part with turnips, which at the end of eight days as I said before sprang out of the earth (90,v. II, p. 667 ).

And the chronicler of Sir Humphrey Gilbert's Expedition to Newfoundland in 1583 states:

Peason which our countreymen have sowen in the time of May have come up faire and bene gathered in the beginning of August of which our Generall had a present acceptable for the ranenesse being the first fruits coming up by art and industry in the desolate and dishabited land (42, v. III, p. 195).

There is a possibility that some Old World plants introduced by the explorers persisted or were adopted and grown by the Indians, so that the later travelers considered these plants native to America.

Southern Explorations.-During this period of exploration the Spaniards had travelled over much of the southern part of the United States. De Soto 1539-41 starting in Florida had reached northward nearly to the southern boundary of Tennessee and westward to and across the Mississippi River. About the same time Alachron had entered the Gulf of California and had explored the Colorado River for a considerable distance. Coronado harl marched north from Mexico City with a force of 330 Spanish 
soldiers and 1000 Mexican Indians supplied with 5000 sheep and 150 eattle and discovered the Grand Canon of the Colorudo (17, 14th Rept. p. LVI). All of these expeditions earried live stock and in addition to those mentioned there were horses for the soldiers and hogs for food.

Poultry in the Southwest.-Castaneda (1541) with Coronado's expedition in the Southwest mentions at one stage of their journey:

No fowls of any sort were seen in any of these rillages except in this valley of suya, where fowls like those of Castile were found. Nobody could find out how they came so far inland, the people being all at war with one another (51).

Alachron (1540) while cxploring the Colorado River conversed with a friendly Indian chief to whom he says:

1 gave him certaine trifles, as well as seedes which I brought, as of the hens of Castile, wherewith he was not a little pleased (42, v. III, p. 521).

The distance separating these two expeditions was "about three days journey," at their nearest points.

Introduction of Cattle.-A remarkable instance of the introduction of cattle and their subsequent perpetuation as a wild breed occurred during this exploration period on Sable Island off the coast of Nova Seotia. Marquis de la Roche in $159 \mathrm{~s}$ left a colony of Frenchmen on that island where they discovered wild eattle and sheep. There were remains near the shore of some wrecked Spanish ships which several years previously had been sent to settle Cape Breton and these Frenchmen naturally inferred that the animals had escaped from those boats. The Frenchmen made boats of the remains of these ressels and eventually a few of the survivors succeeded in reaching France.

The wild eattle on Sable Island were then forgotton for thirtyfive years when John Rose an Englishman was cast ashore there. Rose, who estimated the herd at $\$ 00$ head, eseaped to the French on the mainland and informed them of his d'scovery and afterwards reached Boston. Two years later 1635 two vessels, the James and the Rebecea of Massachusetts Bay, were fitted out to go for these animals and hunt for seahorse. They found a company of 14 Frenchmen already there who had slaughtered many of the cattle but they estimated the herd then at "not above 140 and but two or three calves" (130). These animals were described as solid red_in color. 
Hogs in Bermuda. - A similar instance happened on the Bermuda Islands. Henry May, the first Englishman to write of those islands to which he eseaped in 1591 from a wrecked vessel, found large droves of black hogs. These he supposed had swum ashore from some Spanish wrecks on the coast, the remains of which were still there. These hogs furnished food to Sir Thomas Gates and one hundred and fifty people, when their ship was wrecked on the Bermuda rocks in 1609, while on the way to Virginia. Several expeditions were sent from Virginia to Bermuda for hogs to feed the Virginians in their periods of want. They were also the mainstay of provisions for the Bermuda scttlements in 1612 made by an English expedition under Richard More (110, pp. 633-7).

American Crops in the Old World.-The introduction of American food products into Europe, Asia and Africa had a wholesome effeet in improving the Old World diet. The Spaniurds took back to Spain seeds and plants of everything that gave promise of economic value. The Moors who had been driven out of Spain in 1192 had spread over Northern Africa and Eastward to Asia Ninor but still kept up a trade and correspondence with their Spanish friends in the Iberian peninsula. These Mohammedans were quick to appreciate the new plants from America and so we find the New World products immediately entering into the agriculture of Africa and Asia. Another means of taking American plants to Africa and African plants to America was afforded by the slave traders who began operating as early as 1500 .

Portugese Great E plorers.--The Portugese were instrumental in taking South American plants to Africa the East Indies and southeastern Asia. In the accounts written by the sixteenth century travelers in Africa and Asia one finds many American products mentioned. A few quotations from some of these relations may help the student of American agrieultural history to understand and appreciate the importance of the products belonging to this country. The quotations from Marco Polo and the Nubian Geography are inserted to contrast with those written after the discovery of America. Mareo Polo while in Persia about 1295 states:

They have fine horses here whence they are sold into India; there are very excellent asses sold dearer than horses because they eat little, carry much and travel far. The countries abound with silk worms, Wheat, 
Barley, Millet and other kinds of corm. The soil of this country bears excellent Wheat and Barley without husks . . . for victuals they sow three kinds of seeds, Rice, Panike and Millet (45).

From Nubians Geography written in Arabic about 1150 and translated into Latin 1619, Moore gives the following in regard to Africa:

Those however who live in Cities sow Onions, Gourds, and Pompions which grow there to a wonderful Bigness. The Plenty of Corn, nor of other sorts of Crain, is not so great among them, as the large grained Millet, from which they make their drink ( $7 S)$.

Maize in Africa.-John Leo, in 1535, describing conditions in a tribe "200 miles from the ocean, 500 miles north of Tombuto" on the Niger River in Africa says:

Here groweth some quantity of mil-seed (millet) and great store of a round and white kind of pulse the like whereof I never saw in Europe and a marginal note explains:

This round and white pulse is ealled Maiz in the West Indies (94, v. V, p. 519).

Another traveler this time in eastern Africa in 1597 records:

The Portugals drinke commonly Palme-wine, the Cafres Wine of their Wheate (or Mays) which they make strong and tipsie. Marginal note: Bread of Mais, or Guinny, Turkie, Virginia Wheat . . . . Their food is commonly Mais, Pulse, Fruits, Sugar-canes (94, v. IX, pp. 202-13).

Edward Lopez, a traveler in Africa about 15S8, mentions:

Another Graine which they call Maiz but they make no account of it for they give it to their Hogs: Neither do they greatly esteeme of Rice. The former Maiz they commonly terme by the name of Mazza-manputo, that is to say the Portugal's Corne, for they call a Portugall Manputo (94, V. II, p. 1007, Ed. 1625).

\section{Battell a prisoner in Africa 1589-1607 wrote:}

They have four sorts of corne in Longo the first is called Masanga and it groweth upon a straw as big as a reede and hath an eare a foote long and is like hemp-seed. The second is called Masembala. This is of great increase for of one kernell there springs four or five canes which are ten foot high and they beare halfe a pint of corne a piece. This grain is as big as tares and very good. Thirdly they have another that groweth low like Grasse and is very like Mustard seed and this is best. They have also the great Guiney Wheate which they call Masimpota. This is the least esteemed. They have good Peason somewhat bigger than ours but they grow not as ours do. For the Poodes grow on the rootes underneath the ground. 
The first three of these products pearl millet, sorghum and broom corn millet are of African origin and the fourth maize is American while the last may or may not be American depending on whether peanuts or some other plant is meant.

Sweet Potatoes in India.-Van Linschoten (1583) observed for India :

Ananas (Pineapples) is one of the best fruits, and of best taste in all India, but it is not a proper fruit of India, but a strange fruit, for it mas first brought by the Portugals out of Brasill (94, v. X, pp. 290-8).

\section{Edward Terry (1616) found in the Moguls country (India)}

Everywhere good roots as Carrets, Potatoes and others like them as pleasant. . . The Country full of Musk-melons, Water-melons, Pomegranats, Pome-eitrons, Limons, Oranges, Dates, Figs, Grapes, Plantans, . . Ananas or Pines, which seems to the taster to be a pleasing compound made of Strawberries, Claret wine, Rosewater and Sugar well tempered together. . . They sowe Tobaceo in abundance, but know not how to eure and make it strong as those in the Westerne India (94, v. IX, pp. 18-20).

Later Agriculture in Africa.-Moore (1835) describes the agriculture of the natives on the Gambia river in Africa in these terms:

They plant near their Houses Tobaceo and all round their Towns they open for Cotton, which they fence, in together; beyond that are their Corn Fields, of which they raise the four kinds usual all over this Country; that is to say Indian Corn, or Maize, which grows in Great Pods and is the Food of the Natives of America as well as Africa, therefore is so well known as not to need being described. Besides which they have Rice and the larger and the lesser Guinea Corn. In Gambia is no Wheat, Barley, Rye, Oats, nor any other European Grain but there is a kind of Pulse between the Kidney-Bean and Pea, (probably cowpeas) and Potatoes and Yams, The Indian Corn they set in Holes three or four together about four Foot distant from each other, so that it grows like Hops. This shoots to about eight or ten Foot high being a large Cane, with the Ears growing out of the sides. The Rice which is the seeond kind, and esteemed their ehoicest Food, they set in Rills, as we do Pease; it grows in wet Grounds, the Ears like Oats. The larger Guinea Corn is round and about the size of the smallest Peas. They sow it by Hand, as we do Wheat and Barley; it grows to nine or ten Foot high, upon a small Reed: The Grain is at the Top in a large Tuft, is eall'd by the Portugese Mansoroke. This likewise is sowed by Hand, and shoots to the same Height, upon a large Reed, on the Top which the Corn Grows on a Head like a Bulrush. The Grain itself is very small, and like Canary seed in 
Shape, only larger. These are all the Bread kind that are used in Cambia; and indeed the Natives make no Bread but eat the Flower of the various Grains as Thiekenings to Jiquids. The Indian Corn they mostly use when green parehing it in the Ear upon Coals and then it eats like green Pease. They boil their Rice ehiefly as the Turks do $(78, \mathrm{p} .31)$.

These negroes had also plenty of goats, fowls and cattle.

Spanish Settlements and Influence.--It is to the credit of the Spaniards that immediately after the discovery of America they began preparations to colonize and develop the country. Columbus returned to the West Indies in 1493 bringing a colony composed of farmers, carpenters, ship builders, miners and soldiers which was settled in Hispaniola, now Hayti. They brought with them secds of all the commonly known crops of Spain and various species of live stock.

The agricultural operations in the West Indies were unusually successful. There wcre few predatory wild animals on those islands to destroy the live stock and the natives were soon in complete subjection. Cattle and swine turned loose increased at a rapid rate. These herds furnished cheap sources of foodstuffs.

Government Policy Liberal.-The Royal Spanish Govermment established a very liberal policy to encourage agriculture in the New World. Farmers in the second expedition of Columbus were loaned wheat for seeding, as well as given land and breeding herds of live stock. These loans were to be paid back at harvest time with one tenth of the crop (10).

In 1502 married farmers and their families were transported free to America, allotted free land and freed from taxes except tithes and first fruits for five ycars. The discovery of gold in Mexico and Bolivia offered such alluring inducements that many of these farmers broke their contracts and became miners. Nevertheless agriculture was always a substantial industry in the Spanish colonies although obscured by the spcetacular nature of their military and mining exploits. The well known military principle that an army is as strong as its source of food supplies is well exemplified by the achierements of the Spanish conquering expeditions in their military enterprises in Mexico and South America. The Spanish colonies were never subjected to "starving times" like many of the northern settlements. 
Spaniards Introduced Live Stock. - Spanish agriculture influenced the agricultural practices of the present territory of the United States in several ways. The Spaniards took droves of animals with them on exploring expeditions along the Gulf. Some of these were dispersed by the Indians and the animals became the foundation stock of the large herds of wild cattle and horses on the western plains and the droves of wild hogs along the Gulf of Mexico.

In regard to the De Soto expedition (1539-41) we are informed that:

The Governour brought with him into Florida thirteen sowes and had by this time (about one year later) three hundred swine (41).

De Soto at the time of his death had 700 hogs. He started with 223 horses. At least five of the horses were dispersed when the survivors built boats and started down the Mississippi River in search of the Spanish settlements and it is probable that many others had previously escaped during the journey or were stolen by the Indians. Mention is made in connection with this expedition of certain Indians west of the Mississippi bringing among other products, "hogs, which were the breeding of some sows lost there the year before" (70, pp. 23j-252). And Jean Ribaut (1562) mentions "wild swyne" (31) in Florida, but of course these may have been the native peccaries which were common in the Gulf region.

Florida and New Mexico Settled.-The first permanent settlements in the United States, St. Augustine, Florida and Santa Fe, New Mexico, were made by the Spaniards. St. Augustine was settled by an expedition from Cuba and other West India islands while the Santa Fe settlement was made by Mexicans. The Spanish system of extending their settlements was intimately connected with the founding of the Roman Catholic missions. Missions were continually being establisł.ed at strategic and favorable locations in the more remote places. A mission under the control of a friar with a few associates would be started and this became the centre of all matters civic, political, economic and educational, of a wide region. Indian neophytes at these missions were trained in useful occupations as well as instructed in the Christian religion. Difficulty of transporting foodstuffs and lack of funds made it necessary that agriculture to a self supporting degree at least must be practiced about these centers. The 
agriculture of the Indians was supplemented by the erops and animals of Castile.

Live Stock Husbandry.-Grazing live stock was one of the main features of Spanish agriculture. This fitted in well with the climatic and soil conditions of Mexico and the southern border of what is now the United States. Farmers in Cuba and Mexico became wealthy from the sale of their products. To such an extent was grazing earried that beef and pork possessed little value. Hides and tallow could be shipped to Spain and it was from the sale of those two products that most of the agricultural fortunes were made. Sugar production also beeame a profitable industry. It is well known that the mines of Mexico and South Ameriea returned enormous wealth to Spain. It is not so well known, but a fact nevertheless that the value of the agricultural products of the Spanish farmers in the New World was greater than the out-put of the mines operated by Spaniards in America.

Products Obtained from the Spaniards.-The remains may be found today of a chain of missions from Texas to California marking the northern limit reached by the Spaniards in their efforts to settle and Christianize America before they met and were stopped by other European forces from the North.

It is difficult to appraise correctly the Spanish influence on American agriculture, especially that of the Southwest. There is a great field for research in the records of the old Spanish Missions along the lines of agricultural history. A few facts stand out prominently.

The best of our asses, mules and Arabian horses are of Spanish origin and the first of these imported into the United States came from Spain. Spanish blood in cattle is still in evidence along the border. Fine-wooled sheep were raised by the Spaniards in America long before those breeds were introduced into the English settlements. Of the introduced crops alfalfa and sugar cane stand out prominently as the most valuable, while the culture of sub-tropical fruits as figs, dates, European grapes, olives and pomegranates in New Mexico and California date from the time of the Spanish missions. They had also introduced lemons, oranges and ginger into the New World. The five Spanish missions in the present confines of the state of California possessed in 1773 , three years after they were founded, 205 head of eattle, 94 sheep, 67 horses, and 77 mules. 
Colonial Trade with the Spanish Colonies.-The long seil royage and the small size of the ships made the transportation of horses and cattle from Europe to America a difficult unclertaking. It was much more conrenient for the English and French colonists to buy the spanish animals on this siele of the ocean and whenever the relations between these countries at home were of such a nature as to allow it there was a consiclerablo. traffic and interehange of products between the Spanish, French and English colonists. The North Atlantic English settlers founded a prosperous commerce in taking grain and other temperate climate food products to the West Indies to exchange for sugar, salt and rum.

Large Herds of Cattle.-A few quotations from early accounts of Spanish activities in America are added: Columbus took with him on his second voyage :

Mares, sheepe heyghfers and such other of both kindes for increase: Likewise all kinds of pulse or grayne and eorne as wheate, barley rye beanes and pease and such other as well for foode as to sowe besicles vines, plants and seedes of such trees fruits and herbes as those countreys lacke (12, r. V, p. 170).

\section{A traveler to Cuba in 1570 asserts:}

All the trade of this Island is cattell, which they kill onely for the lides that are brought thence into spaine; for which end the spanyardmainteine there many negroes to kil their eattell, and foster a great number of hogs, which being killed, and cut in small pieces, they dry in the Sun, and so make it provision for the ships which come for spaine

Here (Mexieo) the Clrristians have their mighty mules, which they cary for all the parts of the Indies, and into Peru, for that all their merehandize are carried by this meanes by land (42, v. III, pp. 5tt-6j).

A similar observation was made in 1572 regarding Mexico:

There is in New Spaine a marvelous inerease of Cattel, which dayly do inerease and they are of greater growth then ours are. You may have a great steere that hath an hundred weight of tallow . . . for sixteen shillings; and some one man hath 20,000 head of eattel of his owne. They sell the hides unto the Merchants who lade into spaine. They have great increase of sheepe in like manner. . . . They have much wooll and as good as the woll of sipaine.

They have many horses, mares and mules which the spaniards brought thither. They have as good Jennets, as any are in spaine and better eheape then they bee in Spaine (42, v. III, p. 55t). 
Raleigh's expedition in 1585 to Roanoke Island touched at Hayti regarding which we are told:

Our English general and the Spanish governor discoursed betwixt them of divers matters, as of the state of the country, the multitude of the towns and people, and the commodities of the island; our men provided two banqueting houses covered with green boughs, the one for the gentlemen, the other for the servants, and a sumptuous banquet was brought in, served by us all in plate, with the sound of trumpets, and concert of music, wherewith the Spaniards were more than delighted. Which banquet being ented, the Spaniards in recompense of our courtesy, caused a great herd of white bulls and kine to be brought together from the mountains, and appointed for every gentleman and captain that would ricle, a horse ready saddled, and then singled out three of the best of them, to be hunted by horsemen after their manner, so that the pastime grew very pleasant for the space of three hours, wherein all three of the beasts were killed, whereof one took to the sea, and there was slain with a musket. After this sport many rare presents and gifts were given and bestowed on both parts, and the next day we played the merchants with them by way of truck and exchange of divers of their commodities as horses, mares, kine, bulls, gnats, swine, sheep, bull-hides, sugar, ginger, pearl, tobaceo and such like commodities of the island (90, v. II, p. 572).

\section{Still another account of Hayti in 1587 indicates the importance} of farming on that Island:

For the Spaniards at their first entrance into Hispaniola found neither suger-canes nor ginger growing there, nor any kind of our cattel: But finding the place fit for pasture they sent kine and buls and sundry sorts of other profitable beasts thither, and transported the plants of sugercanes and set the rootes of ginger: the hicles of which oxen, with suger and ginger, are now the chiefe merchandise of that Island $(42, v$. III, p. 365$)$.

Acosta (15SS) says for Mexico:

The Indians have received more profit, and have bin better recompenced in Plants that have bin brought from Spaine, then in any other Merchandise . . there is at the Indies any good thing that Spaine brings forth . . . as Wheate, Barley, Hearbes, and all kinds of Pulses, also Lettuce, Coleworts, Radishes, Onions, Garlike, Parsley, Turneps, Parseneps, Becengenes, or Apples of love, Siccorie, Beets, Spinage, Pease, Beanes, Fetches. . . In the fleete the yeere 1557 there came from Saint Dominique 35,44t hides and from New Spaine 64,350 (94, r. XY, p. 122, 127). 
The Farl of Cumberland 1596 observed for Porto Rico.

It is lawfull for any man to kill what (cattle) he neerleth for his use, if onely hee bee so honest as to bring the skins to the proper owners (94, v. IVI, p. 91). 


\section{('HAPTER XI}

\section{ENGLISH COLONIAL SETTLEMENTS}

C'olonics are cstablished in remote and undeveloped regions of the world to help relieve congestion in the older over-populated countries. The interests of the mother country are: (1), to make homes for an exeess of people which become more and more difficult to support the older and more highly civilized a country becomes; (2), to provide farored markets for the surplus goods of the mother country; (3), to supply raw materials for manufacture and food stuff: which the mother country does not produce in sufficient quantities for her own needs; (4), to furnish assistance in ease the mother country engages in war with some other country.

Colonies on the other hand are dependent on some strong country to give then protection from enemies, to furnish them a market for their produce and to supply them with the manufactured necessities of life. While the colonies are young they and their mother country are mutually dependent on each other, but as the colonies increase in population and advance in manufacturing and commerce this dependeney becomes less and less important and the two of ten become direct competitors with each other. When this competition becomes of sufficient proportions their interests elash. The mother country endearors to hold the colonie: in subjection while the colonies endearor to free themselyes from all restraint.

United States Needs No Colonies.-It taxes the wisest and most far-seeing intelligence of the statesmen of a country to embark on a safe and sound colonial policy. To illustrate; it would be very unwise for the United States to establish colonies to produce grains, cotton, meat and potatoes or to mine coal, iron, copper, gold and lead. On the other hand colonies which could supply us with spices, coarse fiber, coffee and tea might be of some benefit. Our most intelligent statesmen, however, agree that colonies on the whole are a source of weakness rather than strength to the Enited States. This is due to the size of our country, to our undeveloped resources and to our great 
variations in soil and climate which supply or ande ho marle to supply most if not all of our material neerls.

Delay in Settling America.-When America was discovereal none of the European countries with the exeeption perhaps of Spain and Italy was orer-crowded with people. Each nation desired a larger population in order to have more men for soldiers, to give greater power to resist invasion and to punish its enemies. America especially the temperate and colder portions was not essential to the welfare of Europe in the sixteenth ecntury and the need did not become strongly evident until the eighternth. Here ready for settlement was a vast area of land supporting thousands where it was eapable of sustaining millions and there was no advantage taken of the opportunity for nearly a contury.

Strong Manhood Needed in Colonies. When France and England finally attempted to establish colonies in America they were animated as much by the desire to get rid of undesirable elements at home as to develop strong colonies abroad. Paupers and criminals could best be spared and these in a large measure made up the various expeditions in the disastrous attempts at settlements which France and England made in the sixteenth century. No greater mistake in policy can be made than to use colonies as a dumping ground for the vicious riff-raff of overcrowded cities. It is only the strong substantial agricultural middle class that is fit for overeoming the obstacles incident to pioneer life. France dicl not realize this until too late and some of the early English colonies were badly handicapped by the practice of using them as substitutes for penal institutions.

Feudal System and American Colonization.-The settlement of America was finally prosecuted to no small extent by the nobility or aristocratic land-holding class in Jngland in an endeavor to increase incomes from estates held under old feudal grants. The fortunate possessors of these grants deriverl revenue from their holdings in the form of quit-rents, of ten very nominal per acre, but in the aggregate of large amounts, without thr expenditure of thought or effort in the care and management of the estates. It was in the desire to extend this systen to take in the vast tracts of unpatented land in America that many of the nobility of England sought and obtained grants to great areas of land in the New World and in some cases invested large sums of money in transporting settlers and their effects to populate these tracts. Every student of colonial history knows the 
trouble caused by the over-lapping of these grants due to a lack of geographical knowledge of the American continent when the grants were made. While these rival and conflieting claims caused abundant controversy the collecting of quit-rents in America by a non-resident over-lord was a still more serious obstacle to the establishment of the system.

Merchant Promoters.--Another group of individuals who gave material aid in American colonization were the eity merchants. If successful colonies were established, these merehants would have the advantage in trade of supplying the settlers with goods and also in handling the colonists' produce in Europe. Their charters from the Crown usually granted them a monopoly of trade and a pereentage of the profits of all precious metals or minerals discovered in the settlements. It was purely a speculative business venture with these merchants and their efforts to collect dividends on their investments led to much ill-feeling on the part of the settlers. The success of the Spaniards in discovering gold in South America aroused the envy of other European nations and filled the minds of many with dreams of fabulous wealth.

The numerous failures in the early attempts at colonization had little deterrent effect on such enterprises. There were alway's private capitalists ready to risk their fortunes in promoting colonies provided their government was willing to protect their claims from outside aggression, and they could induce others to risk their lives in making the settlements.

The population of several of the colonies was augmented by soldiers, sent to guard the colonists from Indian and foreign attacks, and whose term of enlistment expired while in America. These soldiers often took up clains and remained in this country. In some cases special inducements were offered the soldiers to have them take that course.

\section{VIRGINIA}

The settlers at Jamestown, Virginia, in 1607 , had little intention of engaging in agriculture. None in the first expedition appears to have known much about farming. They came expecting to make their fortunes quickly and looked to the London Company under whom they were operating to furnish them with food and other necessitics from England. When 


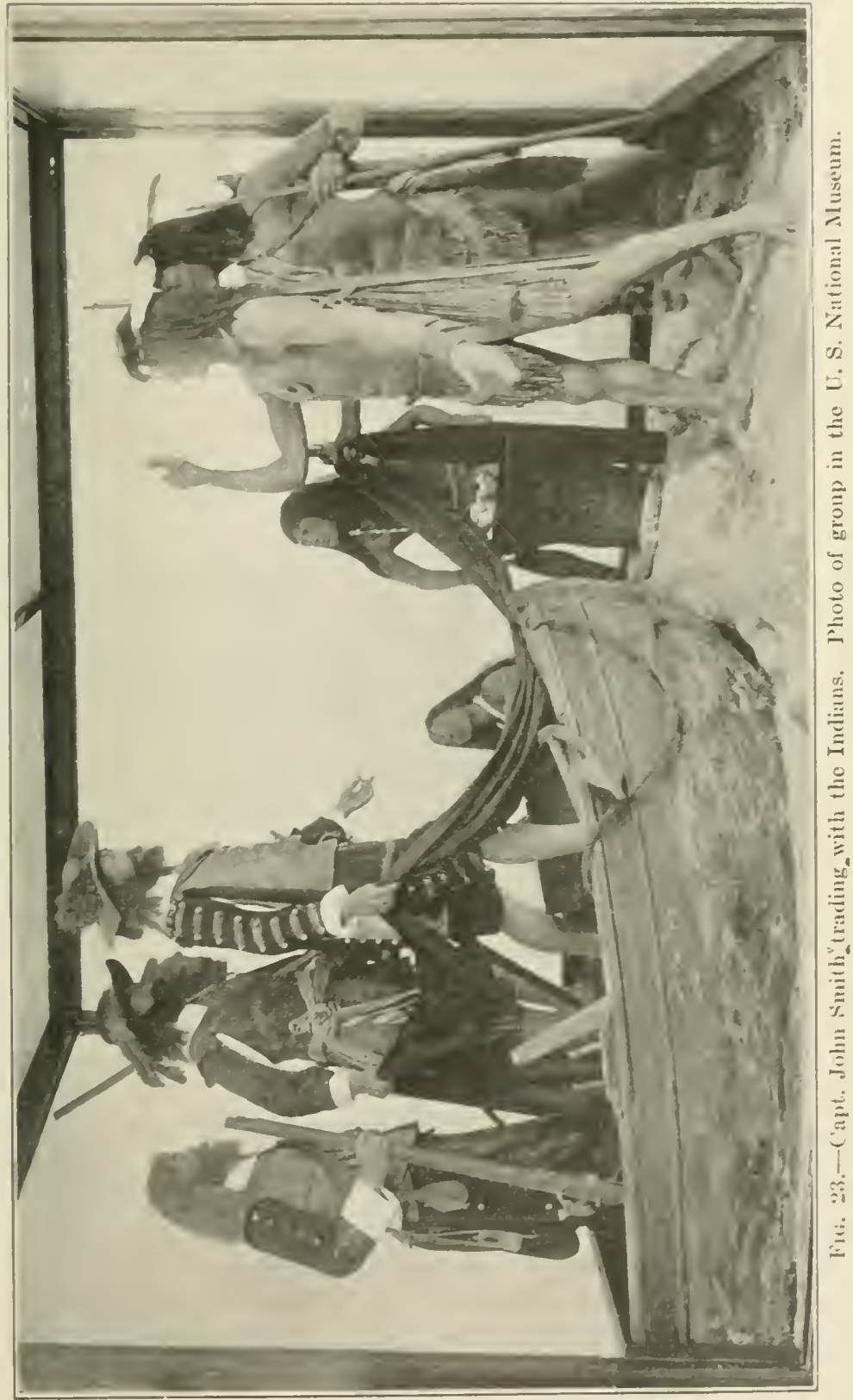


threse supplies failed to arrive and famine threatened, they still rluarelled orer their relative rank in the new society, heedless of the danger that lay about them. But for the energy and foresight of Capt. John Smith in obtaining food from the Indians they would all have starved to death the first year. The charter under which the settlement was made contained the fatal provision for pooling their supplies and doing everything in rommon for five years. No inducements were offered for thrift or to encourage farming. Fortunately the Indians remained friendly, so in July 1607, as expressed by Capt. John Smith:

"It pleased Crod to move the Indians to bring us corn ere it was halfe ripe to refresh us" and in september they "brought us great store both of Corne and bread ready made."

Snith the ablest man in the colony unfortunately did not strongly favor agriculture and believed it feasible to compel the Indians to supply all food stuffs needed (Fig. 23). He little realized that the Indians desire for beads, tin bells and other knick-knacks would soon be satisfied. Then too, public opinion in England aroused by the Las Casas exposures of Spanish eruelties in the West Indies would not permit foreed enslavement of the natives in Virginia.

Policy of John Smith.-Smith's policy when he had an opportunity to put it in practice was to utilize all the white labor in providing clap-boards, pitch and potash from the forests to ship to England. There was a reasonable profit from that industry but it required hard work and few in the early years at Jamestown had any desire or aptitude for labor. They were more content to search for gold and precious stones.

A worse site for planting a colony can scarcely be imagined than the peninsula, now an island, which they chose. Much of the island is still swampy and malarious. There were no springs of water, their supply being obtained from the muddy James. The high ground was heavily wooded while the marshes were covered with tall weeds and badly infested with mosquitoes.

First Attempts at Farming.-Captain Newport assigned a third of the adventurers or about forty men to husbandry but notling came from their labors. At one of their first attempts to plant corn (probably English grain) they were assaulted by a few renturesome Indians which so discouraged the settlers that they made no further efforts to provide crops for food that season. 
One of the adventurer's complains of the diffieulties of preparing land for corn. Another mentions that some made gardens. But the season was too far spent when they finally settled at Jamestown to allow clearing land for spring seeded grains.

The following year they had four acres prepared and seeded to corn. This was probably barley or wheat and garden peas none of which succeed in Virginia from late spring sowing. This second scason's crop was also a failure.

Indian Prisoners Saved the Colony.-It was not until 1609, that the conceit of the English was sufficiently humbled so they could take instruction in agriculture from the natives. Then it is stated two Indians:

Kemps and Tassore were fettered prisoners and did double taske and tought us how to order and plant our fields.

Little is recorded in commemoration of the service which these two Indians rendered the colony. Smith did not mention them himself probably looking upon the incident of their arrest as trifling in comparison with the many stirring events of the time. From others among the adventurers one learns that Kemps and Tassore or Kinsock, as the second was sometimes called were arrested early in the spring, of 1609 , in retaliation for the depredations of other Indians. At the time of their arrest they were described as

the two most exact villaines in the countrie that would have betraied both their king and kindred for a peece of copper.

Kemps and Tassore Set at Liberty.-Kimps and Tassore were given their liberty soon after corn planting time. "But so well they liked our companies they did not desire to goe from us." Later that summer these two Indians had an opportunity to show their appreciation of Capt. John Smith's policy of firmness but fairness in dealing with the natives. Some soldiers deserted the fort at Jamestown and sought Kemps and Tassore to induce them to attack the colony, but in this were disappointed. Kemps made them prisoners and with true Indian humor made sport of them before his companions, illustrating, with these soldiers as the rictims, Smith's famous work or starve decree. Afterwards he delivered the deserters to smith together with several stolen implements which they had offered him as a bribe to gain their liberty (110, pp. 151, 155 and 47t).

Strachey mentions having obtained certain information 
from one Kemps, an Indian, who died the last year of the surveye at Jamestowne, after he had dwelt with us almost one whole year, much made of by our lord generall and who could speake a pretty deale of our English, and came orderly to chureh every day to prayers, and observed with us the keeping of the Sabbothe, both by ceassing from labour and repairing to the church $(120$, p. 53).

During the period of seareity of food in 1609 following corn planting two of the adventurers tell us

Many were billitted among the Salvages, whereby we knewe all their passages, fieldes and habitations; how to gather and use their fruits as well as themselves $(110$, p. 157).

First White Farmer.- The first farmer in the Jamestown colony was William Spence who arrived on the Phoenix, April 20, 1608. He was variously represented as a laborer, gentleman, and ensign. Smith certified to his character as "an honest, valient and industrious man." He survived the fearful ordeals of the early years was a member of the first House of Burgesses (1619) but may have lost his life in the Indian masacre of 1622 . Five persons, names not given, were killed at that time at the Spence farm. Alex. Brown states that "Ensign Spence is reported lost in 1623 but he may have been living in eaptivity."

First Live Stock.-A few head of live stock were brought in the first expedition. Rev. W. Simmonds states that:

three sowes in eighteene moneths, increased 60 and od Piggs. And neere 500 chickings brought up themselves without having any meat given them.

Others were evidently brought in the two supplies which arrived in 1608 as it was reported at the time Smith left the colony in the fall of 1609 that they had

six Mares and a Horse; five or sixe hundred Swine; as many Hennes and Chickens; some Goats some Sheepe.

Starving Time.---Lord Delaware on his arrival in 1610 reported to the London Company:

Our people together with the Indians (not to friend), had the last winter destroyed and kild up all our hoggs, insomuch as of five or six hundred (as it is supposed) there was not above one sow, that we can heare of, left alive; not a henn nor a chick in the forte (and our horses and mares they had eaten with the first) (120).

And Simmonds states in regard to this same starving time of the winter of 1609 : 
as for our Hogs, Hens, Goats, Sheepe, Horse, or what lived, our commanders, officers and salvages daily consumed them, some small proportions sometimes we tasted till all was devoured.

Beginnings of Indian Troubles. - The Indians had in their possession the best land in eastern Virginia. The Powhatan tribes were at the height of theil power. They were populous. No recent epidemics or disastrous wars had caused them to abandon their cultivated fields. Hundreds of acres of rich river bottoms produced abundant crops. In contrast the colonists had to clear virgin forests, fell trees, cut brush, burn logs and plant among stumps. It would have taken a very unselfish set of human beings to have viewed this situation with unenvious eyes. The Indians would not sell their cleared fields and so the colonists began to look for an excuse to seize them by force.

Lord Delaware's Greed.-Lord Delaware, in 1610, wrote home to England,

we have experience, and our owne eyes witnes, how young socver we are to this place, that no countrie yealdeth goodlier corne or more manifold increase, large feildes we have as prospects houerly before us of the same, and those not many miles from our quarter (some whereof, true it is, to quitt the mischeivous Indian, and irreconsilable for his late injuries and murthering of our men, our purpose is to be masters of ere long, and to thresh it out on the flores of our barnes when the time shall serve) (120, p. XXXII).

Smith had already in 1609, seized Powhatan's birth-right an Indian site "at the falls," now Richmond, together with drie houses for lodgings, 300 acres of grounde readie to plant; and no place so strong, so pleasant and delightful in Virginia (110, p. 165).

This was controlled by a son of Powhatan whom the Virginians at first erroneously thought to be the supreme ruler of the tribes in that region.

Gov. Dale Takes Charge.-The beginning of real farming in Virginia was in May 1611, on the arrival of Sir Thomas Dale with "three ships men and eattell" ("100 kine, 200 swine") (110, pp. 506-7).

Dale had had military experience and was a severe and strict disciplinarian. The surviving colonists received a jolt in their manner of living. From habits of slothfulness into which they had fallen after the departure of Smith they were with little ceremony put to work, and to hard work. 
"Hi- first care therefore was to employ all hands in the setting of Corne," wrote Rahph Hamor, "and about the end of May wee had an inelifferent crop) of grood Corne" (110, p. 507).

Other Work Underway, - This corn was planted at Newport News, where strachey says were "alreddy prepared to receive corne or make viniards of twoo or three thowsand acres," and across Chesapeake Bay on the Virginia Capes. No time was wasted clearing land in the hopeless situation at Jamestown. With the corn planting accomplished and two palisaded forts built to protect the workers left to tend it, Dale returned to Jamestown, "where most of the companie were at their daily and usuall works, bowling in the strects." Hamor does not give the cletails of how this game was interrupted, but adds "these hee imployed about necessarie workes, as felling of Timber, repayring their houses, ready to fall on their heads, and providing pales, (pointed pickets) posts and railes to impale (fenee) his purposed new towne." As soon as he had this crowd of idlers at work, Dale took one hundred men and went on an exploring expedition to find a more favorable site than Jamestown for planting, finally deciding in favor of a peninsula of highland "some twelve miles from the Falles" on the James River. This he named Henrico in honor of Prinee Henry.

Settlement at Henrico.-In August of that year (1611) Sir Thomas Gates arrived with "six tall ships, with three hundred men, and one hundred kine and other Cattell." Gates thoroughly approving of Governor Dale's plans let him select three hundred and fifty of the best workers in the colony to build at Henrico. Where in "ten or twelve daies he had inviorned it with a pale." His next work was to construet watch houses, store houses, a church, "three streets of well framed houses, wherein live the honester sort of people as Farmers in England."

With this work well under way he went back about two miles from the town and built a

pale neere two miles in length from River to River, with a good quantity of Corne-ground impailed sufficiently secured to maintaine more than I suppose will come this three yeeres.

Appomattox Lands Seized.-The Appomattox Indians were then seated on a neck of fertile land made up of several smaller peninsulas lying between the James and Appomattox rivers, Dile wanted this area as it contained much cleared land and was easy to fenee so 
About Christmas following, in this same reere 1611 in regard of the injury done us . . Without the losse of any except some few sialrages, tooke it and their Corne.

This he named "New Bermudas" and divided it into soveral humdreds. The term "hundred" a relic of the feudal system as used in England at that time meant a political division smallel than a county. It was probably Dale's intention that these humdreds should include all the land that could be conveniently reached by the farmers from their homes in a town where they were supposed to reside. The scheme was not popular. The planters much preferred to build their homes on their plantations and the word "hundred" lost its significance. Hamor wrote:

In the nether hundred he first began to plant, for there is the most Corne-ground, and with a pale of two miles, cut over from River to River, whereby we have secured eight English miles in Compasie; Rochdale, by a crosse pale wel nigh foure miles long, is also planted with houses along the pale, in which hundred our Hogs and Cattell have twentie miles cireuit to graze in securely.

Dale's Plans.-One must marvel at the accomplishment of this driver in less than a year with men most of whom were unused to labor. No wonder they complained bitterly to the folks back home. While some were working at fence building and construeting houses, others were employed in getting out clapboards making pitch and tar and soap-ashes to ship to England.

It was not Gor. Dale's purpose to set up an agricultural colony. He encouraged farming as an adjunct to his other schemes for reimbursing the London Company with exports. He limited the number engaged in farming and to each granted but three acres of corn-land and these farmers were not allowed to derote their entire time to tillage. The eattle and hogs were allowed to run at will in the enclosed ranges he had provided. The need of more corn soon became apparent and in a letter dated June 14, 1614, Gov. Dale reported that he had set the colonists to the task of

liusbanding of our Corne securely whereof wee have above five-hundred Acres set, and Crod be pratised, in more forwardness then any of the Indians than I have seen or heard of this yeere (94, v. IV, p) $1769 \mathrm{Ed}$, 1625).

We are not informed in regard to the harvest, but, Junc is not at good time to estimate a corn crop in Virginia as many newcomers 
to that State have since found to their sorrow. Lack of cultivation probably resulted in a small yield.

Agriculture Stifled.-Virginia was destined to develop agriculturally and every attempt made to suppress that industry only served to prolong the troubles. There were no natural resources except the forests in the tidewater section. There was no water power, no minerals, no Indian trade of any great value, in fact, nothing on which to build a commerce or commonwealth until there was a surplus of agricultural products beyond the immediate needs of the settlers for sustenance. When Capt. Argall succeeded Dale as governor in 1617 , he reported the colony as having about 400 people but not past 200 fit for husbandry and tillage . . 128 eattle, S8 goats and innumerable numbers of Swine. Of the cattle there were about fortie Bulls and Oxen "but they wanted men to bring them to labour and Irons for the Ploughs and harnesse for the Cattell." They had made an attempt to grow some small grains. "Some thirtic or fortie acres wee had sowne with one Plough, but it stood so long on the ground before it was reaped it was most shaken" (110, pp. 536-8).

Beginnings of Tobacco Culture.-At the time of the Jamestown settlement there was a great demand for tobacco by the English and other north European peoples. The erop had been introduced into England and was being raised by English farmers. But Spain had a monopoly of the trade due to the superior quality of the tobaceo grown in the West Indies. John Rolfe is generally credited with having, in 1612, been the first Virginia planter to engage in its culture.

The Powhatan Indians were growing tobacco but to what extent the colonists were indebted to them for information as to eare and management of the erop it is impossible to say.

Tobacco Varieties Brought from West Indies.-Strachey (1610-12) says the natural tobaceo of Virginia

is not of the best kynd, yt is but poore and weake, and of a byting tast, yt growes not fully a yard above ground, bearing a little yellowe flower, like to hennebane, the leaves are short and thick, somewhat round at the upper end; whereas the best tobacco of Trynidado and the Oronoque is large, sharpe, and growing two or three yardes from the ground, bearing a flower of the bredth of our bell-flowers in England (120, p. 121).

This same writer mentions that tobaceo seed had in his time (1610-12) already been brought from "Trinidado" (120, p. 31). So one may be safe in concluding that the varieties of tobacco 
since grown in Virginia were not grown by the Indians there. The name "Oronoque," spelled in various ways still persists in tobacco nomenclature in Virginia.

Best Varieties Come from South America.-Rochefort (1666) states in regard to the Caribbean islands:

There have been brought from the Continent the seeds of Virinus and the Tobacco of the Amazons, they are divided into four kinds. The two former are of a great produce, but the two others are more esteem'd by reason of their sweet scent $(99$, p. 5i) $)$.

The seed of these improved varieties was probably taken to Virginia from England. Gerarde (1597) lists two sorts one from

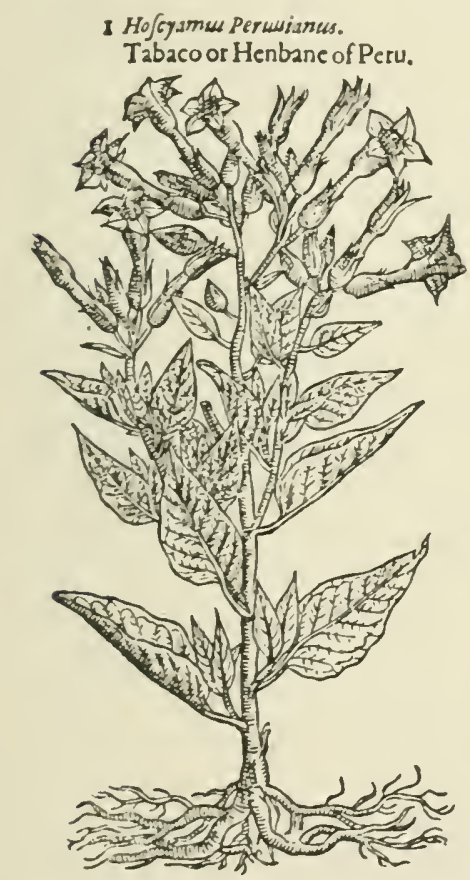

2 Sara Sancta Indorum.

Tabaco of Trinidada.

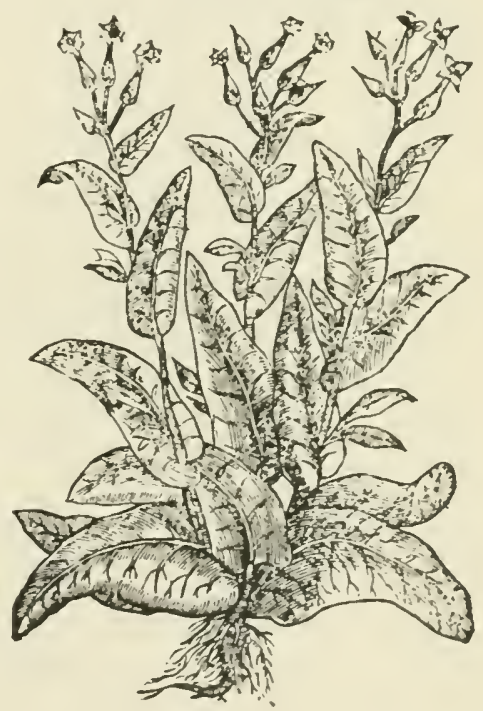

FIG. 24.-Two improved or South American varieties of tobacco. The kinds taken to Virginia by the Jamestown Settlers. Gerarde, 1597.

Peru and the other from Trinidad which he had growing in his garden (Fig. 24). Most likely seed of tobacco was brought to England by Sir Walter Raleigh from his expedition in 1594-5, to the island of Trinidad and the Oronoco River although they may have been obtained earlier from Spanish sources. Mattioli (1586) gives one species of tobaceo which he named peruvianus. 
First Big Crop.- Ciov. Dale dict not favor tobaceo growing as it interfered with growing corn which he needed to feed his laborers. He ruled, in 16il6, that each farmer should seed two of his three aeres to corn. As soon as Dale left (1616) Capt. George Yardley took charge of the colony as Deputy (iovernor and all restrietions on the growing of tobaceo were removed. The next year (1617) saw a remarkible planting. "The marketplace, and streets, and all other spare places" of Jamestown were set with this crop "and the colonie dispersed all about planting Tobaceo" (110, p. 535) with the men "rooting in the ground about Tobaceo like Swine."

Agricultural Policy Changed.-It was not until 1619 or after twelve years of gloom, discouragements and tragedies that a rational agricultural policy was adopted towards the Jamestown Colony. Through the influence of Edwin Sandys, Sir George Yardley was sent in that year as governor of Virginia. He immediately granted to each settler, who eame at his own expense and who had been in the colony prior to the departure of Governor Dale, one hundred acres of land and as much more as he eould pay for at the rate of 12 pounds, 6 shillings, for each hundred acres. Those imported by the company were to be granted one hundred aeres each after they had worked out their period of service to reimburse the company for their transportation. Settlers paying their own passage were allowed 50 acres each (123). Eleven ships with 1216 persons were sent to Virginia that year. Martial law was abolished as was also the policy of communistic production. In this year (1619) negro slavery was introduced. But prior to that time slavery, limited in period of service it is true, had been in general practice. Negro slaves fared no worse at the hands of their task masters than many of the indentured white servants under the old regime of the first eharter to the London Company.

As a fitting climax to the changed policy towards the colonists, ninety young maidens of good character were brought to Virginia in 1619 and distributed as wives to the settlers on the payment of 120 pounds of tobaceo to cover the charges of transportation. As this amount of tobaceo represented but one year's crop of a planter, it is evident that the cost of matrimony had been reduced more than 85 per cent. since the time of Jacob.

Efforts to Restrict Tobacco Growing.-From time to time various restrictions were placed on the culture of tobaceo. Governor 
Wyatt, in 1621, ordered that for every head they should plant but 1000 plants of Tobaceo and upon each plant nine leaves $(110$, p. isti.j).

This would give for each worker about 112 pounds of tobaceo a year. With their erude implements and lack of work stock this was alsout all that one man could cultivate and at the same time raise sufficient eorn for his own needs and have a surplus for the other members of the eolony not engaged in agrieulture. John Rolfe states that:

An indu-trisus man not other waiis imploied, may well tend foure aker of Corne, and 1000 plants of Tobaceo $(110$, p. 541).

Tobacco Growing Became General.-Tobacco growing became a craze with the colonists. Nor is this surprising. After all their hardships and discouragements, this erop alone promised them relief from poverty. Even after the Indian massacre of 1622 they rallied to the planting of Tobaceo. Smith says:

Amongst the rest of the Plantations (those not destroyed by the Indians) all this summer (1622) little was done, but securing themselves and planting Tobaceo which passes there as current Silver and by the oft turning and winding it, some grow rich but many poor (110, p. 598).

With the more liberal inducements in the matter of gaining title to land and despite the Indian Massacre (1622) and the abolishment of the London Company in 1624, ship loads of colonists with live stock flocked to Virginia. The brush hovels with thatehed roofs which had served as dwelling places gave way to framed houses the material of which in some cases was brought from England.

Condition of Colony in 1629. - Smith summarized the condition of the Tirginia colony in 1629 in these words:

Master Hutehins saith, they have 2000 Cattle, and about 5000 people; but Master Floud, John Davis, and William Emerson, and divers others, say, about five thousand people, and five thousand kine, ealves, oxen, and bulls; for goats, hogs, and poultry; corne, fish, deere, and many sorts of wild beast:; and fowle in their season, they have so much more than they spend, they are able to feed three or foure hundred men more than they have (110, p. S5i).

The Colony Grows.-The expulsion of the Indians from the York and Rappahannock rivers about 1640 opened up large tracts of cleared land to the planters. Yirginia secured the lead as an agricultural colony which was maintained for more than a 
century. Food was abundant and cheap and the Virginia planters adopted a policy of generosity and hospitality towarls strangers which for many years made that colony famous.

Fluctuating Prices.--The history of Virginia during colonial times is intimately connected with the tobacco crop. Tobacco was not only their cash crop but their cash itself. Bargains were made and contracts drawn calling for payment in pounds of tobacco. This gave the Virginia planters a medium of exchange with England which some of the other colonists sorely needed. Tobacco prices fluctuated greatly but being the medium of exchange the results were not always disastrous, to the colony as a whole, when the price of tobacco fell. When tobacco prices were depreciated the effect was the same as when currency is depreciated, the prices of other goods were made abnormally high and old debts were more easily paid. The truth of Capt. John Smith's statement in regard to tobacco that "by the oft turning and winding it some grow rich but many poor" has often been demonstrated. The first great set back to tobacco growing came in 1630 when the price of tobacco fell from $3^{s}$. $6^{d}$. to $1^{d}$. per pound. This like many calamitics proved a blessing in disguise. The next year (1631) a boat of 18 tons burden loaded with corn and tobacco disposed of its cargo in Salem, Massachusetts. The corn brought ten shillings a bushel. This inaugurated a brisk trade and a Dutch ship in 1632 took 2000 bushels of corn from Virginia to New England. In 1633, at least ten thousand bushels of corn were sold in Massachusetts besides a number of beef cattle, goats and hogs (130 v. I, pp. 56-73).

Diversified Farming.-The failure of the tobacco crop to sell at a remunerative price stimulated the culture of orchards and gardens and encouraged live-stock husbandry, so that the planters became more and more self sustaining. Peach and apple trees in the seventeenth century were free from many of the diseases which make their culture so difficult now and the crops were often used to feed droves of hogs. Despite the ruinously low prices which sometimes prevailed the amount of tobacco exported steadily increased. In 1639 , about $1,500,000$ pounds were exported from Virginia alone. This increased to $23,750,000$ pounds from America in 1664, and to $107,000,000$ pounds in 1770 (53).

Robert Quary sent to investigate the colonies reported under date of 1703 in regard to Virginia: 
Their almost sole business is planting and improving Tobacco, even to that degree that most of them scarce allow themselves time to produce their necessary provision, and consequently take little leisure to busy themselves about matters of State $(14, v$. IV, p. 1051).

Rolling Houses.-As the population increased the planters were forced back from the rivers and a new difficulty confronted the tobacco grower in getting his product to navigable water. Wagons were scarcely known and the carts which the planters owned were not equal to the task of carrying a hogshead (600 to $1000 \mathrm{lbs}$.) of tobacco over rough roads; so the hogsheads were rolled to the wharves sometimes for a distance of several miles. Tobacco warehouses became known as "rolling houses" and the roads as "rolling roads."

Efforts to Sustain Higher Prices. - With the over-supply of tobacco, the English market became extremely discriminating in regard to the quality of the product which it would purchase. To meet these demands and support the price of tobacco where profits could be made on its production, the Virginia colonial government resorted to numerous legislative expedients. An inspection law was passed in 1628 aimed to curb the ruinous practice of shipping inferior and damaged tobacco. In 1640, it was ordered that all bad tobacco and half the good should be destroyed. Gov. Berkeley made several ineffectual attempts to form agreements with the tobacco planters of Maryland and North Carolina who had become serious competitors of the Virginia colonists to curtail the production of this staple. Each colony was willing for the other two to quit planting or to destroy as much tobacco as they pleased but looking to its own selfish interests failed to carry out the provisions of the agrecment. All culture of tobacco was prohibited by the Virginia assembly in 1666 but the Maryland authorities complained that the law was ignored by the Virginia planters.

Improvement of the Crop.- The planters developed a keen rivalry among themselves to improve the quality of tobacco.

Clayton (1688) in his description of Virginia says:

For there is not only two distinct sorts of sweet-scented and Aranoko Tobacco but of each of these be several sorts much different the seeds whereof are known by distinct names, they having given them the names of those Gentlemen most famed for such sort of Tobacco as of Prior Seed etc. (35, v. III, No. 12 , p. 15). 


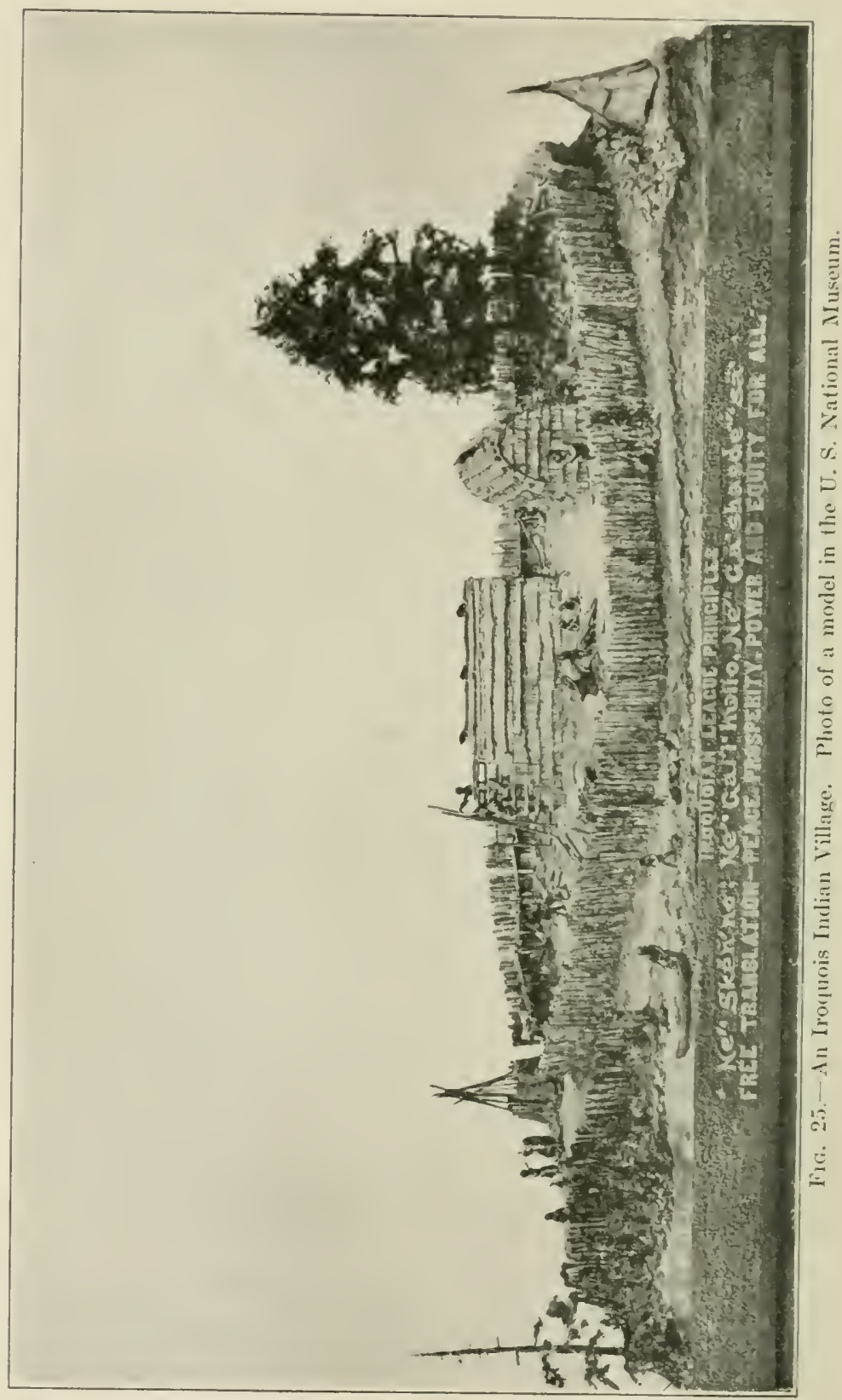


The Aranoko or as nust commonly spelled Oronoto was used on the heavy clay soils and the product which was a strong heary tobacen was consumed mostly in Ciermany. The sweetscented was grown on the lighter sandy soils and although the vield was less it brought a better priee on the market.

Junes (1724) mentions one of the many loealities in Virginia which beeame noted for a particular variety of Tobaceo. He says:

Fur on York River in a small Tract of Land called Digge's Neck, which is poorer than a great deal of other Land in the same Latitude, by a particular seed and Management, is made the famous Crop known by the Name of the E: Dees, remarkable for its mild Taste and fine smell $(6.3,3.34)$.

Other Crops Grown.-While tobaceo had an important part in the prosperity of Virginia, it has never been the most valuable crop grown there. Maize holds that position. Maize saved the colony from total starvation on more than one occasion. Maize was an export commodity when tobaceo prices fell below the cost of production. Maize enabled the Virginia farmers to raise live stock on an extensive scale. In fact the agriculture of the Virginia colony and not only Virginia but all colonial America was built around this great American plant. The Virginia colony could have existed as several others did without the aid of tobacco culture. It is difficult to see how any of the carly settlements could have maintained their existence without maize. This crop has done more to promote the wealth and prosperity of this country than all the other natural resources power, minerals, forests ete. put together.

The importance of maize in Virginia is indicated by a comment of Beverly (1705)

The Bread in Gentlemen's Houses, is generally made of Wheat, but some rather chorse the Pone, which is Bread made of Indian Meal. Many of the pourer sort of People so little regard the English Grain, that though they might have it with the least Trouble in the World, ret they don't mind to sow the Ground, because they won't be at the trouble of making a Fence particularly for it. And therefore their constant Bread is Pone not so called from the Latin Panis, but from the Indian Name Oppore (9, p. 253).

Agriculture by Legislative Enactment.-In order to encourage the production of grain in 1623, the Assembly ordered: 
For the encouragement of men to plant store of corne, the prise shall not be stinted, but it shall be free for every man to sell it as deere as he ean (49).

This policy had a wholesome effect and greatly increased the production of maize and as we have already seen there was a surplus to export seven years later. This is perhaps the first law passed in Ameriea for the direct benefit of the produeer and stands out in strong contrast to many other legislative enactments of colonial assemblies. There were many other grain laws passed in Virginia and the other colonies but the majority of them either fixed the maximum price or else prohibited the exporting of grain.

When the over-production of tobacco reduced the price so low that there was no longer an opportunity for a planter to make a competent livelihood in its culture, the Virginia Assembly passed numerous laws in a frantic effort to remedy the situation. The evidence indicates that many of these laws were passed to please interested persons in England, especially those in the government rather than at the instance of the best judgment of the colonial law-makers. Enormous bounties were offered for the production of staple commodities but the amounts of produce required were usually so large that there was little likelihood of anyone claiming the bounty. Such laws pleased the English authorities and eaused no inconvenience or expense in the Colony. On the other hand, laws compelling all the planters to grow this or that crop were passed under the stress of urgent solicitation of creditor merchants and the ruling class in London which caused much dissatisfaction among the colonial planters. Most of the recommendations that came from across the ocean were for growing crops either unsuited to the soil and climate of America or which for economic reasons could not be profitably grown here. Silk production which had been a favorite theme of the European nobility when discussing American affairs received a great deal of attention.

Silk Production in Virginia.-Governor Wyatt in 1621 was instructed:

Not to permit any but the council and heads of hundreds to wear gold in their cloaths, or to wear silk till they make it themselves . . . Next to corn, (to) plant mulbury trees, and take care of the French men and others sent about that work (49, v. I, pp. 114-5).

In December, 1656, it was ordered: 
That cverie proprietor of land within the collony of Virginia shall for everie one hundred acres of land holden in ffec, plant upon the said land tenn mulberry trees, at twelve foote distance each from the other, and secure them by weeding, and a sufficient ffence, from cattell, horses, etc. between this and the last of December, 1658 (49, v. I, p. 420).

The object of this law was of course to provide green leaves as food for silk worms but the berries from mulberry trees planted in Virginia were of more service in furnishing feed for hogs. This law was repealed two years later as it "seemes rather troublesome and burthensome then any waies advantageous to the country" $(49$, v. I, p. 520).

It was reenacted in 1661, given a respite whereby the provisions of the law were not to be enforeed for three years in 1663, as it was "impossible to procure sufficient mulberry trees" and again repealed in 1666 (49, v. II, pp. 241-2).

Bounties on Silk.-At the same session of the Assembly when the act compelling the planting of mulberry trees was passed it was ordered that:

George, the Armenian for his encouragement in the trade of silk and to stay in the country to follow the same have four thousand pounds of tobaceo allowed him by the Assembly.

And it was also voted in 1657 that:

What person soever shall first make one hundred pounds of wound silke in one yeare within this colloney shall for his so doing be paid ffive thousand pounds of tobacco out of the publique levie.

This law was amended in March, 1659 to increase the bounty to 10,000 pounds of tobacco for fifty pounds of wound silk and in 1661 a bounty was granted of fifty pounds of tobacco for every pound of silk produced in the colony. All bounties were repealed in 1666 and the latter one was reenacted in 1669 $(49$, v. II, pp. 121 and 272). The results of all of these various inducements are indicated in a resolution passed by the Assembly in 1663 .

George, the Armenian having proved the making of ten pounds of wound silk it is ordered there be paid him for his encouragement in the levy according to act $(49$, v. II, p. 199).

Silk was not included in a list of products on which prices were fixed in 1682. Although it has been in a similar list sixteen years earlier, the value then being $20 \mathrm{~s}$. a pound or two-hundred pounds of tobaceo. 
Staple Products Encouraged.-After it had been fully demonstrated that the Virginia planter's were not going to engage in the production of silk, the governunental activities were directed at other crops especially towards introducing the culture of hemp and flax. In this there was somewhat more success achieved than attended the silk campaign. It had heen ordered in 1658 by the Assembly:

That what person or persons soever shatl at any time hereafter make in this collonie so much silke, flax, hopps or any other staple commoditie (except tobacco) as is wortl two hundred pounds sterling, or English wheate to the value of five hundred pounds sterling in one yeare and exporte the same or eause the same to be exported, or shall first make two tumne of wine raized out of a vineyard made in this collonie shall have given him by this country for an eneouragement ten thousand pounds of Virginia Tolaceo (49, v. I, pp. 469-70).

Flax and Hemp.-Apparently no one qualified for the bounty on flax, for in 1661 provision was made for importing some flax seed from England. No price was fixed in 1666 on "flax by reason of the uncertainty of the quality." In 1682, bountics were offered: "for every peck of flax seede, four and twenty pounds of tobaceo, and for every peek of hempseed twenty pounds of tobacco." Bounties were also offered for hemp and flax worked up into cloth. It was also ordered that every tithable person should produce one pound of dressed hemp and one pound of dressed flax or two pounds of either annually (49, v. II, p. 50.5). From that time on considerable hemp and flax were raised in Virginia, but the bulk of the crop was used at home. About 1750 the British government began giving liberal bounties for these products exported to England which led to some being shipped overseas.

Live Stock in Virginia.-As has already been shown the domestie animals brought to the eolony in the first few years of its existence were turned out in the woods to shift for themselves. The foundation breeding animals were probably snall and this lack of care in their maintenance contributed towards inferior quality. Predatory animals as wolves, bears, and wild eats exacted a heavy toll in young animals every year. The Virginia settlements being on the mainland and contiguous with the mountain region the extermination of these animals was a slow process. So troublesome were these pests that the policy of selfprotection which prohibited the giving of firearms to Indians was 
lepeatedly violated in order that they might the more ceffertually kill wolves on which a liberal bounty was paid by the colonial g() vermusut.

Hogs. in spite of the handicaps, increased at a remarkable rater. The losies were not all oceasioned by wild animals. Hog stealers. both whites and Indians worked with little hindrance. Drastic laws with severe penalties were passed by the Assembly to prevent this erime. Hogs were marked on their ears to ristinguish rach man's animals but there soon developed droves of wild swine, that is, unnarked animals. At first, killing of wild hogs was prohibited but as that law was not obeyed it was changed so that any one killing a wild log had to have it viewed by two persons who would testify that the animal was ummarked.

Values of Dressed Meats.-No price was placed on pork or beef in 1666 as it was explained they were perishable products but in $16 S 2$ "fresh porke with head, feet and leafe or without" was fixed at 12 shillings per hundred and "fresh beefe" at 10 shillings. Tobacco at that time ras also rated at 10 shillings: per hundred. This would indieate that the business of salting and cxporting meats developed about that time. From then on, Virginia was an exporter of salt meats, much of the product going to the West Indies.

Exporting of Hides of Sheep and Mares Prohibited.-A law was passed in 1631:

That no eowe hides, oxe hides, bull hides, goate skynes, deer skynes, or other hides or skynes whatsoever, be sent or carryed out of this colony $(49, \mathrm{v} . \mathrm{I}, \mathrm{p} .174)$.

The purpose was obvious, the price of tobaceo being too low to permit the buying of clothing in England the hides were kept at home to supply this need. This law was reenacted scveral times, with beaver skins excluded from the embargo, and in 1657 it was ordered that "Hides, Iron and Wooll not to be exported" (49, v. I. p. 488). At the same time an embargo was laid on sheep and mares. Iron and hides were permitted to be exported in 1655 and the portion of the law pertaining to mares was repealed in 1668 as horses "had become very numerous" (49, v. II, p. 267).

Early in the eighteenth century sufficient wealth harl accunulated to enable some of the planters to assume airs of opulence in imitation of well-to-do farmers in England. Brick began to be used in building. Several of those carly buildings notably the 
church, court house and certain buildings of William and Mary College at Williamsburg, Va., have survived the ravages of time and are still in sound condition. Hugh Jones (1724) noted:

The Gentlemen's Seats are of late built for the most part of good Brick, and many of Timber very landsome and capacious and likewise the common Planters live in pretty Timber Houses neater than the Farm Houses are generally in England.

Alexander Spotswood, governor of the Virginia colony from 1710 to 1722 was one of the most energetic of the colonial governors and did much to improve the economic situation in Virginia. During his administration he promoted the iron industry and at its close retired to an estate on the Rapidan to engage in that work. He brought in Frenchmen to establish a wine business. He led an exploring expedition to the top of the Blue Ridge Mountains. He encouraged the building of William and Mary College, but the greatest service he accomplished was the patriotic pride and vision of the future of Virginia that he instilled in the minds of the planters.

Final Results.-Manufacturing and ship building while undertaken did not reach anything like the proportions in Virginia that these enterprises did in New England. A description written in 1765 by a Frenchman traveling in America of the ports of Portsmouth and Norfolk together with their exports is of interest as it indicates the agricultural changes that had taken place.

Portsmouth is situated on the west Side of Elizabeth river, oposite to Norfolk, which is on the East side and Capitale of a County of its name. Portsmouth is but lately setled. it has the advantage of norfolk haveing Deeper water of its side. ships of any Burden Can Come Close [to] the wharfs of which there are several very Convenient. norfolk on the other hand has been longer setled. . . . it is the most Considerable town for trade and shiping In virginia. this harbour is very safe for ships of any Burthen. this is the only part of virginia where they build any thing of ships. the $(y)$ have all the Conveniences imaginable for that purpose. there is a fine ropery here, there are plenty of masts of all proportions to be had, and great quantitys are shiped of for all parts, Especially for the havana where they have a Contract for this article. there is a Smart trade Caried on from Norfolk to the wes(t) India Islands. their exports Consists in pork, Corn, flower, Butter, Cheese, Candles, hogs fat, tallow, ham, Bacon, lumber of all kinds, shingles, Masts, Yards, and naval stores; hemp is very much eneouraged now, in virginia and grows to great perfection. Iron they have great plenty of, 
it is brought Down here from maryland, and sold at the rate of $10 \mathrm{ps} \mathrm{s}^{3}$ p. tun. that is pig Iron. I look on this place to be one of the properest on the Continent for a King's port. as to the harbour non Can be beter, and the Country is well stoked with timber, they Can make their own Cordage, they have plenty of Iron and all Kinds of navall stores. . . The produce of the Soil is hemp, Indion Corn, silk, Cotton, and great quanty of wild grapes, but tobacco is the staple Commodity of Virginia; there is now a very considerable bounty on hemp, from the Colonies, which makes many people quit the tobacco (which is now very low in England) to raise hemp how that will answer time will tell (3).

${ }^{1}$ Pounds; its price in England at the time was about $£ 7$. 


\section{('HAP'TER XII}

\section{MASSACHUSETTS AND NEW HAMPSHIRE}

The Pilgrins eame to America in 1620 with their families intending to make their homes in America. That they did not properly appreciate the importance at first of developing the agrieultural resources is evideneed by their neglecting to bring any horses, sheep or eattle with them. Perhaps they would have provided these animals if the Mayflower had been a larger ship and their wealth sufficient to buy them. The Pilgrims had little practical farm experience before coming to America although "used to a plaine countrie life and $\mathrm{y}^{e}$ inocente trade of husbandrey" before migrating to Holland (12).

Unlike previous expeditions they had no delusions of fabulous wealth to be gathered at will in the New World. Capt. John Smith of Jamestown fame had explored the New England coast in 1614 and had deseribed the country and the conditions prevailing there faithfully and accurately. He overestimated the supply of food stuffs which could be obtained from the Indians, but his judgement was based on his experience in Virginia and the tribes of Indians he found in New England in 1614. England at that time was importing large quantities of ship timber, elap boards, soap-ashes and pitch from northern European countries and Smith believed a traffic in those commodities combined with fishing would be a basis for a substantial, profitable business. It is evident that Smith's report had great influence in shaping the poliey of the Plymouth Colony.

A Fortunate Discovery.-The Pilgrims were delayed in their royage and reached New England at the worst possible season of the year-the beginning of a bitter cold winter. Their first thought after landing was to locate some Indians with whom they might barter for corn. In this they were disappointed. The Indians along the coast had been exterminated a few years previously by a virulent disease. This was a temporary misfortune but afterwards worked to the advantage of the colonists. They found an area of eleared land and pitehed their habitations on a small plain of light sandy soil. A splendid little fresh 
water stream furnished them wholesome water. The most fortunate event which hefell the Pilgrins aside from being unmolested by the savages was the finding of a quantity of com and beans which had been cached for the winter by the Indians: on C'ape Cort.

As Winslow described this event:

We went to another place which we had seen before and digged and found more corn inz., two or three Basket- full of Indian wheat and a bag of Bean. with a good many of faire wheat ears, we had in all about ten bu-hels which will serve as sufficiently for seede. And sure it was Cod's providence that we found this corn for else we knew not how we should find or meet with any of the Indians except it be to doe us a mischief (94, v. XIX, p. 320).

Building at Plymouth.-The habitations of the Pilgrims, were built in a compact village. It was thought necessary to build their houses or what might better be termed hovels closely together in order to afford protection, from Indians. The building site for each of the nineteen families in the first settlement was settled by lot. As it turned out, the fire hazard was a greater menace to their safety than the Indians.

How Squanto Saved the Colony.-Farming in New England started in the spring of 1621 , and the first instructor in agriculture at that colony was Squanto, an Indian. Squanto sometimes called Tisquantum had been kidnapped by Thomas Hunt, a sea captain with Smith's exploring expedition, (1614), along with a number of other Indians, to be sold as a slave in spain. By some means this Indian boy Squanto escaped to England where he learned the English language and was given his freedom. The evidence indicates that he was purchased by an English merchant. The friendship of this Indian in spite of the outrage he had suffered at the hands of Hunt, stood the Pilgrims in good stearl and was probably responsible for the friendly attitude of his chief Massasoit towards the colony.

The memory of Squanto together with that of Kemps and Tassore of Virginia should be held in the highest esteem. The sorvice which those three Indians rendered can not be measured, but they should be looked upon as benefactors who have contributed much to the general welfare, not only of their own day, but to all future generations. Pocahontas, through her friendship and goorl will, did much to maintain friendly relations brtween the Jamestown colonists and the Powliatan Indians. Her 
service has always and justly been highly appreciated. The assistance which Squanto, Kemps, and Tassore gave was of a more material nature, less romantic, but deserving of a prominent place in recorded history.

A Statement of Squanto's Experiences.-How Squanto happened to be in New England and the part he played in changing the Indians hatred of the English to an attitude of friendship may be gathered from the following aceount based on Bradford's History of Plymouth:

In the year 1619, Capt. Dormer was sent to New England, and with him Squanto, the Indian, as an interpreter, to endearor to make peace with the natives, and settle a colony in Massachusetts bay, but to no purpose; the Indians would not be reconciled, and, in a skirmish with them received further wounds, whereupon he proceeded to Virginia leaving Squanto on shore in New England.

The same author states further:

In Massassoiet's retinue was Squanto who had been carried to Europe by Hunt and brought to New England again. This Indian, it seems, had a very great affection for the English, among whome he had lived several years. . . . The Sachem, who had been informed by Squanto how powerful a people the English were, both by sea and land, promised himself their assistance against the Naraganset Indians, his enemies; and the English stood in no less need of his friendship to establish themselves in that country. The treaty being concluded, Massassoiet returned to his capital, leaving Squanto with the colony, who was extremely serviceable to them, not only as an interpreter, but by instructing them how to plant and manage their Indian corn, in piloting them along the coast and supplying them with fish, fowl and venison (90, v. II, pp. 248-250).

Bradford referred to Squanto as a "spetiall instrument sent of God for their good beyond their expectation." Squanto died in 1622 while on an expedition with the English.

Corn Planting in 1921. - Edward Winslow states that they were able to plant 20 acres of corn fertilized with fish and 5 acres of barley and peas the first year. This was no small undertaking. Half of those who came in the Mayflower were dead, and many of those left were ill and besides they were entirely without the aid of work animals. Bradford says it was wheat instead of barley which was seeded. It matters little which grain was sown for the English grain

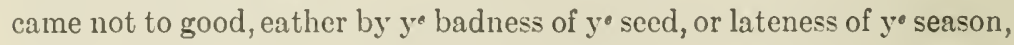
or both or some other defecte. $(12, p .121)$. 
Communistic Labor.-The Pilgrims made the same mistake that was made in Virginia by attempting to work in common. In this case they were probably influenced by Sir Thomas More's book "Utopia" as well as the merehant supporters" regulations, while in Virginia, the London Company alone was responsible for the regulation which was aimed towards keeping the control of the colony in England Civilization had not advanced sufficiently in 1620 , among the white races, so that one housewife would wash clothes for others, without extra compensation; that strong men would labor in the fields that the weak might be fed; that the shirk and drone shared equally with the ambitious, and that those who counterfeited illness should gain the same perquisities of care and attention as were given to those who were really sick.

Communism Abandoned.-The Pilgrims wisely decided to abandon the system in 1623, and each family was then assigned a separate tract of land to plant. This put new life into the enterprise. Men, women, and children flocked to the fields and an abundant harvest resulted. In 1624, Edward Winslow brought over,

3 heifers and a bull, the first beginning of any catle of the kind in $y^{e}$ land (12, p. 1S9).

This statement written by Bradford is confirmed by Josselyn who adds:

Goats were the first small Cattle they had in the Country. He was counted no body that had not a Trip or Flock of Goats (64, pp. 190192).

Private Ownership of Land.-Another change in policy in 1624 resulted in each family being granted one acre of land to be kept from year to year instead of being subject to the uncertainty of assignment by lot as had been the case the previous season. At the close of the seven year compact entered into at the beginning of the plantation twenty acre tracts " 5 acres wide on the water front and 4 acres deep" were granted and title to large tracts remote from the town site began to be acquired by the more influential of the Pilgrims (12, pp. 201-260). No meadow land was laid out. This was kept in common and yearly assigned to each family in proportion to the number of eattle owned by the family. 
Wonderful Perseverance.-Those first few years in the Plymouth Colony were exceedingly trying. The saving of grain so badly needed for food in order that there might be seed to sow, the long months of waiting and work from seed time till harvest, the tragedies of weed supremacy, stunting from droughts, destruction by animals and the numberless aceidents with which agriculturists must contend, tried the Pilgrim's faith as with fire. The Jamestown colonists while their food lasted lived in a fool's paradise ever expecting a ship load of supplies, from the London C'ompany. But the Pilgrims knew that their destiny lay in their own hands and that, if they suceeded, it would be through their own efforts. The fight they made to gain the necessities of life is one of the most heroic struggles in colonial anmals. They persevered and finally won. Eventually they accumulated a meager surplus of food. Bradford wrote for 1624 :

They begane now highly to prise come more pretious then silver, and those that had some to spare begane to tracte one with another for smale things by $y^{\text {e }}$ quarte, potle, and peck; for money they had none (12, p. 200).

Expansion.-The area of fertile land around Plymouth was too limited to provide for a large colony. The restrictions as to land holdings designed to keep the colonists in a compact town did not satisfy the more ambitious immigrants. Individual farms were taken up in 1623, in the vicinity of the present site of Boston, and soon after on the islands in Massachusetts Bay. "Many, yea most of the islands have been inhabited, some being cleared from end to end." These planter's began to raise tobacco following the popular boom for that commodity. When the Massachusetts Bay Company was formed in 1628 stem measures were adopted to stop the growing of that crop. Gor. Endicott (1628) was instructed:

To take eare that noe Tobaceo bee planted by any of the New Planters . . unless it bee some small quantitie for meere necessitic . . . and not to permitt any Tobaceo bee laden there upon our shipps (2, v. III, p. 102).

Seeds and Plants to be Sent in 1628. - A list of the supplies to be sent with the Endicott expedition in 1628 includes:

Wheate, Rye, barly, oates, a hhed of ech, in the eare, benes, pease, stones of all sorts of fruites, as peaches, plumes, filberts cherries, peare, 
aple, quince keruells, pomegranits, Woad seed, saffron heads, hiquorices seed, Rootes sent and Madder Rootes, potatoes, hop rootes, hempeseed(', fHaxe seede agenst wynter, connys (eoneys) eurrant plants and tame Turkeys (2, v. III, p. T).

How many of these were actually sent is not stated but probably most of them either in 1628 or a year later.

"Six sows with pigg" were to be purchased in 1629 from the Pilgrims at Plymouth and 42 goats "at least wise soe many of them as they can convenyently carrie" were to be sent from Fingland.

Such Cattle, both Horss, Mares, Cowes, Bulls, and Cioates, as are shipped by Mr. Cradock, are to bee deryded in Equall halves twixt him and the Companie (2, v. III, p. 90).

Settlement of Massachusetts Bay.-The great impetus to New England colonization came in 1630 with the arrival of Joln Winthrop and a large number of immigrants prepared to take advantage of the natural opportunities for raising live stock around Massachusetts Bay.

Capt. John Smith although not a believer in Puritanism testifies:

Those which are their chicfe Undertakers are Gentlemen of good estate, some of 500 , some a thousand pound land a yeare $(110$, p. 926).

The term Cicntleman was more restricted in its meaning in those days than now.

Josselyn (167t) states for 1630:

The passage of the people in the eagle and nine other vessels to New England came to 9500 pounds. The swine, Goats, Sheep, Neat, and Horses cost to transport 12,000 pounds, besides the price they cost (64, p. 252).

Thus we see several of these immigrants in striking contrast to the Pilgrims were men of means and canc well equipped with stock and tools to clear and work the land.

Difficulties in Shipping Live Stock.-The difficulties in those days of transporting live stock from Europe to America were many nor were the troubles over when the animals were landed this side of the ocean as the following items from Winthrop's Journal for 1630 clearly show:

July 1. The Mayflower and the Whale arrived safe in Charlton harbor. Their passengers were all in health, but most of their eattle dead. (Whereof a mare and a horse of mine.) Some stone horses came over in good plight. 
July 6 . The Suecess arrived. She had (blank) goats and lost (blank) of them.

Aug. 20. The French ship called the Gift came into the harbour at Charlton. She had been twelve weeks at sea, and lost one passenger and twelve goats. She delivered six.

Sept. 30. The wolves killed six calves at Salem, and they killed one wolf. . . . The wolves killed some swine at Saugus (Lynn).

$A$ cow died at Plimouth and a goat at Boston, with eating Indian Corn.

Oet. 29. The Handmaid arrived at Plimouth having been twelve weeks at sea, and spent all her masts and of twenty-eight cows she lost ten.

Nov. 11. Divers had their hay-stacks burnt by burning the grass.

Nov. 26. Many of our cows and goats were foreed to be still abroad for want of houses.

Capt. John Smith states in regard to the shipments to New England that year:

That of two hundred Cattell which were so tossed and brused three score and ten died $(110$, p. 954.$)$

Conditions Changed for the Better.-More optimistic reports were made the following years. On Oct. 25, 1631, Winthrop recorded "A plentiful Crop." And on the arrival of his son, John Winthrop Jr. and family, he says:

The people, of the near plantations, came to welcome them, and brought and sent, for divers days, great store of provisions as fat hogs, kids, venison, poultry, geese, partridges, ete., so as the like joy and manifestation of love had never been seen in New England. It was a great marvel, that so much peoples and such store of provisions could be gathered together at so few hours warning . . . and on Nov. 11, 1631 we kept a day of Thanksgiving at Boston.

Previous days of thanksgiving had been held in New England but on this occasion there were ample reasons for their being thankful.

Source of Live Stock.-Most of the horses, cattle, sheep and goats came from England and Ireland but not all. Two Dutch ships in 1635 brought twenty-seven Flanders, mares, threc horses sixty-three heifers and eighty-eight sheep from Tessell, and the next year fourteen heifers and eighty goats were brought to Massachusetts from Virginia.

Inflated Prices.-Despite the fact there wore frequent shipments of live stock to New England during the decade 1630, to 1640 , the prices steadily advanced. 
"Cattle were grown to high rates," wrote Winthrop in 1636 , "a good cow 25 pounds to 30 pounds, a pair of bulls or oxen 40 pounds, Corn was now at 5 shillings the bushel" (130, v. I, p. 206).

Bradford recorded in 1638 :

Kine were sould at 20 pounds and some at 25 pounds a peece, yea, sometimes at $2 s$ pounds. A cow-calfe usually at 10 pounds. A milch goate at 3 pounds and some at 4 pounds. And femall kids at 30 shilling: and often 40 shillings a peece. By which means ye anciente planters which had any stock begane to grow in their estats. Corne also wente at a round rate, viz. 6 shillings a bushell $(12$, p. 436).

These prices were too high to continue especially as restrictions on emigration to New England began to be laid in Great Britain.

Depression.--Johnson gives the sequel:

This spring (1642) Cowes and Cattle of that kind (having continued at an excessive price so long as any came over with estates to purchase them) fell of a sudden in one week from $22 l$. the Cow to 6,7 or $S l$. the Cow at most, insomuch that it made all men admire how it came to pass, it being the common practice of those that had any store of Cattle, to sell every year a Cow or two, which cloath'd their backs, fil'd their bellies with more varieties then the Country of it self afforded, and put gold and silver in their purses beside (62, p. 209).

Live Stock Management.-The flocks and herds required little attention. They were looked after by flock masters or herdsmen usually boys or men incapacitated for more laborious occupations and allowed to graze in common during the summer. It was ordered by the Council at New Plymouth under date of Nov. 15, 1636:

That every mans marke of his Cattle be brought to the towne booke where he lives, and that no man give the same, but shall alter any other bought by him, and put his own upon them.

Branding live stock which ran on the commons of England was a well known practice in the feudal days and branding irons are listed among the equipment of some of the early expeditions to Ameriea. Branding laws clearly indicate the status of the live stock industry of a colony.

The Plymouth colony also ordered in 1636:

That no man keepe more swine than he can ordinarily keepe about his own place, and that they be doubly rung, or at least sufficiently wrung that they roote not up and destroy the meadorrs etc. Also that from the middle of June to the last of September they be kept sufficiently. yoaked. 
And further:

That whatever damage eame to any by cowes, goats, mares, sheepr or hoggs by breaking into mens sufficient enclosures it shall be lawful for the persons so damnified to impound them, and two indifferent men to view the damage which accordingly shall be given (47).

At the time these laws were being put in foree, Cior. John Winthrop was negotiating with that troublesome preacher, Roger Williams, for the purchase of islands in Narragansett Bay, which these two enterprising Yankees eventually stocked with goats, sheep and swine, where their herds conld multiply and where there were no restricting laws to be observed.

No Fence Law.-Whether the responsibility for protection against trespassing animals rests on the owner of the animals or on the one growing the crops has ever sinee been in controversy. The so called "no fence law" which makes the owners of animals confune their stock to their own premises indicates a condition where eultivated crops are dommant. On the other hand where there is much unimproved land the reverse is the customary procedure. We will see that in some of the colonies animals were given first consideration while in others, as at Plymouth, erops were valued more highly than live stock.

Embargo on Sheep.--In the year 1737 the Plymouth colony laid an embargo:

That no sheepe be sould out of the Colonys if competent price will be hecre given for them.

More stringent rules against the sale of sheep were later passed by Massachusetts and other New England colonies and were in force during the entire seventeenth century.

Hay Making.-Forage for winter feeding consisted largely of straw and corn stalks and marsh hay. Hay making was one of the regular occupations of the New Englanders although not much is said about it in their writings except, as Winthrop occasionally recorded, a hay stack was accidently burned.

We shall see that in all of the northern colonies meadow lands, that is swamp land free from timber, were especially prized. All of the colonists who came expecting to engage in agrieulture were supplied with scythes, forks and rakes for haying. Statements by some modern writers that haymaking was an unknown practice in colonial times, is erroneous. It was so commonly practiced that it like other commonplace work was well understood and it was not thought of sufficient interest to mention. 
Salt Marsh Hay Inferior.-That the native vegetation was very disappointing can not be denied. An anonymous manuscript sent to England, in 1637 , states

IIay we have here of the low lands, such as it is, which in my opinion, is inferior in goodness to our reed and sedge in Lingland, for it is so devoid of nutritive vertue that our beasts grow lousy with feeding upon it, and are much out of heart and likeing; besides it breerds among them sundry diseawes which we know not how to eure. Some have learned to make hetter provision, by burning the grass when it is near ripe. and so suffering a new (rop to spring out of the ashes of the old. This they cut down before it be half ripe and make it into hay (57).

Grain Growing.- The chicf employment of the farmers and their families was planting and hoeing Indian corn and tending to their vegetable gardens. Many food plants thrive well in New England.

Woorl (1645) says:

There hath as good English eorne grown there, as eould be desired; especially Rie, Oates and Barley; there hath been no great triall as yet of Wheate and Beanes only thus much I affirme that these two graines grow well in Gardens (131).

A few years later however wheat growing became general probably due to the introduction of spring sown varicties. According to Hutchinson the blasting of wheat was first noticed in New England in 1664 and Josselyn states that in 1665 the "wheat exceedingly blasted and mildewed in New England" and in 1666 "the mildews and blasting of corn stil continued." Similar complaints were voiced by the Connecticut planters at that time.

Winter Wheat Introduced.-It was soon observed that wheat rust or "blasting" as it was then called was most destruetive in mirl-summer following a warm night accompanied with a heavy fog or dew. Previous to 1664, spring wheats had been found superior to the fall sown strains owing to the heavy winter killing of the latter, but the earlier maturity of winter wheat induced many New England farmers to return to the culture of those varieties. Wheat growing was never afterwards of much importance in Massachusetts.

Rye Adapted to New England.-Rye was the most dependable of the European grains in colonial New England as it is today. This was soon discovered and Winthrop made note, in 1636 "much rye was sown with the plough this year for about thirty 
ploughs were at work." "The erection of mills to grind grain indicate an increase in grain growing.

Winthrop reported in 1632 :

"The wind mill was brought down to Boston because, where it stood near Newtown it could not grind but a westerly wind."

A water mill was built at Roxbury in 1633 and three years later another wind mill was erected at Boston and water mills at Salem, Ipswich and Newbury. These mills did the grinding of grain for a large territory (130, v. I, pp. 87, 116).

Work Animals Introduced.-The introduction of work animals made a great increase in the production of maize and beans,

"For," said Johnson, "it was with sore labour that on[e] man could Plant and tend foure Aeres of Indians Graine and now (1637) with two Oxen hee can Plant and tend 30" (62, p. 154).

The scarcity of English grain was more than compensated by the Indian erops of maize, beans and squashes and the wild game and fish. These gave a much greater variety to the New England diet than the colonists had ever known in England.

Foodstuffs Plentiful.-Wood (1635) in answer to some of the criticisms of American conditions stated:

Surely that place is not miserably poore to them that are there, where foure Egges may be had for a Penny and a quart of new Milke at the same rate: Where Butter is six pence a pound and Cheshire-Cheese at five pence. . . Can they be very poore, where for foure thousand soules, there are fifteen hundred head of cattle, besides four thousand Goates, and swine innumerable (131, p. 51).

While few farmers in this country at the present time would care to exchange their condition of living in its entirety for that of the best situated planters in Massachusetts Bay during the first twenty years of that colony's history yet, it is a striking fact that most of the colonists looked upon their situation as not at all unbearable but extremely fortunate. Johnson wrote for 1642 :

There are not many Towns in the country, but the poorest person in them hath a house and land of his own, and bread of his own growing if not some cattel; beside flesh is now no rare food, beef, pork and mutton being frequent in many houses so that this poor Wilderness hath not onely equalized England in food, but goes beyond it in some places for the great plenty of wine and sugar which is ordinarily spent, apples, pears, and quince tarts instead of their former Pumpkin Pies. Poultry they have plenty and great rarity (62, p. 210). 
Garden Crops.-In the gardens of colonial Massachusetts were seeded most of the common vegetables which thrive there now, such as cabbages, turnips, lettuce, spinach, radishes, onions, peas, beans and various relishes and condiments. An item of "300 trees, cost 6 pounds" shipped to Massachusetts Bay in 1630 probably marks the beginning of New England's improved orcharding which afterwards added greatly to the fame of that region although seedling orchards had been started before that date (130, v. I, p. 47).

Orchards.-Johnson writing for 1642 says:

There are supposed to be in the Mattachusets Government at this day, neer a thousand acres of land planted for Orchards and Gardens, . . about fifteen thousand acres in tillage, and of cattle about twelve thousand neat, and about three thousand sheep (62, p. 211).

Fiber Plants.-Hemp was among the first introduced crops in Massachusetts. An enthusiastic writer said:

Hempe seed prospers so well in New England that it showith up to tenne foote and a halfe which is twice so high as the ground in old England produce it (35, v. II, p. 64).

But after the first enthusiasm had died down hemp and flax were grown only in small patches for home use. New England scarcely produced enough hemp to supply the sails and cordage for her shipping and never had any appreciable amount for export.

New England Needed a Money Crop.-While foodstuffs were cheap and after the first few years plentiful, the Massachusetts Bay colonists were handicapped with lack of money or any thing that could be turned into money to settle their accounts in England for manufactured goods. Beaver skins and other furs from the Indians were among the most valuable cash products which Massachusetts had to ship to Europe.

Iron Manufacture.-It was soon apparent to the able minds in the Massachusetts Bay Company that the colonists must depend on themselves to a large extent to manufacture goods for their own needs. To engage in manufacture they needed raw metals which were denied them by the British government. An experienced iron worker was sent over from England, in 1629, and an iron furnace was in operation in Massachusetts in 1648 which was turning out seven to eight tons a week of "bar iron as good as Spanish" (130, v. II, pp. 355-6). From that date on Massa- 
chusetts became more and more self sufficient. The needs of every farm had to be met largely by the efforts of its own household. Clothing, shoes, hats and blankets were made at home. The local blacksmith became the manufacturer of hoes, scythes and other farm tools. From these modest beginnings it was but a step in advance to supply local fishermen with clothing and twine for nets, ship builders with nails, bolts, braces, sails and cordage, merchant shippers with provisions and so in New England manufacturing began to vie with the agricultural pursuits.

New Englanders Thrifty.--Existence in colonial Massachusetts depended on industry and frugality and these developed habits of thrift and self reliance. Wealth accumulated in rural New England and this was reflected in better houses, more cleared land, bridged streams, roads, stone fences, new schools and churehes, improved live stock and warmer clothes.

As has been shown it was not a first-class, small-grain country in the seventeenth century nor did it become one later. Douglass (1750) gives the New England conditions in regard to the small grains in his day and which are the same as prevail now.

Their wheat is full of cockle 20 bushels per acres is a good ero]). New England wheat is subject to blast; some think that it proceeds from the farina fecundans ${ }^{1}$ of adjacent barberry bushes.

Their barkey is a hungry grain and affords no good malt liquor.

Their barley of four rows called French barley is not so good as that of two rows called English barley. Their oats are lean, chaffy and of a dark colour (2S).

The crops then commonly grown in England which did not become of any importance as field crops in colonial New England were the roots in general as carrots,parsnips, potatoes, artichokes, and beets. Sainfoin and alfalfa if tried were apparently considered of little worth. Peas were conmon, the seed being used for human food and the vines for winter forage.

The handicap in the feature of small grain culture, however, was counterbalanced by other advantages and New England farming during the colonial period was upon a substantial prosperous basis.

New England Described.--Here is a picture of New England in the eighteenth century as given by an Englishman:

${ }^{1}$ A term used by botanists of that period for the pollen of plants. See discussion under Connecticut. 
There is in many respects a great resemblance between New England and Great Britain. In the best cultivated parts of it, you would not in travelling througl the country, know, from its appenrance, that you were from home. The face of the country has in general a cultivated inclosed and chearful prospect; the farm houses are well and substantially built, and stand thick; gentlemen's houses appear every where, and have an air of wealthy and contented people. Poor, strolling, and ragged beggars are searcely ever to be seen; all the inhabitants of the country appear to be well fed, cloathed, and lodged, nor is any where a greater degree of independency, and liberty to be met with; nor is that distinction of the ranks and elasses to be found which we see in Britain, but which is infinitely more apparent in France and other arbitrary countries (4, 1.1, l). 61 ).

\section{NEW HAMPSHIRE}

Settlers began to take up plantations in what is now New Hampshire as early as 1623. These were mostly emigrants from Massachusetts Bay attracted by the fertile lands along the Piscatanua River. The agricultural production of that region was absorbed by the fishing and ship building industries centered at Portsmouth. The farming methods were practically the same as those of Massachusetts. By 1671 the colony was reported to be "abounding plentifully with Corne, Cattle, Timber and fish" (61). The valley of the Piscataqua was especially suitable for growing hay and other forages and live-stock plantations thrived there as they did in other favorable localitics in New England. As Massachusetts increased in population more settlers moved to New Hampshire and many cane direct under the patronage of Gorges and Mason who laid elaim to all that region. The commereial industries however, much overshadowed the agricultural pursuits. Ifurs, fish and timber were the exportable commodities.

Domesticated Timothy.-The most valuable contribution to agriculture which came from New Hampshire was the domestication of the grass since known in New England as herd's grass and in the rest of the world as timothy. In no other of the thirteen colonies was agriculture so completely subordinated to the commercial activities as in New Hampshire. This colony achieved wealth from her natural resources rather than from the soil. Her advantageous position in regard to the Inclian fur trade enabled the colony to exist and trading was more in aceordance with the wishes of the promoters of the colony than tilling the 
soil which in the case of New Hampshire could scarcely be hoped to prove profitable to the proprietors in England.

Agriculture of Secondary Importance.-There were some extensive farms in New Hampshire however owned largely by men engaged in other occupations. An Englishman wrote:

The most ancient settled parts of the province, which are Rhode Island, Connecticut, and the southern part of New Hampshire, contain many considerable land estates, upon which the owners live much in the style of country gentlemen in England. They all cultivate a part of their estates; and if they are small, the whole: this they do by means of their stewards who are here generally called overseers: the rest is let to tenants, who occupy their farms by lease, in the same manner as it is in the mother country; the rents paid for such farms being the principal part of the landlords income (4, v. I, p. 62).

The New Hampshire fisherman and traders took up farms along the coast into the province of Sagadahock now Maine. Some German settlements in that region after the French and Indian War gave promise of a successful agriculture but they did not achieve much prominence until after the Revolution. 


\section{CHAPTER XIII}

\section{NEW YORK AND NEW JERSEY}

The present site of the city of New York was the seat of a Dutch trading post for "some years" prior to 1619. No farming of consequence however was at first attempted. The reports of the Henry Hudson expedition (1609) had turned the attention of several European nations to the possibilities for colonization afforded by that locality. In order to forestall other nations from getting a foothold on the Hudson River and interfering with their profitable Indian trade, the Dutch decided to plant a colony to buttress their claim to the region. So in 1625 , with method and attention to detail characteristic of the race an expedition was equipped under the direction of Pieter Evertsen.

"One hundred and three head of cattle; stallions, mares, steers and cows . . besides all the hogs and sheep that might be thought expedient" (89),

were distributed in two ships. A third ship loaded with hay and water was sent along to insure sustenance in case of delay in the voyage. Only two animals died during the trip. The rest were landed on the island on "Manhates" which had been purchased from the Indians, for a value of 60 guilders and was "abounding with grass and pasture." In addition to these live stock there were "all furniture proper for the dairy. All sorts of seed, ploughs and Agricultural implements." Another ship loaded with sheep, hogs, wagons and ploughs followed that same year.

Inducements to Settlers.-The Dutch West India Company under whose auspices the settlement was made undertook the task of transporting the farmers to New Netherland and giving each family a, "Bouwerie, which was partly cleared, and a good part of which was fit for the plow."

Jogues (1645) says: "The first comers found land fit for use formerly cleared by the savages, who had fields here" (107).

In addition:

The Company furnished the farmer a house, barn, farming implements and tools, four horses together with four cows, sheep, and pigs in propor- 
tion, the usufruct and enjoyment of which the husbandmen should have during six years, and on the expiration thereof, return the number of eattle received. The entire increase remained with the farmer $(14, v$. I, p. 371). For all these benefits and privileges the farmers were expected to pay a yearly rental of 100 guilders and $S 0$ pounds of butter.

Began Grain Growing.-One of the Dutchmen, Schagen by name, wrote under date of Nov. 5, 1626 to the West India Company "They send thence samples of summer grain; such as wheat, rye, barley, oats, buckwheat, eanary seed, beans, and flax," and added that "They had all their grain sowed by the middle of May and reaped by the middle of August" (14, v. I, p. 37 ).

Dutch Good Farmers. - No better farmers ever eame to America than the Dutch. They were industrious and above all knew how to till the soil to make it produce. They were the first settlers to grow European grains in America on a profitable, commercial basis. A sharp rivalry developed among the Duteh settlers in their efforts to gain titles to estates.

Large land holdings, boweries or manors, were laid out along the Hudson river as far north as Albany and crop growing was soon in full swing.

Jogues states that just before he arrived in the colony in $16+5$ three large ships of 300 tons each had come to load wheat. Two found cargos, the third could not be loaded because the savages had burnt a part of their grain.

These ships came from the West Indies.

Early Type of Farm House.-The Dutch settlers in New York constructed houses of a type well suited for pioneer conditions and which was later adopted in New England and many other of the colder parts of the country as temporary living quarters until time and means were available for constructing more imposing and comfortable homes. The method of construction as given by the Secretary of the West India Company in 1650 of these houses was: They first dig a cellar six or seven feet deep as long and as broad as they think proper and floor it with planks, and wainscot it over head for a ceiling raise a roof of spars clear up and cover the spars with barke or green sods. The sides were lined with bark or boards to keep the ground from caving in (14, v. I, p. 368).

This secretary reported in 1650 that they could buy all the live stock they needed, execpt sheep, in New England cheaper 
than the animals could be shipped from the Netherlands and that all the wagons and ploughs needed were construeted in Now Netherland.

Trouble with the Government.-The owners of these manor*, called patroons, showed little appreciation of the expenditures in their behalf made by the Duteh West India Company. They were no sooner settled than they began to quarrel over the payment of rents. This did much to disorganize the colony. A contributing factor to this ill-will was the overbearing attitude of incompetent governors sent over by the Company. Hostilites with the Indians attributed by the patroons to unprovoked acts of eruelity and injustice on the part of the Governors added to the discontent. These disagreements led to the colony's tame submission in 1664, to the English and ended, for all time, Dutch rule in North America.

The change of rule from Dutch to English had no appreciable effects on the agricultural affairs of New York. The Dutch farmers remained in possession of their farms and were augmented by large numbers of Englishmen.

Orcharding in New York. - Not only did the Dutch excel in grain growing but they set out orehards of apple, pear, cherry and peach trees and had introduced the best foundation stock of horses and cattle to be found in any of the American colonies at the time.

Peaches thrived in incredible abundance and much of the fruit went to waste or was eaten by hogs. A Duteh traveler to New York in 1679 records in his diary:

We have nowhere, to my knowledge, seen or eaten finer apples. One kind was very large, fair, and of good taste, fifty-six of which only could be put in a heaped up bushel, that is, half a bag. Another variety, somewhat smaller, but not less fair in appearanee, and of a better flavor, my eomrade was aequainted with, and said they were ealled the Double Paradise. He acknowledged they were very delicate (25, p. \$3).

Clover Introduced.-This writer also gives evidence of the beginning of the practice of seeding elover with wheat.

Their adjoining corn lands (grain fields) are dry and barren for the most part. Some of them are now (October 1679) entirely covered with clover in blossom, which diffused a sweet odor in the air for a great clistance, and which we discovered in the atmosphere, before we saw the fields $(25$, p. 60$)$. 
A new seeding of the common red clover in a small grain is about the only clover plant which will meet the conditions of full bloom in Oetober and which diffuses a sweet odor in the air. Moreover as most of the grain fields were dry and barren one must conclude that the praetice was not general and that it was not a volunteer crop which this traveler observed.

Settlement of Long Island by the English.-Prior to the end of the Dutch regime, Long Island had been settled rather extensively with English farmers from New England and had become quite heavily stocked with cattle. Johnson gives 1640 as the date of the beginning of English settlements on Long Island but that was the date a church was organized. There were apparently individual settlers there a few years earlier. Johnson says:

There are many Indians on the greatest part of this Island, who at first settling of the English there, did much annoy their Cattel with the multitude of Doggs they kept, which ordinarily are young wolves brought up tame $(62$, p. 195).

This difficulty with the Indian dogs was of short duration. Denton observed a few years later for that same region,

that where the English come to settle, a Divine Hand makes way for them, by removing or cutting off the Indians either by Wars one with the other, or by some raging mortal Disease $(27$, p. 7 ).

The Island is plentifully stored with all sorts of English Cattel, Horses, Hogs, Sheep, Goats, ete. No place in the North of America better, which they can both raise and maintain, by reason of the large and spacious Meadows or Marches wherewith it is furnished, the Island likewise producing excellent English grass, the seed of which was brought out of England, which they sometimes mow twice a year $(27$, p. 5$)$.

Social Life.-The Long Islanders began breeding fast horses at an early date and they became noted for the gayety of their rural social life. As many of the settlers on Long Island migrated there from New England to escape the rigors of the religious rule of the Puritans and Presbyterians they naturally went to the other extreme as did the settlers in Rhode Island. Fox chasing was a popular sport. That making a living in America was a simple matter where there was plenty of open meadows and fields cleared by the Indians for cultivated crops is well established by the success of the settlers on Long Island and along the Hudson.

Increase in Land Values.-As New York City began to develop into a commercial metropolis the prices of fertile eleared lands 
along the Hudson and branches rose to very high figures. Smith (1757) put the values of "The Lands in the Vale of Schnectady" at 45 pounds per acre, an extremely high price for those times. Some localities began to be famed for certain products as the agriculture became differentiated or as it was adapted to the different conditions. Orange County produced the best butter and Ulster was "noted for fine Flour, Beer and a good Breed of Draught Horses" (114).

Commerce.-The West Indian commerce took all surplus produce so the farmers along the Hudson soon began farming for profit as well as for making a living. The soil and climate of that region being farorable to grain growing, the English immigrants naturally continued the same type of general farming as had been inaugurated by the Dutch. Foodstuffs from New York figured prominently in the export trade through out the colonial period.

Financial Statement of a Farm.-Nothing is more illuminating about agricultural conditions of the past than detailed statements of individual farms. Such a statement for a 1600-acre farm on the Hudson is at hand. While the exact date to which these figures apply is not given it was probably around 1765 . This tract was purchased with some minor improvements for 370 pounds sterling. Eight hundred acres were cleared at a cost of 1162 pounds. Improvements as fences ditching etc. amounted to 32 pounds (4, v. 1 , pp. 109-13).

The cost of equipment, laborers and stock is reproduced just as given with the lumbering operations, which was an important item of income the first three years, omitted.

\section{Outlay.}

Eight negroes at $3 \$ £ \ldots \ldots \ldots \ldots \ldots \ldots \ldots \ldots \ldots \ldots$

Four indented servants, at $11 £$, each, for three years. 132

Two hired by the year at New York at $12 £ \ldots \ldots \ldots .72$

Three German emigrants at $9 £ \ldots \ldots \ldots \ldots \ldots \ldots . \quad 81$

Servants, provisions, and cloathing for negroes besides what produced .................... 56

Implements of Husbandry, expenses of, exclusive of timber....................... 87

Salary of overseer three years . . . . . . . . . . . . . 110

Seed for the first crop.................... 90

Sundry expences......................... 113

Cattle ........................... 230

Provisions etc. for three years . . . . . . . . . . . . 300 
Receipls.-After the first three years of preliminary work the cropping system and the price received for the surplus produce sold off the farm each year was given as:

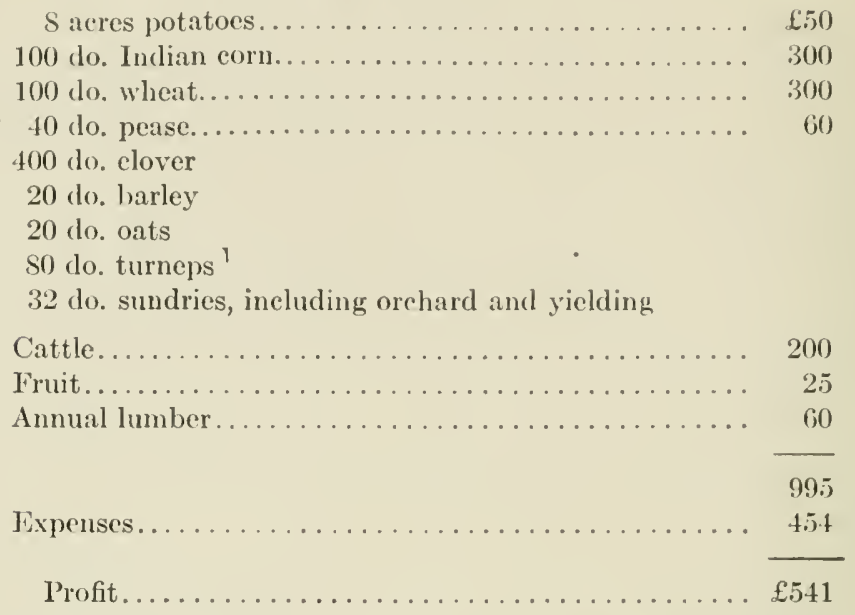

Portions of the Indian corn, potatoes, and wheat raised were used on the farm.

Of course this was an exceptional plantation and does not represent the type of farming carried on by the small land owners, with meager eapital who made up the majority of colonial farmers.

It indieates the kind of agrieulture towards which the New York farmers were striving as fast as their financial condition allowed.

Clover an Important Crop.- Not the least interesting fact about the figures in regard to the farm described above is that one-half of the cultivated land was in clover. The author quoted states that this type of cropping is diametrically opposite to the practice of the New York planters in general "who make not the least scruple of taking six or eight crops successively of maize, wheat, rye, barley, or oats, without ever thinking of the least necessity of introducing pease, buckwheat, turneps, clover, or any other plant which in its nature or culture would prove a preparation for corn."

General Farming.-Potatoes were adopted by the New York colonists as a field crop much earlier than by the New Englanders. Watered meadows, the methods used being the same as will be hereafter described under Pennsylvania, were another feature of 
their farming which deserves attention. By irrigation they were enabled to produce much larger erops of hay than are normally grown with natural rain fall. Moreover a failure of the hay crop from drought was unknown by the farmers who were fortunately situated where they could utilize small streams for that purpose.

A considerable amount of hemp and flax were grown. Flax seed was the only part exported the fiber being utilized at home for elothing and sails for ship building. The value of the average exports from New York for the three years subsequent to the close of the French and Indian War (1763) were (4, v, I, p. 124):

\section{Exports.}

Flour and biseuit 250,000 harrels at 20 .

$£ 250,000$

Wheat 70,000 qrs................... 70,000

Beans, pease, oats, Indian corn, and other grains.... 40,000

salt beef, pork, hams, bacon and venison........ 18,000

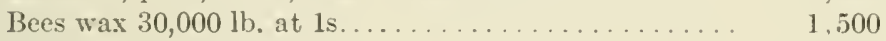

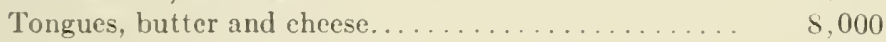

Flax seed, 7000 hhds, at $400 \mathrm{~s} \ldots \ldots \ldots \ldots \ldots \ldots \ldots$. 14,000

Horses and live stock. . . . . . . . . . . . 17,000

Product of eultivated lands.............. £\$18,500

The New-Yorkers were also selling about twenty ships a year of their own construction worth $£ 14,000$ and were exporting iron and copper to the value of $£ 20,000$. The value of the agricultural products shipped from New York was about four times that of the timber, metals and manufactured articles exported.

\section{NEW JERSEY}

The first European agriculturists in New Jersey were stragglers or squatters from New York then New Netherland. The Dutch farmers of 1625 began to take up farms across the river from Manhattan Island, but Indian raids a few years later drove most if not all of these early farmers out of that part of the country. With the wane of Indian power between the Hudson and Delaware rivers the Dutch again spread over the northern portion of what is now New Jersey. The Swedes who settled on the Delaware in the meantime had also taken up farms in the southern and western distriets. The two easy means of entry into New Jersey, the Hudson and Raritan rivers on the east and 
the Delaware on the west led to two distinet settlements and until 1703 the provinee was clivicled into East and West Jerseys.

Two Types of Soil.-There are two very different types of soil in New Jersey which are suited to distinetively different types of agriculture. The north composed largely of heavy loams and clays, is rolling and tending towards mountainous in the northwest. General grain and live-stock farming together with fruit growing are adapted to those conditions. The southern portion is light, sandy, and better suited to trucking than to grain. The Swedes confined their activities largely to the Delaware River banks taking advantage of the natural meadows along the creeks and river leaving the Dutch in possession of the northern parts.

Live Stock in New Jersey.-When the English gained control, in 1665, and undertook systematically to settle that part of America, East Jersey was already stocked with excellent horses and cattle, the original breeds coming from Holland and Sweden. It was early cliscovered that the improved animals from the Continent did not stand the adverse conditions of those early days as well as did the less improved English breeds. For that reason many animals were purchased in New England and brought to New Jersey. The crossing of the two strains gave a good general purpose breed. Some visitors to New Jersey in 1679 noted:

An ox as large as they have in Friesland or Denmark, and also quite fat-a species of which we have observed more among the Swedes, and which thrive well (25, p. 105).

Sheep raising while a useful addition to the farming industry did not reach the same degree of importance in New Jersey that it did in New England. The home needs for wool and mutton and the demand for breeding animals from the neighboring colonies took care of the increase in the flocks. It was insistently urged by the promoters that each farm should maintain at least a small flock of sheep.

Land Ownership.-The terms of land ownership granted by the Lords Proprictors, in 1664, allowed each freeman, emigrating to New Jersey the next year or who was already there, 150 acres of land, the same for each adult man servant transported there and 75 acres for each female servant or indentured youth under 16 years of age. Servants after completing their period of service were granted the privilege of land ownership (111). 
Residents of East Jersey reported the condition of the farmers around Elizabeth Town, in 16S4, as follows:

The richest planters have not above eight or ten servants; they will have some of them a dozen cows, yea some twenty or thirty; eight or ten oxen; horses more than they know themselves; for they keep breeding mares; and keep no more horses at home than they have occasion to work, the rest they let run in the wood both winter and summer, and take them as they have occasion to use them. Swine they have in great flocks in the woods; and sheep in flocks also; but they let them not run in the woods, for fear of being destroyed by wolves; Their profit arises from the improvement of their land and increase of their bestial (beasts) (111, p. 1Si).

Early Accounts of Farming.-These writers give the seeding rates of several crops at that time.

One English butt of wheat which is eight English gallons, or scots quarts, commonly sows an acre: two bushels of barley also an acre; and two bushels of oats an acre and half; English peck, which is four English quarts, or Scots shopens of Indian corn, plants one acre.

These and other writers of those days mentioned the seeding of tame forage plants. One correspondent (1683) effusively exclaimed:

Well, here is a brave country, the ground very fruitful, and wonderfully inclinable to English grass, as clover etc. It predominates over the more wild grass (111, p. 174).

East and West Jersey Contrasted.-The settlers in West New Jersey deroted relatively more attention to crop production and less to live stock than did those on the Atlantic side of the province. Their surplus products sold readily to the merchantmen who came up the Delaware to trade. This sale of foodstuffs together with a drought, in 1687, created a famine in West New Jersey which was finally relieved by a ship load of corn from New England.

Commercial bakerics were operated in a number of New Jersey towns and much of the surplus wheat was marketed as ship biscuit a sort of hard tack or cracker which would keep indefinitely.

The large number of settlers who came to Pennsylvania in the decade 1680-90 was of great assistance to the old settlers of these two provinces in furnishing a nearby demand for surplus food and animals and these New Jersey farmers were of inestim- 
able service to the newcomers in being able to supply that demand.

Farm Practices Described.-Crabrill Thomas (1698) deseribing conditions in West New Jersey says:

The Corn Harrest is ended before the middle of July and most years they have commonly between Twenty and Thirty Bushels of Wheat for every one they sow. Their ground is harrowed with Wooden Tyned Harrows, twice over in a place is sufficient, twice mending of their plow irons in a years time will serve. Their Horses commonly go without being shod; two men may elear between Twenty and Thirty acres of Land in one year fit for the plough in which Oxen are chiefly us'd though horses are not wanting and of them Good and well shap'd. A cart or a Wain may go through the middle of the woods between the Trees without getting any damage and of such land in a convenient place the Purchase will cost between Ten and Fifteen Pounds for a Hundred Acres. Here is much meadow Ground.

For East New Jersey, this same author comments:

This Countrey is exceeding fruitful in cattel of which I have seen great numbers brought from thence viz., Oxens, Cows, Sheep, Hogs and Horses to Philadelphia.

Orchards in North New Jersey.-The northern part of New Jersey like the adjoining sections of New York was famed for its orchards of pears, apples, peaches and cherries. An eighteenth century writer says:

Every farm in New Jersey has a large orchard belonging to it, some of them of a size far surpassing anything in England. The common fruits are apples and peaches, with some cherries and pears; the peaches are of a fine flavour, and in such amazing plenty that the whole stock of hogs on a farm eat as many as they will, and yet the quantity that rot under the trees, is astonishing. Apples are not suffered to go to such waste as they make cyder in vast quantities, and also export them by ship-loads to the West Indies (4, v. I, p. 139).

Newark achieved a reputation for the production of eider with which New York City was supplied.

Fiber Crops.-The growing of hemp and flax reached a higher development in New Jersey and the region around New York City than any where else in the colonies. Mitchell (1767) says:

They lately had a bounty of twelve pounds a ton granted for hemp sent to Britain by the province of New York, which expired without effect $(76$, p. 146$)$. 
But Kalm (1749) informs us that no less than ten ships were sent some years to Ireland loaded with linseed alone. There was too mueh need for the linen fiber in America, to allow large shipments of that product to be made to Europe. The flax seed was then worth about $S$ shillings a bushel or twiee that of wheat.

Exports.-Wynne (1770) gives the exports of New Jersey as 6424 barrels of flour, 168,500 pounds of bread, 314 barrels of beef and pork, 17,941 bushels of grain and 1t,000 pounds of hemp but the year for which these figures are given is not stated. This writer reports that New Jersey had the reputation of producing more wheat than any other colony (133). While this may have been true in the early years it certainly was not during the latter part of the colonial time.

New Jersey Described.-An Englishman's deseription of New Jersey agriculture is as follows:

On the most sandy parts of the province, and which to appearance are very poor, they cultivate maize to advantage; and on this sand it grows eight feet high; but in the cultivation of it they are very inattentive to its nature; sowing rye broad cast between the rows, which precludes that weeding and hoeing which is so necessary to this plant. The asparagus plant is a common weed in maize plantations here which, sowing rye, prevents the farmer from eradicating. Others, yet more slovenly, mark out the hillock for sowing the maize, and leave the intervals of five or six feet untouched. About New Brunswic, Amboy etc., and many tracts on the river Rareton, the soil is much richer, and the maize is finer: about this part the country is in general beautifully variegated, and almost entirely cultivated.

Buckwheat is very generally cultivated in New Jersey, and they find it pays them even as well as wheat, by its superior produce: they never give any other preparation to the land for it than one or two ploughings, and harrow in the seed, about a bushel and half to the acre, which yields them, if the season is wet, for dry years do not suit it, from 30 to 40 bushels on good land, and very seldom less than 28 . They make bread, or, more properly speaking, cakes of it, which are eaten by everybody, but its principal uses here, as in Europe, are for fattening poultry and hogs.

Rye is a common crop in New Jersey, which is rather surprising for wheat yields as good products. What is extraordinary, the farmers in this country sow less seed rye than in England, where two bushels are the common quantity for an acre, but here they sow only one; they commonly receive twenty in return. Barley is cultivated in common over the whole province; they sow two bushels an acre, and receire 30 to 50 
bushels; this seems to be the grain which thrives better in the province than any of the European ones.

All the bread-corn of this country yields sufficient, in the very worst seasons, to feed the inhabitants; and not only to feed them, but at a reasonable and equable price: The bread eat by the lowest ranks, whether of maize, wheat, or rye, is of the finest sort that can be gained from the grain; nor is the crop in general ever known so scanty as materially to affect the market price, which is greatly owing to the constant and regular exportation which always goes forward.

Cabbages are lately cultivated here by almost every planter in the province, the sort is the great white winter cabbage; it is not found only in gardens, but whole fields of it are common; it is eat in large quantities in every family, but the cows get no slight portion of the crop; for hogs also they are much esteemed. There are no tracts of good land in this province, with out having portions assigned to the culture of hemp; which does extraordinary well here.

To the north of New Jersey, the pieces sown with this plant are but small, but here, large fields of it are every where to be seen . . . In the most southern parts of the province, saffron is commonly planted; but the drug produced is not reckoned so good as that which is the product of England (4, v. I, pp. 134-8). 


\section{CHAP'TER XIV}

\section{MARYLAND, DELAWARE AND PENNSYLVANIA}

The first attempt at farming by white men within the present confines of Maryland appears to have been made under the direction of William Clayborne of Virginia on Kent Island in Chesapeake Bay. Clayborne was an Indian trader and had chosen that site for his business supposing it to be within the territorial limits of Virginia. It is impossible to say to what extent agriculture had been carried in this Kent Island settlement before Clayborne was dispossessed of his property and foreed to leave the colony. In 1640, Clayborne petitioned the Maryland Colony for reimbursement for "money, debts, cattle, and tobacco debts," due him from the confiscated property. A court order of that year in Maryland refers to certain tracts of land on Kent Island which had been leased by Clayborne for the yearly rental of two capons, indicating that some of Clayborne's followers remained on the Island after their landlord's departure. The value of a capon at that time (1640), was fixed at $S$ pounds of tobacco or one-half bushel of wheat.

A Well-planned Expedition.-The settlement of Maryland by Lord Baltimore was consummated in March, 1634, by an expedition which sailed from Cowes, in the Isle of Wight on November 22, 1633, taking the southern route by the Azores and West Indies. With foresight unusual with such expeditions, the adventurers stopped for some time at the "Barbadoes, the granarie of all the Charybbies Isles" and thus reached Maryland near the close instead of the beginning of winter. Moreover, they had a few weeks to prepare for planting before seeding time was upon them.

A Fortunate Location.-They fortunately found an Indian tribe preparing to abandon its settlement and remove to more remote regions.

"To avoid all occasion of dislike and Colour of wrong," wrote one of the adventurers, "we bought the space of thirtie miles of ground of them, for axes, hoes, cloth and hatchets" ( 85, p. 42), (11). 
The Indians gave immediate possession of a number of their houses and promised to remove entirely from the region at the close of that season's corn harvest a promise which was faithfully kept.

The settlement was thus marle under' auspicious circumstances. Not much can be said in favor of the Indian habitations along the Atlantic coast. But they were usually superior to what the early colonists could hurriedly construet for themselves. The Indian huts would protect life - in fact were usually teeming with life-and to take over a whole town at the commeneement of a settlement was unique in American colonization. Moreover, the white settlers obtained possession without strife or bloodshed of the cultivated fields appertaining to the town. How extensive these fields were or in what condition of productivity no record is available. From knowledge of similar situations it may be supposed they were ample and fertile enough for the immediate needs of Lord Baltimore's colony.

The settlers had a still greater advantage in living for a few months in close contact with the natives, and observing their methods of hunting, fishing and farming.

\section{Maryland Indians Well supplied with Corn.-A contemporary wrote:}

They found also, the country well stored with Corne which they bought with truck, such as there is desired, whereof they (the Indians) sold them such plenty, as that they sent 1000 bushells of it to New England, to provide them some salt-fish, and other commodities which they wanted ( 85, p. 75). ${ }^{1}$

Lord Baltimore issued explicit instructions:

That they cause all the planters to imploy their servants in planting for sufficient quantity of corne and other provision of victuall and that they do not suffer them to plant any other commodity whatsoever before that be done in a sufficient proportion which they are to observe yearely (\$5, p. 23).

In conformity to these instructions:

they procured from Virginia, Hogges, Poultrey, and some Cowes, and some male cattell, which hath given them a foundation for breed and increase; . . also set up a water-mill for the grinding of Corne adjoyning to the Town $(\$ 5$, p. 76$)$.

${ }^{1}$ This corn was given as 10,000 bushels in John Oldmixon's British Empire in America, 1708, vol. I. p. 188, a mistake which has been used by some later historians, to show the bountiful harvest of the St. Mary's settlement. See Bozman, Hist. of Md., vol. II, p. 32. 
In the same publication from which the above is quoted the prospective emigrant to Maryland is advised to take:

Seede Wheate, Rie, Barley, and Oates (the best way to preserve it from lreating at sea, is to carry it in the eare) Keruells of Pears and Apples (especially of Pepins, Pearemaines and Dusons) for making hereafter of Cider, and Perry: the stones and sceds of all those fruits and rootes, and herbes, which we desireth to have (\$5, p. 9S).

The "duson" apple is probably the same raricty that Hakluyt (15\$2) refers to when he advises explorers to take "The Apple John that dureth two yeres to make shew of our fruits," and that Mortimer (1717) spccifies as "The John Apple or Deux Ans so called from its continuing two ycars before it perisheth" $(42, \mathrm{v}$. I, p. 497) (S0, p. 537, Ed. 1717).

Tobacco Culture.-The Marylanders followed very closcly the prevailing farming practices of the Virginians. Tobacco bccame their first staple crop but to insure against famine every one engaged in the planting of tobacco was required to plant two acres in corn. Tobacco prices at the time of the Maryland settlement were much lower than prevailed when the Virginians first began growing it. Nevertheless, the soil and climate of lower Maryland are well suited to tobacco and it furnished the desideratum of an cxportable product. The settlers in Maryland plunged into tobacco culture on an extensive seale much to the concern of the Tirginia planters. They soon found as had the Virginians that only the very best grades paid for shipment. An inspection law was passed in 1610 and all damaged tobacco, that is, leaves injured by contact with the soil or spoiled in curing, was ordered burned. Two inspectors were appointed in each county to riew and pass on the quality of all tobacco offered for shipment out of the colony and no tobacco could be legally exported without this inspection. Tobaceo became legal tender in payment of debts and taxes and the basis for fixing values of other commodities.

Live-stock Industry.-The status of the live-stock industry in the carly settlement is well indicated by a law enacted in 1640 which reads:

Every man shall fence his corne and other ground against Cattell at his own perill. And the owner of Swine may not be compelled to law his swine. 
Twenty-one years later this law was modified so that a man having a fence five feet high "strongly made" might collect damages for injury to crops caused by trespassing animals.

The various breeds of animals, not needed for work, were turned out to shift for themselves in the woods. A branding law for hogs was passed in 1649 and provision made for registering each owner's mark. This was extended to include cattle the following year. In 1662 it was ordered that:

Hog stealers were to be burned in the shoulder with a Letter $\mathrm{H}$ with a red hott Iron and that such an Iron be provided for every County Court.

By 1661, there were quite large herds of wild cattle that is unmarked animals, about the settlements and permission was granted for hunting these, the profits from which were to accrue jointly to the hunter and the Lord Proprictor. This law was soon repealed probably because the hunters were not over careful in distinguishing the marked from the wild animals (6).

Price Fixing.-An act was passed by the Maryland colonial legislature in 1662 for the encouragement of the sowing of English grain. These grains were made legal tender at the following valuations, wheat 5 shillings, barley and English peas 3 shillings, rye 4 shillings, and oats 2 shillings the bushel or about one shilling a bushel higher than prevailed in New England at that time.

Land Titles.-The conditions for gaining title to land in the Maryland Colony are of interest as they had much influence on its subsequent development. The first adventurers apparently came with no further assurance of land ownership than oral promises made by the Lord Proprietor, but there is no evidence that any attempt was made to work in common. The settlement at St. Mary's was probably looked upon as a temporary abiding place preparatory to a general dispersion over the colony.

In 1636 Lord Baltimore laid down the terms for allotment of land under his official seal.

Every adventurer in the first expedition who had transported five men between 16 and 50 years of age was to receive 2000 acres of land for a yearly rental of 400 pounds of good wheat. An individual who did not transport five men was to receive one hundred acres for himself, a like area for his wife if he had one and for each servant, and fifty acres for every child under the age of sixteen. For this he was to pay a yearly rental of 10 pounds of wheat for every fifty acres. 
Those who should arrive after 1635 were promised 1000 acres for every five men they transported to the colony the rent of which was fixed at 20 shillings a year, payable in the country's produce. The individual grants of one hundred acres for each adult and fifty acres for each child remained the same, the rent being placed at twelve pence for every fifty acres. These tracts were granted to these persons and to their heirs forever.

Titles of Nobility.-Charles I had given Lord Baltimore the privilege of granting titles of nobility provided they were not the same as those used in England. It is readily apparent that the proviso practically nullified the privilege. A title without prestige or emoluments is an unattractive honor. The following order by Lord Baltimore was probably intended to give value to any titles which he chose to grant:

And we do further will and authorize you, that every two thousand acres, and every three thousand acres, and every one thousand acres of land so to be passed or granted as aforesaid unto any adventurer or adventurers, be erected, and created into a manor to be called by such name as the adventurer or adventurers shall desire. And we do hereby further authorize you, that you cause to be granted unto every of the said adventurers within every of their said manors respectively, and to his or their heirs a court-baron and court-leet, to be from time to time held within every such manor respectively (11, v. II, pp. 36-40).

The colony was accordingly divided into many manors or as more frequently designated hundreds and the nearest approach to the feudal system ever existing within the bounds of our country flourished in the neck of land between the Potomac River and Chesapeake Bay. The feudal system was based on respect and loyalty of vassals to their lord. Such could not exist in a new country when fire arms rendered physical prowess of secondary importance. The serfs of the old system were supplanted in the new by negro slaves whose loyalty could be enforced and the need of court-leets and court-barons provided for in Lord Baltimores order no longer existed. The terms for granting land were considerably modified in 1648 but still bid for the favor of wealthy immigrants.

Indentured Servants.-The liberal inducements in land offered the prospective settler in Maryland attracted many men of influence. By advancing the transportation charges for ten men across the ocean the promoter received an estate of 2000 acres at a nominal annual rental. Moreover by the system of inden- 
ture in practice at the time, those transported were made to reimburse with stipulated years of service the cost of their passage. Many poor people in Europe were anxious to try their fortunes in America and would sign away their freedom for years in order to come. Indentured servants were of two classes, adults who voluntarily agreed to the articles of indenture and minors who were indentured by their parents. The population of all of the colonies was augmented by this system. Many laws were passed to curb abuses of indentured servants.

The masters were compelled to furnish food and clothing to the servants and to provide them with means of gaining a livelihood after their period of service expired. It has been shown already how the London Company extended the privilege of land ownership to servants in Virginia who had complied with the terms of their contract. Some servants were indentured for an indefinite period of service and some appear to have been indentured by law after their arrival contrary to promises previously made.

Period of Service of Indentured Servants.-A law passed by the Maryland legislature in 1638 is typical of many colonial regulations relating to this subject. Extracts from which read:

Be it enacted by the lord proprietarie of this province, of and with the advice and approbation of the freemen of the same, That all persons being Christians, (slaves excepted) of the age of eighteen years or above, and brought into this province at the charge and adventure of some other person, shall serve such person at whose charge and adventure they were so transported for the full term of four years only, to commence from his or their arrival in the province, (except any other time were contracted for by covenant)...

And all persons under the age of eighteen years transported into this province at the charge and adventure of some other person, shall serve such person at whose charge he or they were so transported, until such person or persons so transported shall be of the full age of four and twenty-years, (except likewise any other time were contracted for by covenant).

And every maid servant being Christian . . . of the age of twelve years old or under, shall be bound to serve . . . for seven years; and if she be above the age of twelve years, she shall serve for four years only . . . and at the end of any of the said termes of service expired, the master or mistress . . . shall give unto them three barrels of corn, (approximately 15 bushels) a hilling hoe, and a weeding hoe, and a felling axe; and to a man servant one new cloth suite, one new shirt, one pair of new shoes, one pair of new stockings, and a new Monmouth Capp: And to a maid servant, one new pettycoat and waistcoat, one new Smock, 
one pair of new shoes, one pair of new stockings, and the cloaths formerly helonging to the servant (11, v. II, pp. 612-3).

Gain in Wealth.-Maryland passed through the periods of Indian skirmishes, religious disputes, and eivil wars of the seventeenth and early years of the eighteenth centuries without much set-back to her agricultural development. Her land-owning aristocracy accumulated wealth and built large commodious homes. The tobacco grown in Maryland while produeing heavy yields could not command as high prices as the finer grades of North Carolina and Virginia. Nevertheless with slave labor it was a profitable crop to grow.

As the settlements extended into the higher parts of the colony, with heavier soils, tobacco culture was superseded by grain growing and general farming. The agriculture of western Maryland was simply an expansion of the Pennsylvania farming with wheat the leading crop supplemented with maize, rye and barley.

The usual patches of hemp and flax were grown for home consumption and a little fiber was exported.

\section{DELAWARE}

The first settlements in Delaware were intimately associated in history with that of New York. The Dutch West India Company whose claims to territory extended as far south as Cape Henlopen, made two or three attempts to set up trading posts on the Delaware River none of which were successful.

Swedish Settlements.- It fell to the lot of another European nation which could boast no rights of discovery but which has furnished this country many of its most useful citizens, to plant the first permanent settlement in that part of America. Peter Minuit the first Governor of New Netherland was deposed in 1633 , and afterwards had the personal satisfaction of leading an expedition of Swedes under authority of the Swedish government and setting up in 1638 where Wilmington now stands, a rival trading post to that at New Amsterdam. There is no evidence that any farming was attempted until 1640 when several companies of emigrants from Stockholm with "cattle and implements of husbandry" arrived (34). A larger and better equipped expedition was sent in 1643 under the leadership of John Printz which made a settlement on the west bank 
of the Delaware River near the present city of Chester, $\mathrm{Pa}$. Printz was instructed:

To promote diligently all profitable branches of industry; immediate eulture of grain and other vegetables; afterwards procuring good race of cattle, sheep, and other animals, in addition to those sent from Sweden; raising large quantities of tobacco, by appointing many labourers, and skilful managers, for exports to Sweden; . . . gradual increase of sheep for a surplus of wool to the mother country; . . . trials of mulberry trees for breeding silk worms: of the native grape for wine, and of the walnuts for oil $(34$, p. 63).

Swedes Were Agriculturists.--The Swedish settlers on the Delaware were an agricultural people, their time was occupied in tilling their fields and caring for their stock. Unfortunately the ambitious schemes, which prompted the settlements were allowed to languish from non-support by the less ambitious rulers who afterwards gained control of the home government. The Swcdes in America took no part in the exploits which figure in written history. That they were good farmers is evidenced by the testimony of William Penn and others. That they were peacefully inclined is proved by their freedom from trouble with the Indians. That they were clannish is shown by the perpetuation of their language, manners, religions and customs while surrounded by great numbers of other white races. That they were of inestimable help in the upbuilding of the agriculture of Delaware, New Jersey and Pennsylvania, by furnishing improved live stock to the English settlers when they came to that region, is testified by numerous witnesses. Beyond these facts little is known of their activities.

Swedish Influence.-There were several bloodless battles fought on the Delaware and the Swedes in 1655 came under the rule of the Dutch and ten years later under their conquerors, the English. It mattered little to these agriculturists who were the rulers. They continued to clear land, plant crops, make their own clothing, and live in peace. The character of their agriculture was similar to that of the other neighboring settlements of the time. Large meadows along the river furnished hay to winter their stock. Foodstuffs could be grown in abundance. They had few wants which they could not satisfy themselves. Hemp, flax and sheep gave them raw materials to manufacture into textiles for their own use. The abundant use of buckwheat in the three colonies where the Swedes settled appears to trace 
back to these settlements. The quick-growing buckwheat, while known in most parts of Europe, was grown as a staple crop only in the extreme northern countries. In colonial times buckwheat flour was especially popular for cakes for human food and the seed was used to feed swine and poultry.

The later agricultural history of Delaware under the proprietorship of William Penn and his heirs differed little from that of New Jersey and Pennsylvania.

\section{PENNSYLVANIA}

Farming was started in the region now known as Pennsylvania, about 1643, by the Swedes who settled in the south-eastern corner of the State on the fertile lands of Chester up to and including the present site of Philadelphia. Little is known of their agriculture. In 1693, in an appeal for a minister to be sent from Sweden they described their own condition in the following terms:

Almost all of us are husbandmen; we plough, and sow, and cultivate the land; and as to our meat and drink, we live according to the old Swedish custom. This country is very rich and fruitful: it produces, God be praised, all sorts of grain, all that we plant and sow gives us plentiful returns, so that we are richly supplied with meat and drink, and we send out yearly to our neighbours on this continent and neighbouring islands, bread, grain, flour, and oil, . . . Our wives and daughters employ themselves in spinning wool and flax, and many of them in weaving, so that we have good reason to thank the Almighty for daily support.

Swedish Farming.-Biörk one of two preachers sent in response to this appeal wrote home in 1697 :

There are no poor in this country but they all provide for themselves; for the land is rich and fruitful, and no man who will labour can suffer want.

His colleague Rudman, the same year reported:

The houses are built after the Swedish manner; the women brew excellent drink as in Sweden; they have also a liquor made of apples or peaches which they call cider; it is very pleasant to the taste, and very wholesome (52, pp. 90-100-102).

The Swedish farmers had become quite widely scattered over a considerable region. They had appropriated to themselves land to which neither they nor their country had any claim that 
was sanetioned by international law. First the Dutch and afterwards the English tried to dispossess these Swedish farmers of their holdings but they elung so tenaciously to their farmsteads that in most cases they were finally allowed possession of the fruits of their toil in clearing their fields for tillage and other improvements.

Penn's Settlement.-The first expedition of English, which came to Pennsylvania after William Penn received a patent to that province, was in 1681. Penn was extremely liberal in his policies both as to granting titles to land and also in religious toleration. His benevolent spirit attracted the oppressed in countries on the continent of Europe. Pennsylvania became the haven of refuge not only to the Quakers for whom the colony was established but also to the Dutch, Germans and Welch who were dissatisfied with their conditions at home. Among the mixed population which flocked to "Penn's Woods" were skilled mechanics merchants, shippers, doctors, teachers as well as farmers. More than two thousand settlers came to Pennsylvania the first year of Penn's regime. Among the industries established under Penn's encouragement were a tannery, a saw mill, a flour mill and a glass factory.

Title to Land.-Penn gave individual titles to land but not in such enormous tracts as prevailed in the southern colonies. Each servant whether man or woman was granted fifty acres of land when his or her period of service was completed, and each freeman was entitled to fifty acres of land for each servant he kept in addition to his own individual grants of the same amount or more under special arrangement with Penn. Penn frequently instructed his secretary to draw warrants for grants of 500 acres. Grants for much larger areas to groups of colonists were sometimes made.

Servant Class Prominent.-While many of the colonists who came to Pennsylvanis should be classed as wealthy the great majority came as indentured servants. The usual cost of passage for this class of emigrants from Europe to America was $£ 10$. Ship eaptains frequently solicited their passengers from among the poorer classes with the understanding that their services for a stated period usually three years was to be sold to some colonial planter to reimburse the ship owners for the cost of transportation. Each captain usually made a few pounds additional profit on the transaction. While negro slaves were quite com- 
non in Pennsylvania, and there were many free laborers, white servants indentured for definite service were most in demand. They were dependable and the laws of Pennsylvania compelled the employers to feed and elothe them properly. The same system was in operation in the other colonies but for some reason more of this class of servants eame to Pennsylvania than to any other. Not infrequently those possessing sufficient money to pay their passage voluntarily indentured their services, first to gain experience and secondly to save their capital to invest in land. This elass of people usually beeame free holders of small tracts after their release.

Building a Pioneer Home.-The process of creating a home with meager capital is given by a competent obscrver.

They fix upon the spot where they intend to build the house, and before they begin it, get ready a field for an orchard, planting it immediately with apples chiefly, and some pears, cherries and peaches. This they secure by an enclosure, then they plant a piece for a garden; and as soon as these works are done, they begin their house: some are built by the countrymen without any assistance, but, these are generally very bad hovels; the eommon way is to agree with a carpenter and mason for so many day's work, and the countrymen to serve them as a labourer, which with a few irons and other articles he cannot make, is the whole expense: many a house is built for less than twenty pouncls. As soon as this work is over, which may be in a month or six weeks, he falls to work on a field of corn, doing all the liand labour of it, and from not yet being able to buy horses, pays a neighbour for ploughing it; perhaps he may be worth only a calf or two and a couple of young eolts, bought for cheapness; and he struggles with difficulties till these are grown; but when he has horses to work, and eows that giv'e milk and ealves, he is then made, and in the road to plenty. It is surprising with how small a sum of money they will venture upon this course of settling (4, v. I, p. 190).

First Clearings Often Sold.-The settler who possessed a hundred pounds or more could usually buy one of these farms that had been partially improved for much less than the labor spent on it was worth. The pioneer taking the proceeds of the sale and moving farther back would take up a larger tract which he then was able to stock and equip-thus were great tracts of America brought under cultivation. In Pennsylvania it led to a dense rural population of land-owning farmers, the condition cited by rural economists as most beneficial to a commonwealth. 
Help from Surrounding Settlements.-The agrieultural foundation laid by the early Dutch and Swedish settlers in New Jersey, New York, and Delaware was of great value to Penn's followers. Here were excellent draft horses, oxen, dairy cows and swine in numbers to supply all the neweomers who possessed the necessary means to buy them. Penn was a leader in agricultural advancement. He imported well-bred horses, experimented with grass growing and encouraged his people in agricultural improvements. To his Secretary James Logan must be aseribed the honor of being the first scientific agriculturist in this country. Logan's observations on the botanical nature of maize were remarkable for their accuracy (7).

$\mathrm{He}$, it was, who after careful experimentation first recorded how the grain of maize resulted from the union of the pollen of the tassel with the silk of the ear. Several generations of Logans have had a remarkable influence on Pennsylvania farming.

Botanical Gardens. - The great number of new and strange plants which the discovery of Ameriea gave to the world offered immediate compensation to those who first gained a knowledge of the behavior of these plants under cultivation. Several private gardens established primarily for testing new plants were conducted in Pennsylvania. A few of the nobility of England as Lords Petre and Bute, and the Duke of Argyll did much to encourage the introduction of American plants into Britain. The patronage of some of these wealthy lovers of plants whose order's were usually handled through a clearing house for botanists conducted by Peter Collinson a public spirited merchant of London, induced John Bartram of Pennsylvania to start a botanical garden in 1730 on the banks of the Schuylkill river about three miles above Philadelphia. Bartram was an incessant collector, an accurate observer although comparatively unerlucated, a great traveler and he detected and collected more different species of American plants than has any other man of his time. Bartram was a thrifty Quaker and was able to finance, through the sale of seeds and plants, his travels and increase the extent of his garden. He afterwards received an appropriation of 50 pounds a year as Royal Botanist in America. Bartram has been generally credited with having started the first botanical garden in America. Several other notable gardens were conducted in eastern Pennsylvania. 
Pennsylvania Dutch Were Thrifty.-The Duteh and German farmers in Pennsylrania like their kinsmen in New York were thrifty and frugal. Every member of their fanilies labored and as a result in a few years the Pennsylvania Dutch possessed good farms well equipped with barns, tools and stock. The absence of navigable streams to the interior did not deter these carly farmers from penetrating inland and occupying the best land in Eastern America now Lancaster County. In 1750 Douglass says:

There may be from 7000 to 5000 Dutch Waggons with four horses each that from time to time bring their produce and traffic to Philadelphia from 10 to 100 miles distance.

Accumulation of Wealth.-Pennsylvania became the most wealthy and flourishing agricultural colony of the country. General farming, grain growing, tobacco and live-stock husbandry became the leading features of this agriculture. If measured by production per acre the average farming of the Penusylvania colony is probably not equalled there at the present time.

Wheat Growing. - Wheat beeame the leading cash erop in Pennsylvania and contrary to the prevailing conditions in most of the other colonies maize took a secondary position. What Indian corn was grown was mostly utilized on the farms. It should be remembered that wheat harvesting and threshing in colonial times required much more hand labor than it does now. The ripe grain was cut with sickles, bound into sheaves, cured and stacked or barned. The threshing scason lasted throughout most of the winter and was done with flails. After threshing the chaff was winnowed from the grain by tossing the mixture in the air on a windy day or into currents of air from a winnowing fan. The use of horses to trample out the grain on a threshing floor did not come into general practice till near the close of the period.

Manuring to Increase Production.-Many expedients were adopted to inerease production. Manure was limited owing to the fact that the live stock was mostly reared in the open but what they had was as well utilized then as it is now. Ditches were dug to bring small streams along the contour of the hills sometimes for a mile or more, to irrigate their meadows. The top-soil from banks of these streams after they had become 
enriched by sediment from the water for a few seasons, were carted to their grain fields and spread on the land.

Crops Produced.-Penn writing under date of 1683 says:

The artificial produce of country is wheat, barley, oats, rye, peas, beans, squashes, pumpkins, water-melons, musk-melons, and all herbs and roots, that our gardens in lingland usually bring forth. . . . We have no want of horses; and some are very good, and shapely enough; two ships have been freighted to Barbodoes with horses and pipe-staves, since my coming in. Here is also plenty of cow-eattle, and some sheep; the people plow mostly with oxen (93).

One of the early Duteh colonists wrote to a friend in Holland:

The country produces all kinds of cereals similar to what we have here, together with Indian corn of different kinds, and similar beans and peas. Possibly rice may also be cultivated. Peas, kitchen vegetables, pumpkins, melons, roots, hemp, flax, hops, and all other sorts of garden produce flourish and recompense such as cultivate them richly for their labor. Domesticated fruit trees mature quickly, so that the husbandmen ean enjoy the fruit therefrom within seven years. Peaches and eherries are plentiful here and increase spontaneously like weeds. The Europeans who have no trade support themeelves ehiefly by agriculture and breeding cattle. . . . The chief commerce of Pennsylvania is with the Bermudas, Barbodoes, Jamaica and Antigna, to which are shipped flour, ship-biscuit, strong beer, butter, cheese, smoked and salted meats, salt fish ete. (103).

Tobacco Inferior. Rice and Silk. - While considerable tobacco was produced its quality was inferior to that of Maryland and Virginia and did not sell at a price which made its culture profitable. Some rice and silk were produced in the latter part of the colonial period. About 1770 the planting of mulberry trees to feed silk worms had quite a boom in Pennsylvania and New Jersey and a filature for unwinding cocoons was established at Philadelphia. A fund of more than 850 pounds sterling was raised by subscription among the public spirited citizens with which to finance the enterprize. Prices offered to prospective silk raisers for cocoons were to be 25 per cent more than the prevailing prices in Georgia which we will see were subsidized to twice what the actual silk was worth. A prize of 15 pounds sterling for the largest number of cocoons of not less than 30,000 reared by one family and a second prize of 10 pounds for the sccond largest number of not less than 20,000 worms were offered. Even these liberal terms failed to stimulate silk 
raising and, while the boom was carried on for a few years by nurserymen who had mulbery trees to sell, interest in the project quickly subsided among the farmers.

A Farm Described.-Crevecour gives a letter purported to have written by a Russian gentleman describing a visit in 1769 to the farm of John Bartram the botanist. This gives an unusually intimate and vivid description of the farm life in Pennsylrania of that time as the following extracts show:

We went to riew his farorite bank (dike or levee); . . and we walked over the ground: which had already been drained. The whole store of nature's kind luxuriance seemed to have been exhausted on these beatiful meadows; he made me count the amazing number of cattle and horses now feeding on solid bottoms, which but a few years before had been covered with water. Thence we rambled through his fields, where the rightangular fences, the heaps of pitched stones, the flourishing clover, announced the best husbandry, as well as the most assiduous attention. His cows were then returning home, deep-bellied, short-legered, having udders ready to burst; seeking with seening toil, to be delivered from the great exhuberance they contained. He next showed me his orchard, formerly planted on a barren, sandy soil. but long since converted into one of the richest spots in that vicinage." This (said he) is altogether the fruit of my own contrivance. I purchased, some years ago, the privilege of a small spring. about a mile and a half from hence, which at a considerable expense I have brought to this reservoir; therein I throw old lime, ashes, horse-dung, etc.. and twice a meek I let it run, thus impregnated. I regularly spread on this ground. in the fall, old hay straw, and whatever damaged fodder I have about my barn. By these simple means I mow, one year with another, fifty-three hundreds of excellent hay per acre, from a soil which scarcely produced five fingers (i.e. Cinquefoil or Potentilla Canadensis $L$.) some years before." "This is, sir, a miracle in husbandry; happy the country which is cultivated by a society of men whose application and taste lead them to prosecute and accomplish useful works." "I am not the ouly person who do these things (he said); wherever water can be had, it is always turned to that important use; wherever a farmer can water his meadows, the greatest crops of the best hay, and excellent after-grass, are the sure rewards of his labours. With the banks of my meadow ditches, I have greatly enriched my upland fields; those which I intend to rest for a few years, I constantly sow with red clover, which is the greatest meliorator of our lands. For three years after, they yield abundant pasture; when I want to break up iny clover field: I give them a good coat of mud, which hath been exposed to the severities of three or four of our winters. This is the reason that I commonly reap from twenty-eight to thirty-six 
bushels of wheat an acre; my flax, oats and Indian corn I raise in the same proportion" (26).

Lead in Agriculture.-It was stated by a writer in 1755 that Pennsylvania produced enough provisions to feed its own population estimated then at 220,000 and "a hundred thousand men besides" (112).

Unlike the other colonists the Pennsylvanians devoted their entire attention to the production of wealth and made no efforts towards maintaining a militia or to make other preparations for war until forced to take action by the French and Indian encroachments during the war of that name. A comparison between Pennsylvania and any of the other colonies shows clearly the destructive force of the colonial struggles.

Lead in Scientific Knowledge.-Philadelphia became the center of scientific thought and learning. Franklin's Society for the Promotion of Useful knowledge organized about 1743 did not wholly neglect the subject of agriculture.

Why cannot the gentlemen of Philadelphia, and its neighborhood, who are lovers of agriculture, form themselves into a society for the encouragement of that noble art?

wrote a man who had visited that eity in 1774 (4, v. 1, p. 180).

It may be of interest to note that this was accomplished in 1785 and the Philadelphia Society for Promoting Agriculture was the first of several such organization which came into being soon after the Revolution.

Agricultural Exports. - The annual exports of agriculture products from Pennsylvania after the French and Indian War and their value were given as:

Biscuit flour, 350,000 barrels at 20 s. $£ 350,000$

Wheat, $1,000,000$ qrs. at $20 \mathrm{~s}$. 100,000

Beans, pease, oats, Indian corn, and other grain. 12,000

Salt beef, pork, hams, bacon and venison ..........

Bees wax 20,000 lb. at $1 \mathrm{~s}$

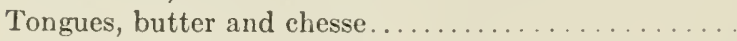

Deer and sundry other sorts of skins

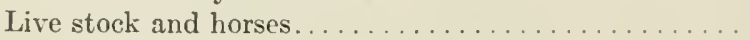

Flax seed 15,000 hidds. at 40 s.

In addition twenty-five ships worth $£ 700$ each were built and sold yearly, iron and copper to the value of $£ 35,000$, were exported 
besides timber products worth $£ 35,000$. A comparison of these figures with those for New York for the same period show that Pennsylvania led in production of wheat and live stock while behind her rival in the exporting of maize and other grains. The productions of New Jersey were probably about equally divided between the two exporting cities New York and Philadelphia.

Summary.-The success of the Pennsylvania Colony was promoted by several factors, chief among which, might be mentioned: (1) Large areas of fertile soil; (2) a population made up of intelligent and industrious people; (3) a nearby supply of excellent breeds of live stock especially horses and cattle for labor and increase; (4) an established commerce in foodstuffs from the Delaware River to the West Indies which furnished them a market for surplus grains and other products; (5) freedom from the disastrous consequences of Indian Wars which handicapped many of the other colonies. 


\section{CHAPTER XV'}

\section{CONNECTICUT AND RHODE ISLAND}

The great influx of immigrants to Massachusetts Bay about 1630 rapidly took up for cultivation all the arable land in that vicinity. 'To elear the heavily wooded rocky hills meant a long period of laborious effort before harvests could be expected. The Plymouth Colony at that time was becoming cramped for land to plant. Coincident with this situation came glowing accounts, first from the Duteh of New York and then from Indians, of large meadows, level land and fertile soil to be had for the taking on the Connecticut River. A trading expedition from Plymouth was sent to that river in 1633. These adventurers found a Dutch settlement already established at the present site of Hartford which they passed and built a trading post at Windsor. The report of these explorers confirmed the previous accounts of the large extent of eleared land, free from rocks and of high quality in the Connecticut Valley.

Plans to Colonize.-Proposals were made to Massachusetts Bay Colony by Plymouth for the two settlements to join together in settling the Connecticut country. While the Massachusetts Bay authorities frowned on the proposition as impracticable nevertheless two years later, October 15, 1635,

about sixty men, women and little children, went by land towards Comeeticut with their cows, horses and swine, and after a tedious and difficult journey, arrived safely there (130, r. I, p. 171).

The usual delays incident to such adventures resulted in their arriving too late to build houses for the winter. A few stayed but others made their way to the river's mouth where they found a boat and returned to Boston to spend the winter.

Connecticut Settled.-Nothing daunted a larger expedition with horses, eattle, sheep and swine made the orerland journey early in 1636.

Pastor Hooker and his congregation took one hundred and sixty eattle and others were equally well provided. In that year the settlement in Connecticut Valley, the largest single area of fertile land in New England, was consummated. 
One of the first acts of the first court set up in Conncetient April 26, 1636 provided for the sale for public benefit of many "strange swine," which were doing danage in the corn fiedds (21). These were probably animals which had been abandoned by their owners the previous year.

Live-stock Industry.-Live-stock husbandry became the leading enterprise of the Conmecticut settlers. The natural meadows furnished hay for winter feed and the woods unlimited range for summer grazing. The eattle and sheep were combined into flocks and herdsmen usually boys were assigned to look after them to prevent straying and to bring the animals home at night. Hogs were ordered to be "ringed and yoked" and were then allowed to run at large. Planters were required to fence their erops and much of the work of the early courts in Connecticut consisted in appointing fence viewers, assigning responsibility for damage done to grain fields by trespassing animals. In 1649 hogs were banished to the west side of the river beeause they were injuring the meadows on the eastern side.

Land Grants.-The allotment of farms was in keeping with the devolopment of a live-stock business. The title to land was apportioned in the ratio of one acre of the choice meadow to about eight acres of upland forest. Holdings at first ranged up to t0 to 100 acres of meadow and 300 to 600 aeres of timber depending on the possesions and influence of the grantee.

At New Haven, in 1643, over 2000 acres of salt and fresh water meadow had been assigned to 123 land owners representing 431 persons ( 87 ).

Regulatory Laws.- Referenees are made in the diseussion of some of the proprietary colonies to the irritating rules and regulations laid down for their management by the promoters in England. But no Lords Proprietors or Royal law makers ever coneeived of such minute paternalism as was self-infleted in the republic of Connecticut. Scemingly every thing was regulated by statute. A few of these "court orders" and laws which related to agrieulture are worth mentioning.

Day wages of common farm laborers were fixed in 1660 at 2 s. in summer and 1Sd. in winter. Carpenter's wages were 2 s.6d. and 20d. respectively for a twelve hour day. Expert mowers received the same wages as earpenters or $3 \mathrm{~s}$. an acre in piece work. These wages prevailed for a number of years and were reported as "deare" in 1680. 
The prices of farm produce were fixed in numerous statutes. Wheat $4 \mathrm{~s}$. a bushel, peas and rye $3 \mathrm{~s}$., Indian corn $2 \mathrm{~s} .6 \mathrm{~d}$., pork $3 \mathrm{~d}$. a pound, beef $2 \frac{1}{2} \mathrm{~d}$. a pound, were the customary figures set in the seventeenth century. This was an essential law, in the absence of money, to facilitate exchange.

Embargos on the shipment of grain were usually ordered whenever there was danger of Indian attacks.

Branding laws relating at first (1644) to ear marks of hogs and sheep and afterwards (1665) extended to horses and cattle were passed and provisions made for recording markings adopted. Each town had a special mark, a single letter until the alphabet was exhausted, branded on the "near shoulder" of its horses (21, v. I, p. 118 , and v. II, p. 28 ).

The exportation of horses was prohibited in 1660 unless a description of the peculiar markings of each animal was filed with the Court. This of course was to prevent the sale by others than the rightful owners of horses from the common herds.

In 1656 , it was ordered:

That no Butcher, by himselfe or any other person, gash or cutt any hide of ox, bull, steare or cow, in fleaing thearof, whearby the same shall be impayred, under the penalty of 12 d. for every such gash in hyde or skin (21, v. I, p. 286).

In 1674, all male horses over two years of age unless above 13 hands high were commanded to be gelded. This law was repealed in 1726 when the demand for saddle horses in the South became a source of income to the New England farmer (21, v. II, p. 244 and v. VII, p. 31).

Fairs or Markets Established.--The New Haven settlement, April 3, 1644, enacted the following:

It is ordered that there shall be two marketts or fayrs for cattell and others goods every yeare att New Haven (viz) one on the third Wednesday in May, the other the third Wednesday in September.

The fairs held in the colonies were adapted from an old English custom of assembling salable animals and produce at one time and at the same place to facilitate barter and exchange. There does not appear to be any similarity between these early fairs and modern exhibitions which have for their main purpose the dissemination of knowledge in regard to improved breeds and innovations in manufacture. 
Self-sufficing Agriculture.-The Connecticut farmers were forced into developing a self-sufficient agriculture. 'They had a little timber suitable for staves and they manufactured some tar and pitch but these commodities fell far short of providing the colony with clothing and other manufactured goods. Strenuous measures were adopted to supply this deficiency.

Over-production of Wheat.-To promote the production of English grain it was ordered in 1640, that for each team which a farmer possessed, he could have one hundred acres of plowing ground and twenty acres of meadow provided he seeded twenty acres the first year, eighty acres the second and the whole one hundred acres the third. The result was disastrous. In 1644 , the crop of wheat grcatly exceeded the demand and the price fell to $2 \mathrm{~s}$. a bushel, raising a storm of protest from the Plymouth and Massachusetts Bay planters. The remedy for this new situation was characteristic. All growers were forbidden to sell any wheat exeept to Edward Hopkins and William Whiteing who were to pay 4 s. a bushel and transport it over scas. Subsequent lawsuits to collect from these gentlemen indicate that the scheme was a financial failure (21, v. I, pp. 58-116).

Some thirty or forty years later the natural encmies of wheat growing "blastings, mildews, catterpillars, worms, tares, floods and droughts" became so prevalent that days of prayer were ordered in 1680 and 1685 , for their amelioration and from that time there was no danger of over-production of wheat in New England.

Barberry Eradication.-One of the most peculiar of colonial laws considering the time it was enacted was passecl, in 1726, in Connecticut, for the eradication of barberry bushes. The preamble of this law reads:

Whereas the abounding of barberry bushes is thought to be rery hurtful, it being by plentiful experience found that, where they are in large quantities, they do occasion, or at least increase, the blast on all sorts of English grain (21, v. VII, p. 10).

Scientists many years later proved that their fears and suspicions were well founded and the fight against barberry bushes is still being waged.

Hemp Ordered Sown.-During the same year (1640) that the boom in wheat growing was started it was ordered that every family of the plantations should procure at least a spoonful of English hempseed and sow it: 
in some frutfull soyle, at least a foute distant betwixt every serel, and the same so planted shall presarve and kecpe in husbanly manner for supply of seced for ancother yeare (2)1, 2. I, 1), 61 ).

Later a bounty of th. a poumd for water rotted hemp was granted and what is more significant a bounty was granted for every rard of fine linen eloth woven in the colony (21, v. VII, p. 512 ).

Ship Sent for Cotton.-Auother activity of the year 1610 was the laying of an assessment "to provide a vessel to trade for cotton wool," not that they wanted eottor clothing especially but they had discovered that a eoat well padded with cotton was an efficient protection against Indian arrows and later every family was ordered to have at least one such coat in its possession.

Sheep Raising Encouraged.-Sheep raising was encouraged by several statutes. They were freed from taxes in 1666 and in 1670 it was ordered that every man above fourteen years of age should work one day a year in clearing the pasture land of brush. To protect those who wisherl to improve their breed of sheep, rams were not allowed to rum in the eommon flocks at pasture (21. v. II, pp. 34. 51, 139, 197).

Rape seed oil production was the next industry to attract the attention of the Connecticut law-makers. In 1675 William Rosewell was granted tax free privileges for his eattle and property for the construction of a "cole seed oil mill." It was also ordered that a bounty of 2 s. an acre up to $S 0$ acres should be paid every planter of rape. This bounty was to l'un ten years and the exportation of rape seed was prohibited. This enterprise evidently did not prove as profitable as its promoters had expecter. At any rate it dir not become an important industry (21, v. II, pp. 254-5). Rosewell had a few years previously been granted special permit to distill corn liquor.

Exports.-The commodities for export in 1650 were reported as:

Wheat, Peas, Ry, Barly, Indiun Corm, and Porch, Beif, Woole, Hemp, Flax, Cycler, Perry, and Tarr, deal boards, Pipe Staves and Horses (21, v. III, p. 297).

These were shipped mainly to Boston in exchange for English goods.

There was also a direet trade with Barbadoes and the Madeira Islands for sugar, rum and wines but all exports taken together were inadequate to supply the wants of the Connecticut planters. 
Manufacturing was inevitable if they were to maintain the standard of living prevailing in some of the more favorably located colonies. The establishing of iron works at New Haven about 1666 to which was granted relief from taxes in 1669 for seven years for the "supply of the country with good iron and well wrought" (21, v. II, pp. 37, 10S) marks an epoch in Connecticut affairs.

Tobacco in the Connecticut Valley.-Tobacco culture, which has since become such an important crop in the Connecticut Valley, did not appeal to the carly colonists of that region. This was probably due to prejudice against the use of tobaceo. A fine of $6 \mathrm{~d}$. for each offense was laid in 1646 in New Haven for "takeing tobacco in an uncovered place" (87, p. 241) that is for smoking in a street or yard. In a report to the Lords of Trade in 1680 it is stated "We have no Virginia trade most.people planting so much Tobaceo as they spend" (21, v. III, p. 297). In 1753, however, tobacco became an article of export. A law was passed providing for official inspectors to grade and pack the product and all growers were forbidden to ship any tobaceo without inspection or to put any private marks or brands on the containers (21, r. X, p. 202).

Later History.- The later agricultural history of Connecticut differed little from that of Massachusetts. The Connecticut planters finally developed a commerce of their own and also condeted a carrying trade between Spain and other Meditcrranean countries in Europe and the Spanish possessions in America. Not much is said about this commerce by the Connecticut colonists themselves in their reports to the Lord's of Trade but oceasional mention is made of it in other sources. One product which figured prominently in this trade was mules which probably accounts for the introduction and use of those animals in Connecticut at a time when they were scarcely known in the other English colonies.

\section{RHODE ISLAND}

The report of the King's Commissioners concerning the New England colonies, made Dcember, 1665, states in regard to the Colony of Rhode Island and Providence plantations "In this Province, also, is the best English grasse, and most sheepe, the ground very fruitful . . . ; corn yiclds eighty for one. and in 
some places, they have had corne twenty sixe yeares together without manuring" (97). This prominence in agriculture gained by this little colony in twenty-nine years after Roger Williams and his five friends had first established themselves at Providence is quite remarkable. It becomes more so when it is recalled that the Rhode Island colony was practically isolated from and boyeotted by the other New England colonies. The Rhode Islanders were not admitted into the organization of the United Colonies of New England and many of the inhabitants were exiles subject to arrest if they appeared in any of the other New England settlements.

Conditions Favorable to Agriculture.-Several reasons may be given for the early development of agriculture around the Narragansett Bay. (1) That region had a good climate. The location on deep water and the general lay of the land were excellent. (3) The Rhode Islanders obtained a well established agriculture along with their purchase of the lands from the Indians. These advantages were of inestimable value to the colony.

Climate and Lay of Land.-The climate of Rhode Island as compared with that of the rest of New England is much more favorable to agriculture. There is less snowfall in the winter and the snow does not remain so long on the ground. The rainfall of summer is more evenly distributed than it is in any other part of the United States. This is essential for good pastures. Droughts in Rhode Island are rare.

The topography of the Narragansett Bay country is well adapted for pioneer agriculture. The numerous islands in the bay, with the exception of Acquedncek, afterwards named Rhode Island, were early freed from predatory animals. Live stock could be turned out to shift for themselves without the danger of losing them for want of fences. The peninsulas or necks as they were called along the mainland were also easy to fence and protect.

Indian Agriculture in Rhode Island.-Perhaps the greatest advantage which the Narragansett settlers had over the rest of New England was the established system of agriculture which they obtained from the Indians. The Narragansett Indians were the best farmers among the aborigines along the Atlantic seaboard at the time of the English settlements. They were probably second in their agricultural attainments only to the Iroquois 
of western New York of all the Indians in the eastern laalf of what is now the United States. The Indians had performed the pioneer work of subduing the land for cultivation.

The land was cleared of timber back from the shores of Narragansett Bay in some instanees to a depth of eight to ten miles (124).

This cleared land, together with the numerous, natural salt marsh meadows which furnished hay for wintering stock offered unusually favorable opportunities to the early settler's.

Indians Furnished Foodstuffs. - How useful the Narragansett Indians were in furnishing food is indicated by the following quotations from Winthrop's Journal.

The Rebecca came from Narragansetts with 500 bushels of corn given to John Oldham. The Indians had promised him 1,000 bushels, but their store fell out less than they expected.

Captain Stoughton wrote to the Governor August 14, 1637:

The Narraganset ts do gather beans in abundance and we are silent at it; yet if they should turn enemy it would be to our damage (130, v. I, p. 400).

Dependence on the Indians.-This convenient and abundant supply of foodstuffs was instrumental in keeping the Rhode Island colony from the extremity of famine suffered in the early years by some of the other settlements. How perilously near they came to want, however, is shown by an item dated January 22, 1639, in the records of the Newport settlement.

Upon a survey of the Corne with the persons inhabiting the Towne, the Corne arising to 108 bushells, and $y^{e}$ persons ninety-six: it is therefore ordered, that the said Corne shall be proportioned forth one bushel and a half a peck to each person, which is to supply the said person for the space of six weeks ensuing the date hereof (97, v. I, p. 95).

That the "high cost of living" is not a modern problem is indicated in letters dated 1649 of Roger Williams to John Winthrop, Jr. at New London in which he states: "I am sorry you had no more corn from Ninegret yet glad you had so much for I am force to pay 4s. the bushel for all I spend," and again four months later. "Mr. Throckmorton hath lately brought in some corn from Hemstead and those parts but extraordinary dear. I pay him $6 \mathrm{~s}$. for Indian and $8 \mathrm{~s}$. for wheat. These rains, if God please to give peace, promise hopes of plenty" (\$3). 
Land Holdings. - Agriculture was given first consideration by the Rhode Istand settlers. In fact it appears to have been their sole business. Roger Williams and his associates, in 1636, allotted the land which Williams had purchased from the Narragansett Indians, anong thenselves and others who settled with them, on the basis of a lome lot and a six-acre tract to each family. Each beneficiary under this arrangement was to reimburse Williams to the extent of thirty shillings. Similar allotments of five and six acres each were made at the beginning of the Portsmouth plantation in 1635 and that of Newport the year following. At Portsmouth it was also agreed that each freeman should have one acre of meadow for each head of eattle or sheep and one and onc-half acres for each horse. These six-acre tracts were evidently eleared for they were sometimes referred to as plowing land.

Land Owners Compelled to Improve Property.- One of the earliest memoranda of the Proridence eolony which has been preserved contains this item:

Mr. Cole, Francis Weston, Richard Waterman, should pay for each person one shilling and sixpence i.e. for damage in case they do not improve their ground at present granted to them ziz.: by preparing to fence, to plant, to build, etc. $(97, \mathrm{r}$. I, p. 15$)$.

Many of the home allotments at Portsmouth were made with the understanding that buildings and fences should be built in one year or the land would revert to the town.

Large Farms.- The land outside of the settlements was allotted in larger units. There is a mutilated record of a general meeting at Portsmouth on the "10th day of $y^{e} 12$ th month 1639 " and furtber confirmed on the "1Sth" $(97$, v. I, p. 73) in which about two thousand acres were divided among eleven men in tracts ranging from thirty acres to four hundred acres. These farms were to be paid for in grain, but the amounts are not now legible. This colony had previously fixed the price of land in the back country on the island at two shillings per acre. The farms in the Narragansett country west of the Bay were commonly of several hundred acres in extent. Among the early settlers of Rhode Island were some men of means. They possessed what was to the infant colony more valuable than gold and that was live stock. One of the most prominent in the Portsmouth settlement was $\mathrm{Wm}$. Brenton. At a general meeting the first summer of that colony's existence it was ordered: 
that the remainder of Cirass, which is yet uncut at Hog Island shall be granted to Mr. Brenton to mow this year for his necessity.

It must not be inferred from this item that it was an act of charity. Twenty-eight years later $\mathrm{Wm}$. Brenton was said to have owned 1500 sheep. There are scarcely five times that number in all Rhode Island at the present time. It was ordered by the General Court at Newport October, 1639:

That keepers shall be appointed to ye sererall heards of Cattle, from the 15th of Aprill to the 1st of Norember, and that the spare cattle shall be separated from the Milch beasts and kept att sachuis.

The word cattle in those days included sheep and goats.

Swine Production.-To increase their stock of swine was a matter of prime importance to these settlers. Roger Williams and Crov. John Winthrop of Massachusetts Bay bought what is now Prudence Island from the Indians in $\mathbf{1 6 3 7}$ and stocked it with hogs. These two men also stocked other small islands with goats.

An order passed at a general meeting scarcely a year after the settlement at Portsmouth shows that "pigs were pigs" three centuries ago. The order states:

That the Swine that are upon the Island shall be sent away from the plantation six miles up into the Island, or unto some Islands adjacent, by the 10th of the 2nd, 1639, or else be shutt up that so they may be inoffensive to the Towne.

On the "6th of the $2 \mathrm{~d}, 1639$ " it was deemed necessary to put some teeth in this law by way of a penalty of "two pence for each hogg" not removed on the date designated.

Branding Law.-The town of Newport in 1639 made a similar ordinance, except that the period of banishment of the hogs was from April 15 th to October 15 th under a penalty of "four pence a foote." A law to protect the owners of stock running at large was passed on the 17th of Sept. 1641 at Newport as follows:

It is ordered, that every halfe yeare ther shall be three men chosen sut of each Towne to view the Swine that shall be killed by any Person or Persons within the Limitts of the said Towne: And that he that doth or shall kill any swine, and not call one or more of the said men to view and see the said swine so killed, or to be killed, he shall forfeitt five pounds; and also it is ordered, that erery Inhabitant or Person keeping swine, shall within one month after the end of this Court, bring in their ear-marke which they have or do usually give, and ther to be kept in the Towne Records upon paine of forfeiting six shillings and eight pence; 
and those that have the Seigniority of the inarke shall keep it, and others that have given the same shall alter the said marke upon notice given to em; and it is also ordered, that the same order in all points shall be observed for Goates: and also that each Towne shall have a eopy of each others earmarks (97, v. I, p. 117).

This law was re-enacted by the General Assembly called at Portsmouth in 1647 under the first Royal Charter (97, v. I, p. 151) and it was later made illegal for any one, especially an Indian to have in his possession either alive or dead any swine which had its ears cut off, unless it could be shown that the cars were "torne off by dog or dogs, or some other lickly accident" ( 97 , v. II, p. 173).

Grist Mills.-A mill for grinding grain was one of the early public utilities built in the colony. 'Two commissioners were appointed at Portsmouth in the fall of 1638 :

To treate with Mr. Nicholas Esson, and shall fully agree with him, in allowing of him suffieient aecommodations for foure Cowes and planting grownd as they shall think meett, all which is for the setting up of a water mill which the said Mr. Esson hath undertaken to build for the necessary use and good of the plantation (97, v. I, p. 62).

The tower of a stone wind mill built about 1665 by Gov. Benedict Arnold is still standing at Newport, R. I.

Small Grain Culture Unsatisfactory.-Wheat, barley and oats are very unsatisfactory crops in the Narragansett country. Rye does best of all the small grains. Frequent fogs during the spring and summer promote the growth of rusts and other diseases to the utter ruin of wheat and oats and abundant rains make harvesting precarious. The Rhode Island settlers adopted Indian corn as their bread grain specializing on a white flint which is admirable for grinding into meal. Wheat flour was practically unknown in many Rhode Island houscholds in colonial times.

Dairy Farming. - One of the chief sources of agricultural wealth of the Rhode Island Colony was from the sale of dairy products. Rhode Island butter and cheese, partly due to the maritime enterprises of her citizens, and partly to the excellence of those products, became known around the world and the Rhode Island dairy cow in colonial times was a popular breed. There is little of record as to the source of the foundation stock of these cattle. They may have been brought over from England but the probability is equally strong that they were of Dutch origin having 
been obtained from the Dutch settlers in the Connecticut Valley or in New Netherland. The records of the Rhode Island plantations contain many references to cows and the men who were fortunate enough to possess a few in the early days were the aristocrats of the colony.

Difficulties in Importing Cattle.-Some of the difficulties encountered in the early transportation of live stock to Rhode Island are vividly pictured by Roger Williams in a letter dated November 7,1645 to John Winthrop, Jr., at New London. He states:

Wm. Peacock hath had a very heavy task in carrying Joseph with cattle from you. Six or seren days and nights the poor fellow was sceking them (being lost and scattered from Niantick). Then he brought six to my house four being finally lost. I took what pains I could to get them sought again and three I hear are found after. which IIin. Peacock is now out, and I look for him this night with those three. Ninigret did his part honestly, but the youths and boys thereabout (by some occasion hollowing) the cattle thence took the woods. Joseph Wild hath written me and I acquaint him with the cause, that one man alone cannot well drive cattle amongst barbarians, especially without an Indian guide. It were exceeding well that three or four poles were enclosed at Niantick to keep cattle there at night, for if God rouchsafe peace and plantations prosperity there is needs of it $(\$ 3, \mathrm{v} . I \mathrm{~T}, \mathrm{p} .159)$.

Dairying Profitable.-The extent to which dairying was carried in Rhode Island by the middle of the eighteenth century is indicated by Douglass:

The most considerable farms are in the Narraganset country. Their highest dairy of one farm milks about one hundred and ten cows, cuts about two hundred load of hay, makes about thirteen thousand weight of cheese besides butter and sells off considerable in calves and fatted bullocks. A farmer from seventy three milch cows in five months made about ten thousand weight of cheese, besides one firkin of butter from seventy to eighty pounds weight. In good land they reckon after the rate of two acres for a milch cow (2S, v. II, p. 100).

Commerce.-The restrictions imposed against Rhode Island by the United Colonies of $\mathrm{New}$ England put the followers of Roger Williams and the other religious undesirables of that colony largely upon their own resources. Denied an opportunity to vend their products in the business metropolis of Boston they took them in their own boats to other markets. This commerce established closer relationships between the southern colonies 
and Rhode Island than existed with any other New England settlement. Putting out superior produets gave the Narragansett settlers a great advantage. One frequently finds Rhode Island mentioned in the literature of the colonial South as separate from or coordinate with New England.

Social Life.-As wealth accumulated in Rhode Island the plantation life took on many of the manners and customs of rural England. The experiment of Charles I to see "whether civil government could exist with liberty of conscience" developed an oasis amid the inhospitable restrictions to human activities in New England. While the Connecticut colonists were perfecting their code of blue laws and the people of Massachusetts were even still more severe in direeting the deportment of individuals along Puritanical lines, the plantation owners of Narragansett were feasting, fox chasing, and horse racing to their hearts' content.

Summary.- Rhode Island has added much to the agrieultural prosperity of the country. While the Rhode Island dairy cow is now no longer known as a breed and the Narragansett pacer has been long extinet, Rhode Island red chickens, Rhode Island greening apples, Rhode Island white cap corn, Narragansett turkeys, and Rhode Island bent grass seed are still well and favorably known and each contributes to the wealth and welfare of the country. 


\section{('H.APTER XVI}

\section{NORTH AND SOUTH CAROLINA AND GEORGIA}

The date of settlement of most of the colonies can be fixed with some degree of accuracy-but not so in the case of North Carolina. While it was the seat of the first English colony-that of laleigh, in 1585, on Roanoke Island,-permanent settlements did not occur until nearly a century later. North Carolina was one of the first of those unorganized frontier settlements, lawless in the sense of being free from laws, which later marked the progressive derelopment of this country. Just when white settlers began to create homes in North Carolina can be no more definitely placed than in the latter half of the seventeenth century.

Means of Communication.--From Petersburg, Virginia, at the falls of the Appomattox River there was a much used Indian path known as the Occaneechi Trail, which extended in a southwesterly direction and crossed the Roanoke river below the junction with the Dan. From there the trail crossed North Carolina and led on to the present site of Augusta, Georgia. Indian traders used this trail in prosecuting their occupation. An exploring expedition in 1650 was made from Virginia into North Carolina along this route. Among the members of this party was Abraham Wood who figured prominently in similar expeditions in Virginia over a period of more than twenty years.

Pioneer Settlers.-Following the Indian tracler came the frontier settler a character that played an important but little appreciated part in the building of civilized America. It is difficult to analyze the motires which induced these settlers to leave the protection and companionship of the legally organized colonies and push back for scores and hundreds of miles into the wilderness and there, amid the hardships of subduing a forest.and the ever present menace of Indian attack, attempt to build a home and rear a family. These intrepid pioneers were usually poor in worldly goods and often lacked the prerequisite of good health for such an undertaking. Land lust, to have and to hold a tract of land which they might call their own, appears to have been one impelling force which drew them on. Not infrequently, 
however, they were men who had cone in conflict with the laws of organized society or differed from their neighbors in religion, and sought a freedom from all restraint. In these desires they were often disappointed. With the rapid expansion of the colonies the holdings of these settlers to which they usually had no legal title were generally granted to others. In case of purchase by newcomers the clearings could be bought for a small fraction of the value of the labor which had been expended on them.

William Byrd one of the commissioners in 1728 representing the Virginia colony in the survey of the boundary line between Virginia and North Carolina has left this interesting deseription of the houses built by some of the early Carolina pioneers:

Most of the houses in this part of the country are log-houses, covered with pine or eypress shingles three feet long and one broad. They are hung upon laths with pegs, and their doors too turn upon wooden hinges, and have wooden locks to secure them, so that the building is finished without nails or other iron work.

First Recorded Settlement.-The first settlement in North Carolina of which any records remain was about 1760 on Chowan River by emigrants from Virginia whose only title to the land they tilled was derived from patents issued by Gov. Berkeley of Virginia.

This settlement afterwards designated as the County of Albemarle persisted. The settlers practiced the same type of agriculture as the Virginians. Tobacco was the main salable erop. Their products were marketed through the help of New England merehant vessels which touched there in their trips to the West Indies. By 1666, then under a government set up by the Lords Proprietors for the Carolinas, tobacco raising had become of so much importance that the governor of Albemarle was invited to a conference with the governors of Maryland and Virginia where it was agreed subject to ratification of the three colonial Assemblies to cease planting of tobacco altogether in 1666 , in order to increase the price of their product. Delay in receipt of the notice of acceptance of the agreement from the Carolinians was given by the Governor of Maryland as a reason for not adhering to the terms, and nothing eame of this attempt to curtail the production of tobacco so far as Carolina was concerned.

About the same time that the Albemarle settlement was made, a company of New Englanders attempted to start a colony at 
Cape Fear but nothing came of this. The adventurers became dissatisfied and abandoned the settlement prior to 1663 leaving some eattle which they had brought there with the Indians of that ricinity (SS).

Utilization of Pastures.-About 1700 a more substantial class of agriculturists than the pioneer squatters began to come to North Carolina. The unlimited range for grazing live stock which taken with the mild winters that allowed the keeping of animals without the protection of barns or the labor of storing forages induced men of means to migrate to that region. Herds of cattle, droves of wild horses, and numerous hogs turned the piedmont of North Carolina into one great live-stock ranch. The cattlemen suffered heavily in the Indian troubles of 1711 to 1715 but made a remarkable expansion of their herds and flocks after hostilities ceased.

Live Stock Increased. - A writer about $174 \bar{\gamma}$ states in regard to North Carolina:

Black cattle have mightily increased since the first settling of the colony. About forty years ago it was reckoned a great deal to have three or four cows, now some people have a thousand head; and for one man to have two hundred is very common. The cows graze in the forest, and the calves being separated and kept in pastures fenced in, they return home at night to suckle them; they are first milked, then shut up in a fold all night, milked again in the morning, and then turned out into the woods. Here are hogs in abundance; they go daily to feed in the woods, where they rove several miles, feeding on nuts and roots; but having a shelter made at home, to keep them warm, and something given them to eat, they generally return in the evening. The beef and pork that are raised here find a good market in the sugar islands (90, v. II, p. 345).

This same writer says that at that time he could not learn that there was a town or church in the country (90, v. II, p. 342).

All-the-year Grazing.-Brickell who was a practicing physician in North Carolina about 1731 notes:

As for Hay, I never observed any made in the Country, tho' they have such plenty of Grass, that they are obliged to burn it off the Ground every 10th of March, hy vertue of a Law made in the Country for that purpose (13).

The purpose of this law was to burn the old unpalatable growth and renew the pastures with tender succulent grass rather than to get rid of an over supply of forage as stated by Brickell. 
'The lack of deep waterways into the interior parts of North Carolina kept many settlers from choosing that locality who would otherwise have gone there. Those that dicl cast their fortunes in that colony were usually able to obtain large land holdings which eventually proved extremely valuable.

While large ocean ships dicl not visit this colony the small sailing ressels of New England took the trade and made a regular business of supplying the settlers with manufactured articles in exchange for their produce.

Early Farming.-The following description of North Carolina agriculture applies to the Piedmont section of the adjoining colonies just as much as it does to North Carolina:

The mode of common husbandry here is to break up a piece of woodland, a work very easily done, from the trees stancling at good distances from cach other; this they sow with Indian corn for several years succesively, till it will yield large crops no longer: they get at first fourscore or an hundred bushel an acre, but sixty or seventy are common: when the land is pretty well exhausted they sow it with pease or beans one year, of which they will get thirty or forty bushels per acre; and afterwards sow it with wheat for two or three years: it will yield good crops of this grain when it would bear Indian corn no longer, which shows how excellent the land must be. But let me remark that this culture of wheat to such advantage is only in the back part of the province, where the climate is far more temperate than on the coast . . In this system of crops they change the land as fast as it wears out, clearing fresh pieces of wood land, exhausting them in succession; after which they leave them to the spontaneous growth. It is not here as in the northern colonies, that weeds come first and then grass; the climate is so hot, that, except on riclı moist lands, any sort of grass is scarce . . . Besides these crops they cultivate all sorts of roots, particularly potatoes, of which they get large crops; some they sell into Virginia, and the rest are given to their hogs. Fruit in none of the colonies is in greater plenty, or finer flavour; they have every sort that has hitherto been mentioned in this work: peaches, as in the central colonics, are so plentiful, that the major part of the erop goes to the hogs $(4, \mathrm{r}$. I, pp. $339-41)$.

Crops Grown.-In the eastern or tobacco growing sections the same practices prevailed as in Virginia. Tobacco was raised to the exclusion of everything else on the soils best suited to its culture until they failed to produce profitable crops. The fields were then abandoned and were in a few years thickly overgrown. 
The cotton grown in North Carolina while not large in quantity was considered of very fine quality, being probably from seed imported from Turkey.

Rice and indigo culture was restricted to the southeastern portions of the colony and they never attained the importance they did farther south.

Exports of Agricultural Products.-During the closing year's of the colonial period North Carolina was exporting annually about 2000 hogsheads of tobacco valued at 16,000 pounds sterling, 2000 barrels of rice worth $£ 4000$, grain including maize, beans, and peas to the value of $£ 7000$, salted meats nearly $£ 4000$, hides worth $£ 2500$, besides minor articles as beeswax, potatoes, tallow, candles, lard, a little cotton and indigo. The forest products exported as staves, shingles, lumber, pitch, tar, turpentine, about equalled the exports of farm produce.

Thus we see North Carolina possessing a climate favorable to farming and much fertile soil developing into a great agricultural colony, through the efforts of immigrants from other colonies and without any material help or hindrance from the Lords Proprietors to whom Charles II had granted that tract of land. A great many Scotch-Irish immigrants settled in the foothill section of North Carolina in the last twenty-five years preceding the Revolutionary War. With the adrantages which that region possessed it was but a natural sequence that stock raising should be more and more supplemented with crop farming but the greatest development along that line took place after the colonial period.

\section{SOUTH CAROLINA}

When the Lords Proprietors received a charter to Carolina, in 1663, the original grant including both North and South Carolina and Georgia, they began preparations for settlements, drawing on the Barbadoes for settlers. This was far sighted. The average emigrant from the British Isles lacked the adaptability which was needed for successful coping with the conditions prevailing in the southern part of the United States. Even with this precaution of getting experienced farmers from this side of the ocean, the Carolina colony harl a dubious existence for several years. 
Unhealthful Coast Conditions.-The lowlands of the South Atlantic coast are very unhealthful. As a physician with several years experience in tide water Virginia during colonial times expressed it:

The acute diseases in these umhealthful parts of North America generally turn to intermittents, which are not mortal even in twenty months; but in a few months more they may bring on that Cachexy, with an emaciated habit, a swelled belly, and a pale sallow complexion, which is the characteristic of the bad state of health in all the southern and maritime parts of North America (76, p. 191).

The mortality of the white immigrants was excessive. Inhabitants of Charleston on salt water eseaped the ravages of the malaria much better than did the agricultural laborers exposed to the mosquito infested fresh water swamps. With desertions and deaths from disease the colony was several times threatened with complete failure.

The Lords Proprietors wrote under date of May 13th, 1691 that:

Men will dye in Carolina for some time faster than they are borne or grow up, and if none come to you yor numbers will by degrees bee so diminished that you will be easily cut off by the Indians or pyrats (9S).

Ashley River Settlement.-In 1669, the Lords Proprietors sent an expedition to settle on Ashley River which is memorable because of the provisions made for the fostering and encouragement of agriculture. Joseph West was placed in command of the expedition during the voyage and had charge of the Lords Proprietor's own plantation on his arrival in America. This was an unusually happy selection. The success of the enterprise was due largely to the good judgment and efforts of West who afterwards beeame governor of the Colony.

Provisions for Agriculture.-West was instructed to stop at the Barbadoes and procure a supply of:

Cotton seed, Indigo Seed, Ginger roots . . some Canes (sugar canes) Ollive setts . . half a doz. young Sows and a Boare.

Special care was ordered to be taken of all these and that the first efforts at culture should be experimental to find out the soil to which each species of plants was best adapted and the season of the year most favorable for planting, also to provide seeds and euttings for the use of the plantation. Cattle were to be imported from Virginia (116, v. V, pp. 124-7) (98, pp. 343-5). 
An Experimental Farm.-The experimental work was to be done with a "man or two" the rest of the people to be: "Emplosed about planting Indian Corme, Beanes, Pease, Tumips, ("arretts and [sweet] Potatoes for provisions."

Information as to the proper season for planting corn beans and pease, they were to obtain from the natives. The establishment of a testing garden by the Lords Proprictors on Ashley River in South Carolina in 1669-70 appears to be the first agricultural experimental farm ever established in America for the purpose of improving agrieulture. We will see later that the Georgia Colony profiting by the experience of the South Carolinians conducted similar experimental work in a publicly orned garden.

Perennial Cotton Unsuccessful.-After two seasons trial the Lords Proprietors were informed that sugar cane and cotton would not withstand the winters in South Carolina and that the most promising commodities for export were: "Wine, Oyle, Silk, Indicoe, Tobacco, Hemp, Flax and some say Ginger."

"I feare this will not prove a Cotton Country," wrote West in March 1671 (116, p. 297). The fact that these fears have been proved so unfounded has been due to the use of annual varieties of cotton instead of the perennial, West Indian sort, which was tried at first. In an advertisement of the Carolina Colony published in 1682, in England, it is stated, "Cotton of the Cyprus and Smyrna sort will grow well, and good plenty of the Seed is sent thither" (S4).

This is a striking instance of many such which might be cited where the whole economic activities of a great area of country have been changed by a simple agrieultural improvement but South Carolina did not become a real cotton country until after the Revolution and the invention of the cotton gin.

Went to New York for Horses and Cattle.--The settlers found that horses and eattle of better quality could be purchased either in New York or in the Bermudas than in Virginia and they earnestly petitioned the Proprietors to change the instructions in regard to the procuring of those animals. "I am informed," wrote Governor West, "that there is at New Yorke a rery large Breed of Cattell and $y^{t}$ one Cow will give 2 gallons or more at a meal" (116, p. 298).

This was about fifty per cent. greater than the best cows in England of that time produced. According to Houghton (1695): 
In April when cows go forth to grass about twelve chuarts in a day Winchester measure is good milking for a new Milch cow, and this if well skim'd yiclds about a sixth part or four pints of cream, which will make almost two pounds of butter.

Houghton was describing what was considered then an excellent dairy farm at Over, located seven miles from Cambridge, England (54, v. I, p. 439).

Live Stock in South Carolina. West reported that he had four cows in March 1671, for their Lordships' own plantation, and Capt. Brayne stated in 1670 that he had six cattle, seven hogs, three sheep, six geese, cight turkeys, twelve fowls, one negro, three servants, one overseer and on the strength of this showing desired five thousand acres of additional land to compensate him for his efforts in behalf of the colony (116, p. 248). These undoubtedly did not represent the entire stock of animals in the colony but were probably the largest individual holdings at that time.

Horse Breeding.-In the Advertisement of 1682 referred to above it is said:

There have been imported into Carolina about an hundred and fifty Mares, and some horses from New York and Rhoad-Island which breed well, and the Coalts they have are finer Lim'd and Headed than their Dams or Sires, which gives great hopes of an excellent breed of Horses, as soon as they have gotten good Stallions amongst them (St, p. 172).

Governmental Policies.-The government and land owning privileges, instituted by the Lords Proprictors had much to do with shaping the agricultural development of South Carolina. It is difficult to find two official documents in more striking contrast in intents and principles than the charter of Rhode Island and the constitution of South Carolina, both written in the same country and in the same decade-the one the most democratic of all the colonial charters, the other strictly autocratic. The Lords Proprietors made no overtures to the proletaire. They kept to themselves the final right to pass on or to promulgate all laws for governing the colony.

Grand Model of Government.-The proprictors proposed an claborate scheme, which they referred to as "Or Grand Modell of Government." The land was to be laid out in squares of twelve thousand acres each. A square taken up by one of the proprictors was to be a "signiory" if taken by a "Landgrave or Cassique" to be a "Barrony" and if settled by other people 
to be a "Collony." These were to be in the proportion of "twenty fower collonyes to eight signiorys and eight Barronyes." Title to the land however unless speeifieally granted otherwise was to remain in the names of the Lords Proprietors(116, p. 121).

Allotment of Land.-To each free person who eame to the colony before March, 1670, was promised one hundred fifty acres of land and in addition the same amount for each man servant and one hundred aeres for each woman servant and male servant under 16 year's of age brought into the colony. These allottments were to be redueed to one hundred acres and seventy acres respectively at the end of one year and to seventy acres and sixty acres in March, 1672.

Grand Model Unworkable.-There were some obstacles in the way of the suceessful operation of this "Grand Modell of Government." In the first place South Carolina with its numerous rivers is not suitable for divirling into squares. 'The surveyorgeneral sent with the expedition was incompetent to establish the necessary boundaries of the estates. 'The first governor was reported as insane. These were minor impediments which could have been overeome; but to get men with sufficient capital to stock and equip a large estate and who possessed the necessary leadership and managing ability to make such an enterprise a success, to forsake the comforts and advantages of an old established well-ordered country like England and risk their lives and fortunes in the wilds of America was beyond the power of the enthusiasts among the Lords Proprietors. The opportunity to own land without quit-rents offered by several other colonies drew many of the ablest freemen from Carolina.

The practical operation of this system in South Carolina resulted finally in very large plantations operated by numerous slaves. Of the 9580 people in South Carolina in 1708, less than half or 3960 , were free, 120 were white servants and 5500 were negro and Indian slaves $(98$, p. 232). The slaves outnumbered the whites during the entire colonial period.

Rice Culture.-The culture of rice marks the beginning of a successful colony in South Carolina. Rice did for South Carolina what tobacco did for Virginia. It gave the planters a commodity for which there was a demand in Fngland and not only England but in all the northern colonies which at that time had developed a considerable commeree. Rice culture was most economically handled on large estates. The work involved called for brawn 
and endurance rather than skill and could well be performed by slaves.

The first essays at rice growing gave little promise of financial suceess due to the inferior seed which was used.

This beneficial Grain was first planted in Carolina, about 168s, by Nir Nathanil Johnson, then Governor of that Provinee, but it being a small unprofitable Kind little P'rogress was made in its Increase. In the year 1696 a Ship touched there from Madagascar by Accident, and brought from thence about Half a Bushel of a much fairer and larger Find, from which small Stock it is increased as at present (20, v. II, p. XV'II).

Swampy Land Suitable for Rice Growing.-The swamps where rice growing was practiced were first drained and diked so the water could be controlled. Trees and brush were cut, piled and allowed to rot in most eases, though when needed, some of the best of the timber was made into lumber. The rice was seeded, in March, April and May, among the stumps in drills eighteen inches apart and three inches deep. Water was allowed to run onto the fields to a depth of eight to ten inches. Alternate draining and flooding was practiced several times during the growing season the ehicf object in the culture being to keep the rice free from grass. To say a "man was in grass" was equivalent to saying he had not sufficient laborers to elean his rice ficlds.

Harvesting Rice.--Rice harvest began about the first of September. The rice was eut, dried, stacked and threshed with flails the same as was wheat in those days. After the threshing the grain was winnowed to free it from the husks by tossing it in the air on a windy day or by using a winnowing fan. Wooden mills about two feet in diameter were used to grind off the outer covering of the seed, after which it was again winnowed. It was then put in a $a^{-1}$ mortar holding about half a bushel and beaten with a pestle. Dust, flour, and broken kernels were separated by screening and the whole rice was then barreled for shipping.

Indigo Culture.--Indigo. was seeond in importance to rice as a commercial product in colonial South Carolina. This crop had been for several years a staple commodity in Guatemala and St. Domingo and through the urgent solicitation of the British Government it was extensively tried in the southern colonies. But the Carolinians were at a decided disadrantage in competing 
with the planters in the West Indies where indigo could be cut five times cluring the year while in Carolina three cuttings was all that could be made.

Objections to Rice and Indigo.- Of all the crops ever grown in America, rice as grown in colonial times and indigo were probably the most objectionable from the laborers point of view. Rice was grown in low wet land, and much of the work was performed with the laborers ankle to knee deep in mud and water. The green indigo plants when harvested were put into large vats to ferment after which the coloring matter was extracted with water. This solution was then allowed to stand in other vats until the indigo settled to the bottom. Then it was put in coarse sacks and hung up to drain off the surplus moisture. The fermentation of indigo gave off a very offensive odor and the piles of refuse which accumulated around the vats were favorite breeding places for flies so that human habitation within a half mile was scarcely endurable.

Labor to Conduct an Indigo Plantation.-According to Wynne:

About twenty five negroes will manage a plantation of fifty acres, and complete the manufacture of the indigo, besides providing their own necessary subsistence. If the land be very good, each acre yields sixty or seventy pounds weight of indigo; at a medium, the produce is fifty pounds (133, v. II, p. 294).

Through the publicity given to indigo eulture about 1748 , a bounty of sixpence a pound was granted which greatly stimulated the production. In 1754 the exportation of indigo from South Carolina amounted to 216,924 pounds and before the Revolution to $1,107,660$ pounds (95).

Social Life.-The culture of rice and indigo and trade with the Indians gave considerable profit to the Carolinians and a limited number became wealthy. There was a marked contrast however between the rural life in the North where the land owners lived on their farms and in South Carolina where the plantation owners lived in the towns and operated their plantations with overseers. Each planter usually maintained a garden near his residence to supply his table and many useful and ornamental plants were there first brought to public notice in America. Charleston was famous for its gardens of native and imported plants both ornamental and culinary.

It must not be inferred that rice and indigo represented the major part of Carolina agriculture. These were the early money 
crops or commercial products. In addition, the usual Indian agriculture of maize, beans, squashes, melons, pumpkins and sweet potatoes augmented with European food plants was practiced to furnish food for home consumption and before 1750 there was an export trade in most of these products in addition to rice and indigo.

Live-stock Ranches. - While the planter's of the lowlands were busily engaged in developing their rice and indigo plantations a live-stock industry spread over the uplands of the western part of the country. An anonymous writer, probably Thomas Ashe, in 1782 states:

The Peach Tree in incredible Numbers grows wild. The great encrease of their Cattel is rather to be admired than believed: not more than six or seven years past the Country was almost destitute of Cows, Hogs, and Sheep, now they have many thousand Head (19).

How far the early colony fell short in producing the commodities which were expected in 1670 from it is indicated in a report of the exports in 1708 to England. These consisted of:

rice, pitch, tar, buck and doe-skins in the hair and Indian dressed; also, some few furs, as beaver, otter, wild cat, raccoon, a little silk, whit oak pipe staves, and sometimes some other sorts.

In addition to these exports to England there was a thriving trade with other colonies on this side of the Atlantic. The report continues:

From this province are exported to several of the American islands, as Jamaica, Barbadoes, Antigua, Nevis, St. Christopher's, the Virgin's, Montserrat, and the Bahama Islands, staves, hoops and shingles, beef, pork, rice, pitch, tar, green wax, candles made of myrtle berries, tallow and tallow candles, butter, English and Indian peas, and sometimes a sinall quantity of tanned leather. . . . We have also commerce with Boston, Rhode Island, Pennsylvania, New York and Virginia; to which place we export Indian slaves, light deer skins dressed, some tanned leather, pitch, tar, and a small quantity of rice. From thence we receive beer, cider, flour, dry codfish, and mackerel, and from Virginia some European commodities. . . . There are not above ten or twelve ships belonging to the province.

There are not as yet any manufacturers settled in the province, saving some particular planters who for their own use only, make a few stuffs of silk and cotton, and a sort of cloth of cotton and wool of their own growth to clothe their slaves (9S, pp. 233-5).

Trouble with the Indians.-Indian attacks, for several years beginning with 1711, almost destroyed the colony and drove the 
white people from their ontlying plantations to within twonty miles of Charleston. In this as in all other similar instances the Indians were finally orer-powered. The settlement of the barrice colony of Georgia in 17333 gave greater security to the south (arolina colonists than they had ever before enjoyed and planting became a great industry. The cattle ranches in the western part of the colony prospered and during the fifty years preceding the Revolution there was a thriving export trade in salted meats and hides.

Silk Culture.-The surplus of slaves in South Carolina furnished such a large number of domestic servants about the plantation homes that at times it was difficult to find anything profitable for them to do. Rearing silk worms was taken up as a fad by the ladies of some of the more wealthy planters. Of course the menial work was all done by slaves. A considerable quantity of raw silk was produced which was mostly woven into cloth for home use. Some specimens of this early American silk industry are still in existence. Mrs. C'harles C. Pinckney, formerly the Eliza Lucas mentioned in regard to alfalfa culture (see p. 244), had enough silk raised under her direction to make three dresses, one of which was given to Princess Dowagel of Wales, mother of George III, one to Lord Chesterfield, and the third she kept for herself. The latter dress is still owned by a descendant of Mrs. Pinckney at Charleston.

\section{GEORGIA}

Various motives prompted the founding of the colonies in America. The settlement of some were undertaken for the sole purpose of private gain by the founders, in some cases the colonists were in search of religious liberty, while others were aided and encouraged by the British govermment on the broad national policy of benefits accruing to Great Britain from trade. The motives behind the movements to settle Georgia did not fall entirely within any of these classes - a new element entered into the matter, that of philanthropy. It is true Parliament expected eventually, adequate retums in trade to Britain for the 10,000 pounds appropriated towards the initial enterprise and much larger sums later but the corporation, of which James Oglethorpe was the prime mover, was animated by a desire to help the conclition of an all too numerous class in England of 
poor people and debtors. Much of the funds for the expedition were obtained by popular subseription without any false hopes of future profits on the part of the donators.

Settlement at Savannah. - The first settlement in Georgia was consummated early in 1733 by "one-hundred and fourteen persons, men, women, and children, being such as were in decayed cireumstances and thereby disabled from following any business in England." James Oglethorpe furnisherl the initiative and enterprise for organizing and establishing the colony. Moreover he spent a large sum of his own money in trying to put his ideals into practice.

Aid from South Carolina.-The South Carolina Colony then a thriving settlement looked at first with much favor on the Georgia enterprise. It afforded protection on their most exposed frontier from the Spaniards at St. Augustine and the Indians in the Mississippi country. The Carolinians were of great help to the infant colony of Georgia in furnishing sceds and live stock.

Oglethorpe's first eare after the construction of a few houses at Savannah was to clear land to plant for provisions. He then expended 500 pounds in Charleston for live stock.

The houses were:

A frame of sawed Timber, 24 by 16 Foot, floored with rough Deals, the Sides with feather-edged Boards unplained, and the Roof shingled $(79$, p. 23).

Land Holdings.-The lands at Savannah were divided into town lots, sixty by ninety feet, gardens of five acres near the town and farms of forty-five acres making a total of but fifty acres to be granted to each settler. It was the expressed purpose of the trustees to build a commonwealth of small land holders rather than imitate the conditions then prevailing in South Carolina.

The title to lands that is the privilege of renting them in Creorgia was at first entailed in the male line. This restriction was soon modified however so that every person had the right to name a successor, in case of death, to the lands granted him. Land holdings, to those who possessed as many as ten servants, were limited to a maximum of five hundred acres. Exception to this however was also made at an early date, the limit being raised to two thousand acres where title was gained by inheritance. 
Their Gardens Described.-A writer for the South Carolina Gazclle visited the Savannah settlement a few weeks after the landing and reported that the land was barren for about a mile back from the river but from there on there was a rich soil; that Oglethorpe had immediately laid out two or three gardens in which he had sown,

divers sorts of seeds; and planted thyme, with other sorts of pot-herbs, sage, lecks, scallions, celery, liquorice, etc., and several sorts of fruit trees $(90, \mathrm{r}$. II, p. 447$)$.

Experimental Garden. - Ton Rich, who a few months later arrived with the Saltzburgers a religious sect from Germany which settled at Ebenezer, gives further information about one of these gardens.

There is laid out near the Town by order of the Trustees a Garden for making experiments for the Improving Botany and Agriculture, it contains ten Acres, and lies upon the River; and it is cleared and brought into such Order that there is already a fine nursery of Oranges, Olives, White Mulberries, Figs, Peaches and many curious Herbs; besides which, there is Cabbage, Peas and other European Pulse and plants, which all thrive (35, r. IV, No. 5, p. 10).

Another Account.- Still another writer to comment on this Garden was Francis Moore who visited Georgia in $1736 . \mathrm{He}$ informs us that it was situated to the east of the town of Savannah.

One half of it is upon the Top of a Hill, the Foot of which the River Savannah washes, and from it you see the Woody Islands in the Sea. The Remainder of the Garden is the Side and some plain low Ground at the Foot of the hill, where several fine springs break out. In the Garden is variety of soils; the Top is sandy and dry, the Sides of the Hill are rlay and the Bottom is a black, rich Garden-Mould well watered.

This writer states that the orange trees had winter killed down to the roots but were sprouting again and that the mulberry trees were flourishing.

The account cnumerates some of the plants found in the Garden as:

Fruit trees usual in England, such as Apples, P'ears, ete. In another Quarter are Olives, Figs, Vines, Pomegranates and such Fruit, as are natural to the warmest Parts of Europe. At the bottom of the Ifill, well sheltered from the North-wind, and in the warmest part of the Garden, there was a collection of West India Plants, and Trees, some Coffee, some Cocoa-Nuts, Cotton, Palma-Christi, and several 
West-Indian physical plants, some sent up by Mr. Eveleigh a publickspirited Merchant at Chardes Town, and some by Dr. Houstoun, from the spanish 11 est Indies, where he was sent at the Expense of a Collection raised by that eurious Plysician sir Haus sloan, for to colleet and send them to (ienrgia, where the Climate was capable of making a Garden which might contain all kins of Plants; to which Design his Crace the Duke of Richmond, the Larl of Derby, the Lord Peters, and the Apotheeary's company contributed very generously; as did sir lfans himself. . . There is a Plant of Bamber eane brought from the Last Indies, and sent over by Mr. Towers which thrives well, there was also some Tea-seeds, which cime from the same place; but the latter, though great care was taken, did not grow (79, pp. 29-32).

There are some mis-statements of facts in this account. Philip Miller, the gardner at C'helsea, appears to have been the organizer and principal adrocate of this enterprise. Dr. Houston died three months after his appointment, and Robert Millar, a botanist, was employed in his place on two contracts totaling five years at a salary of 1.50 pounds per annm and sent on exploring expeditions to the West Indies, Central and South America to select plants for the Georgia Experimental Garden. The funds for carrying on the work were contributed anmually. The Earl of Derby giving 50 pounds, the Duke of Richmond 30 pounds, and sir Hans sloane 20 pounds, were the regular contributors and the rest of the funds for carrying on the work were supplied hy others interested in the project and also by the trustees out of the regular funds for establishing the colony. These public spirited men, apparently ceased to donate after the expiration of Robert Millar's contract in 1735 and the item "For the Encouragement of Botany and Agriculture" does not appear after that year in the financial statements of the Board of Trustees for Georgia (3S).

The Garden Allowed to Decay.-Interest in the experimental or "Publick Carden" as it was known appears to have languished from negleet after 1640. In 1641, one Jolın Gionorali petitioned the Board of Trustees "to be restored to the Care of the Trustees Gardens (from which he was some Time since for good Reasons removed)" (3S, r. YI, p. 5i).

The secretary of the council at savamnah reported in 1743:

That the Publick Garden at Sarannah being the most part of it poor ground the trees and plants in it were decaying but he had dreigned the lower part of it which proves a rery valuable spot (3s, v. V, p. 630). 
The chief benefit obtained from this garden, was in denonstrating that oranges and tropical plants in general could not survive under Georgia conditions. During the later year's of its existence it was used merely as a nursery to grow mulberry trees.

First Public Testing Garden.-If the Lords Proprietors plantation in South Carolina, which dict not differ much from privately owned farms many of which experimented with exotic plants, is excluded from consideration this testing garden at Savammah is apparently the first publicly owned and operated experiment station in America. There were several privately owned botanical gardens at the time, the most notable of which was that of John Bartram, started in 1730, near Philadelphia.

Testing Gardens an Old Idea.- There was nothing original in the establishing of experiment stations in America. Attention had been called to the need of them in many agricultural writings long before official action was taken towards establishing such a farm. The idea had probably occurred to intelligent agriculturists in all ages. It would not be surprising if researches in ancient Mediterranean countries revealed that there were government controlled agricultural experiment stations long before the Christian era. It is not necessary to go back so far to find the beginnings of our experimental system.

One of the earliest experiment stations of modern times and one which had a great influence on English speaking countries was established by the Duteh East India Company at the Cape of Good Hope. This garden was originally planned to serve as a propagating station in the transfer of plants from Eastern Asia to Europe-the long royage around Africa being so often fatal to living material. There were many benefits derived from this garden and it was soon used as a general testing ground for new productions and little known species. The rivalry between the Dutch and the English during the seventeenth century in commercial activities did much to advertise this Dutch undertaking.

Dampier (1694) gave a good description of this testing garden from which, or the writings of other travelers of the same garden, was probably drawn the plans for the Georgia project.

The Dutch East India Company have a large House, and a stately Garden walled in with a high Stone Wall. This Garden is full of divers sorts of Herbs, Flowers, Roots, and Fruits, with curious spaceous Gravelwalks and Arbors; and is watered with a Brook that decends out of the 
monntains; which being cut into many channels, is conveyed into all parts of the Garden. The Hedges which make the Walks are rery thick, and ? or 10 foot high: They are kept exceeding neat and even by continual pruming. There are lower Hedges within these again, which scrve to separate the Fruit trees from each other, but without shading them: and they keep each sort of Fruit by themselves, as $\Lambda$ pples, Pears, abundance of Quinces, Pomgranats, ete. . . . The Roots and GardenHerbs have also their distinct places, hedged in apart by themselves; and all in such order, that it is exceeding pleasant and beautiful (24, I. I, p. 534).

Early Enterprises.-The early visitors to the Georgia colony were amazed at the thrift and energy displayed by the settlers few if any of whom had had previous farm experience. All were at work even to the boys and girls. Slavery was prohibited to encourage industry among the people. Wine, oil and silk were expected to be the commercial commodities of the colony by its founders. Grape vines from Portugal were imported by one Abram de Lyon; the expense being borne by the trustees, but the culture of the European grape did not prove profitable in Georgia and Lyon broke his contract and deserted his plantation and the colony in 1741 .

Silk Production.-Notwithstanding the repeated failures which had resulted from attempts to raise silk in America the trustees of the Georgia Colony made great efforts to establish that industry. An Italian family, Camuse by name, experienced in the rearing of silk worms and the winding of silk were transported, in 1633, to Georgia, given a house and 50 acres of land, provided with provisions for one year, furnished all necessary materials for carrying on the work, granted the profits from their labor and in addition to all this paid a salary of 25 pounds sterling a year for four years. The family was also promised free transportation back to England in ease the scheme of raising raw silk did not succeed (38, v. II, pp. 22-26).

On April 3, 1735, the Board of Trustees in London recorded that they had received:

A Trunk containing Eight large Pounds of Raw Silk of three Sorts, viz. Ordinary, Fine and Superfine, which was sent to Sr. Thomas Lombe to be organzined (3S, v. III, p. 97 ).

For the same year in which this silk was received appears a charge against their funds

For the Production of Raw Silk in Georgia 471 l. 3s. $11 \frac{1}{2} \mathrm{~d}$. 
Nothing more was heard from the silk business in Georgia for two years and in 1735 the trustees instituted an inquiry into the matter with the result that the following year they received a "Bag of Raw silk from Georgia containing about 20 pounds weight" (38, v. III, p. 220).

This was the accumulation from the previous two year's production when none was shipped.

So pleased were the trustees with the prospect that the salary of Mrs. Camuse, who appears to have been the head of the family, was raised to sixty pounds a year, and provision marle for her to instruct ten persons in the art of silk raising at seven pounds per person. A bounty equivalent to the market value of raw silk was granted to anyone who produced cocoons, which were to be turned over to Mrs. Camuse for winding.

Expensive Silk.-After 1739, shipments of silk became more regular and increased in quantity. By 1747, the accumulated stock in the London office of several years amounting to 95 pounds, 6 ounces, was sent to a weaver to be worked into "Organzine, Tram and Singles." The charges for weaving amounted to $22 l .12 \mathrm{~s} .3 \mathrm{~d}$. and the valuation placed on the finished product was $110 l .19$ s. 5 d. Summarizing the expenditures for the twelve years $(1735-47)$ as reported in the records of the trustees there had been paid out "For the Production of Raw Silk in Georgia" not less than 1500 pounds sterling.

Change in Management.-Mrs. Camuse was strongly opposed to instructing anyone else in the mysteries of silk production and as she became more and more insistent and unreasonable in her demands on the trustees, they finally in 1747, discharged her and put the silk business under the management of the "Widow Anderson," who appears to have been of a more tractable disposition.

The Saltzburgers Begin Silk Culture.-Previous to the discharge of Mrs. Camuse two German girls from the Ebenezer settlement who had been sent for instruction but had been employed at menial work around the Camuse home, picked up enough of the technique of silk production by observation to start the silk industry anong the Saltzburgers. These Germans sent a small bag of silk to England, in 1746 and thereafter beeame regular exporters of silk in increasing quantities.

Public Filature.-Not satisfied with the meager results obtained from subsidized private enterprise in growing silk, the 
trustees established a public filature or place for winding silk in Savannah, where cocoons were purchased after 1754 from the producers at 3 shillings a pound or about 50 per cent more than the silk was worth after it was wound. With these inducenents, the funds for which were supplied by the British Parliament. silk production increased in (ieorgia until there was an annual export of 400 to 500 pounds of raw silk, but the anuual expense also increased to over a thousand pounds sterling or more than twice the value of the silk obtained. In spite of this showing many writers at the time on American affairs berated Parliament for not adopting a more liberal policy towards silk culture in Georgia. As the bounty on silk eocoons raised in soutl Carolina was but one shilling, six penee, it was elaimed by some that much of the silk shipped from Georgia was in reality produced in the neighboring colony.

Bounties on Food Stuffs.- The benevolent paternal attitude of the Board of T'rustees in London, which was fostered and encouraged by the liberal appropriations of Parliament, extended the bounties offered in Georgia to the common food stuffs, as corn, beans and potatoes, needed for the self-support of the settlers. In the year 1742 , bounties were paid on 4553 bushels of corn, $7661_{2}^{1}$ bushels of pease (probably beans or cowpeas) and 24721,2 bushels of potatoes (38, v. 23, p. 473). Of these products the Saltzburgers raised 3045 bushels of corn, 537 bushels of pease and 566 bushels of potatoes indicating that the initial industry of the indigent Fnglish people transported to Georgia at public expense soon wore off.

General Agriculture Practiced.-The agrieulture of Georgia when allowed to take its natural course, followed in the trend of that of South Carolina. Rice and indigo beeame the staple commereial crops in the coastal plain, while maize, beans, peas and garden truck furnished the inhabitants with food and later a surplus for export. Live-stock ranches flourished in the uplands the same as in the Carolinas. C'owpens or enelosures for the lierding of eattle were built at several places at the expense of the general fund and keepers of the cowpens received salaries from the trustees.

Cattle production inereased at a rapid rate. A round up at Ebenezer in 1740 brought in five hundred animals of all ages and it was said that wice that number might have been collected if they had had more men and horses to do the work. 
Mr. Elliott, keeper of "a large eowpen near Palachocolas" the same year sold at one time one hundred oxen in Savannah out of twice that many he had at home. Cattle throughout the rest of the colonial period were numbered by the thousands in Georgia.

Cattle Ranches. - These cattle ranches of Georgia and the other southem colonies took on the same general character which prevailed a century later in the great plains area. There were annual roundups and branding of ealves, conflicts between overlapping interests, and long drives of herds to tide-water markets. Cattle rustlers plied their trade and were summarily dealt with when caught. Might was the law of the range then as later. These cattlemen ever alert, always armed, fearless and resourceful, were an effective protection to the ticle-water planters against attacks from the Indians of the Mississippi region. Those interested in the history of the cattle ranges of the Great Plains will find its beginnings in colonial times in the South as well as in the Spanish ranches of the Southwest.

Slavery Introduced.-The ease and luxury enjoyed by the slave holding South Carolinians soon created a spirit of dissatisfaction and unrest among the planters in Georgia. It should be noted too that the Georgians were competing with free labor against slave labor in the same markets and with the same products. Petitions began to be sent to the trustees as early as 1739 for permission to own negroes. Counter petitions in opposition to the introduction of slavery were sent by the Saltzburgers and a number of Scotch Highlanders who had settled at Darien. The trustees refused at first to grant the request for slaves and the question became a live issue, finally resulting in permission to own slaves about 1750 under Governor Reynolds (100, p. 103).

Exports from Georgia. - The total exports in 1756 from Georgia were valued at $15,7+4$ pounds sterling and included 4508 pounds of incligo, 233 bushels of rough rice, 2299 barrels of rice and 438 pounds of raw silk. In 1772 the value of these same commodities exported had risen to 121,677 pounds, the increase being chiefly in rice and indigo, the raw silk exported that year being 485 pounds (100, op. p. 104). 


\section{('HAP'TER XVII}

\section{FRENCH SETTLEMENTS AND INFLUENCE}

The French were among the first of the Europeans to take advantage of the Newfoundland cod fisheries. The French explorer, Cartier in 153t-35 ascended the St. Lawrence and his account is the earliest deseription we have of that interesting region. He found a strong tribe of agriculturally inclined Indians probably Iroquois, near the present site of Montreal who gave him a very cordial welcome. That tribe had disappeared before any other French explorers penetrated Canada. Few results affecting the agricultural development of America can be clained for the French before the closing years of the seventeenth century, while attempts to found colonies and to establish religious missions had been made for more than a century prior to that date. The early French settlers in eastern Canada found wandering tribes of Algonquins who subsisted largely on the natural products of the country. Both the fur traders and missionaries adopted largely the Indian diet and lived with and as did these Indians.

Beginnings of Agriculture.-With the exception of Acadia, initiative was lacking to overcome the obstacles to a productire agriculture. That fertile strip on the coast beeame a garden as it has since remained. M. de Poutrincourt is eredited with having in 1606 sown at Port Royal

French Corue, as well Wheat and Rie, as with Hempe, Flaxe, Turnep seed Radice, Cabages, and other seeds (94, v. XVIII, p. 260).

A limited agriculture was inaugurated by the Jesuits at their missions on the St. Lawrence prior to 1640. Mention is made in 1645-46 in a journal kept by these priests of a cow "which had been in their corn" being killed by the sarages for which the Indians were compelled to pay six beaver's in damages. The following winter another cow broke through the ice in the "St. Charles river" and was drowned. At the same time it was recorded "all the Timber for our house was brought orer the snow by our oxen." "There were sent us by Monsieur the 
governor \& (apons, two bustards (wild geese) and 5 young pigeons by others some 10 or 12 pieces of other poultry" was another erent thought wortly of record, also that "two of our Frenchmen in charge of some cattle" were killed by the Indians. Eighteen head of eattle "both oxen and cows" were reported as killed or missing, in 16.51, at Three Rivers and the following year was noted "a loss of 50 horned eattle." At the same time "The wheat crop has been very good everywere this year especially at Montreal where the land is most excellent" (121, $\mathrm{r}$. XXVIII, p. 225, v. XXX, pp. 153-165, v. XXXII, p. 159 and v. XXXVI, pp. 135,165$)$.

Jesuit Farms.-By 1663, the Jesuit fathers had eleared lands about their various missions ranging from a few acres up to three hundred or four hundred acres (121, v. XLVII, p. 265). The Island of Orleans just below Quebec had one of the largest of these clearings. A description of that island written about that time says:

The Isle of Orleans is remarkable for its size, being more than fifteen leagues in circumference. It is rich in grain all kinds of which are raised there so easily that the Husbandman scarcely does anything but scratch the ground, and it never fails to yield him all he wishes continuing to do so for fourteen or fifteen years uninterruptedly without lying fallow (121, v. XLVIII, p. 157).

Government Aid.- It was not until 1665 that the French Government took serious consideration of the plight of their colonists in Canada. One year after the English had gained control of the Hudson River region from the Dutch, the French King sent a strong military force to Canada. The Richelicu River and Lake Champlain were fortified thus blocking a favorite route of the Mohawk Indians in their attacks on the St. Lawrence settlements. At the same time a shipment of horses was sent over from Havre the first of these animals with the exception of one horse sent in 1647 ever seen in Canada.

Our savages who had never seen any viewed them with admiration and were astonished that the Monse of France (for so they styled them) were so tractable and so obedient to man's every wish (121, v. L, p. s1)

Live Stock Importations.-Quite large shipments of sheep and cattle were also made about this time. The Jesuit correspondent reported, in 1667, in marked contrast to the discouraging statements made in previous years "Flocks of sheep meet our 
eyes and many horses which thrive fincly in this comntry and render it great service."

Besides the ordinary grains that have been hitherto harvested he (M. Tallon) has started the culture of hemp; this will go on inereasing so that all the country will aloumd with it, and will be able not only to supply its own needs but to furnish large quantities to France. As for flax, we ean see from our experience with it during the past year that its yield is excellent and it thrives finely.

These statements show clearly a changed mental attitude towards their enviromment on the part of the Canadian settlers (121, v. L, pp. 243, 247).

Fort Frontenac Built.-In 1676 Lasalle built Fort Frontenac at the lower end of Lake Ontario where Kingston now stands. This was a strategic move as it effectively hindered the Iroquois in their depredations on the St. Lawrence from that direction. Hennepin, who was in Ameriea from 1675 to 16S1, wrote:

The Ground which lies along the Brink of this Lake (Ontario) is very fertile. In the space of two Tears and a half that I resided there (Fort Fontenac) in discharge of my Mission, they eultivated more than a hundred Acres of it. Both the Indian and European Corn, Pulse, PotHerbs, Gourds, and Water-melons, throve very well. It is true indeed, that at first the Corn was much spoiled by Grasshoppers; but this is a thing that happens in all the Parts of Canada at the first cultivating the Ground, by reason of the extream Humidity of all that Country. The first Planters we sent thither, bred up Poultry there, and transported with them Horned Beasts, which multiply'd there extreamly (4S, v. I, p). $46-7$ ).

Agricultural Expansion.-From that date (1676) farming in Canada took on a different aspect. Realizing the immense possibilties of the fertile lands of the Ohio and Mississippi valleys the French made great efforts to strengthen and develop Canada as the most feasible gate-way to that western empire. Iiberal subsidies were granted for farm products. Marriageable ladies were transported to Canada, 82 arriving on one boat July 16, 1665. Many encouragements were offered the farmers there to make them happy and contented. One fatal mistake was made however. In order to retain her substantial rural ( population in France, the jails and slums of her cities were drawn on to furnish too large a number of the emigrants. The Huguenots driven from France by religious intolerance, would have furnished the brains and brawn that was so badly needed but 
these were denied a home in Canada. The experience of the French in America adds another instance to the many in history where failure has resulterl from not having a strong farming class as a foundation on which to build.

Illinois Settled. - A fairly prosperous agriculture eventually flourished around Montreal and by 165.5 missions were started in the country of the Illinois. Vincennes on the Wabash, Kaskaskia on the river of that name and Cahokia on the Mississippi and several other's were established a few years later. Cattle were taken to Kaskaskia in 1712; swine and poultry had been there several years prior to the date. Civen this fertile soil and a more hospitable climate the French started an agricultural boom that promised great results. ('harlevoix, in 1721, found thriving settlements at these places with droves of "black cattle" and flocks of poultry. But the ease of securing a living in the Illinois, the seclusion and the infrequent communication with the outside world stifled the enterprising spirit which marked the beginning of the settlements and they became in half a century sleepy; back woods villages boasting a total population in 1750 of "Eleven hundred white people, three hundred blacks and about sixty red slaves otherwise savages." Hunting furnished about as much revenue as farming and was more suited to the temperament of the French habitants. In the list of exports from the Illinois settlements products of the chase rivalled those from tillage. Quantities of grain were shipped down the Mississippi but the amounts though large were small when compared with the possibilities of that region.

Exports from Illinois.-Mitchell gave the following statement as a reason why England should be on her guard against French encroachments in America.

This country of the Illinois says Charlevoix, in 1721 , will become the grainery of Loui-iana and in 1746, we find it actually becoming so for in that year it sent down to New Orleans fifty ton of flour. In 1748, it exported flour, com, bacon, hams both of bears and hogs, corned pork and wild beef, myrtle-wax, cotton, tallow, leather, lead, copper, ete. We find a regular commerce settled with New Orleans by convoys which came down annually the latter end of December and returned at latest by the middle of February. ${ }^{1}$

Mississippi Settled.-While the settlements in Canada and

${ }^{1}$ Thwaites gives the amounts of flour shipped to New Orleans in 1746 as $\$ 00,000$ pounds. See American Nation, I History, Vol. 7, p. 85, 1907. 
the Illinois were being ereated at great expense of energy and money the French were also attempting to reach the Mississippi Valley from the south. A settlement was made, in 1699 , on the Back Bay of Biloxi on the coast of what is now Mississippi. The soil of the coastal plain at that place is not suitable for general farming and little suceess from an agricultural stand point was attained. It served, however, as a base of operations for future expeditions to the Mississippi.

Mississippi Bubble.-In 1717, the "Company of the Indies" one of John Law's famous sehemes for curing the financial ills of France, was organized to colonize and develop the country on the lower Mississippi River. While the orgies of frenzied speculation in the "Mississippi Bubble" in France ended in disaster some tangible benefits eame of the seheme in Aneriea. In 1718, seven ressels with stores and eight hundered emigrants were sent to the Mississippi, New Orleans and Natehez were founded and eleven ships were sent the following year. Among the laborers brought over, in 1719 , were five hundred African slaves. Interest in colonizing America continued for several years after the collapse of Law's Mississippi seheme and the Company of the Indies continued to send supplies and slaves to develop plantations. The owners, who usually resided in Paris, of these plantations, or concessions as they were ealled, obtained little of material benefit from their investments. The arduous task of elearing eane brakes in mosquito infested swamps was too discouraging for the French laborers sent to America and they usually loafed around the settlements until their provisions were cxhausted and then joined the army of wandering fur traders and boatmen on the rivers. A few plantation owners who came to Louisiana and aetively supervised the elearing of their lands were remarkably suceessful financially in that same period when so many fortunes were sunk in similar enterprizes by non-resident owners.

French Contributions to American Agriculture.-Few of the agricultural practices of American farmers of today trace back in their origin to the French colonial enterprises. Cattle and some forage erops, garden vegetables, and fruit trees were brought to Canada and the Mississippi Valley by these early colonists but not until after they were commonly possessed by the English farmers along the Atlantic seaboard. Orehards of apples, cherry and pear trees at Detroit, and in Indiana and Illinois have per- 
sisted as momments to the French cudeavor to eonquer a continent. Many of our best varieties of pears are of French origin. Perlaps the greatest service which the French achieved was in taking lientucky bluegrass and white clover to the region west of the Appalachian range. When the American frontiersmen finally penctrated to what is now Kentucky and Ohio they found excellent pastures of these plants, a fact which proved of immense value to the trans-Allegheny pioneers. The French also were successul in introducing the culture of sugar cane around New ()rleans about the time of the Mississippi Bubble.

Crops Grown.-From the correspondence of Bossu (1751) it is apparent that the French farming in Louisiana differed little from that of the similarly situated English colonies of the time.

"The negros are brought thither from Africa and are employed," says this writer, "in cultivating the grounds which are cxcellently adapted to the culture of Indigo, tobacco, rice, maize or Indian corn, and sugar canes, of which they have already made plantations that have succeeded very well." While describing the country "forty leagues" above New Orleans he says: "There are a number of Frenchmen in this part of the country who apply themselves to the culture of tobacco, cotton, rice, maize and other corn."

More credit may be due the French for introducing improved strains of cotton into the South than has generally been given. An Englishman well informed on American affairs wote:

Cotton is another article which the French cultivated with success in Louisiana, but which like others never came to be a national object for want of more people, and perhaps for want of encouragement, owing to their fear of rivalling their sugar islands, which also produce it in large quantities. The cotton they cultivated here is a species of the white Siam. This East India and annual cotton has been found to be much better and whiter than what is cultivated in our colonies, which is of the Turkey kind; both of them keep their colour better in washing, and are whiter than the perennial cotton that comes from the islands, although this last is of a longer staple ( 4 , v. II, p. S4).

This is apparently based on a statement to the same effect made by the English translator of Historie de la Louisiana by Le Page du Pratz (69, p. 242).

Perique Tobacco. - A peculiar variety of tobacco produced in St. James Parish, Louisiana called "perique," which is now 
frequently used in smoking nixtures and which owes its peculiarties to a combination of factors as varicty of plant, soil condition on which grown and method of curing, appears to have come down from French colonial times in that locality.

Whether the French in the Mississippi Valley confined their culture of tobaceo to the varieties grown there by the natives or not has not been established. Le Page du Pratz wrote:

There are two sorts of tobaceo; the one with a long and sharp pointed leaf, the other has a round and hairy leaf, which last they reckon the best sort $(69, \mathrm{p}, 210)$.

Effect on the English Colonies.-While not directly shaping agricultural methods in the English colonies the presence of the French in America was of tremenduous influence. Whether of far secing design or from prospects of immediate profits in the fur trade, the French, by confining the English to the Atlantic seaboard, were slowly but surely building up a commercial rival to Great Britain. Thousands of would-be emigrants to the Ohio country were forced to stay east of the mountains on account of French influence with the Indians prior to the French and Indian War. Many of these undoubtedly cngaged in commerce and manufacturing who would otherwise have turned to agrieultural pursuits. 


\section{CHAPTER XVIII \\ COLONIAL EXPANSION}

One hundred and twenty-six years clapsed from the time of the settlement at Jamestown to that of Savannah. Much in that time had transpired, but farm practices had changed very little. Knowledge of farming under American conditions had become more or less definite. Individuals continued to struggle against natural laws and natural forces. The majority of farmers however adapted themselves to the prevailing conditions. European methods which were not successful in America were abandoned. Native born Americans were farming who knew not the European methods - who did not have so much to unlearn. While a large amount of empirical knowledge on the raising of crops and rearing live stock gained by experience amid harsh conditions had been aequired, superstition was a tremendous retarding influence on the improvement of farm practices. This is perhaps best evidenced by the absence of inventions in farm machinery. Methods of the father and grandfather wcre too frequently held by the son as incapable of improvement. The "man of signs" in the old almanacs governed the common farm operations. Land was plowed, crops were seeded and harrested, brush cut, fences built, wells dug, and animals bred according to favorable or unfavorable phases of the moon. Farmers lived in a peculiar mental state which allowed them little control over their own affairs. Things were because they were. Plant diseases or insect pests were regarded as visitations of divine displeasure as were droughts, floods, hurricanes, hail, frosts and freshets. Days of prayer were frequently called to end droughts or ameliorate the ravages of epidemics or crop pests.

The settlement of the last of the thirteen original colonies may be taken to mark a change in American agricultural affairs.

These thirteen colonies occupied a strip along the Atlantic slope of about one-twenticth of the habitable parts of the North American continent north of the Spanish possessions. They were confined to this narrow strip by a number of circumstances, but mainly by hostile Indians. 
New England Difficulties.-New England was especially cramped for fertile soil. Land they had a plenty for the sparse population of those days but much of it was poor and unfruitful, much of it was rocky, rough and difficult to till. There was but one efficient means of transportation and that was by water. This means of communication was closed in the winter to the New Finglanders exeept those immediately on the ocean. There was no opportunity for expansion northward because of the French and Indians of Canada. On the west they were blocked by the territorial elaims of the colony of New York. Many New England farmers became discouraged with their conditions and went to other colonies. A settlement of New Englanders about 1640 was attempted on the Delaware River; another a few ycars later was made at the present site of Amnapolis, Maryland; still another prior to 1661, was ventured at Cape Fear, North Carolina. Many New Englanders migrated to New York, New Jersey and

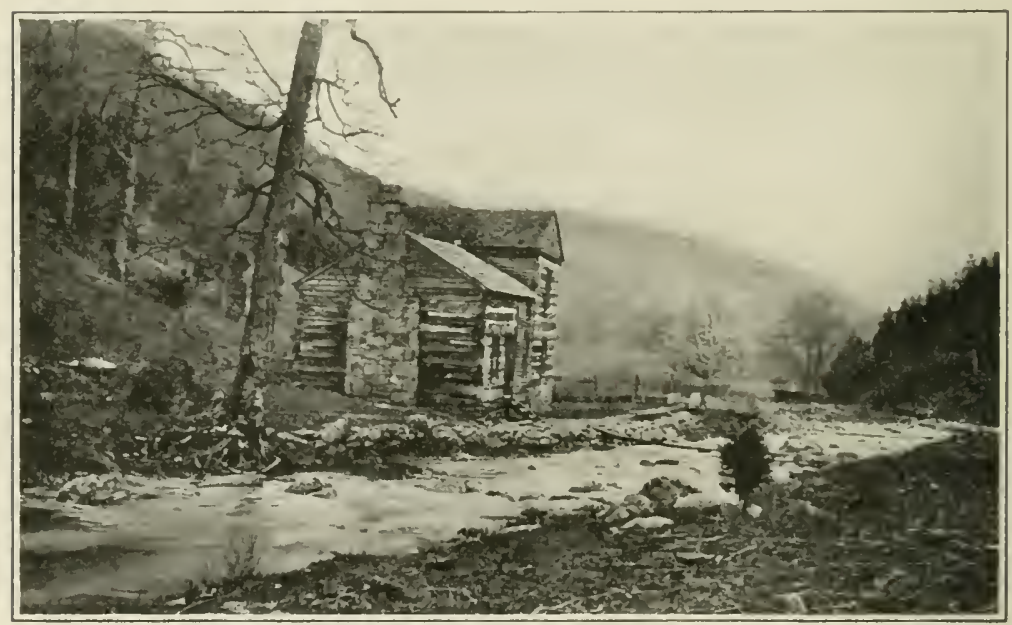

Fig. 26.-A Pioneer home among the mountains. (Photo by Dr. R. A. Oakley.)

Virginia and many resorted to commerce and manufacturing. Sparse settlements were also extended along the coast of what is now Maine.

New York Limitations. - Growth of the New York Colony was held in check by the French in Canada but to a greater degree by the porrerful Iroquois or Five Nations. These Indians inhabited the central and western parts of what is now New York State. 
The English did not dare to offend the Iroquois for fear of retaliation on the part of the sarages if aroused and were further influcneed by the protection which the Iroquois afforded as a barrier against the French and Indians of Canada. The English government paid tribute in clothing, axes, hatchets, hoes and other articles to the Iroquois Indians for many years prior to and including the French and Indian War. After 1763, a barrier was no longer required and the colonists began to assume the normal truculent, swash-buckling attitude towards the Iroquois tribes in that part of the country as had been shown other tribes in other parts of America.

When the Iroquois participated in the Rerolution on the side of the Royalists, the colonists had the long looked for excuse for invading the Indian country and administering a severe ehastisement. It was not, however, until after the Revolution that the great fertile Crenesee Tract of western New York was opened to white settlers.

Restrictions of the Southern Colonies. - The rest of the colonies from Pennsylvania to Georgia were confined within narrow bounds partly by the mountains, and partly by the hostile tribes of Indians dominated and influeneed by the Freneh and Spaniards in the Ohio and Mississippi valleys.

Crossing the Mountains.--The great unknown country lying back of the mountains inspired the English with desires to traverse and explore. One of the principal accomplishments desired by the London Company of the Jamestown eolonists was that they should explore westward and discover the Pacific Ocean or at least a river flowing to that ocean. Capt. John Smith with a small band of soldiers actually explored about forty miles above the present site of Richmond in an attempt to carry out the instructions of the London Company in this laudable even though futile undertaking. After this no serious efforts were made to cross the mountains for more than fifty years. About 1646, Capt. Abraham Wood was given a tract of land at the falls of the Appomattox River, now Petersburg, Va. with the understanding that he was to maintain a band of rangers to protect the colony against Indian attacks from that direction. Wood used these scouts or rangers in exploring the country. One of these expeditions under the leadership of Henry Batts has left a journal giving their discoveries. This party consisting of five white men and seven Indians passed over the mountains 
near the headwaters on the Roanoke River and on the 13th day of September 1671 discovered a small stream "flowing westerly." This was at or very near the present location of Blacksburg, Va. The state of Virginia has built an enduring and appropriate monument their land-grant college, on that site which should be considered as commemorating the first authentically recorded discovery of water flowing into the Ohio River by white men. Following down this creek (Stroubles) they discovered a river, which they explored for about thirty miles. This river, now called the "New" they thought led to the Great Western Sea. ('ivil troubles incident to Bacon's Rebellion in the Virginia colony prevented further efforts in exploration enterprise for several years. In the meantime the discoveries of the French in the Mississippi Valley (1673) had been announced to the world and Captain Batt's achievement was for a time forgotten.

Western Maryland and Virginia Settled.-At the time the last of the thirteen colonies was coming into being, Pennsylvanians had taken up much of the limestone soils of their province, typified by Lancaster County. These they found well suited to grain, and dependable, producing good crops year after year. Newcomers, young men without land, and those not well situated, began to look for similar soils elsewhere and followed that belt of remarkably productive land across western Maryland and into the valley of the Shenandoah in Virginia. Winchester (1732) was one of the first settlements, in the limestone belt of Virginia, Hurrisonburg, and Staunton and other centers were settled soon after. About 1744 a few families, probably following the old route of Batts, crossed the first ranges of the Alleghenies and settled on New River in what is now Montgomery and Pulaski counties in Virginia. (See Frontispiece also Fig. 26.) Similar settlements were made about the same time in the valley of the Holston in what is now Tennessee. It is readily apparent what these pioneers were seeking and that was owncrship of productive land. The constant cropping especially in the tobacco plantations had reduced production. Private ownership in large estates of land in the older settlements and farmed with a large retinue of servants and slaves also gave little opportunity to the individual, deroid of capital, to gain possession of a desirable estate. Pride and poverty led many a family into the wilderness of primeval America. Even the large slave holders were moving back from tidewater to seek more healthful surroundings. The 
farmers of northern Virginia, which is not so well suited to tobaeco culture but far better for grain and forage than the land in the eastern part of the colony, broke away from the well established order of tobacco and began general farming with live stock as a foundation. This region together with western Maryland and Pennsylvania constituted the wheat belt of colonial America.

Meanwhile the cattle ranches of the southern colonies were extending their grazing operations farther and farther westward.

Kentucky Explored.-Between 1749 and 1751, two exploring expeditions, were made into what is now Kentucky. Dr. John Walker of Virginia with a few companions had gone to the New River then to the Holston and through Cumberland Gap into the eastern portion of Kentucky returning across the mountains by the way of Stauton, Virginia without secing anything but rough mountain land and tangled rhododendron thickets.

Christopher Gist employed by the Ohio Company to locate a large body of fertile land which that corporation planned to colonize went down the Ohio River and penetrated the "bluegrass" region of central Kentucky returning across the mountains to Mountain Lake in Giles County, Virginia, and then down Sinking Creek to New River and up that stream to his home in North Carolina. Much information in regard to the Ohio and Mississippi valleys had previously been aequired from Indian traders.

The terrible experiences of some of the outlying planters, due to Indian attacks during the French and Indian War filled all the settlements in Eastern Virginia and the Carolinas with dread of their recurrence. As long as there were no white settlements west of the mountains just so long was there no assurance of safety in the more remote parts of seaboard colonies. A raiding party of Indians could cross the mountains, fall unexpectedly on a single farm or group of farms and then make good its escape by the route it eame. One of the greatest blunders committed by the British Government in its control of the American colonies was in passing the "Proclamation of 1763 " which prohibited settlements west of the erest of the Allegheny mountains. This like many other laws of similar nature was ignored by the colonists as far as making settlements was coneerned. But what made the law obnoxious was the inability of these settlements to organize a legal govenment so long as the 
colonies remained loyal to (ireat Britain. Hundreds of settlers began pushing their way along the passageways of the Alleghenies. These adventurous frontiersmen were a peculiarly mixed class of individuals. During the period between the close of the French and Indian War (1763) and the beginning of the Revolution, (1775) the frontier became a twilight zone between eivilization and savagery. Hither flocked the felons and renegades of the older settlements and the population was greatly increased and the general moral character much benefited by the addition of many foreign immigrants especially Scoteh, Irish, and Germans who were urged and aided by the merehants and planters along tidewater to pitch their habitations in the backwoods country. The comment written, in 1765 , by a French traveler in America, while in North Carolina on the Roanoke River, is pertinent to the subject:

the lands back of the first of mountains, what they Commonly Call the blue ridge, are very rich, they are Inhabited by the scoteh Irish, Germans, and Dutch, which were sent thither to Serve as a bariére betwixt the lower setlers and the Indians; this, however, turned out otherwise, luckily for the poor wretehes, that were sent there to be butcherd; necessity, and the great Distance from any seaport, or town, obliged them to be industrious in riseing all their necessaries within themselves, and at the same time to be watchful of the Indians and secure their litle habitations with palisadoes and out works; the Soil answered beyond their Expectations, in So much that it is at present the plentifulest part of America. They have all sorts of Catle, grain, roots, and fruits buter, Chees, and beer of their own brewing, they manufacture their own aparel and have Everything In short, Except salt and Iron: they Drive great Droves of Catle to the lower setlements, also butter, Chees and hemp which they Dispose of to adrantage and a Considerable quantity of flower . . . (3, p. 737).

Driving Cattle to Market.-Driving herds of cattle and hogs from the Blue Ridge mountains to tidewater shipping points as Charleston, Richmond, Baltimore and Philadelphia continued long after the close of the Revolution and was finally superseded by railroad transportation with stock cars built for the purpose. At the time this French traveler was in America droves of animals were formed in the mountain region and were driven in a very leisurely manner towards the market. Animals were purchased from farmers along the route and also much grain and forage purchased and fed in addition to the free pasturage 
obtained. As a result instead of there being a shrinkage in taking the animals to market they would arrive in better condition of flesh than they were in when started on their journey. This system made possible the sale of considerable forage by farmers who would otherwisc have had no market for it.

Advancement in Agricultural Knowledge.-During the last quarter of a century prior to the Revolution, agricultural development in the colonies entered a new phase.

Strangely enough the first evidences of attempts to combat the idea of predestination in farm operations in America occurred in the Connecticut Colony. The law to destroy barberry bushes to prevent wheat blighting has already been cited. In 1747 Jared Eliot of New Haven, grandson of the "Apostle to the Indians," published on his first "Essays in Agriculture," the begimning of our agricultural literature. The term essay was used in the sense of to try or to experiment. These publications of Jared Eliot induced others to start farm journals or diaries in which they recorded their observations and experiences.

Meager remnants of an extensive correspondence among the leading planters of the various colonies have been preserved from this period, enough to incite a desire that more of these letters may come to light. Agriculture often formed an important subject for discussion. The most intelligent minds in America were awakening to the fact that agricultural improvement offered a field for study.

Trials of Early Agricultural Writers.-A tendency on the part of a majority of farmers to ridicule every attempt at innovations in their occupation compelled many to "hide their light under a bushel." Then too many writers on agricultural subjects were so palpably ignorant of practical farm practices or wrote propaganda for special interests that "book farming" was in bad repute. So those who ventured to write on the subject of agriculture frequently hid their identities behind pseudonyms or confined their literary efforts in letters to friends whom they knew to be in sympathy with their work. The literary suobbishness of the time which decreed that printed matter should be couched in classic terms helped deter the unlcarned farmer from breaking into the realm of letters. "Let it be a secret as if it was some heinous crime" the wife of the author of "Letters from an American Farmer" is said to have advised when that work was contemplated by her husband (119). 
While the colonial farmers were slow in secking definite information pertaining to their occupation, enlightened English writers were becoming more and more insistent that reliable data derived from earefully conducted experiments would have a beneficial influence on agrieulture. Plattes, Hartlib and Cowley all middle seventeenth century writes had emphasized the need of agricultural experiments or instruction in the handling of soils, plant culture and animal husbandry at the higher institutions of learning. One of the elearest of the early statements of the need of replacing the haphazard in farming by precise knowledge of the facts involved was written by Home, in $1757 .{ }^{1}$

Agriculture does not take its rise originally from reason, but from fact and experience. It is a branch of natural philosophy, and ean only be improved from the knowledge of facts, as they happen in nature. It is by attending to these facts that the other branches of natural philosophy have been so much adranced during these two last ages. Medicine has attained its present perfection only from the history of diseases and cases delivered down. Chymistry is now reduced to a regular system, by the means of experiments made either by ehance or design. But where are the experiments in agriculture to answer this purpose? When I look around for such, I can find few or none. There then, lies the impediment in the way of Agriculture. Books in that art we are not deficient in; but the book which we want is a book of experiments. . . . In time this plan may afford fund (of information) sufficient for some future comprehensive genius, who, laying the different, and often seemingly opposite experiments together, and confiding all their concomitant circumstances, may be able to reduce the practice to fixed and permanent rules. This good fortune seldom happens to the first experimenters in any art; for they see things in too narrow a view, and often with too prepossessed a mind. It is reserved for that unbiased and sound judgment, which ean take from every opinion whatever truth it contains; and from the whole united together, raise one regular beneficial and lasting system.

Another observation of a similar nature but bearing directly on the need of an experimental garden in America follows:

It is impossible to know what the merit of the plants indigenous in these colonies, is, unless there was a plantation established at the public expence, under the direction of a skilful botanist, and one perfectly well acquainted with the practice as well as the theory of agriculture.

1 See Letter of R. J. H. De Loach, in Science, v. LV, No. 1414, p. 12 S. Feb. 3, 1922, also Francis Home MD, "Principles of Agriculture," pp. 201207, London, 1757 . 
In such a plantation, improvements might be made in culture of tobaceo: vineyards might be planted and eultivated, both of the native vines, and also of foreign ones. Experiments might be made on the culture of silk. All the native plants, like those I have just mentioned, which promised any thing of utility, might be brought into culture, and trials made of their worth, as materials for manufacture. Such a plantation well :upported, would be attended with some, if not all those excellent consequences which flowed from the gardens of the Dutch Fast India Company, at the Cape of Good Hope (4, v. I, p. 275). (See p. 211.)

Self-sufficing Agriculture vs. Commerce--Colonial agriculture at the close of the period might be likened to a giant unaware of his strength. The inventive genius which later did so much to increase production had little opportunity for expression. Bullied, cajoled and bribed into attempting crop culture that was often economically unprofitable the colonial farmer by cut and try methods had worked out a system for himself that was successful in practice although not popular with economists and governmental officials. I self-sufficing agriculture is not conducive to commercial and industrial enterprises no matter how contented and comfortably situated the farmers may be as a class. The interests of commerce and manufacturing in England were more concerned in creating wants in the colonies for English goods than they were in the production of the means to pay for those articles. There was often serere criticism of the colonists because they did not congregate in cities where there would be a large consuming population instead of dispersing in out-of-the-way plantations. When cities finally developed as Boston, New York, and Philadelphia the results were not as anticipated. The demands were there but the means to buy were obtained only by manufacturing and commerce.

Washington's Opinion of Agricultural America.-No man during the colonial period was better qualified to appraise the agricultural possibilities of America than was Ceorge Washington. He was an able farmer and deeply interested in everything pertaining to that occupation. His public services necessitated his traveling over much of the then inhabited parts of Anerica and his wide acquaintanceship with the foremost planters of his time gave him an unusual opportunity to know prevailing conditions in places he had never seen. He was keen to grasp everything that might be of use on his Mount Vernon estate or might tend to improve the farming practices of others. The 
letter which is given below is taken from the "Correspondence of Sir John Sinclair" (v. II, pp. 9-15, London, 1831). It was written near the close of Washington's second term as President of the United States but there had been no great change in the relative agricultural conditions at that time from those obtaining previous to the Revolution. The letter was sent in response to a request from Sinclair, who, owing to the uncertain political future of Great Britain at the time, was thinking of emigrating to America.

It may be noted that the relative importance of the lands contiguous to the upper waters of the Potomac held true to the era of railroad construetion if not to the present time.

Sir John Sinelair, in a letter to the American Farmer (1820) (v. 2, p. 367) shows his appreciation of Washington's advice. "I think it right to add, that owing to some peeuliar circumstances, I have in my possession, a description of the several states of America, drawn up by the "Illustrious Washington," himself. I have some thoughts of publishing that most valuable and curious document, that every true American, may be able to possess an account of his native country, from the pen, and sanetioned by the signature "of its greatest ornament."

As Franklin Knight did not include this "deseription of the several states" in his Letters on Agriculture from His Excellency George Washington, President of the United States, to Arthur Young, and Sir John Sinclair (Washington 1847) and as the publication in which it does appear is somewhat rare the account is given in its entirety.

Philadelphia, 11th December 1796.

Sir,

The near view which you have of the Revolution in France, and of the political state of things in Europe, especially those of Great Britain, has enabled you to form a judgment with so much more accuracy than I could do, of the probable result of the perturbated state of the countries which compose that quarter of the globe, and of the principal actors on that theatre, that it would be presumption in me, at the distance of 3000 miles, to give an opinion relatively to either men or measures, and therefore I will proceed to the information required in your private letter of the 11th of September, which I will give you 
from the best knowledge I possess, and with the candour you have a right to expect from me.

The United States, as you well know, are very extensive, more than 1500 miles between the north-eastern and south-western extremities, - all parts of which, from the seaboard to the Appalachian Mountains, (which divide the eastern from the western water's), are entirely settled, though not so compactly as they are susceptible of, and settlements are progressing rapidly beyond them.

Within so great a space, you are not to be told, that there are great variety of elimates; and you will readily suppose too, that there are all sorts of land, differently improved, and of various prices, according to the quality of the soil, -its contiguity to, or remoteness from, navigation, - the nature of the improvements, and other local circumstances. These premises however are only sufficient for the formation of a general opinion, for there are material deviations, as I shall mention hereafter.

In the New England states, and the Pennsylvania inclusively, landed property is more divided than it is in the states south of them. The farms are smaller, the buildings and other improvements generally better, and, of consequence, the population is greater; but then, the climate, especially to the eastward of Hudson's river, is cold,-the winter long,-consuming a great part of the summer's labour in support of their stocks, during the winter; - nevertheless, it is a country abounding in grass, and sells much fine beef, besides exporting many horses to the West Indies. A mildew or blight (I am speaking now of the New Fngland states particularly), prevents them from raising wheat adequate to their own consumption; and of other grains they export little or none, fish being their staple. They live well notwithstanding, and are a happy people. Their numbers are not augmented by foreign emigrants; yet, from their circumscribed limits, compact situation, and natural population, they are filling the western parts of the state of New York, and the country on the Ohio, with their own surplusage.

New Jersey is a small state, and all parts of it, except the southwestern, are pleasant, healthy, and productive of all kinds of grain, ete. Being surrounded on two sides by New York, and on the other two by Delaware river and the Atlantic, it has no land of its own to supply the surplus of its population; of course, their einigrations are prineipally towards the Ohio. 
Pennsylvania is a large state; and, from the policy of its founder, and of the government since, and especially from the celebrity of Philadelphia, has become the general receptacle of foreigners from all countries, and of all descriptions; many of whom soon take an active part in the polities of the state; and coming over full of prejudices against their own government,some against all governments, - you will be enabled, without any comment of mine, to draw your own inference of their conduct.

Delaware is a rery small state, the greater part of which lies low, and is supposed to be unhealthy. The eastern shore of Maryland is similar thereto. The lands in both, however, are good.

But the western parts of the last-mentioned state, and of Virginia, quite to the line of North Carolina, above tidewater, and more especially above the Blue Mountains, are similar to those of Pennsylvania between the Susquehanna and Potomac rivers, in soil, climate, and productions; and, in my opinion will be considered, if it is not considered so already, as the garden of America; forasmuch as it lies between the two extremes of heat and cold, partaking in a degree of the advantages of both, without feeling much the inconveniences of either; and with truth it may be said, is among the most fertile lands in America, east of the Appalachian Mountains.

The uplands of North and South Carolina, and Georgia, are not dissimilar in soil; but, as they approach the lower latitudes, are less congenial to wheat, and are supposed to be proportionably unhealthy. Towards the seaboard of all the southern states, (and farther south the more so), the country is low, sandy, and unhealthy; for which reason I shall say little concerning them; for, as I should not choose to be an inhabitant of them myself, I ought not to say any thing that would induce others to be so.

This general description is furnished, that you may be enabled to form an idea of the part of the Cnited States which would be most congenial to your inclination. To pronounce, with any degree of precision, what lands could be obtained for, in the parts I have enumerated, is next to impossible, for the reasons I have before assigned; but, upon pretty good data, it may be said, that those in Pennsylvania are higher than those in Maryland, (and I believe in any other state), declining in price as you go south- 
erly, until the rice swamps of south Carolina and Cieorgia are met with; and those are as much above the medium in price, as they are below it in health. I understand, however, that from thirty to forty dollars per acre, (I fix on dollars, because they apply equally to all the states, and because their relative value to Sterling is well understood), may be denominated the medium price in the vicinity of the Susquehanna, in the state of Pennsylvania; from twenty to thirty on the Potomae, in what is called the valley; that is, lying between the North Mountain anct Blue Mountain, which are the richest lands we have; and less, as I have noticed before, as you proceed southerly. But what may appear singular, and was alluded to in the former part of this letter, the lands, in the parts of which I am now speaking, on and contiguous to tidewater, (with local exceptions), are in lower estimation than those which are above and more remote from navigation. The causes, howerer, are apparent: 1. The land is better; 2. Higher and more healthy; 3 . They are chiefly, if not altogether, in the occupation of farmers;-from a combination of all of them, purchasers are attracted; and of consequence, the price rises in proportion to the demand.

The rise in the value of landed property, in this country, has been progressive, ever since my attention has been turned to the subject, (now more than forty years); but, for the last three or four of that period, it has increased beyond all calculation, owing in part to the attachment to, and the confidence which the people are beginning to place in their form of government; and to the prosperity of the country, from a variety of concurring causes, none more than to the late high prices of its produce.

From what I have said, you will have pereeived that the present prices of land in Pennsylvania are higher than they are in Maryland and Virginia, although they are not of superior quality. Two reasons have already been assigned for this; first, That in the settled part of it, the land is divided into smaller farms, and more improved; and second, Being in a greater degree than any other, the receptacle of emigrants, these receive the first impressions in Philadelphia, and rarely look beyond the limits of the state; but besides these, two other causes, not a little operative, may be added; namely, that until Congress passed general laws, relative to naturalization and citizenship, foreigners found it easier to obtain the privileges annexed to them in that state, than elsewhere; and because there are laws here 
for the graclual abolition of slavery, which neither of the two states above mentioned have at present, but which nothing is more certain than that they must have, and at a period not remote.

Notwithstanding these obstacles, and although I may incur the charge of partiality, in hazarding such an opinion at this time, I do not hesitate to pronounce, that the lands on the waters of Potomac will, in a few years, be in greater demand, and in higher estimation, than in any other part of the United States. But, as I ought not to advance this doctrine, without assigning reasons for it, I will request you to examine a general map of the United States, and the following facts will strike you at first view: That they lie in the most temperate latitude of the United States;that the main river runs in a direct course to the expanded part of the western country, and approaches nearer to principal branches of the Ohio, than any other eastern water, and of course must become a great, if not (under all circumstances) the best highway into that region; - that the upper seaport of the Potomac is considerably nearer to a large portion of the state of Pennsylvania, than that portion is to Philadelphia, besides accommodating the settlers thereof with inland narigation for more than two hundred miles; - that the amazing extent of tide navigation afforded by the bay and rivers of Chesapeak has scarcely a parallel. When to these are added,--that a site at the junction of the inland and tide navigations of that river is chosen for the permanent seat of the general government, and is in rapid preparation for its reception; - that the inland navigation of the river is nearly completed to the extent above-mentioned;that its lateral branches are capable of great improvement at a small expense, through the most fertile parts of Virginia, in a southerly direetion, and erossing Maryland, and extending into Pennyslvania in a northerly one, through which, (independent of what may come from the western country), an immensity of produce will be water-borne, thereby making the federal city the great emporium of the United States;-I say, when these things are taken into consideration, I am under no apprehension of having the opinion I have given, relative to the value of land on the Potomac, controverted by impartial men.

There are farms always and everywhere for sale. If therefore events should induce you to cast an eye towards America, there need be no apprehension of your being accommodated to your 
liking; and if I could be made useful to you therein, you might command my services, with the greatest freedom.

Within full view of Mount Vernon,-separated therefrom by water only, - is one of the most beautiful seats on the river, for sale, but of greater magnitude than you seem to have contemplated. It is called Belroir, and did belong to George William Fairfax, Esq. who, was he living, would now be Baron of Cameron, as his younger brother in this country, (George William dying without issue), at present is, though he does not take on himself the title.

This seat was the residence of the above-named gentleman before he went to England, and was accommodated with very good buildings, which were burnt soon after he left them. There are near 2000 acres of land belonging to the tract, surrounded in a manner of water. The mansion-house stood on high and commanding ground. The soil is not of the first quality; but a considerable part of it lying level, may, with proper management, be profitably cultivated. There are some small tenements on the estate, but the greater part thereof is in wood. At present, it belongs to Ferdinando Fairfax, son of Bryan Fairfax, the gentleman who will not, as I said before, take upon himself the title of Baron of Cameron. A year or two ago, the price he fixed on the land was (as I have been informed), 3315 flollars per acre. Whether not getting that sum, or whether he is no longer disposed to sell it, I am unable with precision to say, for I have heard nothing concerning his intentions lately.

With respect to the tenements I have offered to let, appertaining to my Mount Vernon estate, I can give no better description of them, and of their appearances, than what is contained in the printed advertisement herewith enclosed. But that you may have a more distinct view of the farms, and their relative situation to the mansion-house, a sketch from actual survey is also inclosed, annexed to which I have given you, from memory, the relative situation and form of the seat at Belroir.

The terms on which I had authorised the superintendent of my concerns at Mount Vernon, to lease the farms there, are also inclosed; which, with the other papers, and the general information herein detailed, will throw all the light, I am enabled to give you, upon the subject of your inquiry. To have such a tenant as Sir John Sinclair, however desirable it might be, is an honour I dare not hope for; and to alienate any part of the fee- 
simple cistate of Mount Vernon, is a measure I am not inelined to, as all the farms are connected and parts of a whole. With very great esteem and respect, I have the honour to be, Sir, your most obedient and obliged humble servant,

\section{$\mathrm{G}^{\circ}$. Washington.}

Comment On Live Stock.-From the same source written two years carlier is excerpted a statement in regard to the condition of live stock in America (p. 19).

Our domestic animals, as well as our agriculture, are inferior to yours in point of size; but this does not proceed from any defect in the stamina of them, but to deficient eare in providing for their support, experience having abundantly evinced, that where our pastures are as well improved, as the soil and climate will admit,-where a competent store of wholesome provender is laid up, and proper care used in serving it, that our horses, black cattle, sheep, \&c. are not inferior to the best of their respective kinds which have been imported from England. Nor is the wool of our sheep inferior to that of the common sort with you. As a proof, after the peace of Paris in 17S3, and my return to the occupations of a farmer, I paid particular attention to my breed of sheep, (of which I usually kept about seven or eight hundred). By this attention, at the shearing of 1789 , the fleeces yielded me the average quantity of $5 \frac{1}{4} \mathrm{lbs}$. of wool; a fleece of which, promiscuously taken, I sent to Mr. Arthur Young, who put it for examination into the hands of manufacturers. These pronouned it to be equal in quality to the Kentish wool. In this same year, i.e. 1759, I was again called from home, and have not had it in my power since to pay any attention to my farm; the consequence of which is, that my sheep, at the last shearing, yiclded me not more than $21 / 2 \mathrm{lbs}$. This is not a single instance of the difference between care and neglect; nor is the difference between good and bad management confined to that species of stock: for we find that good pastures and proper attention can, and does, fill our markets with beef of seven, eight, and more hundred weight the four quarters, whereas from 450 to 500 , (especially in the states south of this, where less attention hitherto has been paid to grass), may be found about the average weight. In this market some bullocks were killed in the months of Mareh and April last, the weights of which, as taken from the accounts which were published at the time, you will find in a paper inclosed. These are pampered steers, but from $\$ 00$ to a thousand the four quarters is no uncommon weight. 


\section{CHAPTER XIX}

\section{INTRODUCTION OF EUROPEAN CROPS}

The introduction of a great many crops by the Spaniards, in 1493 , into the West Indies has already been noted. Since that date new plants of economic importance have been added from time to time to Old World agriculture and in turn have found their way to America. The introduction of practically all of the plants mentioned in the discussion of fifteenth century European agriculture into the present territory of the United States was made with the establishing, first of the Spanish colonies and then later and independently of the English and of the French. As has been pointed out in the discussion of the exploration period many seeds were sown that did not have time to mature before the planters packed their baggage and left this continent. So it is usually impossible to give even an approximate date when a certain crop was first grown in this country. Then too, many crops may have been grown for years by a few individuals before their merit has been generally recognized and any mention is made of them in print.

A few Old World crops need special attention in regard to their introduction due to their importance or to the confusion of records concerning their early history. In this group are cowpeas, millet, sorghum, alfalfa, grasses, clovers and hops.

Data concerning other crops are given in the accounts of the various settlements.

Grasses and Clovers.-The introduction of tame forage plants probably occurred soon after the settlements but whether this was done by design or accomplished accidently through the importation of forage to feed the animals during the voyage it is impossible to say.

Under the heading "Provisions for Husbandry" in "A Relation of Maryland" published in London 1635 the prospective colonist is advised to take among other things a "good store of claver-grasse seede to make good meadow," (\$5, p. 98) which indicates that some of the colonists at least brought seeds of forage plants with them. Red clover had then been but recently 
introduced into England and was commonly called Claver grass, Clover grass or Flander's Clover.

Claverack.-The village of Claverack in Columbia county New York derives its name from the Dutch "Kleverack" literally elover reach or elover field applied as early as 1615 to a stretch of land along the east side of the Hudson River (86). This would indicate an early introduction of elover there as no species of elover are known to be native to that region.

English Grass.-The term "English" was early used to distinguish the introduced species of forage from the natural vegetation. Sometimes it was combined with other words as English elover, English hay, ete., but the most common term was English grass, meaning a mixture of several plants including blue grasses, rye grasses, bents, and white clover.

In the report of the King's Commissioners (1665) it is stated in regard to Rhode Island that "In this province also is the best English grasse" (97). Denton (1670) writes:

The island (Long Island, N. Y.) likewise producing excellent English grass the seed of which was brought out of England which they sometimes mow twice a year (27).

Josselyn (1674) states in regard to New England "Our English Clover-grass sowen thrives very well." Budd (1685) says for New Jersey:

Our Mutton is also fat, sound and good, being only fed with natural Grass; but if we sprinkle but a little English Hay-seed on the Land without Plowing, and then feed Sheep on it, in a little time it will so encrease, that it will eover the Land with English Grass, like unto our Pastures in England, provided the Land be good (16).

Penn (1685) mentions seeding both great and small elover with a little old grass seed as an experiment in Pennsylvania, and Hugh Jones (1724) says that "many in Virginia raise good clover and oats and some have planted Sanfoin."

Red Clover in New York.-Kalm under date of June 4th O. S. 1749 wrote in regard to New York:

Red Clover was sown in several places on the hills without the town. The country people were now employed in mowing the meadows. Some were already mown; and the dry clover was put under cover, in order to be carried away the first opportunity (65, v. II, p. 71). 
Bluegrass. - The meager descriptions found in comnection with the term English grass are applicable to Kentucky bluegrass and that was probably the dominant grass in the mixture. Kalm (1751) identifies this grass at Montreal and found the French of Canada using it in a mixture with white elover as their principal hay crop. It is probable that the French were responsible for taking these plants about 1700 , to Indiana and Illinois where they spread to Ohio and Kentucky. The English explorers to that region in 1750 found them growing luxuriously (18).

Little attention was paid to distinct species of grasses in the seventeenth century. The seed used was gathered up in the chaff in hay mows or around stacks. The slow method of cutting grass in those days allowed some of it to become dead ripe before harvesting so this chaff often was well supplied with viable seed. The method did not allow for much eare in the selection of hay plants and was also responsible for the early introduction and dissemination of a great many Old World weeds.

Grass in Rhode Island.-As carly as 1647 Roger Williams in a letter to John Winthrop, Jr., mentions a grass which at that time was apparently of recent introduction and known only to the Rhode Islanders. The description is not sufficiently clear to identify the grass, but it corresponds more nearly to Rhode Island bent than any other species of cultivated grasses at the present time. Williams recommended seeding three bushels to the acre based on the experience of Rhode Island farmers, but added that it was readily spread by wind and animals if a crop were allowed to remain uncut (83, v. VI, p. 146).

Timothy.- Timothy was the first grass cultivated in America to attract much attention. While there have been many confusing statements made in agricultural literature in regard to this grass the evidence indicates: (1) That it was an Old World plant and grew naturally in waste places in England where it was known as cat's tail grass. (2) That it was first used as a hay plant, prior to 1720 , by a man named Herd living near Portsmouth, New Hampshire and has ever sinee been known in New England by the names of herd's grass. (3) That it was taken to New York, Maryland, Virginia and North Carolina by one Timothy Hanson who had probably lived near Portsmouth, New Hampshire. It became popular in these colonies and Pennsylvania and was known as Timothy Hanson's grass which was shortened to timothy (92). It was frequently mentioned from 1746 on and 
it still maintains its place as the dominant hay plant of the country. Timothy seed was taken to England in 1763 but the consensus of opinion there was not strongly in its favor, although it had many enthusiastic advocates favoring its culture.

An Englishman's account of New England at the close of the colonial period illustrates the important part played by this grass in the development of this country.

A large portion of every farm in New England, consists of meadow and pasture land; wherein it much resembles the better parts of the mother country. In the low lands, the meadows are rich, yielding large quantities of hay, which, though apparently coarse, is much liked by all cattle; the common herbage of many of these is a grass which has made much noise in England under the name of Timothy grass. Two or three tons of hay an acre are not uncommon produce in these meadows (4, v. I, p. 57 ).

Orchard Grass.--Orchard grass is another plant which became popular in America although thought of little value in England where it had long been known by the name of cock's foot grass. The cultivation of orchard grass appears to have started in Virginia, prior to 1760 , about which date the Society of Arts and Sciences in England imported some seed of this plant as they had probably not recognized it under its American name of orchard grass. It did not attract much attention in the colonies other than Virginia until after the Revolutionary War. Washington in a letter to William Strickland dated July 12, 1797 says:

Orchard grass of all others is in my opinion the best mixture with c'over: it blooms precisely at the same time rises quick again after cutting stands thick, yields well, and both horses and cattle are fond of it green or in hay. Alone unless sown very thick it is apt to form tussocks (127).

Rye Grass.-Among the other tame hay plants which were cultivated in colonial times may be mentioned rye grass. The term rye being a corruption of the word ray which in turn came from the French word ivrai, which usually was applied in France to tall meadow oat grass (Arrhenatherum elatius) but in England ray grass was Lolium perenne.

In a Diary of William Logan of Philadelphia written about 1755 "rye or ray grass" is recommended for meadows, the chief drawback being as he says: 
to gett Good seed it is frequently perished before it is shipped or suffers in its Passage and Little or no seed is to be had here as the Farmers will cutt before it is Ripe.

This same farmer mentions Salem grass or white head, probably velvet grass (Holcus lanatus) also fowl meadow grass, seed of which he had from "Jared Elliot in New England" (71).

Jefferson (17S2) lists the grasses grown in Virginia in his time as lucern, St. Foin, burnet, timothy, ray and orehard grass; red white and yellow clover; greensward, blue grass and crab grass" (59). It is quite probable that Jefferson meant tall oat grass when he used the word ray as he was well versed in French.

Crab Grass.-Romans (1775) writing for Florida indicates the scarcity of good forage grasses for that region.

The artificial grasses here are 1st: That kind of grass known in the islands by the name of dog grass, and in Carolina and Georgia by that of crop grass, and by the French of Florida chiendent: this so greatly resembles the annual meadow grass, that I would rank it as one of that class; its leaves are broader; this rises naturally after the ground is broke up and will continue in the ground two or three years, when the ground being again plowed up, a fresh crop ensues, this is all the culture it wants; in Carolina and Georgia this is apt to plague the planter much by reason of its continual renovation, and the strong matting of its roots whereby it renders the surface of the earth in a great measure impenetrable to the hoe, wherefore they wish to destroy it.

This grass was known in Virginia at that time as crab grass which name has persisted.

\section{Nut Grass.}

A second species of the same kind with narrow leaves called by the French Herbe au cheval, from the fondness of horses for it; in Carolina it is called nutt grass from a nutt found at its root; this, when once it takes in the ground, is as easily entertained as the first and makes a very good pasture on poor ground, but it must be well fenced against hogs, which being very fond of the nutts would root all up in a short time $(100$, p. 128,129$)$.

Both of these plants, erab grass and nut grass, are now considered pests although the former still makes up a large part of the hay crop in the cotton belt. Roman's fear that hogs would destroy nut grass has unfortunately not proved true in practice, as it is one of the most difficult of all weeds to eradicate when once it gets well started in a cultivated field.

Alfalfa.-Alfalfa has long been grown in the Mediterranean region. The name, according to Dodoens (1578) is Spanish from 
Alfasfasa an Arabic word (73). In France it was generally called lucerne while in English it has been variously called both alfalfa and lueerne; also Burgundy trefoil and Spanish trefoil. This plant is described in most of the old herballs though of ten confused with bur clover.

Alfalfa in the West Indies.-Alfalfa was undoubtedly among the seeds of plants brought to the West Indies by Columbus (1493) although not mentioned specifically.

Hughes (1750) found it in the Barbadoes and says:

This kind of Grass hath been but very lately cultivated in this Island and even now but by some curious Persons. It is of a very quick Growth in wet weather; but so soon dies in dry seasons, that it is not worth cultivating here however valuable it may be where there fall more constant Rains (55, p. 202).

Alfalfa in Georgia.-The first mention of alfalfa in connection with English North America so far found is that of Moore who, in 1736, visited Frederica on St. Simons Island in the Georgia colony.

There was Barley, Turnips, Lucern-Grass, Pumpkins, Water-Melons, and several other Seeds sown or sowing daily (79, p. 53).

Alfalfa Seed Sent to Pennsylvania.-Peter Collinson of London in a letter dated January 26, 1735-9 to John Bartram of Philadelphia accompanying a shipment of seed mentions "some Burgundy Trefoil (Mcdicago sativa I. or Lucerne) for J. Logan" (26, p. 124).

Alfalfa in South Carolina.--Under date of July 1, 1739, Eliza Lucas, then a girl of eighteen who was managing several large plantations in South Carolina for her father, a colonel in the British army stationed in Antigua, wrote in her notebook:

Wrote my father a long letter on his plantation affairs . . . on the pains I had taken to bring the Indigo, Ginger, Cotton and Lucern and Casada to perfection and had greater hopes from the Indigo (if I could have the seed earlier next year from the West Indies) than any of $y^{\circ}$ rest of ye things I had try'd.

Apparently the lucern or alfalfa culture was not successful for three years later she noted "shall try different soils for the Lucern grass this year" (72).

Mentioned by George Washington.-While alfalfa is occasionally mentioned in connection with colonial agriculture it is generally in the form of a recommendation as a crop thought 
worthy of trial. 'There is no evidence that it reached beyond the experimental stage in the English settlements. Washington writing to Jefferson in 1795 states:

Luecrne has not succecled better with me than with you; but I will give it another and a fairer trial before it is abandoned altogether $(127$, ห. 12, p. 320).

Millet.-The seed of the millets variously designated by the carly writers as mil, mill, milium and panic, has been an important source of human food from time immemorial. At the time

II. PANICVM DOMESTICVM. III. PANICVM SYLVESTRE.
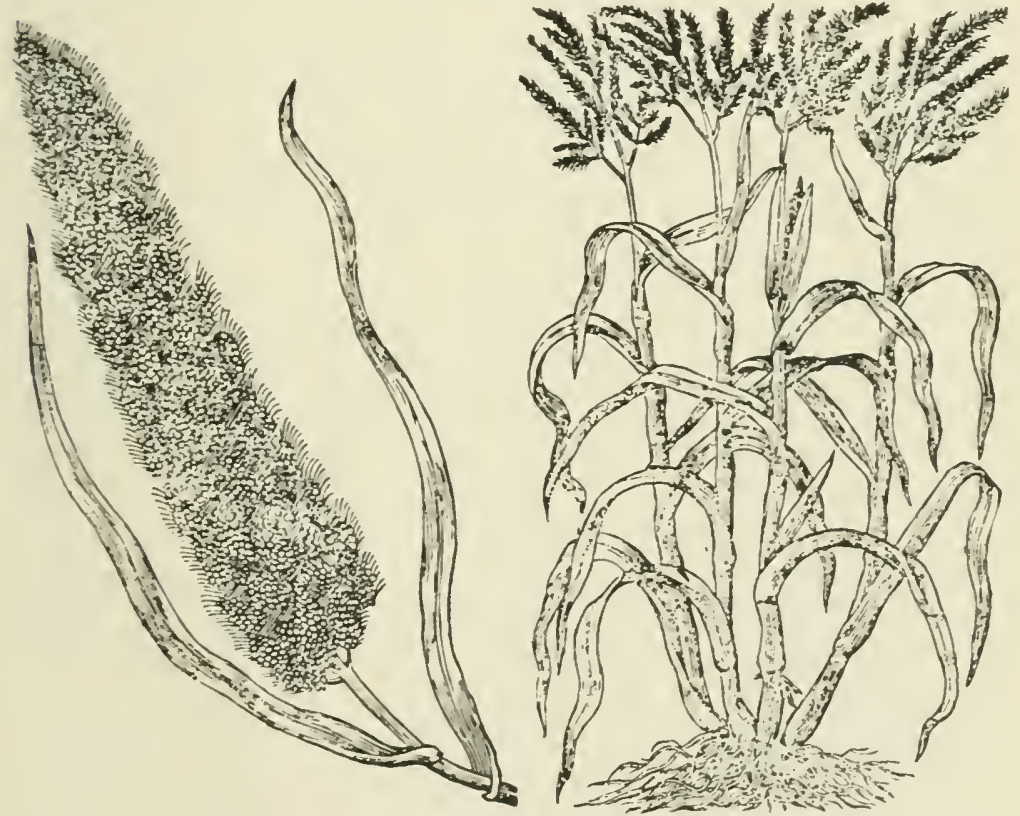

FIG. 27.-Two varieties of millet. (Bouhin, 1598.)

of the discovery of America, perhaps, as many people subsisted on millet seed as on all the other cereals put together. Not only was it a favorite food of the hordes of natives in Africa and Asia but was also plentiful in the markets of central Europe. Millet bread is much in evidence in the piles of kitchen refuse left by the European Lake dwellers (81).

All of the millets are probably of Old World origin. The foxtail speeies (II Fig. 27) appear to have originated in Asia from 
the common foxtail grass (Setaria viridis) and broom corn millet (Fig. 2S) appears to be of Asiatic origin also while penieillaria or pearl millet judging from the number of related species found there was probably native to Africa. Clusius (1601) incorporated the word Americani in his deseriptive Latin name for pearl millet. This has led some writers to ascribe an American origin to that species. Clusius no doubt obtained as he stated the specimen which he described from the West Indies where it might have been grown for a century previous from an African introduction.

That the millets never became of much importance as a source of human food in America is apparently due to the superiority

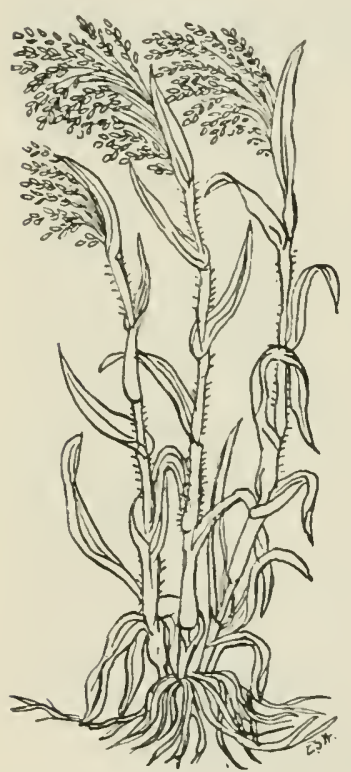

Fig. 28.-Broom Corn Millet, often called Milium or Mil. (After Lytes' Translation of Dodens. 1578.) of maize and wheat; also to the fact that the peoples who settled America had not become millet eaters.

Peter Martyr in his seventh Decade while describing the products of Yucatan wrote:

They sawe also another kinde of corne called Zathi; they suppose it to be Milium or Millet; nor doe they certainly affirme it especially because few of the Castillanes understand what milium is seeing they never sowe it in Castile.

Millets Used by Slaves.-The introduction of pearl millet was coincident with the bringing of slaves to the West Indies.

Sloane (1689) found pearl millet in Jamaica about "Negro's Plantations" as did Catesby in the southern part of this country. Catesby noted "These two grains" (sorghum and pearl millet) "are rarely seen but in Plantations of Negros, who brought it from Guinea, their native Country, and are therefore fond of having it." He also observes that it was used to feed fowls (108, v. I, p. 104) (20).

Brickell (1737) mentions millet which he says: 
The Plenty of other Grain, prevents the Planters from sowing much of it, being only made Use of in Carolina to fatten their Poultry with (13, p. 16).

Millet in New England-Common Millet was grown in Massachusetts before 1637 but its use there was not general (57, p. S2).

Jared Eliot tried millet in Connecticut before 1747 the seed of which he obtained under the name of East India Wheat. "I soon discovered" says Eliot "that it was no species of wheat, but that it was millet" (32) indicating that it was not unknown in Connecticut at that time. Eliot recommended millet as a eatch crop to use when clover had failed.

While the millets as shown were introduced during colonial times their use in this country was extremely limited until about the middle of the nineteenth century.

Cowpeas. - The time of the introduction of the cowpea into America has been an interesting subject of speculation for several investigators. That the cowpea was known in the Old World prior to the discovery of America has been settled beyond any reasonable doubt. This is strong evidence against the probability of its being native to America. Yet the very earliest writers of American products mention plants which might easily be taken to mean cowpeas. The first definite description of the cowpea in America is that of Sloane in 1707, which is accompanied with an illustration of the plant. Sloane states:

Phaseolus erectus minor, Calavances . . Almost round white Pease something resembling a kidney with a black Eye not so big as the smallest Field pea. They are accounted the sweetest and best for food of any of them.

Sloane dominated English botany until he was superseded a half century later by Linnaeus. After Sloane's deseription, Calavance became the common name among the English for cowpeas all over the World. But the term had been in common use for several years previous to the time of Sloane. It is not easy to determine the origin of the word. It has been spelled in many ways and is thought by some to have been a corruption of the Spanish word "garbanzo" for chick-pea, but such a derivation is unlikely. Breton (1665) gives "calaouana" as a Carib Indian word for peas and beans of Brazil ("pois de bresil and Febue de brasill") Calaouana or Calaovana (as u and v were interchangeable in the 17 th Century) is probably the original 
souree of this term. It is quite likely to have been used at first in a general sense covering more than one species. Hughes (1672) - uses the term but he deseribes the chick pea or a similar plant. He says:

Some call them the Indian Vetches, some the Indian Pease; but those that are Inhabitans there, call them Calavances, or Calievancie (56).

While it is not possible to fix the date of the introduction of the cowpea into Ameriea, Piper has clarified the situation by calling attention to the Afriean origin of cowpeas (91). In all probability they were used as a food by the African natives prior to the diseovery of America and that their introduction into the West Indies was coincident with the bringing in of African slaves soon after 1500 .

Cowpeas in Asia.-The eowpcas reached eastcrn Asia at such an early date that many investigators eonsider that region its native habitat. Herbert (1626) describing a town in East India wrote:

We durst not land, the people are so treacherous, and bloudy, howbeit they came aboard vs in their small Canoes, and sold vs for other trifles, Coco Nuts, Mangoes, Iacks, greene Pepper, Caravances or Indian Pease, Hens Egges, and Buffols, which because rare are deere $(50)$.

This item helps confirm the identity of the East Indian bean which is undoubtedly the cowpea with the West Indian ealavance as Herbert had also visited the West Indies.

Cowpeas in the American Continent.-How and when cowpeas reached the mainland of North Ameriea is still more problematical. The earliest writers to mention them considered them a native Indian product. It seems eertain that the Indians adopted the eowpea very soon after the settlement at Jamestown, or elsc had them before.

An aet passed by the Virginia Assembly in 1666 fixing the prices at which eertain products would be accepted in payment of taxes plaeed "Wheate, Garravances and English Peas" at 4 shillings the bushel and "Indian peas of all sorts (except Garravances)" at 3 shillings, 6 pence (49,v. II, p. 233). While garravances might have meant chick-peas it is much more probable that cowpeas was the crop so designated. It is apparent that the Virginians looked upon them as a native Indian product even at that early date. A crop like cowpeas might have been aceidently introduced in the sixtecnth eentury by some of the 
European fishermen or exploring expeditions such as De Soto's. The fishing boats usually stopped in the West Indies before proceeding up the coast, and not infrequently had to put into any ereck or river they found in order to get fresh water.

Cowpeas in New England.-Josselyn who spent several years in New England between 1638 and 1663 wrote:

French beans, or rather American beans, the Herbalists call them kidney-beans from their shape and effects, for they strengthen the kidneys, they are variegated much, some being bigger a great deal than others; some white, black, red, yellow, blew, spotted, besides your Bonivis and Calavances and the kidney-bean, that is proper to Roanoke, but these are brought into the Countrie, the other are natural to the elimate (64, p. 73$)$.

There is nothing unusual in New England settlers having "Bonivis" (Dolichos lablab) "Calavances" (Vigna sinensis) or the "kidney bean that is proper to Roanoke" (Phaseolus vulgaris). They probably obtained the seed of these from Virginia and raised them in their gardens, using the pods green the same as snap beans are used now.

Cowpeas in South Carolina.-A writer who claims to have been in South Carolina 1680-82 says:

Pulse they have of great variety, not only of what Europe yield, viz. Beans, Pease, Callavance, Figdlaes ${ }^{1}$ and Bonarist ete. but many other kinds proper to the place and to us unknown $(19$, p. 68).

Cowpeas in North Carolina.-Lawson (1709) who was made Surveyor-General of North Carolina soon after that colony was settled by the whitemen and who about 1700 traveled much through the Indian country, wrote:

Of the pulse-kind, we have many sorts. The first is the Bushel Bean, which is a spontaneous Product. They are so called, because they bring a Bushel of Beans for one that is planted. They are set in the Spring, round Arbours, or at the Feet of Poles up which they will climb, and cover the Wattling making a very pretty Shade to sit under. They' continue flowering, budding and ripening all the Summer long till the Frost approaches, when they forbear their Fruit and die. The Stalks they grow on, come to the Thickness of a man's thumb and the Bean is white and mottled, with a purple Figure on each side it, like an Ear. They are very flat. ...

'Spelled "Figolaes" in Narratives of Early Carolina, p. 146, probably a corruption of the Spanish frijoles for kidney beans. Bonavist (from the Cape Verde island once known by that name now Boavista) means the chick pea (Dolichos Lablab) an Old World plant. 
We have the Indian Rounceval or Miraculous Pease so ealled from their long Pods and great Increase. These are latter Pease and require a pretty long Summer to ripen in. They are very good; and so are the Bunaris, Calavancies, Nantichokes, and abundance of other Pulse, too tedious here to name, which we found the Indians possessed of, when first we settled in America, some of which soris afford us two Crops in one Year; as the Bonavis and Calavaneies, besides several others of that kind.

The kidney-Beanes were here before the English eame being very plentiful in the Indian Corn-Fields (67).

Cowpeas Exported from Virginia and Maryland.-Douglass (1775) using the same Latin name and description as given by Sloane says in regard to Maryland and Virginia,

Calavances are exported to several of the other colonies white and red calavanees, or Virginia pease; they yield better than the common pease of Europe, and are good profitable food for the poorer sort of white people and for negro slaves $(28, \mathrm{v}$. I, p. 122 and $\mathrm{v}$. II, p. $375)$.

The Term Cowpea First Used.-The term cowpea appear's to have been at first attached to a particular variety of Vigna sinensis. Its first recorded use so far found is that of Jefferson.

The peas and the vetch are most acceptable incleed. Since you were here, I have tried that species of your field pea which is cultivated in New York, and begin to fear that that plant will scarcely bear our sun and soil. A late acquisition too of a species of our country pea, called the cow pea, has pretty well supplied the place in my husbandry which I had destined for the European field pea. It is very productive, excellent food for man and beast, awaits without loss our leisure for gathering, and shades the ground very closely through the hottest months of the year. This with the loosening of the soil, I take to be the chief means by which the pea improres the soil (60).

It is significant that Jefferson who achieved a considerable reputation as an amateur botanist should have considered cowpeas as a native American product and confirms the statement of other writers that cowpeas were commonly grown by the natives.

Cowpeas Grown by the Indians. - Le Page du Pratz (1718-34) an unusually good observer in distinguishing between native and introduced species mentions among the beans of western Mississippi:

The Apalachian beans are so called because we received them from a nation of the natives of that name. They probably had them from the 
English of Carolina, whither they had them brought from Guinea. Their stalks spread upon the ground to the length of four or five feet They are like the other beans, but much smaller, and of a brown colour having a black ring round the eye, by which they are joined to the shell. These beans boil tender, and have a tolerable relish, but they are sweetish, and sometimes insiped (69, p. 22S).

Sorghum.-Africa is so richly supplied with wild sorghums that there seems no reason for questioning that continent as the native habitat of the sorghums. The earliest recorded observations of travelers to Africa mention sorghum as one of the main food plants of the natives. The seed was beaten into flour and used to make bread or gruel. Making syrup of the juice of sorghum was practiced in Egypt. John Leo, who wrote extensively of northern Africa where he was in 1526, noted:

The sugar canes there bring not foorth perfect sugar, but instead thereof a certaine kinde of Honie like Sope, which they use throughout all Egypt (94, v. II, p. \$35, Eł. 1\$25).

The culture of sorghum spread to Asia Minor very early.

Sorghum Introduction Coincident with Slavery.-The introduction of sorghum into America dates like several other African products with the bringing of slaves to the West Indies. The seed was used to feed the slaves during the voyage and the Africans grew sorghums in their gardens in the New World.

Clusius described it in 1601 and notes that it was used as a food for "perroquets." It was known as Guinea Corn in America. Sloane found it in 1689 growing about negro plantations in Jamaica. Lawson says it was grown by the colonists in Carolina in his time which would be about 1700 and was used to feed hogs and poultry $(67$, p. 76$)$. It is quite likely that sorghum had been brought to the southern colonies, by negros during the seventeenth century. Catesby 1743 using the common name "Bunched Guinea Corn" notes:

But little of this Grain is propagated, and that chiefly by Negros, who make Bread of it, and boil it like Nanner of Firmety. Its chief Use is for feeding Fowls for which the Smallness of the Grain adapts it. It was first introduced from Afriea by the Negros (20).

It was not until the drier regions west of the Mississippi were settled that sorghum became of much value to America. Its superior drought resistant qualities make it more valuable than maize outside of the humid area but it has never been a real competitor of Indian corn where that grain thrives. 
Hops.-Hops were commonly grown in all North European countries as an ingredient to put in beer and ale to stop fermentation and impart a bitter taste. It was one of the few intertilled or cultivated crops grown in England in the seventeenth century. The culture of hops was commonly understood by all the colonists and as no special encouragements were necessary to induce them to grow the erop little mention is made of them in colonial literature. Enough was written however to inclicate that they were grown in practically every garden for home use.

Hop roots were mentioned among the plants to be sent with the Endicott expedition, in 1628, to Massachusetts Bay and they were frequently listed, by name only, among the erops grown in the various colonies.

Native Species. - Wild hops were found in vallies and moist places over the entire country east of the Great Plains and these often were used in place of the cultivated sort. "Hops grow naturally in Louisiana" wrote LePage du Pratz in 1758:

Yet such as have a desire to make use of them for themselves or sell them to brewers, eultivate this plant. It is planted in alleys, distant asuncler six feet, in holes two feet and one foot deep, in which the root is lodged. When shot a good deal, a pole of the size of one's arm and between twelve and fifteen feet long, is fixed in the hole; care is had to direct the shoots towards it, which fail not to run up the pole. When the flower is ripe and yellowish, the stem is cut quite close to the earth and the pole pulled out, in order to pick the flowers which are saved (69, p. 197).

The specilization of growing hops in the localities of America which are most farorable for its culture took place in the nineteenth century. 


\section{CHAPTER XX}

\section{INTRODUCTION OF DOMESTIC ANIMALS}

Too much emphasis can scarcely be placed on the importance of the role played by domestic live stock in the settlement and development of this country. We have seen how the early colonists were at first dependent on maize for their existence. But we have also seen how uncertain was that existence until domesticated animals had been introduced and sufficient time had elapsed for them to multiply and give a surplus for slaughter. After the first years of colonial settlements, when there finally developed a surplus of animals here in America, living became bearable and live stock raising was the pioneer type of agriculture as the frontier spread farther and farther back from the coast. Cattle, horses, hogs, poultry, sheep and goats if protected from wild animals could be kept before the forest was cleared for raising crops. Any family which possessed a few breeding animals of these species, more especially those having a cow or two, a sow, and a few chickens, might safely penetrate the wilderness to build a home. But the creation of many farm homes in America was successfully accomplished where the adventurers possessed none of these animals but depended upon capturing foundation stock from the wild herds of escaped domestic animals back of the settlements. Most of the wealth of the colonial agriculturists was represented, (1), by the land and its appurtenances to which they had title and, (2), the domestic animals which they possessed.

The colonial family that was supplied with a cow or two or a few milch-goats was safe from starvation, the game and other natural products of forest, supplying enough additional food to insure sustenance.

Swine.-We have seen how hogs became a prolific source of food in all of the colonies. If there had been a ready market at anything like fair prices for live hogs the rearing of this class of animals would have undoubtedly outstripped all others. As it happened the demand for beef, pork, and lard after the colonists 
own needs were supplied came almost entirely for provisions for ships and to supply the sugar islands in the West Indies. This, of course, necessitated salting and salt at that time was a scarce article the principal sourees being sea water and the deposits on some of the Spanish controlled islands of the West Indies. Despite these handicaps salted beef and pork beeame important articles of export and their preparation for shipment furnished employment to many men in getting out staves and headings and making barrels.

Salt Pork Exported.-The Virginia planters gained a lead in pork exports due to the excellence of their cured hams and bacon. Jones (1724) informs us that.

Their Pork is famous, whole Virginia Shoots being frequently barbacued in England; their Bacon is excellent, the Hams being scarce to be distinguished from those of Westphalia (63, p. 42).

Smithfield became famous for these products, and years have only added more glory to the reputation which that locality in eastern Virginia achiered in colonial times. Smithficld hams have never been excelled and seldom equalled in quality by those of any other locality. The methods of producing these as practiced today differ little from the methods in vogue two hundred years ago. The reason for the excellence of Smithfield hams appears to be due; (1) to the way the hogs are raised and (2) to the curing process.

The hogs were allowed to shift for themselves during the greater part of the year. In midsummer when the regetation was tough and unpalatable they became greatly emaciated, mere walking skeletons. In the fall during mast time, that is, when the acorns and nuts fall, the hogs took on flesh rapidly. They were then finished on corn and slaughtered during cold spells of November and December. The same system prevails today except some farmers provide fields of soybeans to be grazed to supplement the mast, and as nearly everyone in that region raises peanuts the hogs are used to gather the nuts left in the ground in harvesting that crop.

Cattle.-No modern improved breeds of eattle trace back to colonial ancestry. The almost universal opinion of European travelers to America during the seventeenth and eighteenth century was that the stock in this country was inferior to that of England and other north European countries. This was 
largely due to the santy winter feed and the rough eonditions under which they were kept. The smaller the animals the easier they were to transport and the cheaper the aniuls were bought the less loss was sustained if they died in transit. The Dutch and swede were the only people who brought good eattle to America in the early days.

In the south mueh of the breeding stock was obtained from the spanish colonies and these had been reared under range conditions which did not favor improvement. In Virginia and New England a type of animal suitable for oxen was favored rather than those of either a strictly beef or dairy type. 'The Swedes and Dutch of New York and New Jersey had the best breeds of general purpose beef and milk eattle to be found among the colonies and as we have seen these were drawn on largely by the Pennsylvania settlers for breeding stock when that colony was settled. The Rhode Island farmers possessed the highest producing dairy cows but these probably would not compare farorably with the strietly dairy breeds of the present time.

Black Cattle.-The term "black cattle" is frequently found in cighteenth century colonial and English agricultural literature. The French in Canada had an "excellent breed of black cattle" and they took them to Illinois. Black cattle were numerous in the southern Colonies. Premiums were offered in England for the best methods of feeding "black cattle." It is difficult now to determine just what signifieance the term "black cattle" had at that time and from what source the animals came. According to Mortimer (1717)

The red cow is reckoned to give the best milk and the black to bring the best calves (S0, p. 167, ed. 1717).

The largest eattle and those most estecmed for work animals in England in that period were the black breeds of Yorkshire and Staffordshire( 13 ).

The foundation stock of these breeds, was probably imported into England from the Continent and may have had the same ancestry as the black and white dairy breeds of the present time.

Mortimer (1717) mentions a "shorthorn'd cow of the Dutch breed." "Many of these cows," he says, "give two gallons of milk at a meal" (S0, p. 166, Ed. 1717).

The black Seoteh eattle, so popular now, were in the early years of the eighteenth enntury considered of little importance. Hale (1758) says: 
'The Lancashire breed is large, the Welch are smaller and the Seoteh least of all $(43, v$. II, p. $2 \$)$.

'To go back a little earlier, the Norman word "catel" came from the Latin capitale meaning wealth or property which for the Normandy farmers was mainly domestic live stock of all kinds. Qualifying words as cow, horned, neat and black were applied to the bovine animals to distinguish them from sheep, horses and swine. Perhaps, the clominating color at that time was black but later the term black cattle was used in England and America regardless of the color of the animals.

While the term was oceasionally used in a general sense synonymously with neat eattle, it became more and more restricted to beef eattle or those kept under range conditions for slaughter rather than to dairy eattle.

Black calves had a decided advantage over red ones in pionecr days in America. They were less likely to be attacked by wolves, the red calves being more readily mistaken for deer. For this reason black ealves brought a higher price than did red ones (131, p. 25).

With the rapid rise in popularity of the reds, whites and roans about the close of the eighteenth century, the term black cattle in its original sense dropped out of use entirely. Then as the word eattle became more and more restricted to the bovine species qualifying words were not necessary.

Sheep and Goats.- Some small animals such as poultry, sheep, goats and swine were included in nearly every colonizing expedition to America. They did not take up much space in the diminutive ships of those times and in case of need could be used for food. Fresh meat on ship board was an efficient safeguard against sickness as well as an aid in convalescence. In those days long before the art was known of preserving fresh meats in sterilized hermetically sealed containers or artificial refrigeration, it was their only means of providing these delicacies on ocean voyages.

Sheep and goats were doubly servicable to the colonists. Their wool was invaluable for clothing and their flesh for food. When protection could be given from wolves and other predatory animals there was little trouble in their maintenance. They could graze the natural vegetation in summer and gather much of their sustenance from young shoots of shrubs and trees in winter. Practically every plantation owner endeavored to keep 
a few at least of these animals. The climate and discases of the South have always made sheep raising except in the higher altitudes a precarious business but there were no such obstacles to be overcome in the North. Flocks of sheep and goats left to themselves on the islands off the New England coast multiplied rapidly and their rearing on the mainland was restricted only by the ability of the colonists to enclose their lands with fences.

It is one of the questions difficult to explain why the authorities in England did not encourage the production of fine wool in America. The English sheep had been bred for mutton and a light fleece of coarse staple. At the same time English weavers were importing large amounts of fine wool from Spain, and paying high prices, according to King James, ten shillings a pound which was just half the customary value placed on raw silk.

At that time there were no governmental inducements offered for the encouragement of wool production, in America as there were for hemp and silk. Mitchell (1767) noted this neglect of an opportunity for creating a valuable export commodity. "Were we to consider the proper improvements for the colonies in North America" say"s this writer: "wool should be the very first of them. They have already Wool enough, which is as fit for their use, as if it were finer, and the only way to hinder them to manufacture it, is to improve it so as to make it fit to send to England, in order to purchase their Manufactures instead of making them, and to supply the place of Spanish Wool" (76, p. 143).

The goat rivalled the sheep in popularity in New England in the early years of the settlements. Goats were hardy, and better browsers than grazers, a point of considerable importance before the advent of tame pastures and they were also used as milch animals.

Sheep and goats were an important factor in the development of the self-sufficient agriculture of the northern colonies. From the wool and hides of these animals efficient articles of dress were made for protection against the rigors of the coldest winters.

Prejudice against Mutton.--Discouraging as were the restrictions imposed by the English government on the manufacture of woolen goods to the development of the sheep industry, the prejudice in this country against mutton as a food was a greater hindrance. The objectionable flavor in mutton is now known to 
have been caused largely by not removing the thin membrane which surrounds the careass just bencath the pelt before cooking, and partly to slow unskilful methorls used in slatughtering and dressing the animals. The efficient methorls of modern slaughter houses have done a way with much of this objectionable favor of mutton and has greatly increased the popularity of this meat as a food. But in colonial times mut ton was about as objectionable to the Americans as pork is to an Israclite.

Poultry. - While not figuring prominently in colonial writings chickens, ducks, geese, and tame turkeys were of immense value to the settlers. Of all domestic animals they were the easiest to transport. Their increase was rapicl. The delicacy of the flesh of the birds and the high nutritive value of eggs contributed in no small measure to the home table and their feathers no less to the comfort of repose. No family except in extreme cases of famine was so poor that it could not have its flocks of poultry. The wild birds of the forests and migrating flocks of geese and ducks supplied the necls during early years while surplus stock was accumulating.

Chickens at Plymouth.-Winslow had messengers sent in 1623 from Massasoit, who was sick, to Plymouth for chickens in order to make broth for the invalid. The distance from Massasoit's dwelling to Plymouth was about 40 miles and by the time the messengers returned Massasoit had so far recovered through the help of Winslow's remedies that the chickens were saved for breeding by that thrifty Indian (134, pp. 320-2). While wild turkeys were very plentiful in America the tame breeds, in New England at least, were obtained from England. The French in the lower Mississippi Valley obtained tame turkeys directly from Indian flocks in that region and perhaps the southern colonies obtained their breeding stock from the same source.

Bees.-Honey-bees were introduced early among the English colonies. Cane sugar was scarce, high priced and honey was a favorite substitute both for swectening food and for preserving fruits. The frequent escape of swarms of bees stocked the forest with numerous "bee-trees" in adrance of the settlers. Many such swarms were recaptured, and the accumulated stores of honey furnished a delightful addition to the food supplies in the pioneer homes. Denton (1670) observed for Long Island: "You shall scarce see a house, but the South side is begirt with 
Hives of Bors, which increase after an incredible Manner" (27, p. 21).

Beverly (170.5) says for Virginia: "Bees thrive there abundantly and will very easily yield to the eareful Huswife a full Hive of Honey, and besides lay up a Winter-store sufficient to preserve their stocks" (9, p. 2S2).

Horses.-The chicf means of travel in colonial times was on horse back. C'oaches of various kinds were possessed by the wealthy at the beginning of the eighteenth century, but the character of the roads limited their use. Horses were imported freely during the early days of the settlements and their numbers increased rapidly. Nearly every colony had its droves of wild horses in the back settlements. The Indians took a great fancy to horses and stole numbers of them which not infrequently were recaptured by the white men in the skimishes between these races. Capturing wild horses was a favorite sport among the young colonials, especially in Virginia and North Carolina.

Horse Racing on Long Island.-Horse racing naturally appealed to the spirit of the time. Many of the settlers were familiar with fox-chasing and horse-racing in England.

The first regular race course appears to have been the New Market on Hempstead Plains, Long Island. This plain is perhaps best deseribed in the words of Denton (1670):

Toward the middle of Long Island lyeth a plain sixteen miles long and four broad, upon which plain grows very fine grass, that makes exceeding good Hay, and is very good pasture for sheep or other Cattel; where you shall find neither stick nor stone to hinder the Horse heels, or endanger them in their Races, and once a year the best Horses in the Island are brought hither to try their swiftness, and the swiftest rewarded with a silver Cup, two being Annually procured for that purpose $(27$, p. 6).

The popularity of the New Market course continued until after the Revolution. The races during that war being conducted by the British officers who held New York.

Horse Racing in Virginia.-Gov. Francis Nicholson of Virginia in 1690 ,

initiated public exercises and gave prizes to those that should excell in Riding, Running, Shooting, Wrestling and cudgeling.

Of these sports riding became by far the most popular. Interest in horse-racing, fox-chasing, stecple-chasing, and riding tourna- 
ments has never died out in Virginia and some of the best strains of saddle horses in the worlel have been developed in that commonwealth. Camels were introduced into Virginia during Nicholson's administration according to Wynne, but never were popular and the experiment proved a failure (133, v. II, p. 235 ).

Narragansett Pacer.-There was nothing in an agricultural sense which brought more fame to Rhode Island in colonial times than a breed of horses known as the Narragansett pacer. These horses were remarkable for speed, endurance, and ease in riding. An Englishman writing about 1747 in regard to the horses of New England states:

They are, notwithstanding the inferiority of their size, extremely serviceable; and though they have but one pace, and that too not very agreeable, being a kind of a shuffle, yet they go at a very great rate; some say, not less than twenty miles an hour, which would be a little ineredible, if some New England horses had not been brought over to Britain, which are said to have put the matter beyond dispute; but though there are plenty of these horses, yet they sell at a good rate, twenty pounds being looked upon to be a very low price for a sound horse at the prime of his age (90, r. II, p. 255).

This account probably refers to the Narragansett pacer and not to New England horses in general. The Rev. James McSparran who was for many years rector of the Old Narragansett Church near Kingston, R. I., writing in 1752, says:

The produce of this Colony is principally Butter and Cheese, fat cattle and fine horses that are exported to all parts of English America. They are remarkable for fleetness and swift Pacing, and I have seen some of them pace a mile in little more than two minutes, a good cleal less than three.

Origin of the Breed.- This breed appears to have originated on the Point Judith farm owned by William Robinson, one time Deputy Governor of Rhode Island. Governor Robinson was born in 1693 and died in 1751. The original sire of this breed was a stallion called Old Snip. One account states that Governor Robinson imported Old Snip from Andalusia, Spain. Another given in an old unsigned manuseript stated that Old Snip was found in a drove of wild horses on Point Judith. Both of these accounts are perhaps in the main correct. Governor Robinson probably imported this horse or its ancestors from Spain and it is quite likely that he let many of his horses run wild on his 
estate which consisted of several thousand acres (124, v. II, p. 452).

Horse racing was very popular in Rhode Island during the eighteenth century and intercolonial races were arranged with Virginia where the Narragansett pacers were matehed against the Vilginia runners.

The Narragansett pacer became extinct about 1800, due largely to the great demand for these horses from the southern colonies, especially the Carolinas and the sugar planters of the West Indies. Buyers were stationed in Rhode Island who purchased every horse of pacing blood which they could find. This breed seems to have differed somewhat from the pacers of today. The purebreds could not trot at all and were very popular as saddle horses for ladies.

Pacers Popular in America.-Pacers appear to have been the most popular breed in the latter part of the seventeenth and during the eighteenth centuries, not only in New England, but in all the southern colonies as well. Sloane who was in the West Indies prior to 1689 says:

New England Horses are frequently brought to Jamaica, they are bought for Five Pounds a piece in New England, and kept by the way on bran, they usually are sold in Jamaica at Fifteen Pounds, they are rougher than the Horses in the Island, usually Pace, and lose their Hair at first coming (10S, v. I, p. LXXXIY).

Rev. Wm. Smith who was on the island of Nevis in 1718 observed:

Some few of our Horses are brought from London, now and then from Rhode Island, but chiefly from New England, where they are all natural pacers. . . . I think it particular enough, that $\mathrm{New}$ England has but one sort of Horses viz., Riding Horses (113).

At that time Nevis sugar planters were importing oats from New England to feed their saddle horses.

Hugh Jones (1724) describes the saddle horses of Virginia as being not very large, hardy, strong, and fleet and that they "pace naturally and pleasantly at a prodigious rate" (63 p. 49). The Virginia Assembly passed a law in 1684 which prohibited the allowing of male horses under $13 \frac{1}{2}$ hands in height running at large (49, v. III, p. 37). A law of similar intent as we have seen (p. 184) was passed ten years earlier by the Connecticut lawinakers. 
The Chicasaw Indians of Alabama hat a breed of horses, descendants of Arab horses originally brought over by the Spaniards, that were famous for their speed. The Indians west of the Mississippi possessed so many horses that they would exchange one for a hatchet (23). 


\section{CHAP'TER XXI}

\section{FARM IMPLEMENTS AND THE USE OF FERTILIZERS}

No other agricultural feature has undergone such radical improvement between colonial times and the present as has oceurred in the case of farm machinery. One looks in vain for evidence of any material advancement in the invention or construetion of farm implements during the whole colonial period with the exception of the horse drawn seed drill invented by Jethro Tull of England. The colonists who came without work animals as did the Pilgrims and Virginians brought as their implements of husbandry hoes, usually of two sizes, one narrow for chopping weeds from among growing plants and another broader in the blade for preparing land for seeding; spades, shovels and picks or mattocks for digging and loosening the soil; sickles for harvesting grain; seythes for cutting grass and forks for handling hay and bundles of grain. These constituted the principal and in most cases the entire outfit.

The secretary of the Dutch West India Company requested in 1662 that the following tools and implements be sent to the Colony on the Delaware River:

12 ploughshares with eoulters, 1 first class wheel plow with its pulleys, 12 two-prong hay and grain forks, 12 three prong. do., 100 iron teeth to make harrows, 24 best scythes, 24 good reaping hooks, 50 steeled axes, 20 winnowing fans, 25 wheel barrows, 30 spacles, 30 shovels, 30 hoes, 20 iron rakes, 12 hay knives (14, v. II, p. 1S4).

Plows. - With the introduction of oxen and horses plows came into use. These were cumbersome affairs consisting of a large wooden beam on the upper sicle of the tail of which was inserted two erooked sticks to serve as handles for guiding. Underneath was one or more coulters of metal for entting through the soil; then came the body of the plow with a wooden mold board and a landslide (Fig. 29). The cutting edge of the mold board was faced with a share or plain strip of metal. Plows were strengthened with metal strips whenever iron was in sufficient abundance to allow its use for such purposes. In most eases the appendages 
were held in holes or sockets of the beam by wooden pegs. While a number of plows were sent to Anerica from Europe in most eases the metal parts, coulters and shares, were all that were imported the rest being constructed in this country. Wheel plows, differing little from the other except the beam was sup-

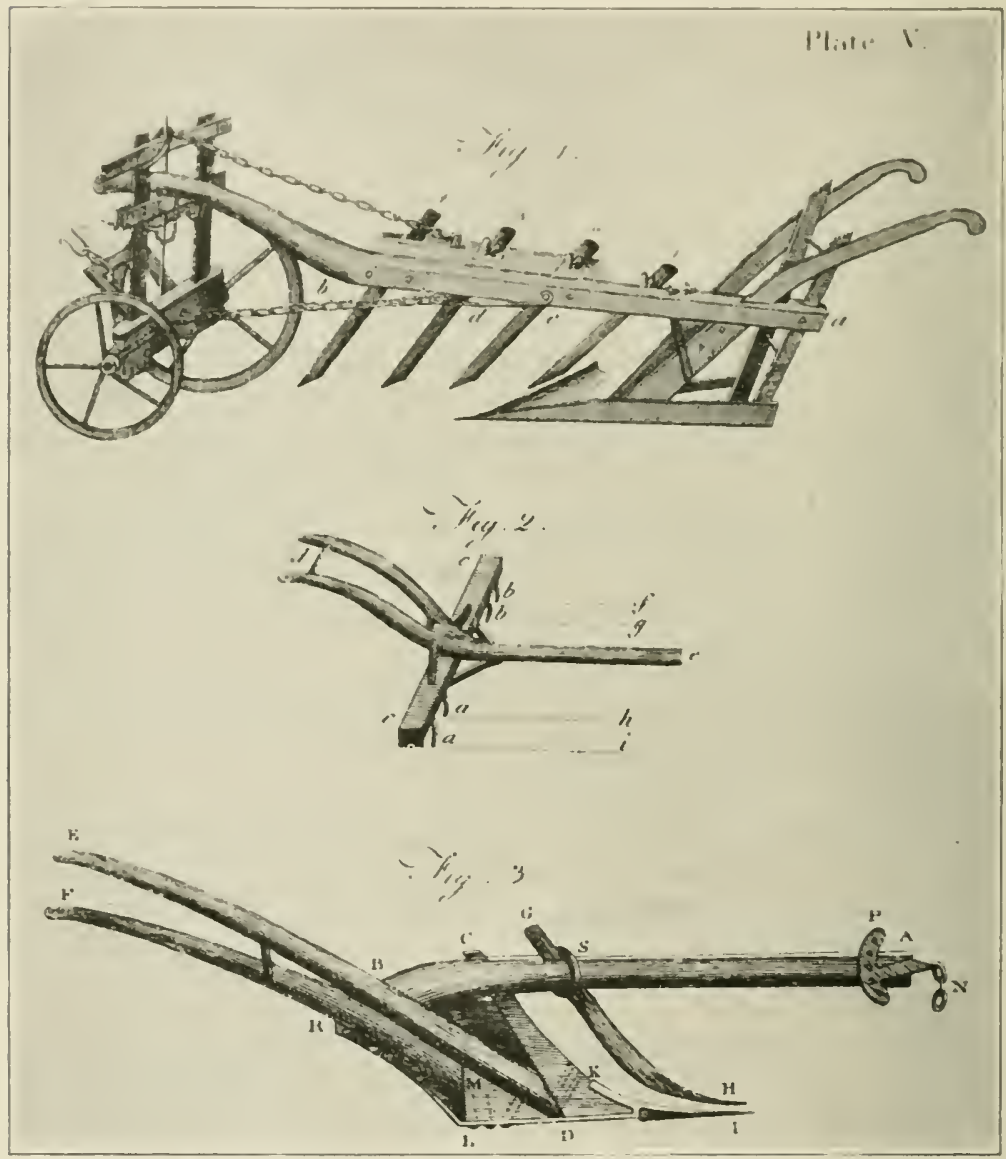

FIG. 29. -Wooden plows of the colonial period. No. 1. Jethro Tull's 4 coultered plow about 1750 . No. 3. Rotheram plow, should be made of "ash or elm." (From Robt. Forsyth "Principles of Agriculture," 1S04.)

ported on two wheels one on each side, were in common use on the continent of Europe and to a less extent in England. A few of these were imported into America, especially in New York. The strength of these crudely constructed plows is indicated in 
the following by Willian Word who was in New England in $1629-33$.

This ground is in some places of a soft mould, and easie to plow; in other places so tough and hard, that I have seen ten Oxen toyled, their Iron chains broken, and their Shares and Coulters much strained, but after the first breaking up it is so easie, that two Oxen and a Horse may plow it $(131$, p. 14).

Harrows.-Iron toothed drags or harrows were in use in Europe at the time of the English settlements in Anerica and harrow teeth are listed among the supplies of some of the early expeditions (Fig. 30). There were not enough of these imported however to allow for general use. A wooden toothed substitute was most commonly employed to smooth down the furrows after plowing to prepare a seed bed. These drag harrows were most commonly constructed with two timbers five or six inches in diameter and six to eight fect long perforated with square holes eight to ten inches apart into which were inserted the tecth. These timbers were joined together in the form of a letter A. Sometimes the spreader or cross piece was also fitted with teeth to serateh the interval missed by the teeth in the wings. Such a harrow is especially good for working among stumps and is still frequently used in new elearings.

A small branching tree was often dragged over the ground to cover the seed after it was sown.

Cultivators Invented. - Tlie utilization of horse labor in cultivating inter-tilled crops was unaccountably slow in coming into practice. Cultivators, or as they were called in England "horsehoes," were quite generally used in England before they made their appearance in America. This can best be ascribed to conservatism of farmers against innovations. The Indian hill planting had proved valuable in the early days of the colonial history and that practice persisted although labor and inclination for hand weeding the intervals among the hills, were often wanting. Cultivators were not entirely absent from colonial farms as the following quotations show:

In one respect, however, they have made an improvement in North Carolina in the tobacco culture, which is the introduction of a machine between the rows of tobaceo instead of a plough, being between a plough and a harrow, and something in the nature of horse-hoes used in England. It is not however a common tool there, but from its use, it is expected to become more general (4, v. I, p. 350). . Even common 
farmers in some parts of New England have been struck with the excelleney of the practice of ploughing between the rows of this grain,

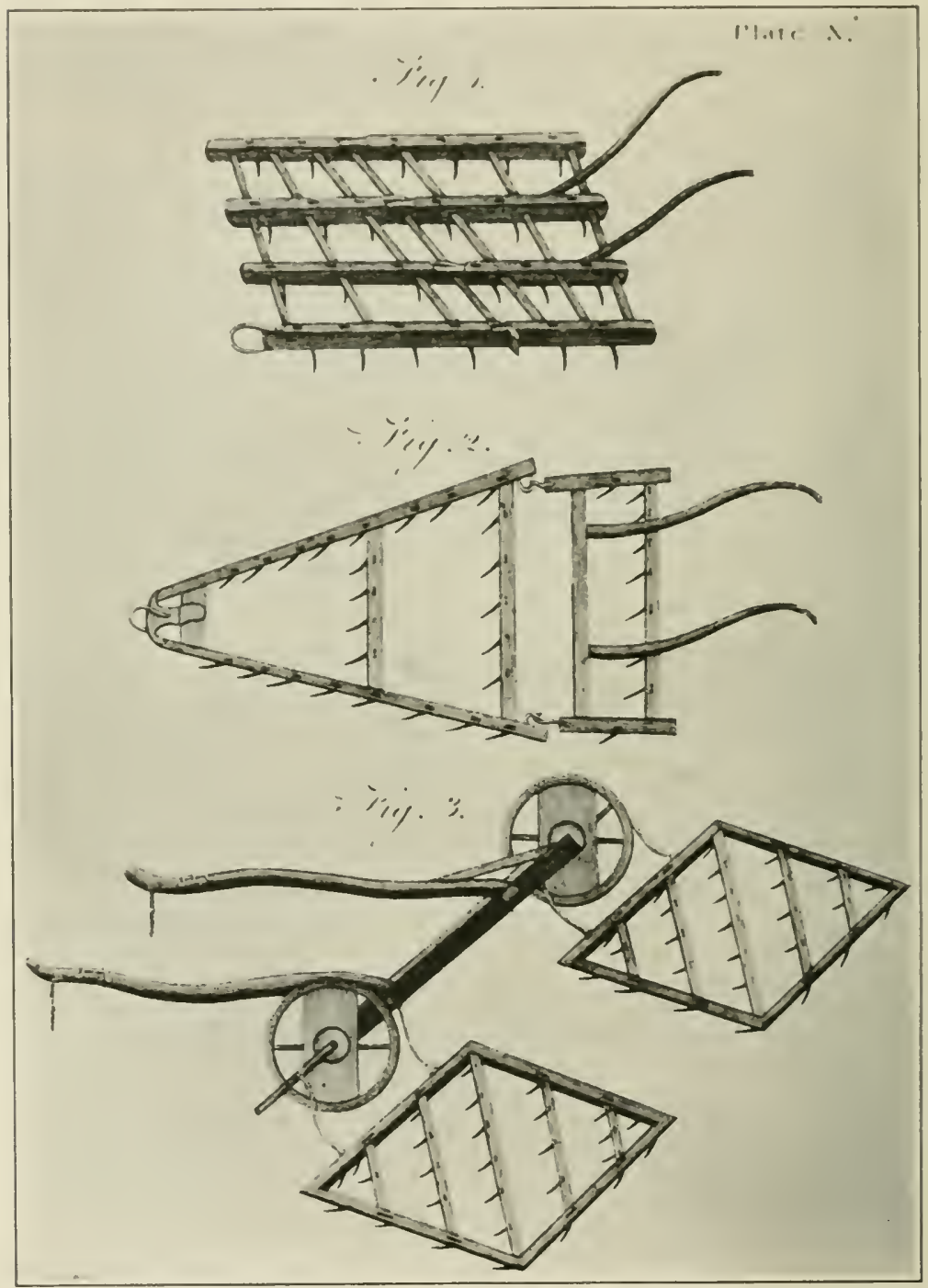

FIG. 30.-Harrows of the Colonial period. (From Robert Forsyth "Principles of Agriculture.")

(maize) that they have been presently brought to practice it in common, so that it is now no longer an unusual method $(t, v . I, p .51)$. 
Rollers.-Rollers consisting of a log cut from the trunk of a large well shaped tree, drawn by means of a frame attached to pins inserted in the ends of the log or a portion of the ends of the $\log$ itself reduced to the proper size were in common use to erush clods and to compact the soil.

A crude implement much on the order of the "bull tongue" now used in the South was quite generally employed to dig trenches for row seeding. In New England this was used for corn planting. A series of shallow trenches was laid off at regular spaces across the field. Then another set of trenches made at right angles and across the first. The corn was planted at the intersections of these furrows thus imitating the eheck rowing of the Indians.

Metal Working Prohibited.-The searcity of metal and the prohibition of the exporting from England to the Colonies of metal working tools, forges, etc. by the English government held back for many years the development of metal construction but the colonists overeame this hindrance to some extent through the use of wood. They became skilled in making carts and wagons the tires for which in the carly years came from England. It was not many years after the settlements when the smelting of iron in America first eneouraged by the mother country to supply the British manufacturers with pig iron, became of sufficient volume that home needs were met with home products. To such an extent had metal manufacturing become in 1750 that a special law was passed by Parliament entitled:

An Act to encourage the Importation of Pig and Bar Iron from His Majesty's Colonies in America; and to prevent the Erection of any Mill or other Engine for Slitting or Rolling of Iron; or any Plateing Forge to work with a Tilt Hammer; or any Furnace for making steel in any of said Colonies (21, v. IX, p. 551).

This law was ordered published in each of the colonies but it served only to hinder and not to stop the working of iron in America into farming tools and for other purposes.

Use of Manures.-The benefits from manuring cultivated fields was well understood by the more intelligent serenteenth century farmers in Great Britain and on the continent of Europe. This knowledge was brought by the early settlers to America. Hariot (1585) noted the lack of appreciation of manures especially ashes by the Carolina Indians as did other writers. John Rolfe whose work in behalf of agriculture in the Jamestown colony is 
no less worthy of remembrance than his marriage, mentions the beds of marl in eastern Virginia to emplasize the agricultural advantages of that region.

Use of Lime.-Of the mineral fertilizers, lime, ehalk and marl were the favorites of the British farmers. Hartlib (1651) states:

Lime, which is made of divers sorts of stones, is an excellent thing for most Lands, and prock uecth a most pure grain; 160 bushels is usually laid on an Aere but I suppose that if men did lay but halfe the dung on the groumd, as they usually do, as also lime and Chalke, and dung and lime it oftener, it would be better Husbandry; for much dung causeth much weeds, and eauseth Corn to lodge; and too mueh Chalke doth too much force the land, so that after some good crops, it lyeth barren many jears. . . Marle is of divers kinds; some stoney, some soft, some white, some yellowish, but most commonly blew. It's in most places in England but not known by all (46, pp. 43-4).

In an anonymous manuseript sent to England in 1637 from Massachusetts the writer observes:

I do believe, that if we had marl, lime, or other manure, this barreness might, in part, be cured, but, as yet, we are destitute of these supplies. The natural coldness confutes the opinion of those, who did conceive it (soil in New England) to be originally fertile, and experience confirms this to be true, for beans, millet, and fitches and roots, which delight in a cold soil prosper here alike (57, v. I, p. 4\$2).

Oyster Shell Lime.-The absence of lime stone along the Atlantic coast worked a hardship on the colonists as it was needed not only for agricultural uses but for building purposes as well. A fairly efficient substitute was at hand, however in the beds of oyster shells in the middle colonies in some cases probably the accumulations of ages from oyster gathering Indians while in others the shells were washed ashore by the waves of the sea.

Budd (1655) says:

There is no Lime Stone as we yet know of, but we make Lime of Oyster Shels which by the Sea and Bay side are so plentiful, we may lond Ships with them $(16$, p. 34).

And Jogues (1645) reported for New Amsterdam:

There are some dwellings built of stone: they make the lime with oyster shells of which there are great heaps made in former times by the savages who partly live by that fishery $(121, \mathrm{v}$. XXVIII, p. 3).

The New York Assembly passed a law in 1703 prohibiting the "distilling of Rum and the burning of Oyster Shells into Lime 
within the City of New York." The func's from these operations were considered responsible for an epidenic which prevailed there the previous summer $(14, \mathrm{v}$. IV).

Limestone in New Jersey. - Kalm in 1745 mentions a "red limestone" which crumbles on exposure to the air which the farmers near New Brunswick, N. J. were using to manure their lands. It was "said to stifle the weeds; it is therefore made use of both on the fields and in gardens." Forster the translator of this observation adds:

Probably it is a stone marle, a blue and reddish species of this kind is used with good success in the county of Banff in Scotland (65, v. I, p. $150)$.

Used as Fertilizer in New York. "On our journey to $\mathrm{New}$ York" continues Kalm "we saw high heaps of oyster shells near farm-houses upon the sea shore and about New York we observed the people had carlied them upon the fields which were sown with wheat. However they were entire and not crushed: "On several high grounds near the river" (Hudson) he observed "the people burnt lime" (65, v. I, p. 187).

Lime in Pennsylvania.- William Logan, in 175t, whose farm was near Philadelphia, records putting "50 Bushells of stone Lime in small heaps to an acre which 10 mo. 1st. was obliged to slack with water hauled Put in Hogsheads being a very Dry time." He also says "I laid on Tret soap ashes about 40 to 50 Bushells to ye acre or more" (71). The soap ashes, that is, the refuse after leaching for the manufacture of soap, was a popular mineral fertilizer both in England and colonial America, and the use of such material dates back to Roman farming. In colonial days soap manufacture was largely a local or home industry and there was always a limited supply of spent ashes to be had near at hand. Burning trash and litter on the land was also looked upon as a beneficial practice to kill weed seeds and the resulting ashes were known to have an ameliorating effect on the soil. A writer in 1756 makes the statement that:

Mountjoy is a manor that belonged to a daughter of Mr. Penn and here the first limestone was dug that ever was found in America (5).

Land Plaster.-The application of sulphate of line or gypsum to agricultural purposes dates from the colonial period But the remarkable spread in the use of that substance with its far reaching influence on farming practices took place after the Revolution. 
Cypsum or as it was at first more commonly designated "plaister of Paris" from the quarry of Montmarte near Paris where it is sail to have been obtained, had long been used for building purposes before its agricultural value was ever suspeeted. Many conflicting statements regarding the introduction of gypsum afterwards known as land plaster into American farming practice appear in our agricultural literature and various Pennsylvania farmers have been credited with having been the first to use this material as a fertilizer.

Land Plaster Used by Richard Peters.-The following account, by Richard Peter's who unquestionably did more than any other of the early American agriculturists in disseminating knowledge in regard to land plaster and advocating its use, appears to be the most authentic discussion of the American history of the subject now arailable.

The first time I saw the agricultural effects of the gypsum, was several years before the commencement of our revolutionary war; on a city lot belonging to, or occupied by; Mr. Jacob Barge, on the commons of Philadelphia. He was the first person who applied the gypsum in America to agricultural purposes; but on a small scale. This worthy citizen still lives, (1S07) at a very advanced age. He informed me, that he had communicated his knowledge of it to one or two persons in the country; I think to the late Mr. Thomas Clifford and another. He showed me a letter, in German, from one who had gone over from Pennsylrania to Germany, for redemptioners; as was customary at that day. The writer sent over a specimen of the gypsum; and desired Mr. Barge to seek for land in this then Province; in which it could be found. It was probably, to assist in this object, among other considerations, that I was taken into a secret, then utterly unknown to others in this country. But from that time to this, I have not been able to discover any quarries of gypsum, proper for husbandry, in this or any other of the United States . . Burr mill Stone makers, and stuceo plaisterers, were the only persons acquainted with any of its uses. From one of the former (the late John Brown) I procured a bushel; which enabled me to begin my agricultural experiments; and I faithfully pursued and extended them, as I obtained more means. A quantity imported as ballast (I believe 20 tons) by the late Captain Nathaniel Faulkner of Philadelphia, then in the London trade; and thrown out on a wharf, without knowledge of its value, was the first important foundation, on which this extensive improvement to our husbandry was established. With this Mr. Barge began the business of pulverizing the gypsum, first in an hand, and subsequent to this. in an horse mill; and soon afterwards, it was carried on in a water mill, in my neighborhood. . . The person who wrote 
from Germany to Mr. Barge, infurmed him (with what correctnes: I know not) that the discovery was then of no long standing in Germany: and that it had been accidently made by a labourer, employed in mixing stucco mortar, at a large building. He saw that the path used, or made, by him, in going from his work to his cottage, threw up a luxuriant crop of clover, in the succeeding season, when all other parts of the field exhibited sterility. He attributed this extraordinary vegetation, to the dust flying of his clothes; and in consequence of this idea, le strewed offals of the gypsum near his cottage. The effects astonished every spectator; and he received from the Edleman, or landlord, a reward for divulging the secret $(7 t)$.

In this same article witten in $1 S 07$ Peters states that his first experiment with gypsum was 37 years previous, making 1770 the approximate date of the introduction of land plaster as a fertilizer in America.

Stable Manure.-Of the organic substances used as fertilizers, stable manure took first rank with the exception of New England where, as we have seen, the Indian method of fertilizing with fish was practiced. With the development of the fishing industry along the New England coast the refuse heads and offal from the salting stations were used instead of whole fish for manuring purposes. Fish refuse is still a popular fertilizer wherever it can be obtained.

The utilization of stable manures in colonial times differs little from modern practices. Much was wasted by neglect. The best farmers were those who took the most pains to manure their lands. The superabundance of virgin land and the seemingly inexhaustless productiveness of bottom lands led many into slipshod methods of manuring with the inevitable results of greatly reduced yields.

The farmers of the middle colonies especially Pennsylyania and New Jersey and Delaware were the leaders in the conservation and use of litter and the solid and liquid excrements of their farm animals. In his farm diary previously mentioned William Logan made the notation "Sowed after uree Dunging it my Fruit pasture with Clover and Timothy Seed."

Manure a Commercial Commodity.-Any substance rich in vegetable matter was popular with the best farmers for manures. Leaf mold from the woods, muck and peat from the swamps, the sediment in ditches, and the surface soil from ditch banks were considered especially valuable to scatter over their grain 
fields. 'The composting of these materials for' use in gardens was also practiced.

Ferris quoting from an account book of William Shipley dated about 1750 at Wilmington, Delaware gives the price of stable manure as $6 \mathrm{~d}$. equal to $6 \frac{1}{2}$ cents for a single horse load and 10 cents for a two horse load. This is a very carly instance for a commereial valuation being placed on farm manure (34, p. 302). 


\section{CHAP'TER XXII}

\section{SLAVERY}

The statement "About the last of August came in a clutch man of warre that sold us twenty negars," written in 1619 by John Rolfe, is the mention of an event, which has had most far reaching consequences. Human slavery was common at that time in many countries of Europe as well as in the Spanish possessions in America. The moral right of one person to own the services of another does appear to have been seriously questioned.

The introduction of negro slaves into the West Indies by the Spaniards took place about the beginning of the sixteenth century. Native Indians had been enslaved still earlier. Ferdinand granted Ovando, Governor of Hispanola, in 1500, the privilege of taking negro slaves to the West Indies provided they were taken from Spain where they had been instructed in the "Christian faith." Apparently this does not mark the first negro slavery in America for Ovando wrote in 1503 that there were large numbers of negroes there and requested that no more be sent. In 1510, Ferdinand ordered a number of Africans to be taken to the West Indies to work in the mines.

Slave Trade.-Sir John Hawkins was the first Englishman to engage in the American slave trade. In 1562, he made a voyage carrying slaves from Africa to the West Indies which proved so successful financially that he made another trip with slaves threc years later. This also was successful. In 1567, Hawkins joined with Sir Francis Drake in a third expedition which ended in disaster. The accounts of these exploits were published and much discussed in England at the time so the English people were well acquainted with the slavery system in the New World. The Virginia slaves were not the first to be owned in an English colony. A negro and an Indian slave were taken in 1616 to the English colony on the Bermuda Islands by a ship owner (110, p. 656). These were obtained from one of the Spanish islands.

Slavery an Aid to Colonial Farming.-It is the purpose to discuss bricfly here the effect of slavery in developing agriculture in the colonies and leave out all other matters pertaining, to this 
complicated subject. For a few years prior to the introduction of slaves, the Virginia planters had engaged in the then highly profitable eulture of tobacco. This crop demanded a large amount of hand labor which negroes could perform just as well as white men. There was also an abundance of virgin land which the planters were anxious to clear for tillage. No one who has not been through the experienee of elearing new ground can realize the slowness of the process and the amount of labor involved.

Slaves appeared to be the solution of the labor problem in Virginia and appealed greatly to the pride of the young planters who aspired to own and control large estates.

Negroes More Immune to Malaria Than Whites.-There was another incentive in the coastal plain sections of the South and these were the first to be settled. Malarial diseases prevalent in low swampy countries in hot elimates made the mortality among the white laborers excessively heary. Negroes were found to be more resistant than the whites to these unhealthful conditions. Especially on the Carolina coasts it was found practically impossible to lieep the planters supplied with white labor. Oglethorpe made a serious attempt to exclude slavery from Georgia but the colony before the introduction of negro slaves led a very precarious existence and the restrictions relative to owning human chattels were raised as soon as the influence of the founder could be ignored.

Slavery Profitable in the South.--Slavery was immensely profitable in the South. The cost of elothing was reduced to a minimum in the Carolinas. The weekly ration for an adult negro of a peck of corn meal and three and one-half pounds of fat pork required in a year but two razor-backed hogs which could be raised in the woods at practically no outlay by the planter and the produce of one acre of maize.

The slaves in the lower Mississippi Valley under French ownership had a still more restricted dict than the standard ration of the slaves in the southern English colonics. Le Page du Pratz (1719-34) gives his fellow-countrymen who contemplate emigrating to Louisiana, this advice,

For the better subsistence of your negroes, you ought every week to give them a small quantity of salt and of herbs of your garden, to give better relish to their Couscou, which is a dish made of the meal of rice or maiz soaked in broth $(69$, p. 356$)$. 
This is not unlike the diet to which the negros were accustomed in Africa. "Their common Food" wrote Moore (173S) in regard to the natives of the Cimbia River region, "is ealled cooseoosh, being Corn beaten in a Wooden Mortar" sifted and boiled ( $7 S$, p. 10S).

In South Carolina where the slavery system reached its highest development the negroes outnumbered the whites about two to one. It enabled the Carolina planters to compete in the production of rice and indigo with the rest of the world despite 3000 miles of ocean to be traversed to reach a market.

Slavery in Massachusetts and Rhode Island.--The system of slavery was not eonfined to the South. Josselyn found Samuel Maverick possessing negro slaves on Noddles Island in Massaehusetts Bay in 1639. The New England colonial records show many laws relating to slave holdings. An act of the Ceneral Court of Election held at Warwick, R. I. May 18, 1652 prohibited the holding of negroes as slaves longer than ten years or after they were twenty-four years of age if they were under fourteen when brought "within the liberties of this Collonie" (97, v. I, p. 243). Similar prohibitive acts were passed by other colonial assemblies but these laws were probably never enforeed. At any rate, perpetual slavery was afterwards common all over New England. A tax of 3 pounds sterling was laid on each negro imported into Rhode Island and a similar tax of 4 pounds was assessed by the Massachusetts Bay colony.

Slavery in the climate of New England was more of a luxury than a utility. The extent to which it was carried in Massachusetts is indicated by an enumeration made near the close of the colonial period. Massachusetts had at that time 5249 negroes a gain of but 35 in thirteen years.

Slaves in Connecticut.-Slavery did not become of much importance in Connecticut until the eighteenth century. A negro servant was mentioned in 1645 ( 87 p. 169) at New Haven, and in 1680 there were 30 slaves and but "fewe blacks" two of which were reported as Christians (21, v. III, p. 29S). By 170 S however, a law states "negro and molatto servants or slaves are beeome numerous in some parts of the colonie" (21, v. V, p. 52). From time to time the usual laws for eapturing fugitive slaves, for punishing by whipping a slave that should strike a white man, and taking away the liberty of traveling away from home at night, were passed by the New England legislatures. There 
were 1000 negroes in Connecticut in 17.45 and 6-16t in 1774 many of whom were free (21 v. IX, p. 596).

Slavery in New York. -l'here were 37 negros in New Netherland in 1658, and 2395 were brought to New York between 1701 and 1726. New Jersey had 2581 negros in 1726 and New York 7202 in 1731 (14, v. II, p. 31, v. V', pp. S14, S19, 929).

A census of slaves taken in 1755 in the New York colony shows that the system was widespread. In most cases there were but two or three slaves to a family. With the exception of some large slave holding plantations around Narragansett Bay this condition prevailed in New England as well as in New York.

When the government of New Netherland was taken over by the English (1664) a number of negro slaves owned by the Dutch West India Company were given their freelom and allowed to possess tracts of land along Broadway. These free negros were the source of much unrest among the New York slaves and several serious insurrections took place carly in the eightecnth century.

Slaves as Skilled Artisans. - The use of slaves was not restricted to agricultural labor. It was soon found that they could be trained into skilled artisans and the well equipped plantations often had blacksmiths, carpenters, coopers, cobblers, wcarers, etc. among their slaves. Many of these were hired out when their services were not needed at home. ${ }^{1}$

It was customary in all the colonies to enslave the Indians captured in war. But they were usually transported and sold in some colony other than the one making the capture. Carolina Indian slaves were frequently sold in New England and New England Indians in Carolina. The difficulties incident to holding Indians as slaves usually made them of little value and hundreds were transported to the West Indies.

Slaves Freed in the North.-The growth of the "free spirit" in the events leading to the scparation of the colonies from England extended to the slaves. Practically all of the New England slaves were freed either before, during or immediately after the Revolutionary War. A New England slave that would

${ }^{1}$ For an excellent discussion of the negro as an artisan sec an article by M. W. Jernegan entitled "Slavery and Industrialism in the Colonies in The American Historical Review, Vol. XYV, No. 2, pp. 220-240 Jan., 1920. 
enlist in the Continental Army was usually granted his freelom and his owner reimbursed by his colonial government.

In the middle eolonies slavery was sporadic. In a few localities of Penusyrania the system was well developed. The same was true of New Jersey and Delaware while popular prejudice kept it entirely from others.

Slavery Limited in Existence.-While slavery greatly hastened the development of the colonies and added immensely to their wealth and prosperity, the system had within itself elements which limited its existence. Slavery demanded large additions of new land to take eare of its steady increase in numbers. During the seventeenth and the first half of the eighteenth centuries there was no trouble about getting land-all the planters had to do was to move back a little from the rivers and take up new claims. Many owned large undeveloped tracts. At the beginning of the Revolutionary War, the land suffieiently near the castern channels of transportation to allow the marketing of produce had practically all been improved and the pioncers were pushing back over the mountains into the Ohio Valley with the determination to develop a route of commerce down the Ohio and Mississippi rivers. This scareity of land along the Atlantic coast was well stated in American Husbandry in 1775, the writer referring to the Virginia and Maryland colonies.

This want of land is such that they reckon a planter should have 50 acres of land for every working hand, with less than this they will find themselves distressed for want of room.

Conditions Relieved by New Settlements.-The settlements of Kentucky and Tennessee and the development of cotton growing in the Gulf States only temporarily relieved the situation.

The profitable existence of slavery demanded one of two things. Either the aequisition of more land or the unrestrieted sale of surplus slaves. Public opinion was strongly opposed to traffic in slaves and many of the slave owning planters especially on the older plantations, had more slaves than could be profitably maintained. No one realized the weakness of the system more keenly than some of the slave holders. The statesmen most responsible for the clause in the federal constitution abolishing the slave trade and for the law prohibiting slaves in the Northwest Territory were southern slave holders.

Stratified Social Life.-Previous referenee has been made to the attempts to transplant into America the various strata of socicty 
which had developed in England. These can be broadly elassified as (1) An aristocratic governing class of land owners, (2) a middle class of merchants or trades people; skilled artisans, overseers and managers of estates, (3) a multitude of serfs or unskilled workers, (4) paupers and criminals. Such a system could not be operated in colonial America. It was difficult to get many of the first elass except those with depleted fortunes to migrate to this country. Then too in this land of opportunity the peasantry would not remain peasants but soon aspired to land owning independence. Instances of immigrants who came to America as indentured servants and who after completing their period of servitude achieved wealth and influence in the colonies might be given by the scores. The best imitations of the old world order in America were the large plantations operated with slave labor. 


\section{CHAP'TER XXIII}

\section{THE EFFECT OF COLONIAL COMMERCE ON AGRICULTURE}

An opportunity for interchange of products with peoples in different regions is essential to a successful agriculture. A favorable climate and soil allows the production of the crops adapted to a locality in excess of loeal needs. This surplus is waste until it can be exchanged for goods or other food products not produced at home. Even with erops which ean be grown in any given locality there is always the possibility that they may be grown to such better advantage elsewhere that it is more economical to buy and pay transportation than to grow them locally.

Traffic in foodstuffs as we have seen began with the Indians of Virginia soon after the settlement at Jamestown and at Plymouth as soon as communications were established with the savages of that region.

Capt. John Smith was able to persuade the Indians while he was in command at Jamestown to furnish him large quantities of corn, the chief foodstuff of the Powhatan tribes. No other man at that time was able to accomplish so much. Smith frequently mentions his success in obtaining corn from the Indians, but usually does not state the definite amount. The following items gleaned from his writings give an idea of how useful the Indians were to the colony during the first two years in furnishing this staple food product:

At the mouth of the river- 16 bushels.

On the south side of the river- 30 bushels.

From Paspahegh (that Churlish nation) 10-12 bushels.

Twice afterwards Capt. Martin obtained from Paspahegh S-10 bushels.

November 10th, 1607 from up the river-7 hogshead (barge load).

November 14th, 300 to 400 baskets little and great (barge load) $7-8$ hogsheads.

March 9th 1608, Returned to the Fort with 250 bushels.

"We might have fraughted a ship of 40 tons and twice as much might have been had from the rivers of Tappohannock, Pata- 
womeck and Pawtuxunt." On February 8, 1609 "We delivered at Jamestown to the Cape Marchant 279 bushels."

Commerce Started in New England.-The ship Fortune which brought the Weston colony to Plymouth in the fall of 1621 was "laden with good elapbord as full as she could stowe and 2 hoggsheads of beaver and other skins" (12, p. 130) and returned for England but unfortunately was eaptured during the voyage by a privateer.

In 1625, the Plymouth colony loaded a boat with corn which made a trip up the Kennebec river to exchange for furs with the northern New England Indians (12, p. 246).

Mention has already been made of the shipment in 1631 of corn from Virginia (p. 128) and in 1634 from Maryland (p. 166) to the rapidly developing Massachusetts Bay Colony.

Early New England Boats.-The bark Warwick eame ovel from England to Massachusetts Bay in 1630 where she remained in the service of that colony. The bark Blessing was built in 1631 at Mistick and was owned by Gov. Winthrop. The Rebecea "a small ship of 60 tons" was built in 1633 at Medford. These three ships figured prominently in the coastwise commerce of New England and frequently made trips to Virginia, Bermuda and the Barbadoes.

The Dutch West India Company.-In the meantime the Dutch West India Company with trading posts on the Connecticut, Hudson and Delaware rivers was carrying on quite an extensive commerce between the Indians and their own settlements in those regions on one hand and the West Indies on the other as well as with Holland. These ships frequently stopped at Newport News to trade with the Virginians.

Ships from the sugar producing islands made trips to the northern colonies for grain. Then there were the regular fishing fleets from Europe which were usually in need of supplies when on this side of the occan and furnished a market for surplus grains, butter, cheese, meats and fish.

Ship Building in Rhode Island.-The rapid development of agriculture in Rhode Island soon produced a surplus of foodstuffs in that colony which enabled the plantation owners to turn to other activities. Ship building was one of the first of these added enterprises. Authority was granted at a public meeting at Portsmouth about 1640 to load a ship with pipe staves and clapboards. This was evidently a cooperative undertaking, 
but the record is not now entirely legible. At first it was customary to build a ship from the excellent timber close at hand, load it with timber for masts and shipbuilding and then sell the ship and cargo to England for her navy. Shipbuilding, however, soon outgrew the wants of the English nary and the Rhode Island plantation owners began to compete in the carrying trade of the world much to the concern of the mother country. This commerce reacted to the benefit of the agriculture of the colony.

River Craft.-There were a large number of small boats which traded in the rivers and small streams. In the summer they worked the northern territory trading with the Indians and remote settlers and as winter approached they gradually directed their operations southward.

A writer on Maryland affairs described in 1666 the activities of these itinerant traclers,

Madera-Tines, Sugars, Salt, Wickar-chairs, and Tin Candle-Sticks, is the most of the Commodities they bring in: They arrive in Mary-land about September, being most of them Ketches and Barkes, and such small Tessels, and those dispersing themselves into several small Creeks of this Province, to sell and dispose of their Commodities, where they know the Market is most fit for their small Adrenturers ( 85, p. 364).

Ship Ownership Centered in New England.-As the colonies became older and conditions more stable the commercial activities became more generally centered in New England. Shipbuilding was an extensive business in itself and the fishing off the New England coast could always be relied upon to furnish a cargo when other products failed.

The trade routes of these early shippers were frequently about a triangle. Ships loaded in New England or New York with fish, grains, and other food stuffs generally stopped at southern ports as Charleston, and would then go on to the West Indies where the cargoes were exchanged for sugar which was taken to Europe traded for manufactured goods and then the boats would sail back to New England. At the same time there was a considerable traffic directly back and forth between the colonies and the West Indies, the ships on the return voyage being loaded with sugar, molasses and rum. The traffic with the Spanish colonists together with a clandestine trade directly with Spain and other Mediteranean countries accounts for the frequent practice in colonial times of basing values in terms of Spanish money rather 
than English. It is said that the metal used in the colonial pine-tree shillings eame mainly from Spanish coins.

Commercial Products. - The traffic between the southern colonies and the West Indies was principally the exchange of meats for salt, sugar and rum and furnished an outlet for the products of the ranehmen in the Carolinas and Cicorgia.

The slave trade added greatly to the profit of this commeree. New England ships loaded with foodstuffs would touch at the West Indies and exchange for produets of the Islands then sail to European ports, dispose of the cargo sail to Afriea load with negros and then cruise back to the colonies.

Incidentally this commeree was a great aid to American agriculture in the introduction of foreign plants and animals. Many ship owners also owned plantations and vied with one another in bringing back curious and improved species. The introduction of the foundation stock of American fast horses, mules, rice, subtropical and tropieal fruits and a great number of ornamental plants may be attributed to such sources.

Commerce of Pennsylvania and New York.-In the books on American affairs written about the middle of the eighteenth century there are a number of accounts of America which give further information in regard to the West Indian commerce. The following quotations are taken from one of these.

As to the Commerce of Pennsylvania with respect to Europe and America, the case, according to the best accounts we have, stands thus; their merehandize consists of horses, pipe-staves, pork, beef and fish, salted and barrelled up, skins and furs; all sorts of grain, izz., wheat, rye, pease, oats, barley, buck-wheat, Indian corn, Indian pease and beans, pot-ashes, wax, etc., and in return for these, they import from the Caribbee Islands and other places, rum, sugar, molosses, silver, negroes, salt and wine; and from Great Britain household goods and eloathing of all kinds, hardware, tools and toys. They have also some rice, but no great quantities, and a little tobaceo of the worst sort (90, v. II. p. 3S4).

This author gives about the same list of exports for the New York colony and gives in addition:

The New York merehants drive also a very advantageous trade with Madeira and the Azores in pipe-staves and fish, for which they load their ships back with wine and brandy; and generally speaking, there is searce a more profitable trade in the British Commerce. . . . They say that they trade with what they have, with those who will purchase 
it, and that while they do they shall live well, clothe themselves in English stuffs, and pay for them honestly; but if they are deprived of this trade. . . they must endeavor to make use of their own wool, and supply themselves as well as they can (90, v. II, p. 352).

New England Exports. - In regard to New Fingland this same writer says:

The commeree of these colonies is very considerable, and extends itself over all Ameriea, and into some parts of Europe; they furnish our sugar-colonies with fish, eattle, boards, hoops, pipe-staves, bark, skins, butter, cheese, oil, tallow, corn, apples, turpentine, ete. and this in such vast abundance, that it is computed the island of Barbadoes alone takes off to the value of two hundred thousand pounds every year (90, v. II, p. 261).

Decline of Farming in New England.-One can notice at that time, 1748 , a considerable change in the character of the agriculture of the different colonies. While they had all tried to grow about the same crops at the begimning of the settlements, New England had to a large measure given up the small grains, making Indian corn their ehief erop and had used their natural resources; as fish and lumber, to supply the deficiency. Dairying had also become established especially around the Narragansett Bay. The small grain belt had moved southward to the fertile soils of New York, New Jersey, Pennsylvania, Maryland and Virginia.

Navigation Laws. - It was the purpose of the English Government to see that the commeree resulting from the colonies in America should be to the advantage of the mother country. Frequent and drastic navigation laws were promulgated all with a single purpose to compel the colonists to exchange their surplus produce in England for English goods, the commerce to be handled entirely by British owned ships.

Such laws were frequent hindrances to agricultural development and were flagrantly disobeyed. It would have been as wise to try to force by legislative enactment sugar cane culture on New England as to compel the New Englanders to go without manufactured goods for the reason that the soil and climate in New England did not produce a staple crop which England needed. Of course the bulk of colonial commerce was conducted legally. But this trade with England was a steady drain on the resources of the colonists. They cxchanged raw materials for finished products and paid the freight both ways. That is 
American goods had to be landed in Eugland and there sold in competition with English and other producers and the charge for English manufactured goods in America included the expense of shipping them over here. As a result of this unequal exchange the balance of trade was heavily against the colonists. Most plantation owners were in debt to English merchants. Tobacco from Maryland and Virginia and rice and indigo from the Carolinas were marketed directly in England but did not offset the expense for English goods imported into those colonies. We will see in the next chapter the chain of commercial activities resorted to by the northern colonists in order to meet their obligations in England.

Manufacturing Inevitable.-It was inevitable under these conditions that the colonists should engage in manufacturing for their own needs despite all the restrictions imposed by the British government to discourage such enterprises. The conversion of wool, hemp, and cotton into clothing and hides into shoes, mittens and other articles of dress for their home use led slowly but gradually into the making of these commodities for sale or exchange. Development of the American iron industry gave an enormous impetus to American manufacturing, putting the colonists more and more on an independent footing and weakening their relationship with Great Britain.

An English advocate of a thorough development of agriculture in the American colonies writing at the close of the colonial period states the British attitude towards the colonists very clearly and gives as well a brief insight into the extent of American competition in manufacturing with the mother colony.

It should not be forgotten that one man cmployed upon tobacco is of far more worth to Britain than forty New England farmers . . . when we see them making cloth of 12s., a yard, linen of 5s., hats of $16 \mathrm{~s}$. each, locks, kers, and curious articles of hardware, we may then be certain that the policy of this kingdom is deficient ( $4, \mathrm{r}$. II, pp. 252-65).

Another extract from the same source indicates the general financial condition of the colonists who depended upon Great Britain for their manufactured goods and those who supplied their own needs at home.

Some modern writers, very well informed in the affairs of our American colonies, have been particularly attentive to the circumstance of the mortgages which the merchants and others of London have on their estates. This wants an explanation: the country gentlemen of New 
England are at free from this as any men in the world: it concerns only those who have dealings with London, these are the tobaceo and rice planters; but as to the people of property in New England it is not the case with, I may say, any man in the provinee that is not engaged in tracle (4. v. I. p. 66). 


\section{CHAP'TER XXIV}

\section{THE INFLUENCE OF THE MANUFACTURE OF ALCOHOLIC BEVERAGES ON COLONIAL AGRICULTURE}

The agricultural development of America has been shaped and modified to no small degree by the liciuor industry. To fully appreciate this influence it is necessary to go back to the very beginning of our nation. Three centuries have wrought many changes-none greater than the shattering of popular beliefs. If we turn back to the early part of the seventeenth century we find a striking contrast to the conditions subsequent to July 1, 1919 in the United States. It is a matter of common knowledge that the drinking of spirituous liquors was much more general in the olden days than in the times through which the present generation has lived. But it is not fully understood how thoroughly our forebears believed these beverages to be essential to good health. Nearly every one in Great Britain and European countries in general, whether of the elergy or laity appears to have considered alcoholic drinks a necessary part of the dietjust as important as bread or meat. Drunkemess was then as now looked upon as disgraceful, but total abstinence, or as we have come to know it by the legal term prohibition, is a pure American product which has developed since our country became a nation.

Alcoholic Beverages Considered Healthful.-The reason for the belief in the healthfulness of alcoholic beverages in past centuries is easy to understand. The dire results from drinking impure water were learned by sad experience but not knowing the cause of the danger people looked on all water with suspicion. The ill effects were especially evident to the seafaring class where the water on ship board often taken from any available fresh water stream or pond became foul and unwholesome. Spirituous liquors were not subject to this deterioration.

Liquor Supply Inadequate at Jamestown.-In his indictment of the first president of the Jamestown Colony, Capt. John Smith complained. 
The sack, Aquavitie, and other preservatives for our health, being kept onely in the Presidents hands, for his owne diet, and hi- few associates $(110$, p. s).

Other members of the expedition made similar criticism of the actions of the officers of the colony.

By 1627 the conditions had so much improved in Virginia that Smith wrote:

For drinke, some malt the Indian corne, others barley; of which they make good Ale, both strong and small, and such plentie thereof, few of the upper Planters drinke any water: but the better sort are well furnished with Sacke, Aquavitae, and good English Beere (110, p. S86).

Pilgrims Preferred Beer to Water.-While the Pilgrims were in Provincetown harbor on Cape Cod, Capt. Miles Standish and a small number of men went on an exploring expedition along the coast. Becoming almost famished for something to drink they finally found some fresh water which Bradford tells us being ye first New England water they drunke of, and was now in thir great thirste as pleasante unto them as wine or bear had been in fortimes (12, p. 99).

And Edward Winslow mentions in connection with the landing of the Pilgrims, December 25, 1620 an instance of unusual sobriety it

being Christmasse day, we began to drinke water aboord, but at night the Master caused us to have some Beer, and so on boord we had divers times now and then some Beer, but on Shoare none at all (94, v. XIX, p. 327 ).

Some disgruntled Pilgrims who had returned to England spread disparaging reports in regard to New England. Among other things they said the water was unwholesome. To which Bradford (1621) replied:

If they mean, not so wholsome as $\mathrm{y}^{\text {.e }}$ good beere and wine in London, (which they so dearly love,) we will not dispute with them; but els, for

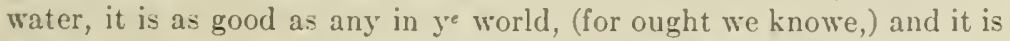
wholsome enough to us that ean be contente therwith (12, p. 194).

Wood (1635) evidently with this same criticism in mind wrote:

It is thought there ean be no better water in the world, yet dare I not preferre it before good Beere, as some have done, but any man will choose it before bad Beere Wheay or Buttermilke. Those that drinke it be as healthfull, fresh, and lustic as they that drinke beere (131, p. 15). 
Heavy Drinking Prohibited in Connecticut.-De Vries was struck by the comparative abstemiousness of the English settlers on the Connecticut River.

"These English," noted this sea-captain in 1639, "live soberly, drink only three times at a meal, and whoever drinks himself drunk they tie to a post and whip him, as they do thieves in Holland" (S6, p. 203).

Even as late as 1775 Romans makes the assertion that "Liquor is as necessary as victuals; $i$ would therefore recommend the culture of vines" (100, p. 131).

Wine as a Possible Commercial Product.-The early adventures in American affairs were alive to the possibilities of ereating a liquor supply in the New World, not only for home consumption but for export. Much of the propaganda advertising the advantages of America was fortified by figures showing the number of "casks" of wine or cider which had been produeed. The excellence of the quality of these liquors was often exaggerated much to the disappointment and disgust of the connoisseurs when they had an opportunity to sample them. A few quotations from early writers show the extent to which this industry was carried.

New England Beer.-William Wood (1635) says in regard to Massachusetts:

There hath as good English corne growne there, as could be desired: Especially Rie and Oates and Barley: there hath been no great triall as yet of Wheate and Beanes, only this much I affirme, that these two graines grow well in Gardens.

It would seem now that it would have been the poliey of the colonists to grow wheat for bread like to that which they had been aceustomed in England. Instead their first care appears to have been to provide barley for brewing and they at once adopted the Indian corn bread made of meal for their solid diet. Some of the first laws passed by the Massachusetts Bay Colony prohibited the malting of wheat. This, however, was not a prohibition measure in the commonly accepted meaning of the term, but rather an effort to conserve their wheat for bread of which they did not have half enough for themselves and the influx of poorly provided immigrants which yearly eame to New England.

Strawberry Wine in Rhode Island.-Roger Williams, (1642) the founder of Rhode Island, states: 
They (the Indians) also make great use of their strawberries having such abundance of them, making strawberry bread . . . but the English have exceeded, and make good Wine both of their Grapes and strawberries also as I have often tasted (129, p. 122).

Williams also says:

And of the chips of the Walnut Tree (the barke taken off) some English in the Country make excellent Beere.

Williams attributed the remarkable physical strength and endurance of the New England Indians to the use of maize in their diet in lieu of spirituous beverages which they had never known before the advent of the whites.

In connection with the New Netherland colony, now New York, Jogues (16+4) tells us that the Hollanders in that colony: sow wheat and oats for beer and for their horses of which they have great numbers.

Virginia Beverages.-Beverly, in his History of Virginia, gives a detailed account of Virginia drinks:

Their small-drink is either Wine and Water, Beer, Milk and Water, or Water alone. Their richer sort generally brew their SmallBeer with Malt, which they have from England, though Barley grows there very well; but for want of the Convenience of Malt houses, the Inhabitants take no Care to sow it. The poorer Sort brew their Beer with Molasses and Bran; with Indian Corn malted by drying in a Store; with persimmons dried in Cakes and baked; with Potatoes; with the green Stalks of Indian Corn cut small, and bruised; with Pompions and with Batates Canadensis, or Jerusalem Artichoke, which some People plant purposely for that use; but this is the least esteem'd of all the Sorts before mentioned. Their strong Drink is Madera Wine, Cyder, Mobby Punch, made either of Rum from the Caribbee Islands, or Brandy distill'd from their Apples and Peaches; besides Brandy, Wine, and strong . Beer, which they have constantly from England.

Hugh Jones (1724) at one time a professor in Williams and Mary College at Williamsburg and Chaplain to the House of Burgesses of the Virginia Colony, also gives in considerable detail the Virginia life of his time. He states:

The Peaches abound, and are of a delicious Taste, and Apple-trees are raised from the Seeds very soon, which kind of Kicrnel Fruit needs no grafting, and is diversify'd into numberless Sorts, and makes, with good Management, an Excellent Cyder, not much inferior to that of Herfordshire, when kept to a good Age; which is rarely done, the Planters being good Companions and Guests whilst the Cyder lasts (63, p. 41). 
This same author also states:

Some Planters make good Small Drink with Cakes of Parsimmons but the Common small l3eer is made of Molossus, which makes extraordinary brisk good tasted Liquor at a cheap Rate, with little Trouble in brewing . . A As they brew, so they bake daily, Brearl or Cakes. . . Some raise Barley and make Malt there, and others have Malt from England with which those that understand it, brew as good Beer as in Englind, at proper Seasons of the Year; but the common strong Malt-Drink mostly used, is Bristol Beer; of which is consumed rast Quantities there yearly; which being well brew'd and improv'd by crossing the Sea, drinks exceedingly fine and Smooth; but Malt Liquor is not so much regarded as Wine, Rack, Brandy, and Rum, Punch, with Drams of Rum or Brandy for the Common Sort, when they drink in a Hurry.

The common Wrine comes from Maderia or Phial, which moderately drank is fittest to cheer the fainting Spirits in Heat of Summer, and to warm the chilled Blood in the bitter Colds of 11 inter, and secms peculiarly adapted for this Climate: Besides this, there are plentifully drank with the better Sort, of late Years, all Kinds of French, and other European Wine, especially Claret and Port (63, p. 52).

Liquors Become a Commercial Commodity.-The citations just given are enough to show the general attitude of the early settlers in America towards the use of spirituous drinks. Let us sce how this alcoholic industry affected the agricultural development of the country.

As previously mentioned the great need of all the northern colonies was a staple commodity which would sell for enough to pay for the manufactured goods as clothing, tools, ete., which they had to import from England. Foodstuffs were in comparative abundance but money was scarce. England in those days did not need grain sufficiently to pay a price that would justify its being imported from America. For that reason the surplus food went to the West Indies largely in exchange for sugar, rum and molasses. So long as these products were consumed at home there was no chance to accumulate surplus wealth or cash. There was still another exchange of products necessary before the commercial cycle was completed.

Indian Trade.-Much of the molasses was manufactured into rum after it reached the colonies and this was used in traffic with the Indians for furs which in turn sold readily in Great Britain. The debauching of the American Indians for commercial gain is one of the pathetic episodes of our history. It was the only 
feasible means however which the English possessed for drawing the fur trade away from the French in Canada. Perhaps it was as humane as shooting the Indians or getting rid of them by any other method. Surely it was no more eruel than the wholesale slaughter for the purpose of seizing their cleared fields which took place in a number of instances and which have been featured in many historical texts as heroic aehievements of our aneestors. The conflict between the English and Indians was as inevitable as the results were certain. The two races differing so raclically in eustoms and instincts, and mutually despising each other, could not for long live harmoniously together.

Daniel Denton (1670) observed:

They (the Indians) are great lovers of strong drink, yet they do not eare for drinking, unless they have enough to make themselves drunk; and if there be so many in their Company, that there is not suffieient to make them all drunk, they usually select so many out of their Company, proportionable to the quantity of drink, and the rest must be spectators. And if any one ehance to be drunk before he hath finisht his proportion (which is ordinarily a quart of Brandy, Rum or Strongwaters) the rest will pour the rest of his part down his throat $(27$, p. 7$)$.

Beverly makes a similar observation about the Indians of Virginia in these words:

For their strong Drink, they are altogether beholden to us, and are so greedy of it, that most of them will be drunk as often as they find an Opportunity; notwithstanding which, it is a prevailing Humour among them, not to taste any strong Drink at all, unless they ean get enough to make them quite drunk, and then they go as solemnly about it, as if it were part of their Religion (9, p. 153).

Evils of the Indian Thirst for Liquors.-The evils of the liquor traffic with the Indians early beeame apparent to the better class of people in all the colonies. Stringent laws were passed with heavy penalties preseribed against offenders in efforts to suppress the trade. But the danger of depredations by the Indian while under the influence of liquor had more to do with the passing of these laws than did the moral question involved. In 1659, the Rhode Island Assembly passed this peculiar law:

It is also ordered, that it shall be lawfull for any person in case they spie an Indian convayinge or havinge of liquors, to seize of it for their owne proper use (97, v. I, p. 414). 
The Pennsylvania colonial govermment made it illegal to sell or give liquor's to Indians and so did South Carolina and a number of other colonies. But among the Indian trader's there was little respect for or observanec of laws and the traffic continued among all the tribes without much hindrance.

Colonial laws are sonctimes unsafe guides to an understanding of the real sentiments of people of those days. Colonial lawmakers were not always actuated by unselfish motives. In a preamble to a law restrieting the sale of liquor to Indians passed by the Rhode Island Assembly in 1673 may be found these significant words:

Although in this Collony by former Assemblys there hath been great eare to prerent it, some as there is great cause to eredit have been soe filthy have been eager to have such lawes established that others might be in awe thereby, and themselves have the more custome in such filthy tradeing (97, v. II, p. 500).

Rum as a Medium of Exchange with Indians. - A group of traders and merchants at Albany, N. Y. about the middle of the eighteenth century was especially flagrant in rending liquors in exchange for pelts. Once an Indian was drunk, his entire stock of furs eould be purehased for little or nothing. The Indian traders of Virginia as early as 1720 used to load earavans of horses with rum, hatchets, guns, munitions and elothing and strike out northwest into the Ohio country or south into the Mississippi region and would be gone months, sometimes years at a time. They would then come back with loads of valuable furs.

The Beginning of Whiskey Manufacture.-Early in the eighieenth century large numbers of Scoteh and Irish immigrants eame into the colonies bringing a thirst for liquors stronger than those in eommon use. Many of these were interspersed through out Pennsylvania, Maryland, Virginia and North Carolina and had much to do with the introduction of whiskey manufacture. The distillation of brandy from peaches and apples had been practiced in the colonies from the earliest settlements and the transition to the distillation of whiskey from wheat and rye was simple and easily accomplished. Stills were not possessed by all on account of their expense but those who had this apparatus would loan it to their neighbors so that each household could replenish its supplies. Later this business gradually became segregated, especially in Pennsylvania, western Maryland and the Shenandoah Valley of Virginia. Instead of each family 
making its own liquors the business of manufacture becane more and more commereialized.

Provision was made for public malt houses in the Massachusetts colony as early as 1637 but licquor manufacture in New England other than fermenting molasses into rum did not flourish to any great extent on aceount of the lack of suitable raw materials. A surplus of grain in the middle colonies offered great financial gain to those who chose that oecupation. As the distilling business became more separated from the home activities it offered a ready cash market for farmer's grain a feature of the matter which had a great influence in settling the more remote localities where the value of grain would not pay the expense of transporting it to the seaboard.

Summary.-To summarize the effeets of the alcoholic industry on agricultural development, we find that in the southern colonies generally, the use of spirituous liquors was a steady drain on their resources with little eompensating benefit in the way of Indian traffic. A few Indian traders gained by it but the great mass of people were made poorer by its use.

In the northern colonies there was an enormous waste of useful wealth in a vain endeavor to satisfy a eraving for stimulants. To offset this loss there was a large financial benefit. It gave the colonies a commodity to trade with Indians who had much more valuable furs than did those of the South. In later years it made a cash market for surplus grain in regions too remote to allow grain shipments to be profitable. Before manufacturing became an important industry the liquor traffic was one of the principal means by which the colonists were able to get cash or a product which could be converted into cash to exchange for European goods. 


\section{CHAPTER XXV}

\section{RELATIONS WITH THE MOTHER COUNTRY}

Colonizing America cost Creat Britain a vast amount of money. Smith says the London Company had spent over 200,000 pounds sterling on the Virginia colony alone (110, p. 927). Gee estimated the cost of the Colonies to Great Britain before the French and Indian War between $70,000,000$ to $80,000,000$ pounds sterling. Much more had been furnished by private capitalists as a speculative business venture as in Virginia, Massachusetts, and South Carolina. Some had been donated from a charitable impulse as in the founding of Georgia. But the bulk of the expense of defending the colonies from attacks and aggression from other eountries had been appropriated by Parliament out of public funds. The proprietary corporations lost practically every pound invested in American colonization when their colonies were taken over by the gorernment. Few direct dividends accrued to the government of Great Britain for its enormous outlay. Yet inclirectly the American colonies had been of immense value in building up the wealth and commerce of Great Britain. On the 96,000 hogshead of tobacco shipped annually to Great Britain near the close of the colonial period an import duty of over 350,000 pounds sterling was laid. About six-serenths of this tobaceo was reshipped to other European countries and an additional export duty was collected. The margin between the price paid the American planter and the retail price to the European consumer was excessively wide and this was clear gain to Creat Britain.

Similarly with rice-not more than one-twentieth of the produet shipped to Great Britian was consumed there. 'The remainder was resold on the continent at a good profit.

English Commerce Built up on American Trade.-The manufactured articles purchased by the colonists furnished employment to many British workmen. It was estimated that one man working on tobacco in Virginia gave employment to four Englishmen, that is, to sailors in transporting the produets and the merchants and laborers in manufacturing the articles given in exchange. 
New England Lacked a Staple Product.-An entirely different situation existed in the colonies north of Maryland than prevailed in that colony and those to the south. In the northern colonies grain was the principal crop and England during favorable crop years had surplus grain to sell to other European countries. The northern exports to Britain of furs, ships and ship building materials, potash, and other minor articles totaled but a fraction in value of that of tobacco alone. In developing fishing and trade in its products, New England was competing successfully with an old established industry of the mother country.

It should be noted that by supplying the sugar planters in the West Indies with foodstuffs those islanders were enabled to produce more abundantly an article, sugar, which was much desired in England. But the round about process by which this was accomplished obscured the real service which New England and the middle colonies were rendering. More readily apparent was the illegal commerce and manufacturing which those northern colonies were carrying on in direct competition with the mother country.

Ship Building Materials an Aid to England.--Another great benefit which had accrued to Great Britain was the large number of American built ships which had been sold to shippers in England and also the large amount of ship building materials such as pitch, tar, masts and timbers which helped in her shipbuilding industry. The superiority of the British navy and shipping in general had been built up quite largely from superior material from America and the American trade had made the British shipping economically possible and profitable.

Other Beneficial Commodities.-The colonies contributed many articles of use or luxury which England without the colonies would have lacked. While tobaceo was the principal agricultural product shipped to the mother country more useful were the American furs and pelts. Great Britain and France during colonial times were able to buy the finest furs at the lowest prices the civilized world has ever known. On the whole the American colonies especially those on the mainland had been very disappointing to Creat Britain in not furnishing the products expected from them when the colonies were founded. No great deposits of gold, silver or other valuable minerals had been discovered. 
Textile Raw Products Inadequate.-Silk production for which liberal bounties had been offered to the American colonists had been a failure. A few hundred pounds of raw silk were sent from Georgia and South Carolina but the American people have never seen fit to confine themselves to the poorly renumerative occupation of rearing silk worms in competition with the pauper labor of Asia. Moreover the rearing of silk worms conflicted with other plantation labor, the busy period being in April and May in the South. Hemp and flax suitable only to very productive land was grown but in limited amounts beyond sufficient quantities for home needs. Cotton was produced in quantity in the South. But here again the tedious methods of separating the lint from the seed placed the Americans in competition with the cheap labor of Turkey and India.

Dye-stuffs a Failure Except Indigo.-Dye-stuffs were in great demand in England for use by her textile manufacturers. Practically all of these were of an animal or vegetable nature. Cochineal production-a red dye-made from the dried bodies of a tropical insect which thrived on a species of cactus was monopolized by the Spaniards owing to the fact that these insects would not survive north of the frost line.

A limited amount of sumac seed from which a red dye was extracted was gathered from the native bushes in America and shipped to England. Saffron, the roots of which when dricd gave an orange-yellow eolor, eould be grown. It took however three years from the time the plants were started before they were ready for harvesting. Most of the colonists did not possess sufficient capital to wait so long for returns on their labor. Weld another plant yielding a yellow dye does not appear to have been tried to any extent in America. Woad a plant of the mustard family from the leaves of which was produced a blue coloring substance was grown in the middle and northern colonies. It was also as well adapted to England so the American product competed with that of the English farmer. In the production of indigo alone did the American production meet expectations as far as dye-stuffs were concerned. It should be noted however that even the Carolinians were at a great disadvantage in growing this erop in competition with the planters of San Domingo and other West Indian Islands owing to the shorter season on the continent. 
American Wines Unsatisfactory.-The reports of early travelers of the abundance of wild grapes growing everywhere along the Atlantic coast raised the hopes in England of an unlimited supply of wine which would make her independent of her rivals Spain and France in the production of this beverage. Wine was made in enormous quantities in the colonies from the native grapes and some was shipped to England but the result was disappointing. The American wine lacked the fine quality of the famous French brands made from the European grapes and served only to stimulate ridicule of America and American products among the fastidious wine drinkers of England.

Oil Products. - Vegetable oils valuable as they are at the present time were relatively of far greater importance during the colonial period. Before the discovery of petroleum, all of the oils used in cooking, illuminating, and lubricating in the manufacture of paints and soaps, and in the numerous arts were obtained from animal fats as tallow, lard, butter, whale and fish oils and regetables sources as olives, flax-seed, castor bean, sesame and rape seed. It was supposed in England that the American colonies would be able to supply the industries of the mother country with an abundance of oils: Olives were expected to thrive in Georgia and South Carolina equally as well as in Italy. There seemed to be no reason why rape seed oil and linseed oil could not be produced in the northern colonies as they were in Flanders and Holland. Unfortunately the method of expressing oil from cotton seed had not been perfected. Neither had the large oil content of the peanut been recognized and the value of this source appreciated until near the close of the period. While the exports of oil were considerable they fell far short of meeting the demand and England was largely dependent on European sources to supply her industries.

Metals a Disappointment.-Similarly the production of iron and copper had never reached the proportions desired by British manufacturers. The total value of copper and iron did not average more than about 90,000 pounds sterling during the later years of the colonies. With these disappointments frequently given publicity by prejudiced writers and the heavy taxation resulting from the Seven Years War or as it was known in America the French and Indian War which to the average Britisher appeared to be of American origin and waged solely for American advancement, it is not surprising that many of the responsible 
officials in the British Government began to look to Ameriea as a means for relieving the intolerable burden of taxes in Great Britain. The results of the attempts to lay taxes as the stanp tax on the American colonies are too well known to need mention. Yet there had been taxes collected in some of the American colonies by the British govermment from their first settlements in the form of quit-rents on land.

Quit-rents.-There were two general classes of quit-rents assessed in Ameriea, those laid by proprietary interests and those fixed by the British government. There was much less opposition to paying the latter taxes than the former. The American farmel's could see no good reason for paying a continual tax to a non-resident over-lord who in numerous instances had contributed nothing towards making the settlements and had been granted the land as a personal favor by the crown. The odium of being termed a vassal deterred many of the colonists from recognizing the system even when the giving of a valueless token was all that was requested. The attitude towards quit-rents varied greatly in the different colonies. Some of the settlers eame primarily to eseape the abuses of the system in Europe and of course were violently opposed to having the same unjust burdens imposed here. Others were far more tolerant. No quitrents were ever assessed in the four New England colonies, Plymouth, Massachusetts Bay, Connecticut or Rhode Island. In all of the others attempts were made to collect these taxes with more or less success.

Proprietaries who eame to America to live as William Penn, Lord Baltimore or Lord Fairfax were usually able to collect quit-rents but their non-resident heirs and other non-resident elaimants were seldom able to do more than stir up a riot when collections were attempted. ${ }^{1}$

Independence Inevitable.- Had Great Britain seen fit to grant colonial representation in Parliament as urged by the colonists and a few far seeing British writer's the results would probably not have been materially changed. There were economic reasons why taxes could not be collected in America which overshadowed the prineiple of "taxation without representation."

${ }^{1}$ For a thorough diseussion of the whole subject of quit-rents see, Beverly W. Bond, Jr. The Quit-Rent system in the American Colonies, New Haven, 1919. 
Frequent mention has been made in this book of the indebtedness of the colonial planters to the merchants in Great Britain, and of various expedients which were adopted to keep even a small amount of an exchangeable medium of currency in this country. All attempts at taxation which called for payments in cash by the colonists were bitterly resisted from the start. Even the nominal taxes as levied by the Stamp Act and that laid on tea would have soon depleted America of all her meager supply of hard money. There was but one means of recouping that supply and that was by open competition with Great Britain in manufacturing and trade in the markets of the world.

A Summary of the Situation.-A few statements from a liberal minded British writer of the time may help elarify the situation. Summarizing the trade with all the American colonies from Maryland to the West Indies inclusive this writer estimates that it took 650 ships and 13,000 seamen to handle the total colonial exports approximately valued at $£ 5,000,000$.

But whether something more, or sometling less, the conclusions to be drawn are the same: the possession of colonies that produce staples which cause such a prodigious commerce of the most advantageous sort in the world; which is entirely carried on in our own products and manufacturies, the balance of which is ours - the profit of which, on both sides is ours - the ships ours - the seamen ours - the freight ours-a flourishing revenue raised on them, ours - the population of the countries which support this trade, of our brethren and subjects of the same crown. . . can hardly fail of being and increasing and improving support $(4 \mathrm{v}$. II, pp. 233-4).

Now if we turn our eyes to the northern eolonies, we shall find that the case is extremely different. As the climate will not produce staples of value enough to purchase manufactures, etc., the inhabitants are necessitated to apply to other professions; these are commerce, fisheries, and manufactures; the moment they get into this train, they engage in a rivalship with the mother-country; both are in the same pursuits; they meet each other in the same markets, and with the same commodities; when once the mother country feels the effect of such a competition, jealousies, heart-burnings, restraints, opposition and a number of effects of rivalry arise, and are the fore-runners of that independency of which we are treating at present.

But the agriculture of the northern provinees, that is, of all the settlements north of the tobacco colonies yields only corn and provisions; valuable articles it is true, but not sufficiently so to bear the freight to Europe, except in years when they are very cheap in America, and very dear in Europe, consequently the sale of them to the merchants of 
Britain must, in the nature of things, be a mere uneertainty, a contingeney depending on accident: whereas the sale of manufactures must be regular, and absolutely to be depended upon (4, v. II, pp. 301).

Arthur Young discourses in a similar vein after independence had been gained by the colonies which helps to conneet that prolific writer with the editorship of American Husbandry the work quoted above. Young says:

Long before a single musket was fired in that ill-fated quarrel, I publicly attempted to show that those commonly called the Northern Colonies, that is, north of tobacco, so far from being possessions valuable to us, were in reality our very successful rivals in two artieles of as much eonsequence as any colonies in the world could be, the earrying freight trade and the Newfoundland fishery. I calculated that while (1770) the sugar colonies added above three millions (pounds sterling) a year to the wealth of Britain, the rice colonies near a million, and the tobacco ones almost as much, that those more to the north, so far from adding anything to our wealth as colonies, were trading, fishing, farming countries, that rivalled us in many branches of our industry; and had actually deprived us of no inconsiderable share of the wealth we reaped by means of our industry. ${ }^{1}$

It is easy to see how this one-sided arrangement, where profits from agriculture were contingent upon accident while the sale of manufactured goods must be "regular and absolutely to be depended upon" did not appeal strongly to the colonial planters. This feeling became intensified when they found through the capture of Louisburg in 1744 and the prosecution of several successful campaigns in the French and Indian War that they were not dependent for protection on any outside power. That the southern colonies joined with those of the North in the Revolutionary War may be traced directly to the heavy tax imposed on the agricultural products shipped to England and the terrific loss occasioned by the cumbersome commercial system which prerented the colonists from vending their own products more directly to the consumers. With New England equipped to conduct the carrying trade to the markets where there was the greatest demand for the products without duties

1 Yodxg, Arthur. Annals of Agriculture, Vol. I, p. 13, London, 1786. See American Husbandry, VII, Chaps. XXXIX to XXXVII for the discussion to which this likely refers also the closing chapters of The Present State of Great Britain in America by John Mitchell, London 1767 for the source of much of this argument. 
other than freight being imposed enroute it was clear to the southern planter that his interests lay in independence.

\section{DISCUSSION OF HISTORICAL SOURCES}

The student of colonial American agricultural history must be content with meagre data. There is but one comprehensive discussion of agricultural conditions, American Husbandry, and that was published just at the beginning of the Revolutionary War. But items gleaned here and there from the early sources when matched together often give a clear and convincing picture. The literature relating to America is voluminous, but much is irrelevant to our subject. The patient reader after perusing page after page of mutinies on shipboard, of sickness and suffering, skirmishes and slaughter interspersed with chapters of religious discussions, may be rewarded with a casual statement that has some bearing on the little known domestic life of an important period. If the reader is a careful student he will immediately make a verbatim copy of that item with complete citation of author, volume, page, date and place of issue, even though the passage at the time appears useless. Often a statement obscure and of little meaning when taken by itself may afterwards, when used in connection with observations of other writers become the key that unlocks some historical riddle. Copious notes are the work tools of the historian.

Voyages and Travels.-Sources in the English language of American affairs begin with the journals and relations of explorers from Eric the Red to the Revolutionary War. There have been a number of collections of voyages and travels issued. One of the earliest is that of Richard Hakluyt published about 1600. Hakluyt was a great scholar, a hard worker and a friend and helper of Sir Walter Raleigh in the latters historical work. Many of the Spanish, French and Portugese relations were first translated by Hakluyt or under his editorship and his renditions have been widely copied by others.

An extended edition of these voyages was issued in 1625 known as Purchas his Pilgrimes. An excellent edition of Hakluytus Posthumus or Purchas his Pilgrimes was issued in 1906 by James MacLehose and Sons of Glasgow. Unfortunately the Rev. Samuel Purchas abbreviated many of the manuscripts which came into his hands and the originals appear lost forever. 
Another collection known as the John Harris Collection of Voyages and Tracels especially the editions of 1744-48 and later, contains some accounts relating to America not to be found in the older publications. Other collections, while containing little if any original material as the Robert Kerr Collection of Voyages and Trarels and the John Pinkerton Collection of Voyages and Trarels may sometimes be more easily found than the original publications.

Still another work needs attention as it contains a number of relations not previously published. That is the Peter Foree collection published in 1836 at Washington entitled Tracts and Other Papers. Many of the best of all of these old journals have recently been reissued together with some very important documents not before published, in a series of "Original Narratives of Early Travel," edited by expert scholars on the various subjects under the able direction of Dr. J. Franklin Jameson and publisher by the Charles Scribners Sons. There is also a great deal of information in the translations of French sources made by J. G. Shea and R. G. Thwaites.

There is much need of study of the agriculture of the ancients. The more that is known about the Old World background the easier it becomes to appraise the methods and influence of American farmers. Researches into Chinese sources are bringing to light much interesting data. The writings of the Egyptians contain a great many items relating to their farming. Roman writers have left by far the most complete and satisfactory accounts of their agriculture of any of the ancient literature so far known. There are several good works in English on Roman farming. A book of lectures on Roman Husbandry delivered at the University of Oxford by Prof. Daubeny published at Oxford, 1857 is excellent.

In the Journal of the American Agricultural Association, Vol. 1, Nos. 3 and 4, pp. 37, 50, July and October 1881, Dr. J. M. McBryde has an interesting discussion of Ancient HusbandryRome and her Proninces. Roman Farm Management by Fairfax Harrison is one of the most complete translations of the Latin agricultural classics and contains many helpful notes.

Indian Agriculture.-There have been scores of books written about the American Indian but strangely enough there is not a comprehensive treatise on Indian agriculture. The history of some of the most important erops as corn and tobacco has been 
earefully worked out. There have been also some detailed deseriptions publisherl of the plants used by Indians in certain distriets but these, usually written by botanists, are mainly catalogues of the plants found in the localities studied and make little diserimination between those plants which were raised by artificial culture and those which grew naturally and the writers frequently fail to appreciate or understand agricultural practices. The investigators of the Bureau of American Ethnology have made exhaustive studies of all things pertaining to the life of certain tribes including their agrieulture. The efforts of these investigators to do justice to the much vilified Indian deserves the highest commendation. The various reports and bulletins which they have published offer the best secondary source material to be found.

There are also a few books dealing with particular phases of this subject which possess especial merit. One of the best is Corn among the Indians of the Upper Missouri by Creorge F. Will and George E. Hyde. The Mounds of the Mississippi Valley by Lucien Carr represents a thorough search of the historical material dealing with the Indians of the eastern part of the country, and the same may be said for Iroquois Uses of Maize by Arthur C. Parker. The History of America by E. J. Payne is a philosophical treatise of the American aborigines and deals primarily with the Indians of Mexico and Central America. George K. Holmes prepared an excellent article entitled Aboriginal Agriculture which appears in the Cyclopedia of Ameriean Agriculture Vol. 4. There is need of much further study of Spanish and Portugese sources in South America showing the agricultural practices of the Indians before they were influenced and modified by contact with Europeans. When this is clone a complete agricultural history of the American Indians devoid of all extraneous matter should be possible and would prove very helpful to those interested in the subject.

History of Plants.-One of the most difficult fields of historical research is that dealing with the history of plants. While there is a voluminous literature the deseriptions are so often faulty or indefinite that positive irlentifieations are frequently impossible. Prior to the work of the great Swedish botanist Linnaeus books on botany were usually mere eatalogues of plants and attempts to form groups of related species frequently added to the confusion. The early botanists were almost always physi- 
cians. In their zeal to find help for diseased and suffering humanity the physicians of the ancients as well as their followers during the Renaisance were interested in plants primarily for their medicinal properties. Especially in the sixteenth century every physieian of note aspired to the laudable purpose of giving the publie a treatise on the virtues of plants. Some of the ideas inculcated at that time still persist in popular beliefs. At the present time however these "herballs" are of more interest to the botanist or plant historian than to the medical profession. Most of them are in Latin.

One of the earliest of these publications relating to America is the rork of the Spanish physician, Nicholas Monardes, first published Sevile (1574). This was "Englished by John Frampton, Marchaunt. Imprinted at London in Poules Churcheyarde, by Willyam Norton. Anno Domini, 1577." This small and rare book entitled Joyfull nevves out of the newe founde worlde contains many interesting original descriptions of American plants.

A New herball, by William Turner London 1551, is a valuable English treatise on plants for its time. The next important botanical publication in English was Henry Lyte's translation of Rembert Dodoens' Cryder Boeck which appeared in 1578. Jolnn Gerarde's The Herball or General History of Plants, London 1597 completes the English list for that period. All three of these "English herballs" were indebted to Leonhard Fuchs, De Historia Stirpium 1542 for illustrations at least. Anyone interested in these eurious old books should first consult Hcrballs Their Origin by Agnes Arber 1912 or Landmarks of Botanical History by Edward Lee Green, 1909.

Hans Sloane a physician who had spent several years in the West Indies prior to 1689 issued a catalogue of plants in 1696 which proroked consiclerable riclicule among his English constituency due to the publication being in Latin and also being of a highly technical character. In 1707, he issued a comprehensive and more popular treatise in English entitled A Voyage to the Islands of Madera, Barbadoes Nieves, S. Christophers and Jamaica. This work contains a great many useful observations in acldition to its biological descriptions.

John Lawson surveyer Ceneral of North Carolina, killed by the Indians at the beginning of hostilities in 1711, traveled extensively through the Indian settlements of that province about 1700 
and wrote a manuscript which was published as a II istory of Vorth Carolina, 1709. This contains many observations on Indian agriculture as well as colonial.

Mark Catesby's work the Natural History of Carolina, Florida and the Bahama Islands contains much of interest in regard to the plants of the soutliern part of our country. It was issued in two folio volumes the first appearing in 1731, the second in 1743. A work of similar nature, copicd from Lawson, is The Natural II istory of North Carolina by John Brickell, Dublin 1737.

The Natural History of the Barbadoes, in ten books by the Rev. Griffith Hughes, London 1750, is worthy of study as is also the 'ivil and Natural History of Jamaica by Patrick Browne London, 1756.

Contemporaneous with Linnaeus were several American botanists of note. In this group may be mentioned Cadwallader Colden of Ner York, John Bartram of Pennsylvania, John Clayton and John Nitchell of Tirginia and Alexander Garden of South Carolina. Their work however consisted largely in furnishing specimens and informations to European botanists and little has come down to us directly from those eminent men except a portion of their correspondence which has been preserved.

A series of books beginning in 1731 and running through several editions and published in London entitled The Gardners Dictionary by Philip Miller is a store house of valuable information in regard to plants and their culture. Many American plants are discussed. Since Carl von Linne commonly referred to as Linnacus established order out of botanical chaos his work beginning about 1735 , there has been a tendency to neglect the more ancient botanists and date everything botanical from 1753 the date of publication of the Species Plantarum.

(nne of the most competent botanists to visit America during colonial times was Peter Kalm, an assistant to Linnacus, who spent portions of three years $(17+4-51)$ collecting plants around Philadelphia, New York and Montreal. His report first published in the Swedish language was translated into English by John Forster, London, 1772. Kialm makes many interesting observations on the vegetation and farming practice.:

The Origin of Cultivated Plants by Alphonse de Candolle the first English erlition being in 185.1 followed by two or three later editions in Englaud and Anerica, is a clasicic. Unfortunately Candolle was not fully conversant with Anerican flora and history 
which led him to draw some erroneous conehusions but there is much of value still to be gained from that treatise.

Colonial Records.-Documents relating to colonial history have been issued in voluminous quantity often under state supervision but more frequently by historical associations. Material of this kind which bears on each of the original colonies is available. Colonial laws which have been so often quoted in this book throw light on agricultural conditions but are frequently late in their appearance, for the subject legislated upon.

American Histories. - There are several books on America worth reading for their natural history by the agricultural student though they were not intended as agricultural literature. These include Thomas Hariot's Description of Carolina (15SS) reprodueed in a number of collections of royages.

Capt. John Smith, "Works on Virginia, New England and Bermuda" (1612-30) reproduced in one Volume by Arber 18st.

William Wood, "New England Prospect" (1635) several later editions.

Edward Johnson, "Wonder Working Providence" (1653) (1910).

Daniel Denton, "Deseription of New York" (1670).

John Josselyn, "New England Rarieties" (1672) and "Two Voyages to New England" (1673-4).

William Bradford, "History of Plymouth Plantation" published from the original (1898).

John Winthrop, "Journal" (in several editions).

Gabriel Thomas, "An Historical Aceount of West New Jersey and Pennsylvania" (1698).

John Oldmixon, "The British Empire in Ameriea" (1708).

Robert Beverly, "History of Virginia" (1705).

Daniel Coxe, "Carolina" (1722).

Hugh Jones, "Present State of Virginia" (1724).

LePage du Pratz, "History of Louisiana" (175S) (First English Edition 1763, 2nd 1774).

William Douglass, "A Summary Iistorical and Political of the British Settlements in North America" (1749) (1755).

John Mitehell, "Contest in Ameriea between Great Britain and France" (1757) and "Present State of Great Britain in America" (1767).

Bernard Romans, "East and West Florida" (1775).

Robert Proud, "IIistory of Pennsỵlvinia" (1797).

Agricultural Literature.- When it comes to strietly agricultural publications of the colonial period the bibliographer has an easy task although the agricultural historian is put to trouble by their scarcity. The lack of early American agricultural books is relieved to some extent by English books on husbandry. The student of colonial agriculture should read all the available 
contemporaneous English literature on the subject. Many of the colonists came imbued with English ideas of farming and the English publieations exerted no small influence on American methods. In this class worthy of special mention are:

Samuel Hartlib, "Legacie," (1651).

John Houghton, "Husbandry," a periodieal (1693-99).

J. Mortimer, "Art of Husbandry" (1716 and several later editions).

Jethro Tull, "Horse Hoeing Husbandry" (1733).

William Harte, "Husbandry" (176t).

R. E. Prothero, "English Farming Past and Present" (London 1912). This is an excellent modern book which includes a discussion of English agriculture of colonial times.

In America the colonial agricultural literature is limited to Jared Eliot, "Essays on Husbandry" (1748-59) six in number, afterwards published in one volume and J. Hector St. John (Crevecoeur) "Letter from an American Farmer" written before the Revolution but published after its elose (1793).

"American Husbandry," by An American London (1775). Principally the work of Dr. John Mitchell (d. 1768) but apparently prepared for publication by Arthur Young is by far the most valuable discussion of Agricultural conditions of the American colonies now in existence. It is also a valuable treatise on agriculture representing the highest degree of scientific knowledge on the subject existing at the time it was written to be found in the English language. A comparison of a statement made by Young in his "Annals of Agriculture," Vol. I, p. 13, with the last four Chapters in "American Husbandry" indicates that Young was responsible for that portion of the work although Mitchell's arguments permeate that discussion as well as the rest of the two volumes. For proof of Mitchell's part in the preparation of "American Husbandry" sce American Historical Association, Annual Report, Vol. 1, pp. 201-219, 1918. 


\section{BIBLIOGRAPHY}

1. Alyord, C. W. and ILE: Bidgood, First-Explorations of the TransAllegheney Region by Virginians.

2. American Antiquarian society, Rec. of Mass. Bay, v. III, p. 77, 1850.

3. American Hist. Review, v. XXVI, No. 4, pp. 739-743, July, 1921.

4. American Husbandry, by An American, v. 2, pp. 75-76, London, 1765.

5. A New and Complete Hist. of Ameriea, Anon., v. II, p. 4\$3, London, 1756.

(i. Archives of Maryland, v. I, p. 96.

7. Armistead, W., Memoirs of James Logan, p. 158, London, 18.51.

S. Bauhin, Casper, Matthiolus Opera, p. 397, Frankfort, 1598.

9. Beverly, Robert, Hist. of Virginia, p. 153, London, 1722.

10. Bourne, E. G., The American Nation, A History, v. II, pp. 21j-217, N. Y., 1907.

11. Bozmax, J. L., Hist. of Maryland, v. II, pp. 25-31, Baltimore, 1837.

12. Bradford, Williai, History of Plymouth, p. 16, Boston, 1898.

13. Brickell, John, Natural History of North Carolina, p. 10, 1737.

14. Brodhead, J. R., Documents Relating to the Colonial History of New lork, v. I, p. 277.

15. Browne, Patrick, Civil and Natural Hist. of Jamaica, Book 2, p. 175, London, 1756.

16. Budd, Thomas, Good Order Established in Pennsylvania and New Jersey, p. 37, 1902.

17. Bureau of American Ethyology.

1S. Carrier, Lymax and K. Bort, Hist. of Kentucky Blue Grass. Jour. American Soc. of Agronomy, v. VIII, p. 256, 1916.

19. Carroll, B. R., South Carolina Hist., v. II, pp. 64-71, New York, $1 \$ 36$.

20. Catesbr, Mark, Natural Hist. of Carolina, v. II, p. XVIII, 1743.

21. Connecticut Colonial Records, v. I, pp. 1-2.

22. Cox, Isaac Joshin, Travels of Ia Salle, v. II, p. 139, New York, 1905.

23. Coxe, Daniel, Carolana, p. 62, 1840.

24. Dampier, Willian, A Voyage Around the World, v. I, p. 333, 1697.

25. Danckaerts, Jasper, Journal Ed. by B. B. James, p. 200, New York, 1913.

26. Darlington, William, Memorials of John Bartram and Humphrey Marshall, p. 50, Philadelphia, $184 S$.

27. Denton, Daniel, Deseription of New York, 1 S 45.

2S. Douglass, Willian, An Historical Account of the British Settlements in America, v. II, pp. 206-7. Boston, 1755.

29. Early English and French Travels, p. 125, New York, 1906.

30. Eden, Richand, Decades of Peter Martyr, Arber Ed., pp. 73 and 16S.

31. Eden, Ricinard, Decades of the New World or West Indies, p. 30, London, 1555. 
32. Eliot, Jari-1), New England llusbandry or Essays un -Igriculture, p. jl.

33. English Historical Review, p. 261, London, April, 1917.

34. Fermis, Bexs., Hist. of the settlements on the Delaware, p. 52, Wilmington, $1 \mathrm{~s} 16$.

35. Force, Peter, Traets and Other P'ipers, v. I, No. 12, p. 6, Washington, 1336 .

36. Frexch, B. F., Hist. Coll. of Louisiana, v. I, pp. 173-4.

37. Gabriel, Thomas, Hist. of Pennsylvania and Vest New Jersey, pp. 8-32, London, 169 S.

3S. Georgia Colovial Records.

39. Gerarde, Johx, The herball or history of plants, p. 751, London, 1597.

40. Gist, Christopher, Journal, Filson Club Publication, No. 13.

41. Haklert, Richard, Discovery of Florida by Ferdinanda de Soto, London, 1609.

42. Hakluyt, Richard, Toyages and Travels, v. II, p. 28t, London, 1809.

43. Hale, Thomas, A Complete Body of Husbandry, v. 2, pp 2S-32, London, $175 s$.

44. Hariot, Thomas, Narrative of the First English Ilanting of Virginia, Frankfort, 1590.

45. Harris, Johx, Coll. of Voyages, v. I, pp. 59S-609, Loncton, 1741-S.

46. Hartlib, Saheer, His Legacie, p. 79, London, 1651.

47. Hazard, E., State Papers, v. I, p. 413-7.

49. Hexpeprx, Louis, A New Discovery Thwaites Ed., v. II, p. 652.

49. Henisg, Statutes at Large for Virginia, v. I, p. 125.

jo. Herbert, Thonas, A Relation of some Years Travaile, p. 182, London, 1626.

51. Hodge, F. W., Spanish Explorers in the Southern United States, p. 348, New York, 1907 .

52. Holm, Thomas Campanics, A Short Description of New Sweden, Trans. by Peter S. De Ponceau, p. 43, Phila., $1 \$ 34$.

53. Holmes, George K., Three Centuries of Tobaceo, Year Book, U.S.D.A. p. 152, Washington, 1919.

54. Hovghtox, Johx, Hushandry, v. II, p. 468-9, 1728.

55. Hughes, Rev. Griffith, Natural Hist. of the Barbadoes, Book ViII, p. 228 , London, 1750 .

56. Ifughes, William, The American Physieian, p. 1S, London, 1672.

57. Hutchissox, Johs, Hist. of the Colony of Mass. Bay, v. I, p. 485, Boston, 1765.

5S. ImLAY, Deseription of the Western Territory of North America, p. 42, 1792.

59. Jefferson, Tiromas, Biography, v. VIII, p. 2 S0.

60. Jefrersox, Thomas, Writings, Jefferson Memorial Soc. Pub., v. X, p. 12, Washington, 190:5.

61. Jexisess, Jorn, Early Documents Relating to New Ifampshire, p. 54. Portsmouth, 1878.

62. Jomsox, CAPt. Edward, Wonder Working Providenec, p. 29, New York, 1910.

63. Joxes, Hugh, Present State of Virginia Sabines, Ed., p. $41,150.5$. 
64. Jossemy, Juin, An Aeenunt of Two Voyages 10 New England, p. 7 t, London, 1674.

65. Kán, Peter, Travels in America, Trans. ly John Forster, v. 1, p. 24, Jondon, 17\%2.

66. Latrer, Bertiold, Sino-Iranica, pp. 438-45, Chicago, 1919.

67. LAwsos, Jomx, A Description of North Carolina, p. 76, London, 1714.

68. L'Léluse, Cimarles, Plantarum His., p. 79, 1601.

69. LePage 1) Pratz, 1 Description of Louisiana, p. 250, London, 1774.

70. Lewis, Theodone H., Spanish Explorers in the Southern United Stites, p. 16.5, New York, 1907.

71. Logax, Wilham, Memoranda on Husbaudry, Original in the U. S. Dept. of Agr. Library, Washington, D. C.

72. Lucas, Eliza (Mrs. C. C. Pinckney), Journal and Letters, p. 16, Wormsloe, 18.50.

73. Lyte, Hexrr, Trans, of Dodoen's Cryder Boeck; p. 500, London, 1575.

74. Memoirs Philadelphia Agr'l. Soc., v. I, p. 158, Phila., 1808.

75. Miller, Phillip, Gardner's Dictionary, London, 1754.

76. Mitchell, Joir, M. D., The Present State of Great Britain and North America, London, 1767.

77. Monardes, Nicholas, Joyful News out of the newe founde World. Trans. by John Frampton, Fol. 34, London, 1577.

78. Moore, Francis, Travels into the Inland Parts of Africa, London, 1738 .

79. Moore, Francis, A Voyage to Georgia, pp. 53-55, London, 1744.

S0. Mortimer, J., The Art of Husbandry, p. 472 , London, 1707.

S1. Munro, Robert, The Lake Dwellings of Europe, p. 536, London, 1890.

82. Murray's New English Dictionary.

S3. Narragansett Club Publieations, r. IV, p. 165.

84. Narratives of Early Carolina, p. 175.

S5. Narratives of Early Maryland, Ed. by C. C. Hall, p. 3S, New York, 1910.

86. Narratives of New Netherland, p. 46, New York, 1909.

s7. New Haven Records, pp. 91-93.

SS. North Carolina Colonial Rec., v. I, p. 71.

S9. O'Callagian, E. B., Doeumentary Hist. of New York, v. III, p. 38, Albany, 1850.

90. Pinkerton, John, Travels, v. III, p. 294, London, 1819.

91. Prper, C. Y., The Wild Prototype of the Cowpea, Circ. 124, U. S. Bu. of Plant lnd., Wash., 1913.

92. Piper, C. V. and K. Bort, The Early Agricultural Hist. of Timothy, Jour. Am. Soe. of Agronomy, v. VII, p. 1, $191 \overline{.}$

93. Proud, Robt., History of Pennsylvania, v. 1, p. 250, Phila., 1797.

94. Purchas, Sanuel, His Pilgrimes, v. XVII, p. 468, Glasgow, 1906.

95. Ramsar, David, History of South Carolina, v. II, pp. 211-12, 1809.

96. RaY, Jorr, Coll. of Curious Travels and Voyages, v. II, pp. 16-50, London, 173s.

97. Rhode Island Colonial Records, v. II, p. 129.

9S. Rrvers, W. J., History of South Carolina, p. 415, Charleston, 1856. 
!1!. Rochefort, Citarles de, The History of the Caribly Islands, Trans. by John Davies, p. 47, 1666.

110. Romsis, Bensind, Natural History of Eust and IVest Florida, p. 16, lew lork, $17 \%$.

101. Rose, J. X.. Contributions, U. s. National Herbarium, r. V, p. 227.

1(12. Ressell, Pat., Natural History of Aleppo, v. I, p. 91, London, 1794.

103. Sichse, J. F., Falehner's Curiuse Taehrieht, (1702) pp. 103-193, Phila., 1905.

104. Saga of Eric the Rerl, Northmen, Columbus and Cabot, Original Narratives of Early Travel, pp. 25-36, New lork.

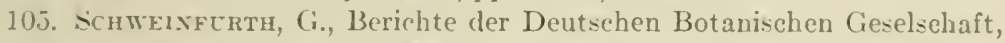
v. II, p. 261, Berlin, 1sist.

106. Sies, J. C., Hist of Jew Jetherland, p. 57, New Jork, 1856.

107. Nhes, J. G., The Jogues Papers, p. 5i, New York, 1556.

105. Silonye, H.s.s, Voyage to Jamaica, v. I, p. LXXIII, London, 1707.

109. Siral, Johx Ki., Journal New York Botanical Garden, ఛ. XXII, pp. 121-13T, 1921.

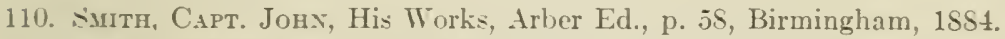

111. Simph, S.Ajeel, History of New Jersey, p. 517, Phila., 1765.

112. Surth, WrllaM, A Brief State of the Province of Pennsylvania, p. 10, New York, 1865.

113. Surth, Rev. Williar, A Natural History of Tevis, pp. 220-2, London, 1745 .

114. Surth, William, History of New York, pp. 19S-201, London, 1757.

115. Smithsonian Collection, No. 169S, ఛ. III, p. 435, 1907.

116. South Carolina Historical Coll., Shaftsbury Papers, v. Y, p. 442.

117. Spanish Explorations in the Southwest. Trans. by Herbert Eugene Bolton, p. 21\%, New Jork, 1916.

11S. Stevexs, Hexry, Thomas Hariot and his Associates, 1900.

119. Зт. Johx (CRevecotr), J. НестоR, Letters from an American Farmer, p. $21,1793$.

120. Stracher, Willian, Travaile into Virginia, Hakluyt Soc. Pub. v., VI, p. XXX, London, $18+9$.

121. Thwates, R. G., Jesuit Relations.

122. Terser, Williai, A New herball, p. 149, London, 1551.

123. Trler, L. G., The American Nation, A History, v. IV, p. 79, New York, 1907.

124. Tpdike, Wilkiss, History of the Narragansett Chureh, r. I, p. S, 1S47.

125. Vries, Datid De, Narratives of New Netherland, p. 203, New York, 1809.

126. Vries, D. P., Voydgien van 161S-44, 1911.

127. Washixgtox, George, Biography, Sparks, Ed., v., p.XII 333.

128. White, Avdrew, Narrative of a Voyage to Maryland, Baltimore, $187 t$.

129. Williars, Roger, A liey into the Language of America. Narragansett Club, Pub. v. I, pp. 123-1.

130. Wivthrop, Jonx, New England, v. I, p. 162, 1 S25.

131. Wood, William, New England Prospect, $189 S$.

132. Woods, Jonx, Two Year's Residence in the Settlement on the English Prairie in the Illinois Country, p. 211, London, 1522. 
133. WrNe, J. II., British Empire in America, v. I, pp. 214-i), London, 17ส(1. 134. Yodxa, Alex, Chronicles of the Pilgrim Fathers, p. 234, Boston, 1841. 135. Yele, Sir Hexry, The Book of Marco l'olo, v. II, p. 393, I,ondon. 1903. 


\section{INIDEX}

A

Abuakis, 51

Acadia, 216

Acosta, 89

Adam's apples, 14

Agricultural, history, 1

literature, 306

Agriculture, importance of, 11

of Asia Minor, 13

of Indians, 41

primitive, 7

Roman Catholic Mission, 109

Alachron, explorations of, 103

Albemarle County, 196

Alcoholic beverages, 286, 257

Alewives, 98

Alfalfa, 243

grown in Italy, 17

in Georgia, 244

in Pennsylvania, 244

in South Carolina, 244

in West Indies, 244

introduced by Spaniards, 110

Algonquin Indians, 21

Allotment of lands, 108, 126, 160, $168,174,183,203,208$

American beans, 203

Amcrican histories, 306

American Husbandry, 307

Ancient deposits, 4, 5, 49

Andropogon, 29

Anguria, 65

Animals, domestication of, 9 domesticated by Indians, 9

Apios tuberosa, 32,8 ?

Apocynum cannabinum, 90

Appalachian beans, 250

Apples, 8, 14, 155, 162, 209

Appomattox Indians, 122

Apricots, 19

Arabian horses, 110
Arpus, 58

Arrenatherum elatius, 242

Artichokes, 150

Jerusalem, 59

Asparagus, 13, 163

Assentamens. 51

Asses, 105,110

B

Bakeries, 161

Bananas, 41, 79

Barbacoa, 92

Barberry, eradication of, "15.5 thought harmful to wheat, 150

Barley, 8, 15, 19, 103, 106, 140, 142, $150,192,244$

without husks, 106

Barony, 202

Bartram, John, 176, 211

farm described, 179

Batatas, 62

Batteca, 74

Batts, Henry, 225

Beans, 49, 50, 51, 103, 142

found on Cape Cod, 139

in Palestine, 52

methods of seeding. 52

Bears, month of, 78

I3ecr, 2S8, 289

Bees, 258

Bects, 15, 150

Beginnings of life, 1

Belvoir, 237

Bermuda, settled, 105

Berries, 30

Biological evidenee, 1

Black cattle, 23, 219

term defined, 255

Blackberries, 8, 30, 41

Blacksburg, Virginia, 226

Blasting of wheat, 147 
13lue grass, 221, 211, 24:3

Bonavis, 249, 250)

Book farming, 22?

Botanical gardens, 176

Bounties, 133, 134, 178, 186, 214

Branding irons, 145, 168

laws, 145, 165, 184, 191

Brandy, 259

Brazil nuts, 79

Bread-corm, $16 t$

Bread of Virginians, 131

Brick, 135

Bristol beer, 290

Brogham, silk, 90

Broom eorn millet, 107

Broom straw, 29

Buckwheat, 17, 163, 172

Buffalo, 101 month of, is

Bull fight, 112

Bunched Guinea corn, 251

Burgundy trefoil, 244

Burnet, 243

Bush cotton, 91

Bushel beans, 249

Bustards, 101, 217

Butter, 148

Butternuts, 41

C

Cabbages, 13, 103, 164

Cacao, 79

Cajoba, 53

Calavances (see Cowpeas)

Camels, 260

Camuse family, 212, 213

Canada, explored, 216

field pea, 49

Canary seed, 19

Candole, Alphonse de, 43

Cane, 35

Canebrakes, 220

Capons, 165, 217

Carpets, 102

Caribbean Islands, tobaceo of, 125

Carrots, 13, 150

Cassava, $33,41,87,244$

Castor bean, 15
Cisttle, 108, 127, 254

driven to market, 228

killed by Indians, 217

losses from shipping, 143

Cauliflower, 13, 19

Celery, $1: 3$

Chalk, $26 \mathrm{~s}$

Cheese, 14 s

Cherries, 8, 19, 142, 220

Cheshire eheese, 148

Chestnuts, 36,41 month of, 78

Chick peas, 247, 248

Chiendent, 243

Chinquapins, 36,41

Chunno (potato flour), $\$ 1$

Cider, 162, 259

Cinnamon, 102

Citrons, 1t, 15, 69

Citruls, 13, 15, 65

Civilization, conditions favoring, 7 , S, 9,10

Clam-shell hoes, 95)

Claret, 290

Claverack, 240

Claver-grass (see Clover).

Clayton, John, tobacco culture, 56, 129

Clearing land, 175

Indian methods, 38

Clearings, 39, 40

Cliff Dwellers, 5, 20

Cloth, bounty on, 134

Clover, 17, 19, 155, 239

Cloves, 102

Cochineal, 296

C'oconuts, 79

Cocoons, $17 \mathrm{~s}$

Codfishing, 102

Cole-seed oil mill, 186

Colocasia, 13, 15

Colocynth, 64

Colonial, expansion, 223 foreign trade, 111 records, 306

Colonies, cost of, 294 purpose of, 114

Commerce, 193, 279, 294

Communism, 126, 141 
Coneys, 14:3

Connecticut, 1 s: export of, $1 \mathrm{St}$;

Conti, 34

Convolvulus batatas, si

Cooscoosh, 275

Copper exported, $1>0,297$

Corn, 43, 279 (see also Mraize). breeding, 45

cribs, 92

exported, 12s, 166

found on Cape Cod, 139

pits, 92

planting, $3-$

Coronado explorations, 103

Cotton, 41, 90, 91, 1S6, 200, 221, 244 eloth, 102

Old world sorts, 201

origin of varieties, 91

perennial, 201

West Indian, 91

White siam, 221

Coulters, 263

Court-baron, 169

Court-leet, 169

Couscou, 274

Cowpeas, 50, 107, 247, 249, 250 term first used, 250

Cowpens, 214

Cows in Canada, 216 yield of milk, 201

Crab grass, 243

Cranberries, 30

Crops, African, 107

Asiatie, 107

Indian, 41

introduetion of, 239

Cueumbers, 15

Curumis eitrullus, 65

Cucurbits, 57

Cultivators, 26.5

Cushaw, 59

Cymling, 59

Cyprus cotton, 201

\section{D}

Duiry cows, 201, 25j

farms, 192, 193 1)airying in Italy, 17 in New England, 283

Dale, Gov. Thomas, 121, 122, 123, 124,126

Dates, 15,110

Deer, month of, 77

Deluware, 171

Dent eorn, 47

De Soto's explorations, 103, 109

Deux ans apple, 167

Dioseorea alata, 63

Diversified farming, 128

Division of labor, 11, 24

Dogs, Indian, 99, 156

Dolichos lablab, 249

Domestic animals, 253

Draft horses, 176

Drake, Sir Francis, 55, 81

Dressed meats, trade in, 135

Drinking, penalties for, $28 \mathrm{~S}$

Dry climates, early civilizations in, 9

Dutch East India Company, 211

Dutch farmers, 154 settled Connecticut, 182

New Jersey, 159

trading posts, 280

Duteh West India Company, 153

Dye-stuffs, 296

E

Earth nuts, 62

East India cotton, 221

East Jersey, 161

Ebenezer, settled, 209

round-up at, 214

E Dees tobaceo, 131

Egypt, agriculture of, 15 ancient remains, 4 early civilization, 9

Egyptians, crops of, 15 grew melons, 64

Eliot, Jared, 229

Endive, grown in Syria, 13

England, agriculture of, 17

English, barley, 150

eolonial settlements, 114

griss, 187,240

hay-seed, 240 
Euvironment, effect on species, 3

Eriophorum virginieum, 90

Essays in agriculture, 229

European erops tried in America, 103

Evolution, Theory of, 2

Experimental farm in south Carolina, 201

garden in Creorgia, 209, 210

Exploration period, 102

Exports from Connecticut, 186

Georgia, 215

Illinois, 219

New Jersey, 163

New Jork, 159

Pennsylrania, 1s0

South Carolina, 206

Virginia, 136

of tobacco, $12 \mathrm{~S}$

F

Faba vulgaris (sec Horse bean).

Fairs, 184

Fagioli, 51

Farm implements, 263

Favas, 50

Fuxones, 50

Fence building, 123

law, 167, $16 \mathrm{~s}$

Fennel, 13

Fertilizers, 271

used by Indians, 97

Feudal system, aids colonization, 115

Fiber plants, 90

Figs, 78, 110 of the sycamore, 15

Filature, 178, 213

Filberts, 142

Fir, 71

Fishes, month of, 77 used for fertilizer, $9 \mathrm{~S}$

Fishing, Newfoundland, 102

Fitch, 49

Flanders, agriculture of, 17

Flax, S, 134, 159, 162, 172, 296

Flemish agriculture, 17

Flint corn, 47
Florida, 109

Flour, made of nuts, :36;

Food, 10, 29, 12ऽ, 290

Fossil ear of maize, 43,41

Fossils, an historical aid, 2

Forage plants, 26, 239-51

Fox chasing, 156

France, agriculture of, 17

in Anerica, 216, 217, 219, 220

Frederica, Cieorgia, 40

Free labor, 175

French barley, 150

beans, $50,52,70$

Frijoles, 249

Furs, 149

G

Garlanzo, 247

Gardens, 149, 209

at Cape of Good Hope, 211

Garlic, 13

Garnanses, 51

Geese, 217

George, the Armenian, 133

Georgia, $20 \tau$

described, 234

exports of, 215

German settlers, $17 \%$

Ginger, 102, 200, $24 t$

Croats, 120, 256

Gold cloth, 132

discovered, 108

Gooseberries, 30, 41

Gossypium, 91

Gourds, 13. 57, 5s, 59, 106, 21s

Grain growing, $14 \bar{\tau}, 15 \pm$

Grand Model of Government, 202

Grapes, American, 30, 31, 41

European, \&, 15, 110, 212

Grass sced, 241

Grasses, 240

bluegrass, 241

crab, 243

greensward, 243

herd's, 241

nut, 243

orchard, 242

Rhode Island bent, 241

Salem, 213 
(irashelpers, 2IS

Ciround nuts, 3:2

(irist mills, 14s, 162, 192

Guinea corn, 107, 251

"heat, 46, 100

Cypsum, 269

\section{liabitants, 219}

II: nsou timothy, 241

Ilariot, 'Thomas, 30, 31, 36, 45, 55, $\$ 4, \$ 5$

Harrows, 26.3, $26 \tilde{5}$

Hartford, settled, 182

Hartlib, samuel, 15

Ilawkins, John, 55

Hay, $146,151,197$

forks, 263

knives, 263

stacks burned, 141

IIazelnuts, 36

Heathens, 12

Henp, S, 149, 159, 162, 172, 21S, 296

bounty on, 134

ordered sown, 18.5

wild, 90

Hemstead Plains, 2.59

Herballs, 304

Herd's grass, 151, 211

Heredity, law of, 2

Hickory nuts, 41

Hides, embargo on, 13.5

exporterl, 110, 112

Hill planting, 94

Hindnanes, 58

Ilistory, defined, 1 of plants, 303

Inoes, 263 elain slıell, 95

IIogs, how marked, 13.j

in Bermuda, 105

kept by Iroquois, $2: 3$

stealers, 135 (see also Swine).

Hlolcus lanatus, 243

Holland, ugriculture of, 17

Honw. Dr. Francis, quoted, 230

IIominy, 4s

Hopi Indians, 22
IIops, 1s, 19, 25:2

IIorse beans, 11,50

lıoeing Ilusbandry, 93

hoes, 26.5

raciug, 259

radisl, 13

IIorses, 101, 105, 109, 110, 217, 259

Ifouses, how built, 136, 15t, 175, 196j

Huckleberries, 30

Huguenots, $21 \mathrm{~s}$

Human beings, first, 6

Ilundred, term defined, 123

Hunt, Capt. Thomas, kidnapped Squanto, 139

Hurtleberries, 71

Hybrids, 2

Illinois settled, 219

exports from, 219

Implements, 263 used in England, 18

Indentured servants, 169,174

Indian, fields, 39

figs, 36

houses, 166

rice, 31,35

slaves, 206,219

traders, 195, 290

tribal contrasts, 22

Indians, 20

agriculture, 41,320

classified, 20

crops destroyed, 23

grown, 41

division of labor, 24

domestic animals, 99

life, 24

heavy drinkers, 291

methods of tillage, 91

plant breeders, $t 1$

storage of crops, 92

Indigo, 200, 201, 205, 215, 241

Inflated prices, 144

Iniamos, 62

Inspection laws, 12!), 157

Intertillage, 93

Introluction of crops, 23!) 
Iroquois, 21, 21s

manured their ficlds, $9 \mathrm{~s}$ received tribute, 225

Ireland potatoes first grown in, st

Irish potatoes, S0, S1

Irrigation, 158, 177

Iron, 135, 137, 149, 180, 297

Isle of Orleans, 217

Italy, agriculture of, 17

Ivrai (see Rye grass).

\section{J}

James I quoted, 18

Jamestown, 118, 127

Jerusalem artichokes, 41, 60

Jibbes, 75

John Apple, 167

Johnny cake, 48

Judias, 50

\section{Ki}

Kialm, Peter, 33, S6

liarpus, 58

Kaskaskia settled, 219

Katnis, 34

Keepers of compens, 214

Kiemps, 119

Fient Island, 165

Kentueky, bluegrass, $2 \cdot 21$

explored, 227

Kidney beans, 14, 249, 250

Kinsock (Tassore), 119

\section{L}

Labor, division of, 11, 24

Jake Dwellers, 4, 8

Land grants, 10S, 126, 160, 168, 174, $1 S 3,203,20 S$

I,andgrave, 202

plaster, 269, 270

values, 157,235

Lathyrus, 29, 49

Laufer, B., quoted, 76

Laws governing servants, 170 relative to prices of corn, 132

Lemons, 14,15
Lentits, 1.)

Lel'age du P'ratz, quoted, 47, 22:1

Lettuce, 13, 10:3

Iicoriee, 19, 14:?

Lime, use of, $26 \mathrm{~s}$

Limestone, 269

soils, 226

Linen, 134

Linseed exported, 163

Linum virginianum, 90

Llama, 99

Live stock, Indian, 99

Colonial, 12t, 13t, 143, 14t, 1140, $162,16 \overline{7}, 183,202$

in California, 110

in Canada, 217

in ligypt, 15

in Fngland, 18

ranches, 206

Logan, James, 176

London Company, 123

Long Island settled, 156

Louisiana, crops of, 221

Lucas, Eliza, 244

Lucerne, 244, 245

Lyon, Abram de, 212

\section{II}

Macocquer, 94

Madder, 143

Madera wine, 289

Maidens sent to Virginia, 126

Maine, 152, 224

Maize, 41, 279

early referenees to, 46

how fertilized, $9 \mathrm{~s}$

in Africa, 106

methods of cooking, is planting, 94

month of, $7 \mathrm{~s}$

origin, 43

protection against birds, 94

value, 131

vields, 45

Malaria, 200

IIallows, 15

Malt, 2S9, 290

houses, 293 
Man of signs, 223

Manhattan Island, 153

Manors, 155

Mansoroke (sorglium), 107

Manufacturing, 136, 187, 284

Manures, 177,271

Maple sugar, $37,3 \mathrm{~S}$

Marco Polo, quoted, 105

Mares, embargo on, 135

Market days, $18 \pm$

Marl, 26S

Maronites, food of, 52

Marsh lands, 156

wheat, 70

Maryland described, 235 settled, 165

Mas, 14

Maskoki Indians, 21

Massachusetts, 138, 143

Massacre, Indian, 127

Mayflower, 138

Mazza-Manputo (maize), 106

Meadows, 172, 190 how apportioned, 141 irrigated, 177 yields, $2+2$

Neats exported, 135 prices of, 135

Medicago sativa, 244

Melden, 94

Melicotones, 19

Melongena, 13

Melons, 13, 15, 67, 69, 74

Merchant promoters of the colonies, 116

Metals exported, 297 working prohibited, 267

Mexico, early civilization, 9

Nice-with-tails, 80

Mildew on wheat, 147, 233

Milium (see Millet).

Millar, Robert, botanist, 210

Nillet, 8, 15, 106, 245, 246

Nills, grist, 148, 162, 192

Miraculous peas, 250

Mississippi Bubble, 219, 220

Mobby punch, 2S9

Moguls country, 102

Molasses, rum made of, 289, 290
Monardes, Nicholas, 53

Monkeys, 6

Moors, 10;

Moose of France, 217

Morelloes, 14

Mound builders, 20

Mulberries, 172 month of, 77 ordered planted, 133

Mules, 157

Mung bean, 14

Muskmelons, 58, 6S, 71

Mutation, 3

Mutton, prejudice against, 257

Myrtle wax, 219

\section{Y}

Nana (pineapple), 86

Nanticokes, 250

Narragansett Indians, 39, 188 pacers, 260 turkeys, 194

Natural selection, 2

Navigation laws, 283

Neat cattle, 143, 149

Negroes, first brought to Virginia 126

food of, 274, 275

resistant to malaria, 274

skilled artisans, 276

New Amsterdam, 153, 171

New England, described, 150, 23.3 exports, 283

limitations, 221

New Hampshire, 138, 151

New Jersey, 159 described, 163, 233

New Market race course, 259

New Mexico settled, 109

New River discovered, 226

New York, 153 commerce of, 292 limitations, 221

Nobility, titles of, 16!)

No fence law, 1.t6

Norlenskiold, G., eited in mute, j

North Carolina, 19; (lescribed, 231 exports, 199 
Nubian Geography, quoted, 106

Nut grass, 243

Nutmegs, 102

Nuts, 36

\section{O}

Oats, S, 103, 142, 150, 192

Occaneechi Trail, 195

Oil products, 297

Oils, 201

Old World crops, 239

Olives, 110, 200

Onions, 13, 106

Onthan (watermelon), 73

Oranges, 14, 15

Orchard grass, 242

Orehards, 149, 155, 162 of the French, 220

Oronako tobaceo, 131

Oronoque tobaceo, 125

Openawk, \$3

Over-production of wheat, 185

Oviedo quoted, 53

Oxen, 162, 216, 255

Oyster shell lime, 268

\section{$\mathrm{P}$}

Pacers, popularity of, 261

Pagans, 12

Pale (fenee), 122

Palm-wine, 106

Panic, 106

Parclied corn, 108

Parliamentary appropriations for silk, 214

Parsnips, 150

Pastures, 1S8, 197

Patroons, 155

Peaches, 14, 19, 78, 142

Peacocks (turkeys), 99

Peanuts, 41, 79, 80

Pearl millet, 106, 246

Pears, S, 14, 142, 220

Peas, S, 18, 49, 51, 103, 142

Peasants, 12

Pecielt (tobaceo), 53

Peeans, 36,41

Peltandra virginica, 32
Pennsylvania, 173

commeree of, 282

deseribed, 233

Penn, William, 174

Peppers, 41, 88, 102

Perique tobaceo, 221

Perry, 167

Persimmons, 31, 290

Peru, 9, 79

Phaseolus vulgaris, 52, 2.1!

Pilgrims, 138

Pillow, food of Turks, 52

Pinckney, Mrs. C. C., 207

Pineapples, 41, 88

Pinetree shillings, 282

Pinon nuts, 41

Pioneers, 175,195

Piseataqua River, 151

Plant history, how determined, 4

Planta solis, 94

Plantains, 15

Plaster of Paris, 270

Plebes, 12

Plow, 124

shares, 263

Plums, 8, 31, 142

Plumstones planted, 103

Plymouth, how built, 139

colony grows, 142

Pomegranates, 14, 15, 110, 143

Pompions, 57, 106

Pone, 48, 131

Poppy seeds, 8

Portugal, grapes from, 212

Portugese explorations, 105

Potatoes, 41, 83, 85, 107, 158

flour of, 84

history of, 80

in England, 19, 85

introduction into North America, $\mathrm{S} 5, \mathrm{~S} 6$

Poultry, 15, 23, 104, 148, 217, 219, 258

Powhatan's birth right, 121

Predatory animals, 134

Presbyterians, 156

Price fixing, 168, 183

Prices, fluctuating, 128

of foodstuffs, 14S, 189 
Prickly pear, 36

Primitive agriculture, 7

Prior tobaceo, 129

Prizes for silk cocoons, $17 \mathrm{~s}$

Proclamation of 1763,227

Produce of a dairy farm, 193

l'ublic garden, 210

Pumpkin pies, 145

Pumpkins, 41, 57, 70, 24.4

Puritans, 143, 156

\section{Q}

Quary, Robert, report of, $12 \mathrm{~S}$

Quince, 143

tarts, 148

Quit-rents, 295

$\mathrm{R}$

Rack, 290

Rakes, 263

Raleigh, Sir Walter, $5 \overline{5}$

Ranches, 197, 206, 214, 215

Ranges, 215

Rape, 19

seed oil, 186

Raspberries, 8, 30, 41

Rates of seeding, 161

Raw silk, 214, 215

Ray grass, 242, 243

Reaping hooks, 263

Rebecea, an early ship, 159

Red clover, 240

Resting land, 97

Rhode Island, 187

bent grass, 194

dairy cows, 194

Rice, 15, 52, 106, 178, 215, 221

culture of, 203, 201

liarvesting, $20-4$

objections to, 205

liver craft, 281

liolfe, John, 12 1,127

liollers, 267

Rolling houses, 129 roads, 129

Roman Catholic Missions, 109

Rotation of Fields, 97
Rounceval bean, 250

Row planting of corn, 9.)

Royal botanist, 176

Ruckoli, 13

Rum in Indian trade, 29:2

Rye, S, 103, 142, 147, 192

rate of seeding, 163

Rye grass, 242

\section{S}

Sable Island, cattle on, 104

Saddle horses, 261

Saffron, 164, 296

Sagadahock, 152

Saint Foin, 243

Saint Mary's settlement, 166 ;

Salem grass, 243

Salt marsh, hay, 147

meadows, 26

pork, exported, 251

Saltzburgers, 209, 213

Savannah, settled, 208

Scuppernong grape, 31

Scythes, 263

Sebesten, 14

Self-sufficing agriculture, 1S5, 231

Serfs, 12

Servants, indentured, $126,169,-17 t$

Sesame, 13, 15

Setaria viridis, 246

Sheep, 15, 120, 160, 186, 187, 256

embargo on, 146

finc-wooled in New Spain, 110

weight of fleece, $23 \mathrm{~s}$

Shenandoah Valley settled, 226

Shijtamen (watermelon), 73

Ship building, 1S0, 2S0, 295

Shorthorned cow, 255

Shovels, 263

Shukshi (watermelon), 73

siam cotton, 221

Signiory, 202

Si kwa (mellon), 76

Silk, 102, 132, 133, 178, 201, 207, 296

cost of, 212

Silk grass, 90

Silk worms, 105

Slavery, 126, 215, 273, 27t 
Slave trade, 273

introduced plants, 10;

Slaves, $169,220,276$

first introduction, 126

Indian, 206, 219

land needed for, 277

when freed in the North, 276

Sloes, $\mathrm{S}$

small beer, 289

corn, month of, 77 grains, 124

Smilax hortensis, 52

Smith, Capt. John, 32, 51, 118, $13 \mathrm{~S}$

Smithficld hams, 254

Smyrna cotton, 201

Soap ashes, 269

Social life, 156, 194, 205, 277, 27s

Soils of New Jersey, 160

Solanum tuberosum, 86

Sorghum, 106, 246, 251

syrup, 251

South Carolina, 199

described, 234

exports from, 206

Soybeans, 41

Spactes, 263

Spain, agriculture of, 16

Spanish settlements, 108

live stock at, 109

Spotswood, Gov. Alex., 136

Species, origin of, 2

Spence, William, first white farmer in Virginia, 120

Spring wheat, 147

Squanto, 139

Squashes, $41,57,69,70$

Stable manure, 271

Starving time (1609), 120

Strawberries, 8, 30, 41, 77, 288

Sugar canes, 14, 15, 106, 200 introduction of, 110,221

Sugar trade, 295

Sulphate of lime, 269

Sumac, 296

Sunflowers, 41, 59

Supcrstition, 223

Survival of the fittest, 2

Swedish settlements, 159, 171

farming at, 173
Sweet potatoes, $60,62,63,107$

Switie, 108, 120, 191, 253

laws regulating, 145, 191

wild in Bermuda, 105

$\mathrm{T}$

Tall meadow oat grass, 242

Tallow, exported, 110

Tapestries, 102

Tapir, 6

Taragon, 13

Tarchon, 13

Tassore, 119

Tea, 210

Testing gardens, 211

Textile raw products, 296

Thanksgiving days, 144

Theory of evolution, 2

Timothy, 151, 241, 243

Tisquantum (squanto), 139

Title to land, 160, 203, $20 \mathrm{~S}$

Tobacco, 41, 54, 126, 167, 17S, 196. 221

exports, 128, 294

inspection laws, 129,187

planting limited, 127, 142

use prohibited, 142, 187

varieties of, 124,222

when taken to Europe, 54,55

Tomatoes, 41, 89

Topping tobacco, 57

Trans-Allegheny explorations, 225

Trinidado tobacco, 124

Tuckahoe, 32,61

Tull, Jethro, 93

Turkey wheat, $46,4 \mathrm{~S}$

Turkeys, 99, 101, 143

month of, $7 \mathrm{~S}$

Turkish beans, 50

Turks, food of, 52

Turnips, 13, 103, 244

\section{V}

Variation, law of, 2

Vegetation of eastern America, 26

Vicia faba, 50

Vigna sinensis, 50, 249 
Villains, 12

Vincennes settled, 219

Virginia, 119, 127, 289 described, 235

Voyages and travels, books on, 301

II

IV iges fixed by law, 1S:3

IValnuts, 36,41 month of, is

IVampee, 32

IV ashington, George, quoted, 231

Waternelons, $41,5 S, 71,77,21 S, 24 t$ earliest deseription, 67 history of, 64 month of, 77

Water mills, 14S, 162, 192

Wealth, earliest forms of, 10

Weld, a dyestuff, 296

West Jersey, 161

White cap corn, 194 clover, 241

Siam cotton, 221

Wheat, S, 15, 19, 103, 105, 140, 142, $14 \overline{7}, 17 \overline{7}, 192$

blight of, 233

exported, 154

how harvested, 177

over-production, 185

Whecl barrows, 263 plow, 263

Whiskey, 292
Widow Anderson, 213

Wind mills, 14 s, 192

Wine, 30, 106, 201, 25s, 2\$9, 247

Winnowing rice, 204

Winslow, Edward, 31, 140, 111

Winter wheat, 8,147

Wild animals, 134 eattle on Sable Island, 10 H

flax, 90

hemp, 90

horses, 109, 259

potatoes, 87

rye, 27,25

turkeys, 100

William and Mary College, 136

Williams, Roger, 25, 30, 146

Wire grass, 29

Wittmack, L., cited in note, 5

Woad, a dye stuff, 296

Wolves, 144

Woods, open condition of, 26

ITool, embargo on, 135

weight of fence, $23 \mathrm{~S}$

Worms, silk, 178

\section{Y}

Yams, 62, 107

Young, Arthur, 238, 300

Z

Zizania aquatica, 34

Zuni Indians, 22 






\section{University of Toronto Library}

\section{DO NOT}

\section{REMOVE}

THE

GARD

FROM

THIS

POCKET

Acme Library Card Pocket Under Pat. "Ref. Index Fllo" Made by LIBRARY BUREAU 
